DEPARTAMENTO DE MECÁNICA DE FLUIDOS Y PROPULSIÓN ESPACIAL

ESCUELA TÉCNICA SUPERIOR DE INGENIEROS AERONÁUTICOS

\title{
Extinción de llamas premezcladas en el límite inferior de inflamabilidad
}

Tesis Doctoral

\author{
Autor \\ Victor Muntean \\ Ingeniero Aeronáutico
}

Director de la Tesis

Francisco José Higuera Antón

Doctor Ingeniero Aeronáutico 

Tribunal nombrado por el Sr. Rector Magfco. de la Universidad Politécnica de Madrid, el día. de.. .de $20 . .$. .

Presidente:

Vocal:

Vocal:

Vocal:

Secretario:

Suplente:

Suplente:

Realizado el acto de defensa y lectura de la Tesis el día..........de.......................de 20 ... en la E.T.S.I. /Facultad..

Calificación

EL PRESIDENTE

LOS VOCALES

EL SECRETARIO 



\section{Agradecimientos}

Aunque gran parte de esta tesis está escrita en forma impersonal y en primera persona, el trabajo subyacente no se ha realizado solo y tampoco todo el mérito es mío. A lo largo de estos años he recibido apoyo y ayuda de muchas personas que han enriquecido tanto el desarrollo del trabajo como el mío propio.

En primer lugar me gustaría agradecer a mi director de tesis, Francisco Higuera, la oportunidad que me ha brindado, la enorme paciencia que ha empleado para corregir mis continuos fallos, así como su total disponibilidad para resolver cualquier duda que me ha surgido a lo largo de estos años. Mención aparte merecen sus clases informales de historia clásica que han amenizado más de una espera en los aeropuertos.

Me gustaría también agradecer a José Graña el haberme introducido en el mundo de la investigación al finalizar mi segundo año de carrera y de recomendarme a mi actual director de tesis. Esta elección, vista desde el prisma de todo lo aprendido, ha sido totalmente acertada.

El trabajo experimental me ha supuesto más de un quebradero de cabeza y me gustaría agradecer a Gabriel García, Benigno Lázaro y Ezequiel González su disponibilidad para ayudarme siempre que he acudido a ellos.

La instalación experimental ha requerido varias iteraciones de diseño y construcción, y sin la ayuda de Fernando y José no habría sido posible avanzar tanto.

El desarrollo de la tesis me ha obligado a robar tiempo a antiguos amigos: Alberto, Dani, Luis, Pablo, Alfonso, amigos de ISF y de Qwan ki Do. Aunque también me ha brindado la ocasión de hacer muchos amigos nuevos con los que he compartido más de una pena: Fernando, Marcos, Félix, Xin, Artur, Ana, Quique... A todos ellos les quiero agradecer el gran apoyo moral que han supuesto para mi.

Es imposible expresar en unas líneas lo mucho que agradezco a mis padres el enorme sacrificio que han tenido que realizar para que yo haya llegado hasta aquí.

Y por último y también más importante, quiero agradecer a Ane su apoyo y comprensión. También agradecerle el aceptar sin pedir nada a cambio la consecución de un objetivo algo egoísta por mi parte, así como los sacrificios futuros necesarios para completar los actuales hitos de la carrera académica. Gracias por estar a mi lado y por animarme esos días en los que la jornada acaba con una hoja más en el cuaderno de laboratorio y que únicamente registra cuándo la llama no se enciende. 
El trabajo realizado ha sido financiado a través del programa HYSYCOMB de la Comunidad de Madrid (S2009/ENE-1597), del proyecto Consolider SCORE del Ministerio de Economía y Competitividad (CSD2010-00011) y gracias a una beca del Programa Propio del Personal Investigador en Formación para la realización del Doctorado en sus Escuelas, Facultades, Centros de $I+D$ e Institutos Universitarios de la UPM (RR01/2011). 


\section{Resumen}

Se presenta un estudio experimental y numérico de la propagación ascendente de una llama en una mezcla muy pobre de metano y aire contenida en un tubo vertical que está abierto por su extremo inferior y cerrado por el superior. La flotabilidad juega un papel dominante en la propagación de estas llamas, cuya forma y velocidad de ascenso son similares a las de una burbuja que sube en un tubo lleno de líquido. En un sistema de referencia ligado a la llama, cuando la riqueza se aproxima a la correspondiente al límite inferior de inflamabilidad, aparece una zona de baja velocidad en el gas quemado inmediatamente detrás de la llama, cuyo tamaño es del orden del radio del tubo y aumenta al disminuir la riqueza de la mezcla. La presencia de esta región, donde el tiempo de residencia del gas caliente es muy alto, intensifica el efecto de las pérdidas de energía por radiación, que es despreciable para riquezas algo mayores porque la concentración de las especies radiantes (principalmente $\mathrm{CO}_{2}$ y $\mathrm{H}_{2} \mathrm{O}$ ) es pequeña. Estas pérdidas enfrían el gas y dan lugar a un flujo de calor por conducción desde la llama al gas quemado, que es suficiente para causar la extinción de la llama por efectos térmicos para un valor de la riqueza próximo al medido experimentalmente en el tubo de inflamabilidad estándar.

En el estudio numérico se ha modelado la combustión mediante una reacción global única, y se han tenido en cuenta las pérdidas por radiación debidas a las especies $\mathrm{CO}_{2}$ y $\mathrm{H}_{2} \mathrm{O}$ admitiendo que el gas es ópticamente delgado y la pared del tubo es transparente y está fría. El efecto de la radiación es importante en el tubo de inflamabilidad estándar, de $51 \mathrm{~mm}$ de diámetro, pero disminuye con el diámetro del tubo. Los resultados numéricos y las estimaciones de órdenes de magnitud llevadas a cabo muestran que, en ausencia de radiación, la propagación de la llama sólo deja de ser posible para valores muy pequeños de la riqueza, para los que existe una zona de recirculación que contiene una parte de la región de reacción.

En el estudio experimental se ha medido la velocidad de ascenso del frente de llama mediante una serie de fotodiodos equiespaciados a lo largo de la pared del tubo y por métodos fotográficos, y se ha usado un sistema de PIV para medir la velocidad del gas inducida por la llama en un plano vertical que contiene al eje del tubo. Se han usado partículas trazadoras micrométricas de alúmina, y se ha extraído de las imágenes de PIV el contorno de la región luminosa de la llama, supuesta axilsimétrica. Se ha propuesto un modelo unidimensional del flujo y la llama cerca del eje del tubo, basado en ecuaciones de conservación simplificadas, que permite calcular aproximadamente las distribuciones de temperatura y concentraciones de las especies a partir del perfil de velocidad medido.

Se ha mostrado que las partículas trazadoras no siguen el movimiento del 
gas en el interior de la llama, debido a la fuerza de termoforesis que actúa sobre ellas en esta región, donde el gradiente de temperatura es muy intenso. Esto causa un error importante en las medidas de velocidad con PIV. Se ha propuesto un método iterativo de corrección de este error basado en el modelo unidimensional mencionado más arriba. El método se ha validado empleando imágenes de PIV sintéticas. 


\begin{abstract}
The stationary upward propagation of a very lean methane/air flame in a long vertical tube open at the bottom and closed at the top is investigated experimentally and numerically. On the numerical side, a single overall chemical reaction is used to model combustion, while radiation losses from $\mathrm{CO}_{2}$ and $\mathrm{H}_{2} \mathrm{O}$ are approximately accounted for by assuming an optically thin gas bounded by a transparent or non-reflecting tube wall. Buoyancy plays a dominant role in the propagation of these flames and causes a large region of low velocity of the burnt gas relative to the flame to appear below the flame front when the equivalence ratio is decreased. The size of this region scales with the radius of the tube, and its presence enhances the effect of radiation losses, which would be otherwise negligible for a standard flammability tube, given the small concentration of radiating species. Heat conduction is found to be important in the low velocity region and to lead to a conduction flux from the flame to the burnt gas that causes extinction at the flame tip for a value of the equivalence ratio near the flammability limit experimentally measured in the standard tube. The effect of radiation losses decreases with the radius of the tube. Numerical results and order-of-magnitude estimates show that, in the absence of radiation, a very lean flame front fails to propagate only after recirculation of the burnt gas extends to its reaction region and drastically changes its structure. This condition is not realized for the standard flammability tube, but it seems to account for the flammability limit measured in a tube of about half the radius of the standard tube.
\end{abstract}

On the experimental side, the velocity of the flame front has been measured with an array of photodiodes set along the tube wall and, independently, from photographic records. A PIV system triggered by a photodiode signal has been used to measure the velocity of the flow induced by the flame front in a vertical plane through the axis of the tube. Alumina particles are used to seed the gas. The contour of the luminous region of the flame front, assumed cylindrically symmetric, has been extracted from the recorded images. As expected, the shape and velocity of a very lean flame front, and the velocity of the fresh gas relative to the front, are similar to those of a bubble rising in the tube. The flow of the burnt gas features the region of low velocity (relative to the flame front) mentioned above which enhances radiation losses and seems to play an important role in the extinction of the flame at the flammability limit. This limit is found to depend very sensitively on the temperature of the tube wall. A simple model is proposed of the flow around the axis of the tube and the combustion around the tip of the flame front. This model uses the measured gas velocity at the axis of the tube together with simplified conservation equations to compute the temperature and species concentrations along the axis for a given kinetic scheme and radiation law. The results for a single overall 
Arrhenius reaction and for a four-step reduced scheme, both in an optically thin gas, are in reasonable agreement with the experimental data and shed some light on the roles played by radiation losses and kinetic effects on the flammability limit measured in the standard flammability tube. Namely, these results show that a conduction-radiation balance is approached in a region of low velocity that develops behind the flame front when the flammability limit is approached. Radiation losses from the combustion products in this region become then important and may cause the extinction of the flame.

The thermophoretic drift of the seeding particles relative to the gas is shown to cause an error in the PIV measurements in the transport region of the flame, where the temperature gradient is large. An iterative correction of the measured velocity is proposed based on the quasiunidimensional model mentioned above, in which simplified energy and species conservation equations are used to compute an approximation to the profile of gas temperature across the flame in terms of the profile of gas velocity. The correction is tested using synthetic velocity fields and applied along the axis of the tube. 


\section{Índice general}

Índice general

1. Introducción 1

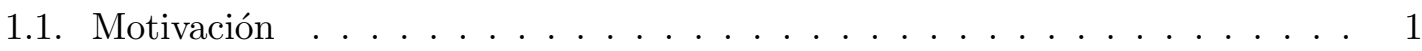

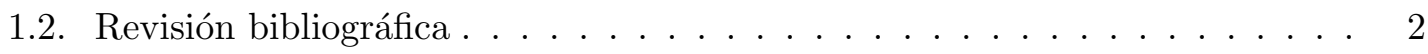

1.3. Objetivo de la tesis . . . . . . . . . . . . . . . . 8

2. Definición del problema $\quad 11$

2.1. Formulación del problema . . . . . . . . . . . . . . . . . . . 12

2.1.1. Esquema cinético de una única reacción . . . . . . . . . . . . . . 14

2.1.2. Modelo de las pérdidas por radiación . . . . . . . . . . . . . . 15

2.1.3. Adimensionalización del problema . . . . . . . . . . . . . . . 19

2.2. Resultados . . . . . . . . . . . . . . . . . . . . 21

2.2.1. Resultados sin pérdidas por radiación . . . . . . . . . . . . 21

2.2.2. Influencia de las pérdidas por radiación . . . . . . . . . . . 26

2.3. Modelo unidimensional de la llama . . . . . . . . . . . . . . . . . . . . . 29

2.4. Modelo cinético de cuatro reacciones . . . . . . . . . . . . . . . . . 31

2.5. Conclusiones . . . . . . . . . . . . . . . . . . . 35

3. Instalación experimental $\quad 39$

3.1. Tubo de inflamabilidad estándar . . . . . . . . . . . . . . . . . 39

3.2. Diseño del mezclador de gases . . . . . . . . . . . . . . . . . . . . . . 40

3.2.1. Riqueza . . . . . . . . . . . . . . . . . . . 44 44

3.2.2. Incertidumbre en la medida de la riqueza . . . . . . . . . . . . . 46

3.3. Encendido de la llama . . . . . . . . . . . . . . . . . . . . . . . 48

3.4. Proceso experimental completo . . . . . . . . . . . . . . . . . 52

4. Técnicas de medida $\quad \mathbf{5 7}$

4.1. Velocidad de subida de la llama . . . . . . . . . . . . . . . . . . 57

4.1.1. Medición de la velocidad usando una línea de fotodiodos . . . . . . . 57

4.1.2. Medición de la velocidad usando imágenes fotográficas . . . . . . . . 59

4.2. Particle Image Velocimetry (PIV). Introducción. . . . . . . . . . . . . . . 62

4.3. PIV I - Densidad de sembrado y resolución. Efecto de la expansión térmica. 63

4.3.1. Elementos de la técnica. Ventanas de interrogación y correlaciones

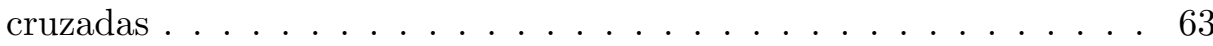

4.3.2. Aplicación a nuestro experimento . . . . . . . . . . . . . . . 69 
4.4. PIV II - Dinámica de las partículas. . . . . . . . . . . . . . . . . . 74

4.4.1. Partículas sólidas en un flujo isotermo . . . . . . . . . . . . 74

4.4.2. Termoforesis . . . . . . . . . . . . . 76

4.4.3. Efecto de la termoforesis en el interior de la llama . . . . . . . . 78

4.4.4. Corrección de la deriva de la velocidad causada por la termoforesis . 79

4.5. Sembrado de partículas . . . . . . . . . . . . . . . . . . 81

4.5.1. Lecho fluidizado . . . . . . . . . . . . . . . . . . . 81

4.5.2. Impactador . . . . . . . . . . . . . . . . . 8 83

4.6. Conclusiones . . . . . . . . . . . . . . . . . . . . 88

5. Resultados experimentales $\quad 91$

5.1. Comportamiento de la llama . . . . . . . . . . . . . . . . . . . 91

5.2. Velocidad de ascenso de la llama . . . . . . . . . . . . . . . . . 93

5.2.1. Efecto de la sensibilidad de los fotodiodos . . . . . . . . . . . . 97

5.2.2. Errores en la medición de la velocidad empleando imágenes fotográficas 101

5.2.3. Velocidad de la llama en función de la riqueza . . . . . . . . . . . . 107

5.3. Campo de velocidades . . . . . . . . . . . . . . . . . . . . 110

5.3.1. Extinción . . . . . . . . . . . . . . . . . 116

5.4. Pérdidas por radiación . . . . . . . . . . . . . . . . . . 118

5.4.1. Resultados experimentales . . . . . . . . . . . . . . . 120

5.4.2. Cálculo de la temperatura . . . . . . . . . . . . . . . . . . 122

5.5. Conclusiones . . . . . . . . . . . . . . . . . . . . 125

$\begin{array}{lr}\text { 6. Conclusiones y trabajo futuro } & \mathbf{1 2 7}\end{array}$

6.1. Conclusiones . . . . . . . . . . . . . . . . . 127

6.2. Trabajo futuro . . . . . . . . . . . . . . . . . . . . . 129

A. Funcionamiento de los controladores Bronkhorst El-Flow 131

B. Imagen de una llama axilsimétrica en un tubo 139

B.1. Óptica geométrica . . . . . . . . . . . . . . . . . . . 139

B.2. Refracción en la pared del tubo . . . . . . . . . . . . . . . . . . 141

B.3. Resultados . . . . . . . . . . . . . . . . . . . . . . . . . . 144

$\begin{array}{ll}\text { Referencias } & 147\end{array}$ 


\section{Capítulo 1}

\section{Introducción}

\subsection{Motivación}

La combustión es una reacción química entre un combustible (como el carbón, los hidrocarburos o el gas natural) y un comburente (como el oxígeno del aire) que libera energía en forma de luz y calor. Las aplicaciones de la combustión se deben al carácter exotérmico de estas reacciones y a la radiación luminosa emitida. Los humanos han aprovechado estas propiedades para calentarse, alumbrarse o para cocer alimentos desde el descubrimiento del fuego, que no es más que una manifestación visual de la combustión. A medida que la sociedad ha avanzado las aplicaciones de la combustión se han ido ampliando hasta el punto de ser fundamentales en los hitos del desarrollo de la humanidad, como la revolución industrial. La necesidad de mejorar el rendimiento de las máquinas para reducir los costes ha impulsado el estudio de los fenómenos que intervienen en la combustión.

La combustión sigue siendo hoy en día uno de los métodos más utilizados para obtener la energía térmica necesaria para su transformación en otras energías finales. Dentro de la gran diversidad de los procesos tecnológicos, la combustión se realiza con el oxidante y el combustible inicialmente separados, en llamas de difusión, o con el oxidante y combustible mezclados de antemano, en llamas premezcladas. Un ejemplo típico de la aplicación de las llamas de difusión son las calderas de gas empleadas para calefacción, y uno de llamas premezcladas los motores de gasolina. En algunas aplicaciones concretas, como por ejemplo la combustión de un spray de combustible, aparecen los dos tipos de combustión en función de la zona de estudio.

Para las llamas premezcladas, la mezcla puede contener diferentes concentraciones de combustible. Existe una concentración óptima (la estequiométrica) que es la que libera el mayor calor por unidad de masa de mezcla, pero si se añade a esta concentración combustible o aire, las nuevas mezclas también tienen importantes aplicaciones. En el caso de los motores de gasolina sin catalizador se puede obtener mayor potencia añadiendo un extra de combustible a la concentración estequiométrica. Este tipo de mezclas se llaman mezclas ricas, mientras que aquellas que tienen menos combustible que la mezcla estequiométrica se llaman mezclas pobres. A raíz de las limitaciones en la emisión de contaminantes y de la búsqueda de ahorro de combustible, las mezclas pobres se han ganado un hueco en las aplicaciones industriales. La combustión empleando mezclas pobres permite aumentar la eficiencia energética de los procesos, ya que la presencia de oxígeno en demasía favorece la 
reacción completa del combustible. Además, al ser reacciones con una temperatura final de combustión más baja que la mezcla estequiométrica, se reduce la formación de óxidos de nitrógeno, un contaminante atmosférico muy perjudicial.

La desventaja del empleo de mezclas pobres es la complejidad que implica en el diseño de las máquinas que se basen en su combustión. En la combustión de las mezclas pobres la velocidad de reacción es pequeña y la cantidad de calor obtenido por unidad de masa de mezcla es pequeña, por la necesidad de calentar el exceso de aire presente en la mezcla. De esta forma las llamas obtenidas pueden presentar inestabilidades, y para llamas muy pobres se puede provocar la extinción de la llama.

El empleo de la llamas pobres plantea importantes dificultades y requiere un conocimiento profundo de los distintos mecanismos que afectan la estabilidad de su combustión y a su capacidad de arder. Hay un límite en la concentración de combustible en la mezcla por debajo del cual la llama ya no puede iniciarse o no es capaz de auto-sostenerse. Este límite es el límite de inflamabilidad. Como un límite análogo se encuentra también para llamas muy ricas, para diferenciarlos se usan las denominaciones límite inferior de inflamabilidad para el caso de llamas pobres y límite superior de inflamabilidad para llamas ricas. El estudio del límite inferior de inflamabilidad aporta información sobre los mecanismos que provocan la extinción, que es necesaria para el desarrollo de sistemas de combustión más eficientes y menos contaminantes.

\subsection{Revisión bibliográfica}

Una de las primeras constataciones sobre la existencia de los límites de inflamabilidad de mezclas fue realizada por Gay-Lussac y Humboldt [14] al estudiar la composición del aire de la atmósfera. Para hallar el volumen de oxígeno presente en el aire recogido a distintas altitudes en la atmósfera, estos investigadores realizaron un experimento que consistía en añadir un volumen conocido de hidrógeno al aire, para después encender la mezcla resultante dentro de un eudiómetro que permitía medir el cambio de volumen de la mezcla después de la reacción. Para deducir la cantidad de oxígeno presente en la mezcla en función de la cantidad de hidrógeno añadida, hicieron primero pruebas utilizando mezclas únicamente de hidrógeno y oxígeno, aunque en distintas proporciones, conservando el volumen de hidrógeno y añadiendo cada vez más oxígeno. Observaron que el cambio de volumen era el mismo para gran parte de los experimentos (combustión completa del hidrógeno), pero, a medida que la mezcla se diluía añadiendo oxígeno, el volumen de la mezcla variaba menos (combustión incompleta) para finalmente no variar en absoluto (límite de inflamabilidad). Constataron de esta forma que existen proporciones de oxígeno e hidrógeno que no permiten que la reacción de combustión se produzca.

Aunque en este trabajo la existencia de los límites de inflamabilidad se presenta como algo anecdótico, ya que su estudio no era parte del objetivo principal del experimento, para la industria carbonera de la época eran de vital importancia. La seguridad en las minas de carbón se veía comprometida por la presencia en del grisú (firedamp en inglés), un gas compuesto principalmente por metano, que se encuentra adsorbido en el carbón. El grisú se libera al ambiente de la mina al producirse el debilitamiento de las paredes por el avance de las galerías. La disminución de la presión o el aumento de la temperatura también favorecen la liberación del gas. La mezcla entre el grisú y el aire puede resultar inflamable en ciertas 
proporciones y este hecho fue la causa de muchas explosiones con víctimas mortales en las minas de Inglaterra en los siglos XVIII y XIX. Ante la detección de una concentración demasiado alta de grisú en el ambiente de la mina, la zona se ventilaba y, aunque no se conseguía eliminar por completo el gas inflamable, su concentración bajaba por debajo del límite de inflamabilidad. Cuando no se conseguía evacuar el gas o detectar su presencia, el encendido se producía a causa de los sistemas rudimientarios de iluminación empleados: velas o lámparas de aceite. A veces se empleaba una rueda de acero que generaba chispas al girar sobre pedernal (Spedding mill), que era más segura que la vela, pero en ocasiones también era capaz de encender la mezcla.

Después de un accidente muy grave en las minas Felling en 1812 causado por el encendido de la mezcla de grisú y aire y en el que murieron 92 trabajadores, los problemas de seguridad en las minas atrajeron la atención de la opinión pública, que propició la implicación de varios investigadores para intentar reducir los accidentes. El empleo de llamas para iluminar ambientes potencialmente inflamables instigó a buscar métodos más seguros de iluminación. Como solución a este problema Davy [9] diseño una lámpara de seguridad que impedía que la llama empleada para iluminar encendiese la mezcla del ambiente. Para ello diseñó una lámpara cuya llama estaba rodeada de una malla fina de acero que permitía el paso de la luz, pero extinguía la llama en caso de que ésta intentara propagarse más allá de la malla de acero[9].

Como parte del mismo estudio, este autor investigó la inflamabilidad de mezclas de grisú de alta pureza recogido de las minas con distintas cantidades de aire. Introducía la mezcla en una botella y la encendía acercando una vela a la boca de ésta. Observó que, aunque las mezclas de una parte de gas y ocho de aire se encendían de forma enérgica, las llamas generadas se debilitaban al usar mezclas con mayor cantidad de aire hasta que dejaban de encenderse totalmente para una mezcla de quince partes de aire y una de gas. Esta última concentración sería el límite inferior de inflamabilidad y corresponde a un valor de $6.3 \%$ de concentración volumétrica de grisú en aire.

La invención de la lámpara de seguridad no ha conseguido eliminar las explosiones en las minas. Si se acumula una cantidad suficiente de grisú para que la mezcla sea inflamable en una galería, esta mezcla se puede encender mediante otros mecanismos, tales como las chispas generadas por golpes de los picos de los mineros contra las rocas y, a veces, por el deterioro de la malla protectora de la lámpara de seguridad. La prevención de los accidentes pasa por la detección de la inflamabilidad de la mezcla. Inicialmente la presencia del grisú se detectaba cualitativamente por la altura de la llama dentro de la lámpara de seguridad; cuanto más alta es la llama mayor concentración de grisú hay en el ambiente. Reducir las explosiones está claramente condicionado por la mejora en la detección del grisú en el aire, pero, sobre todo, estaba condicionado por conocer cuál es la concentración mínima de grisú en el aire por debajo de la cual la mezcla no es inflamable.

En la primera mitad del siglo XX se publicaron numerosos trabajos en los que se determinaba el límite inferior de inflamabilidad del metano, componente principal del grisú, pero más fácil de obtener en un laboratorio, sin necesidad de recogerlo en las minas. La mayoría de esos trabajos son experimentales, ya que los resultados buscados eran de aplicación práctica inmediata. El principal problema que se encontraba era que los límites obtenidos variaban demasiado entre los distintos autores, desde el $2.5 \%$ de concentración volumétrica de metano obtenido por Perman [44] hasta el $6.3 \%$ obtenido por Davy [9]. Otros autores obtuvieron concentraciones entre estos dos valores, aunque gran parte de 
ellos estaban comprendidos entre el $5.5 \%$ y el $6.3 \%$. La conclusión principal de estos trabajos es que el límite de inflamabilidad no es una propiedad intrínseca de la mezcla, sino que depende de las condiciones del experimento [43]. Cada autor empleaba su propio montaje experimental y su propia definición de mezcla inflamable, que eran las causas de que los límites de inflamabilidad obtenidos fueran tan distintos. Además de la instalación experimental y el criterio para definir la inflamabilidad de la mezcla, para un mismo montaje experimental el límite de inflamabilidad depende de otros factores como la composición del aire [43] o la temperatura y la presión de la mezcla [37].

La falta de uniformidad en los resultados evidenciaba la necesidad de una estandarización de la instalación experimental y de la definición de la inflamabilidad de una mezcla. La elección de una instalación experimental no era trivial, ya que no se podía saber cuál de las empleadas por los investigadores era la más idónea. Con el objetivo de reducir las explosiones en las minas o en cualquier otro ambiente industrial con atmósfera potencialmente inflamable, la Oficina de Minas de Estados Unidos (United States Burreau of Mines) propuso un montaje experimental usando un tubo como recipiente para la combustión y siguiendo una serie de criterios al elegir las condiciones experimentales [6]:

Dirección de propagación: en los resultados de los ensayos de inflamabilidad de distintos autores en tubos se ha observado que el límite inferior de inflamabilidad de una mezcla es menor cuando la llama se propaga verticalmente hacia arriba que cuando la propagación es hacia abajo. Para el límite superior ocurre lo contrario, obteniéndose un valor más alto de concentración para el caso de propagación hacia arriba e inferior para la propagación hacia abajo. Para otras inclinaciones del tubo, la concentración del reactante minoritario en el límite de inflamabilidad toma valores intermedios entre los dos valores antes mencionados.

Desde el punto de vista de la seguridad ante incendios es preferible usar el límite más conservador y que la llama no sea capaz de propagarse en ninguna de las posibles direcciones. Por lo tanto, en el experimento, la propagación de la llama debe ser vertical hacia arriba.

Diámetro del tubo: la propagación de una llama depende necesariamente de su capacidad mantenerse por sí sola, lo cual requiere que el calor generado en la llama se emplee en calentar la capa de mezcla contigua a la llama, que será la siguiente en reaccionar. Las paredes del recipiente pueden extraer parte de este calor e influir en los valores de los límites de inflamabilidad. En consecuencia el tubo debe ser lo suficientemente ancho para que el efecto de sus paredes sea despreciable en la propagación de la llama.

Se ha observado que, para la mayoría de los gases, los límites de inflamabilidad varían apreciablemente al aumentar el diámetro del tubo hasta los $5 \mathrm{~cm}$, pero que al incrementar el diámetro más allá de este valor la variación de los límites es muy pequeña.

Longitud del tubo: la importancia de la longitud del tubo radica en la necesidad de poder despreciar la influencia del encendido en la propagación de la llama y por lo tanto en los límites de inflamabilidad. Un distancia de unos $120 \mathrm{~cm}$ desde el punto de encendido se ha encontrado suficiente para que la ignición no tenga efecto sobre la posterior propagación de la llama. 
Tipo de tubo: si el tubo está abierto en los dos extremos la propagación de la llama es muy rápida y su forma muy irregular. En un tubo con los dos extremos cerrados hay variación de presión y también de la velocidad de propagación de la llama. Se ha observado que, para mezclas cercanas a los límites de inflamabilidad, la llama se propaga de manera suave y con una velocidad uniforme a lo largo del tubo cuando su extremo superior está cerrado y el inferior abierto.

En base a estos criterios Coward y Jones [6] han propuesto que la instalación estándar para la obtención de los límites de inflamabilidad tenga como elemento central un tubo vertical de $5 \mathrm{~cm}$ de diámetro y $150 \mathrm{~cm}$ de longitud. El tubo se llena de la mezcla a estudiar, que se enciende en el extremo inferior, que está abierto mientras el superior se mantiene cerrado. Estos autores también unificaron los criterios para decidir si una mezcla es inflamable o no, proponiendo calificarla como inflamable si la llama es capaz de propagarse desde el extremo inferior del tubo hasta el superior sin apagarse.

Una vez implantada la instalación experimental estándar, las diferencias entre las concentraciones límites obtenidas por diversos autores dejaron de ser tan grandes. Aún así, había pequeñas diferencias causadas por la sensibilidad de los límites de inflamabilidad a las condiciones del experimento. Sin embargo, la predicción teórica del valor de éstos límites era muy distinta de los valores reales obtenidos de los experimentos [57]. Las lagunas de los modelos teóricos pusieron de manifiesto la necesidad de comprender los mecanismos que determinan la extinción de la llama.

Levy [31] utilizó la instalación experimental propuesta en [6] para realizar un estudio óptico de la extinción en límite inferior de inflamabilidad. Una vez encendida en el extremo inferior del tubo, la llama asciende a velocidad constante y con forma de casquete esférico, con una falda más o menos alargada dependiendo de la riqueza. Además, la velocidad de ascenso de la llama se mantiene constante para distintas concentraciones de la mezcla cerca del límite de inflamabilidad. La propagación de la llama guarda gran similitud con la de una burbuja de aire que asciende por un tubo lleno de líquido [7]. Se vio que la velocidad de la llama depende de la gravedad y del radio del tubo. En cuanto al mecanismo de extinción, se observó que la extinción comienza en la punta de la llama y se propaga desde este punto a lo largo del frente de llama hasta que ésta se extingue completamente.

Durante la propagación vertical de la llama, se crean gradientes de velocidad en el gas delante del frente. Estos gradientes provocan un alargamiento de la llama (stretch) [25] que es más acusado en el punto más alto del frente, donde se inicia la extinción. Para estudiar la importancia del alargamiento de la llama, hay que calcular la velocidad adimensional de alargamiento, definida en [64],

$$
S=\frac{\delta_{L}}{U_{L}}\left(\frac{1}{\Delta A} \frac{\mathrm{d} \Delta A}{\mathrm{~d} t}\right),
$$

donde $\delta_{L}$ y $U_{L}$ son el espesor y la velocidad de la llama plana adiabática, y $\Delta A$ es el área de un elemento infinitesimal de la superficie de la llama. La velocidad de alargamiento puede causar la extinción local de la llama para valores de $S$ de orden unidad, ver [32, 33]. El factor $\delta_{L} / U_{L}$ de la ecuación (1.1) depende de la riqueza de la mezcla, mientras que el alargamiento de la llama (el factor $(1 / \Delta A)(\mathrm{d} \Delta A / \mathrm{d} t))$ depende de la configuración del flujo delante del frente y de la forma de éste,

$$
-\frac{1}{\Delta A} \frac{\mathrm{d} \Delta A}{\mathrm{~d} t}=U_{L} \boldsymbol{\nabla} \cdot \boldsymbol{n}+\boldsymbol{n} \cdot \boldsymbol{\nabla} \boldsymbol{v} \cdot \boldsymbol{n},
$$


donde $\boldsymbol{n}$ es la normal al frente dirigida hacia el gas quemado y $\boldsymbol{v}$ es la velocidad del gas delante de la llama. Para una llama que asciende dentro de un tubo vertical de radio $R$, el primer término de la ecuación (1.2) es proporcional a la curvatura del frente y, teniendo en cuenta que la llama en su parte superior tiene forma de casquete esférico de radio similar al radio del tubo [31], es del orden de $U_{L} / R$. Para la evaluación del segundo término es necesario conocer la distribución de velocidad del gas delante de la llama. Llamando $U_{0}$ a la velocidad de ascenso de la llama respecto al tubo, que como ya se ha mencionado es del mismo orden que la de una burbuja de radio comparable al del tubo, $U_{0} \sim(g R)^{1 / 2}$, el segundo término de la ecuación es de orden $U_{0} / R \sim(g / R)^{1 / 2}$.

En su artículo, von Lavante y Strehlow [61] estudiaron cómo afecta la velocidad de alargamiento a las llamas ascendentes en tubos verticales de distintos diámetros. Emplearon la técnica Schlieren para registrar el movimiento y la forma de la llama, y midieron su velocidad vertical. Mediante un sensor de flujo de calor, midieron la cantidad de calor que llega a la pared del tubo durante la propagación de la llama. Comprobaron que el flujo de calor desde la punta de la llama es despreciable, confirmando que las pérdidas de calor a las paredes no pueden ser la causa de la extinción que comienza en el punto más alto de la llama. Ante la falta de datos experimentales de la velocidad del gas delante de la llama para el cálculo del alargamiento calcularon numéricamente el campo de velocidad del gas fresco usando la forma del frente registrada en los experimentos y admitiendo que el flujo es irrotacional y la velocidad de la llama relativa al gas coincide con la velocidad de la llama adiabática plana en todos lo puntos del frente. El valor del alargamiento obtenido de este modo es máximo en la punta de la llama, donde comienza la extinción, lo cual concuerda con la hipótesis de que el alargamiento es el mecanismo responsable de la extinción. Además, el valor adimensional (1.1) de la velocidad de alargamiento calculada en este punto es de orden unidad, condición que puede causar la extinción local de llama $[32,33]$.

Los resultados de von Lavante y Strehlow [61] también muestran que el segundo término de la ecuación (1.2) es del orden $U_{0} / R$ anticipado más arriba, donde $U_{0}$ es la velocidad de ascenso de la llama. Si se comparan los órdenes de magnitud de los dos términos de la ecuación, se tiene $\left(U_{L} \boldsymbol{\nabla} \cdot \boldsymbol{n}\right) /(\boldsymbol{n} \cdot \boldsymbol{\nabla} \boldsymbol{v} \cdot \boldsymbol{n}) \sim U_{L} / U_{0}$, que es pequeño en las condiciones de los experimentos, por lo que el alargamiento de la llama se debe fundamentalmente a la velocidad de deformación del flujo (strain rate) delante de la llama. Buckmaster y Mikolaitis [3] han usado estas observaciones sobre el flujo delante de la llama para proponer un criterio de extinción de una llama ascendente en un tubo. Basándose en el análisis bien conocido de una llama en un flujo de punto de remanso axilsimétrico, estos autores proponen que la extinción ocurre en la punta de la llama cuando la velocidad del gas relativa a la misma se hace nula en la región de reacción. El criterio propuesto limita el valor máximo de la velocidad adimensional de alargamiento de la llama (1.1) a un valor de orden unidad. Este criterio predice de forma satisfactoria la extinción de la llama de metano-aire en el tubo de inflamabilidad estándar.

La velocidad de alargamiento de la llama en el punto más alto del frente disminuye al aumentar el radio del tubo. Así pues, si el alargamiento fuese el mecanismo responsable de la extinción, la concentración de metano en el límite de inflamabilidad debería disminuir al aumentar el radio del tubo. Sin embargo, los valores experimentales obtenidos en los trabajos de Levy [31] y Babkin et al. [1] para tubos de diferentes diámetros muestran un ligero aumento al aumentar el diámetro del tubo. La hipótesis de que la extinción es 
causada por el alargamiento de la llama no concuerda con estos resultados experimentales. La hipótesis también entra en conflicto con el análisis teórico si se tienen en cuenta los efectos de la difusión preferencial. Cuando una zona de una llama pobre de metano-aire, con número de Lewis del combustible ligeramente menor que la unidad, se ve sometida a alargamiento, la difusión preferencial aumenta la riqueza de la mezcla en esa zona, intensificando la combustión (ver [64]). La influencia contradictoria de la velocidad de alargamiento en la extinción de la llama sugiere que éste no es el mecanismo que causa la extinción o, al menos no es el único.

La aparición de nuevas técnicas para medir la velocidad del gas, tanto delante como detrás de la llama, ha permitido conocer con mayor profundidad el comportamiento de la llama en el límite de inflamabilidad. En el trabajo de Shoshin y Jarosinski [51] sobre la combustión de mezclas pobres de metano-aire se empleó la técnica de PIV para obtener el campo de velocidades del flujo que induce la llama al ascender por el tubo. Las medidas realizadas en el gas delante de la llama confirman que el alargamiento de la llama es máximo en el punto más alto del frente y que se debe fundamentalmente a la velocidad de deformación del gas. La velocidad del gas en un sistema de referencia ligado a la llama presenta una zona de baja velocidad detrás de la llama. Si se observa la velocidad del gas en el eje del tubo, se pueden ver cuatro regiones [53]:

1. Velocidad constante e igual a $U_{0}$ lejos aguas arriba de la llama.

2. Reducción de la velocidad causada por el ascenso del frente de llama, que actúa como una burbuja.

3. Aceleración del gas causada por la expansión térmica a través de la llama.

4. Zona de baja velocidad detrás de la llama causada por la flotabilidad de los gases calientes.

En los campos fluidos medidos en estos experimentos, Shoshin y sus colaboradores observaron que la zona de baja velocidad detrás de la llama sólo está presente para las riquezas más bajas, y que a veces se acumulan en esta zona las partículas empleadas para sembrar el gas. Considerando que el movimiento de la llama es estacionario y a presión constante, calcularon la temperatura del gas empleando la ecuación de estado de los gases perfectos y la conservación de la masa en un tubo de corriente axilsimétrico coaxial con el tubo, $v A / T=$ cte, donde $v$ es la velocidad del gas, $T$ es su temperatura y $A$ es el área de la sección normal del tubo de corriente [48]. A partir de estas temperaturas determinaron la isoterma de $400 \mathrm{~K}$ que emplearon como posición aproximada del comienzo del frente de llama, donde calcularon la velocidad de deformación del gas siguiendo el procedimiento de la referencia [61]. Obtuvieron así una velocidad de alargamiento parecida a la calculada por von Lavante y Strehlow [61], con valor máximo en la punta de la llama, pero un $25 \%$ menor que el de estos autores.

Aparte de la medición de la velocidad del gas, Shoshin y Jarosinski [51] registraron la temperatura de la llama a partir de la intensidad emitida por unos filamentos de carburo de silicio colocados transversalmente dentro del tubo. Este registro fue cualitativo, ya que la intensidad emitida no fue calibrada, pero permitió observar la distribución de temperatura en una llama pobre. Observaron que la intensidad emitida por los filamentos es mínima 
en el punto más alto de la llama, lo cual refuerza la importancia del estudio de esta zona para comprender los mecanismos de la extinción.

Los resultados experimentales indican que para que se produzca la extinción es necesario que la llama se debilite en el punto más alto del frente. Al obtener en este punto una velocidad de alargamiento de la llama un $25 \%$ inferior a la obtenida por von Lavante y Strehlow [61] y a raíz de que el límite de inflamabilidad en función del diámetro del tubo tiene un comportamiento contrario al que tendría si el alargamiento fuese el mecanismo causante de la extinción, Shoshin y Jarosinski [51] y Shoshin et al. [53] han propuesto que la llama se extingue a causa de las pérdidas por radiación. Este mecanismo ha sido normalmente descartado como responsable de la extinción, al tener normalmente un efecto pequeño sobre las llamas [57], pero la presencia de la zona de baja velocidad detrás de la llama encontrada por estos autores aumenta el tiempo de residencia de los productos de la combustión detrás de la llama y potencia el efecto de estas pérdidas.

En un trabajo previo, Shoshin et al. [52] estudiaron las condiciones de extinción de mezclas de metano-aire en un tubo con 24 mm de diámetro. Mostraron que la llama está sometida a una velocidad de alargamiento mayor que en el tubo estándar y no encontraron velocidades pequeñas detrás de la llama. Estas diferencias indican que los mecanismos de extinción de la llama pueden ser distintos en tubos de diferentes diámetros, o que la extinción se debe a una combinación de varios factores cuya importancia relativa varía al cambiar el diámetro del tubo.

$\mathrm{Al}$ igual que las técnicas de medición recientes han permitido mejorar el conocimiento de los mecanismos responsables de la extinción en el límite de inflamabilidad, también los modelos teóricos han ido haciéndose más precisos, incluyendo efectos que inicialmente se despreciaron. En la referencia [16] se modela una llama axilsimétrica y se tienen en cuenta las pérdidas por radiación. Se ha visto que el valor del límite de inflamabilidad exacto sigue sin ser fácil de determinar, por la falta de un criterio que marque la extinción en los resultados numéricos, aunque la aparición de la zona de baja velocidad detrás de la llama encontrada en $[51,53]$ invita a concluir que el efecto de las pérdidas por radiación juega un papel importante en la extinción de las llamas pobres que se propagan en tubos verticales.

\subsection{Objetivo de la tesis}

Como se ha comentado más arriba, es importante conocer el comportamiento de las llamas en mezclas cercanas al límite de inflamabilidad y poder predecir si la llama se extingue o no, tanto para la seguridad en entornos industriales como para mejorar la eficiencia y reducir las emisiones de contaminantes de las máquinas térmicas. Los esfuerzos empleados en mejorar los modelos teóricos y en ampliar los resultados experimentales a partir de los años cincuenta no han conseguido aún una explicación satisfactoria completa de los mecanismos que intervienen en la extinción de las llamas pobres. En base a las aportaciones previas y a los últimos trabajos experimentales explicados más arriba, el objetivo de esta tesis es ampliar los conocimientos sobre los mecanismos de extinción de la llama realizando un estudio experimental y proponiendo un modelo teórico simplificado que pone de manifiesto la importancia de las pérdidas por radiación en la extinción de llamas pobres en el tubo de inflamabilidad estándar. 
En el capítulo 2 se formula el modelo matemático de la propagación estacionaria de la llama dentro del tubo de inflamabilidad estándar. Se propone un modelo de un frente de llama axilsimétrico, mientras que la combustión se modela mediante una reacción global exotérmica irreversible. Este problema bidimensional se completa con un modelo para evaluar las pérdidas por radiación considerando que el gas es ópticamente delgado. Se presentan los resultados numéricos del modelo para dos casos, tanto incluyendo como despreciando las pérdidas por radiación. También se propone un modelo unidimensional de la llama a lo largo del eje del tubo, que se completa con los datos experimentales explicados en el capítulo 5. Para el modelo unidimensional se emplea tanto el esquema de una única reacción para modelar la combustión como un esquema cinético reducido de cuatro reacciones.

La descripción de la instalación experimental se presenta en el capítulo 3. En este capítulo se explica el montaje del tubo de inflamabilidad, la configuración del sistema que se emplea para realizar la mezcla a ensayar y el método elegido para encender la mezcla.

En el capítulo 4 se presentan las técnicas de medida usadas para el estudio experimental de la llama. Se explica cómo se ha medido la velocidad de ascenso de la llama usando fotografías de la llama y una línea de fotodiodos sensibles a la luz azul, y se explica la técnica de PIV empleada para medir la velocidad del gas alrededor y a través de la llama. Se presenta con detalle la influencia de la resolución de las imágenes empleadas en los errores de estas medidas y cómo afecta a su fiabilidad la dinámica de las partículas empleadas para sembrar el gas. Se hace especial hincapié en la influencia de la fuerza de termoforesis sobre el movimiento de estas partículas a través de la llama y se propone un método para corregir la desviación inducida por este efecto. Finalmente se detalla el sistema de sembrado utilizado.

En el capítulo 5 se presentan y discuten los resultados experimentales obtenidos. Primero se presentan los resultados visuales de la extinción de la llama, que concuerdan con las observaciones realizadas por otros investigadores expuestas más arriba. Se muestra la velocidad de ascenso de la llama en función de la riqueza, incluyendo un análisis de los errores de estas medidas. Se presentan a continuación los campos de velocidad del gas alrededor de la llama para varias riquezas cercanas al límite de inflamabilidad, y se explica la evolución de la velocidad del gas en el eje del tubo previa a la extinción. Finalmente se analiza la influencia de las pérdidas por radiación al sustituir parte del nitrógeno del aire por dióxido de carbono para potenciar de forma controlada la magnitud de éstas pérdidas.

Finalmente se resumen las conclusiones finales del trabajo, que completan las conclusiones presentadas al final de algunos capítulos. También se exponen las posibles líneas de trabajo futuro como estudiar el comportamiento de la extinción en mezclas con combustibles con menor difusividad en aire que la del metano y medir de forma directa la temperatura a través de la llama. 


\section{Capítulo 2}

\section{Definición del problema}

La gravedad, en combinación con la variación de la densidad del gas que atraviesa la llama, juega un papel dominante en la propagación ascendente de una llama en un tubo lleno de una mezcla pobre de metano y aire. La forma y velocidad del frente de llama son muy similares a las de una burbuja que sube en un tubo lleno de un líquido. El frente consiste en una cabeza aproximadamente hemisférica seguida de una falda casi cilíndrica cuya longitud aumenta al disminuir la riqueza de la mezcla. El orden de magnitud de la velocidad de ascenso de la llama $\left(U_{0}^{*}\right)$ es $U_{0}^{*} \sim \sqrt{g R^{* 1}}$, donde $g$ es la aceleración de la gravedad y $R^{*}$ es el radio del tubo. Este resultado se obtiene del balance entre la aceleración del gas y la de la gravedad; $\rho \boldsymbol{v} \cdot \boldsymbol{\nabla} \boldsymbol{v} \sim \rho \boldsymbol{g}$ en la ecuación de cantidad de movimiento en un sistema de referencia ligado al frente de llama). Con más precisión, la fórmula de Davies y Taylor [7] para la velocidad de ascenso de una burbuja en un tubo,

$$
U_{0}^{*}=0.464 \sqrt{\left(1-\frac{\rho_{2}}{\rho_{1}}\right) g R},
$$

donde $\rho_{1}$ y $\rho_{2}$ son las densidades de los fluidos en el tubo y en la burbuja, proporciona una buena aproximación para la velocidad de ascenso de la llama cuando $\rho_{1}$ y $\rho_{2}$ se sustituyen por las densidades del gas delante y detrás de la llama.

Cuando la mezcla es muy pobre la velocidad $U_{0}^{*}$ es grande comparada con la velocidad de avance de la llama respecto al gas fresco $\left(U_{0}^{*}\right.$ es del orden de $20 \mathrm{~cm} / \mathrm{s}$ para el tubo de inflamabilidad estándar, de radio $R^{*}=25.5 \mathrm{~cm}$, y $\rho_{2} / \rho_{1}=1 / 5$, mientras que la velocidad de avance de la llama adiabática plana $\left(U_{L}^{*}\right)$ es unos pocos centímetros por segundo para la riqueza correspondiente al límite de inflamabilidad). Debido a esto, el punto más alto del frente de llama, en el eje del tubo, está cerca del punto de remanso delantero del flujo equivalente alrededor de una burbuja, mientras que el resto del frente es próximo a la línea de corriente de este flujo que coincide con la superficie de la burbuja. Por la misma razón, el cociente entre la longitud de la falda de la llama y el radio del tubo es grande, de orden $U_{0}^{*} / U_{L}^{*}$.

\footnotetext{
${ }^{1}$ En la ecuaciones se empleará el superíndice * para designar las variables que tienen dimensiones y cuyos nombres se puedan confundir con los de las variables adimensionales que se definirán más adelante.
} 


\subsection{Formulación del problema}

Para el planteamiento de un modelo analítico de la propagación de una llama dentro de un tubo vertical se considera que el frente de llama es axilsimétrico y se propaga con velocidad vertical. La longitud del tubo es mucho mayor que su diámetro, por lo que se considera infinito. El radio del tubo es $R^{*}$ y su pared se mantiene a temperatura constante e igual a la temperatura ambiente $T_{u}$. El tubo está lleno de una mezcla pobre de metano-aire de densidad $\rho_{u}$ y temperatura $T_{u}$, y la fracción másica del combustible es $Y_{u}$. La velocidad de ascenso de la llama, $U_{0}^{*}$, que debe calcularse como parte de la solución, es mucho menor que la velocidad del sonido, por lo que se desprecian los efectos de compresibilidad en la mezcla.

La mezcla se considera un gas perfecto con capacidad calorífica, $c_{p}$, y masa molecular media, $\mathcal{M}_{T}$, constantes. La viscosidad, $\mu^{*}$, la conductividad, $\lambda^{*}$, y las difusividades de las especies, $D_{i}^{*}$, varían como potencias de la temperatura:

$$
\frac{\mu^{*}}{\mu_{u}^{*}}=\frac{\lambda^{*}}{\lambda_{u}^{*}}=\frac{\rho^{*} D_{i}^{*}}{\rho_{u}^{*} D_{i_{u}}^{*}}=\left(\frac{T}{T_{u}}\right)^{\kappa}
$$

En la ecuación anterior el subíndice $u$ se refiere a las condiciones aguas arriba de la llama y el subíndice $i$ se refiere a cada una de las especies de la mezcla. Utilizando un valor de $\kappa=0.75$ se obtienen resultados adecuados para este problema, por lo que no se considera necesario recurrir a modelos más exactos del transporte molecular para mezclas de metano-aire, como el desarrollado por Smoke y Giovangigli [54]. Al modelar la viscosidad, la conductividad y la difusividad molecular usando la misma función potencial de la temperatura, los números de Prandtl, $\operatorname{Pr}=\mu^{*} c_{p} / \lambda^{*}$, y Lewis, $\mathrm{Le}_{i}=\lambda^{*} / \rho^{*} c_{p} D_{i}^{*}$, se mantienen constantes al variar la temperatura de la mezcla.

En la figura 2.1 se presenta de manera esquemática el problema de la propagación de la llama. Para la descripción del movimiento se usa un sistema de referencia ligado al frente de llama. Se emplean los ejes $\left(x^{*}, r^{*}\right)$ de la figura, con origen en un punto del eje del tubo que se define más adelante y $x^{*}$ apuntando hacia abajo, y se modela la combustión en la llama como una única reacción de Arrhenius irreversible para metanoaire, $\mathrm{CH}_{4}+2 \mathrm{O}_{2} \rightarrow \mathrm{CO}_{2}+2 \mathrm{H}_{2} \mathrm{O}$. Las ecuaciones que describen el problema son

$$
\begin{aligned}
& \boldsymbol{\nabla} \cdot\left(\rho^{*} \boldsymbol{v}^{*}\right)=0, \\
& \rho^{*} \boldsymbol{v}^{*} \cdot \boldsymbol{\nabla} \boldsymbol{v}^{*}=-\boldsymbol{\nabla} p^{*}+\rho^{*} g \boldsymbol{i}+\boldsymbol{\nabla} \cdot \tau^{\prime *}, \\
& \rho^{*} \boldsymbol{v}^{*} \cdot \nabla T=\boldsymbol{\nabla} \cdot\left(\lambda^{*} \nabla T\right)+q w-L^{*}, \\
& \rho^{*} \boldsymbol{v}^{*} \cdot \nabla Y_{i}^{*}=\frac{1}{L e_{i}} \boldsymbol{\nabla} \cdot\left(\rho^{*} D_{i}^{*} \nabla Y_{i}^{*}\right)+s_{i} w, \\
& r^{*}=R^{*}: \quad \boldsymbol{v}^{*}=U_{0}^{*} \boldsymbol{i}, T=T_{u}, \frac{\partial Y_{i}^{*}}{\partial r^{*}}=0, \\
& x^{*} \rightarrow-\infty: \quad \boldsymbol{v}^{*}=U_{0}^{*} \boldsymbol{i}, T=T_{u}, Y_{i}^{*}=Y_{i_{u}}^{*}, \\
& x^{*} \rightarrow+\infty: \quad \frac{\partial \boldsymbol{v}^{*}}{\partial x^{*}}=\frac{\partial T}{\partial x^{*}}=\frac{\partial Y_{i}^{*}}{\partial x^{*}}=0,
\end{aligned}
$$

completadas con las ecuaciones de estado de un gas perfecto. En la ecuación (2.4) $g$ es la aceleración de la gravedad, $\tau^{\prime *}=\mu^{*}\left[\boldsymbol{\nabla} \boldsymbol{v}^{*}+\left(\boldsymbol{\nabla} \boldsymbol{v}^{*}\right)^{T}\right]$ es la parte no esférica del 


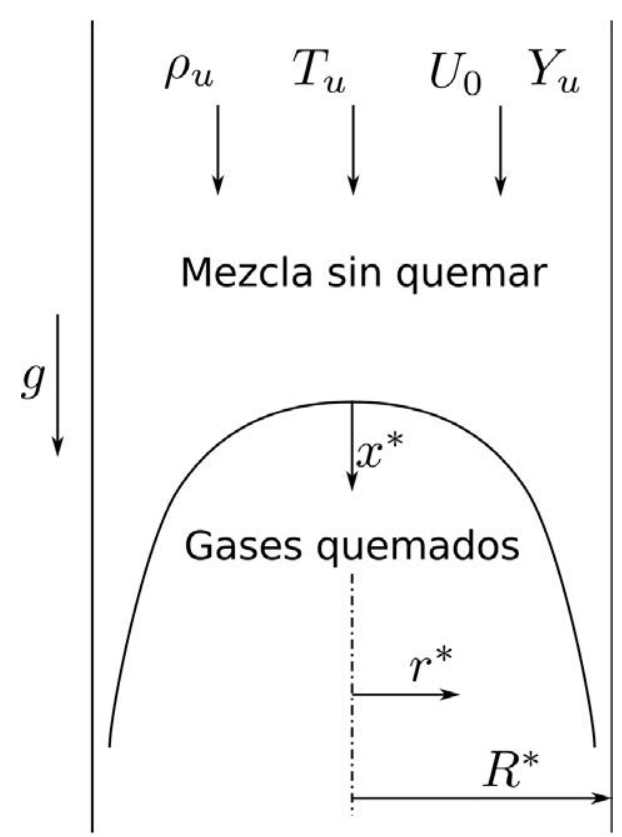

Figura 2.1: Esquema de la llama dentro del tubo empleado para el planteamiento del modelo.

tensor de esfuerzos viscosos y $p^{*}$ es la presión del gas más la parte esférica del tensor de esfuerzos viscosos, $\left(\mu_{v}^{*}-2 \mu^{*} / 3\right) \nabla \cdot \boldsymbol{v}^{*}$. El término $q w$ de la ecuación (2.5) es la energía liberada por la combustión por unidad de volumen y de tiempo, siendo $q$ el poder calorífico del combustible (cantidad de energía desprendida por unidad de masa de combustible quemado) y $w$ la masa de combustible consumida por unidad de volumen de gas y por unidad de tiempo, cuya expresión se da más abajo en (2.11). El término $L^{*}$ de esta ecuación representa las pérdidas de calor por radiación del gas caliente, dadas por (2.14) más abajo. En las ecuaciones de conservación de las especies (2.6), $s_{i}$ son coeficientes constantes que relacionan el consumo de combustible con la producción de productos. Para el combustible se tiene $s_{F}=-1$. En las condiciones de contorno (2.7-2.9) se considera que la pared está a la temperatura ambiente, $T_{u}$, y su velocidad en el sistema de referencia ligado al frente de la llama es igual a la velocidad de ascenso de la llama en el tubo. Lejos aguas arriba de la llama, para $x^{*} \rightarrow-\infty$, la mezcla se encuentra en su estado inicial, y la concentración de cada especie es la correspondiente a la mezcla fresca que se ensaya en el tubo de inflamabilidad. En particular los productos de la reacción tendrán concentración nula. Lejos aguas abajo de la llama, para $x^{*} \rightarrow \infty$, se considera que se ha alcanzado el equilibrio químico, por lo que la temperatura y las concentraciones de las especies no varían. (En realidad la temperatura disminuye suavemente hasta $T_{u}$ debido a las pérdidas por radiación y por conducción hacia la pared del tubo, pero esta disminución es muy lenta para los valores de $L^{*}$ y $R^{*}$ que se considerarán).

El problema estacionario (2.3)-(2.9) sólo tiene solución para un cierto valor de $U_{0}^{*}$, que debe calcularse. Para otros valores de $U_{0}^{*}$, el frente de la llama avanza continuamente hacia arriba, contra la corriente de aire fresco, o es barrido por ella. Para fijar la posición de la llama en el dominio donde se calcula la solución, se impone que en un cierto punto del eje 
del tubo que se toma como origen $\left(x^{*}=r^{*}=0\right)$ la temperatura tenga un valor constante, $T=T_{u}+\left(T_{e q}-T_{u}\right) \theta_{0}$, donde $T_{e q}$ es la temperatura adiabática de llama introducida más abajo y $\theta_{0}$ es una constante, típicamente igual a 0.8 . Esta condición determina $U_{0}^{*}$.

\subsubsection{Esquema cinético de una única reacción}

Como se ha comentado anteriormente, la llama se modela empleando una única reacción irreversible de Arrhenius para describir la combustión del metano en el aire:

$$
\mathrm{CH}_{4}+2 \mathrm{O}_{2} \rightarrow \mathrm{CO}_{2}+2 \mathrm{H}_{2} \mathrm{O} \text {. }
$$

Aunque éste es un modelo cinético demasiado simplificado para describir fielmente la cinética real de la combustión de una llama, es suficiente para poder analizar otros efectos, tales como el efecto de la gravedad, el de la expansión térmica o el de las pérdidas por radiación, cuya descripción es parte del objetivo de esta tesis. El consumo de combustible para una reacción de Arrhenius es

$$
w=\rho^{*} B Y_{F}^{*} \exp \left(-\frac{T_{a}}{T}\right),
$$

donde $\rho^{*}$ y $T$ son la densidad y la temperatura local del gas, $B$ es el factor de frecuencia y $T_{a}$ es la temperatura de activación de la reacción.

La temperatura adiabática de llama que se obtiene de un balance global de entalpía para una llama plana no sometida a alargamiento es $T_{e q}=T_{u}+q Y_{u} / c_{p}$. Se emplea el parámetro adimensional $\gamma=\left(T_{e q}-T_{u}\right) / T_{u}$ para medir la expansión térmica del gas en la llama, mientras que el número de Zeldovich, $\beta=T_{a}\left(T_{e q}-T_{u}\right) / T_{e q}^{2}$, mide la sensibilidad de la reacción química con la temperatura. La velocidad de la llama plana adiabática que se obtiene del análisis asintótico para $\beta \rightarrow \infty$ es [64]

$$
U_{L}^{\infty}=\frac{\left(2 D_{e q} B\right)^{1 / 2} \operatorname{Le}_{F}}{\beta(\gamma+1)} \exp \left(-\frac{\beta}{2} \frac{\gamma+1}{\gamma}\right)
$$

donde $D_{e q}=D_{F}\left(T_{e q}\right)$ es la difusividad del combustible a la temperatura $T_{e q}$ y $\operatorname{Le}_{F}$ es su número de Lewis. La velocidad (2.12) se emplea para determinar el espesor de la llama plana,

$$
\delta_{L}=\frac{\lambda_{u}}{\rho_{u} U_{L}^{\infty} c_{p}} .
$$

En la ecuación (2.11) se desconocen los valores del factor de frecuencia y de la temperatura de activación. Para determinar estos valores se ha optado por escoger un caso de referencia del que se conozcan datos experimentales de la velocidad de la llama plana. Los datos del caso de referencia elegido son $T_{u}=300 \mathrm{~K} \mathrm{y} Y_{u_{r}}=0.03^{1}$, de tal forma que, usando los valores $c_{p}=1287 \mathrm{~J} / \mathrm{kgK}$ para el calor específico de la mezcla y $q=51.48 \mathrm{MJ} / \mathrm{kg}$ para el poder calorífico del metano, se obtiene $T_{e q_{r}}=1500 \mathrm{~K} \mathrm{y} \gamma_{r}=4$. En este caso la velocidad de la llama plana es $U_{L_{r}}=4.63 \mathrm{~cm} / \mathrm{s}$ [8]. Para cada valor de la temperatura de activación $T_{a}$ se elige el valor del factor de frecuencia $B$ para que la velocidad $U_{0}^{*}$, calculada resolviendo el problema (2.3)-(2.6),(2.8) y (2.9) en una dimensión y sin pérdidas por

\footnotetext{
${ }^{1}$ Se empleará el subíndice $r$ para las variables cuyo valor sea el correspondiente al caso de referencia
} 
radiación $\left(L^{*}=0\right)$, coincida con el valor de la velocidad real, $U_{L_{r}}$ para el caso de referencia. Para reducir las posibles combinaciones de $T_{a}$ y $B$ a un única posibilidad, se ajustan las velocidades calculadas numéricamente usando el modelo de una única reacción a los resultados experimentales de Yamaoka y Tsuji [66] para mezclas muy pobres extrapolados al límite de velocidad de alargamiento nula (ver referencia [62]). El valor de $T_{a}$ que mejor se ajusta a estos datos experimentales es $T_{a}=18500 \mathrm{~K}$, para el que se tiene $\beta_{r}=10$. Este valor de la temperatura de activación es acorde a los resultados de Westbrook y Dryer [63]. En la figura 2.2 se muestran los valores experimentales de la velocidad de la llama plana así como la velocidad calculada numéricamente con esquema cinético de una reacción (curva continua) y con la fórmula asintótica (2.12) (curva de trazos), como funciones de la riqueza de la mezcla; $\phi=4 Y_{u} / Y_{\mathrm{O}_{2 u}}=17.39 Y_{u} /\left(1-Y_{u}\right)$ para una mezcla de metano y aire, para la que la fracción másica de oxígeno es $Y_{\mathrm{O}_{2} u}=0.23\left(1-Y_{u}\right)$.

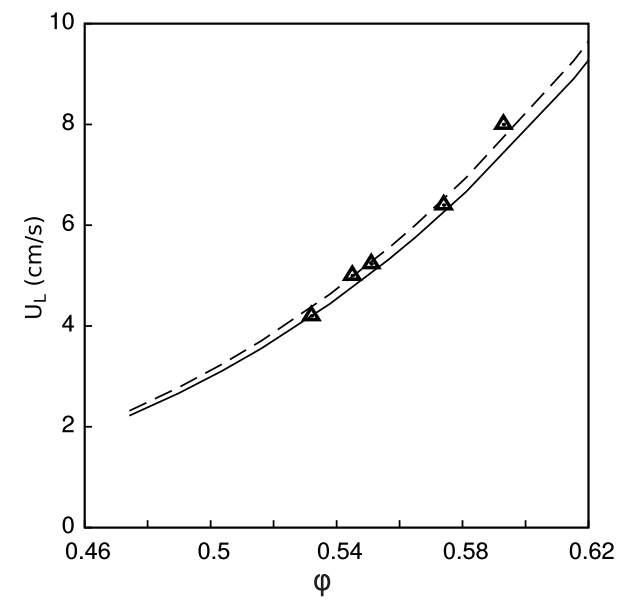

Figura 2.2: Velocidad de la llama plana como función de la riqueza de la mezcla. Los triángulos son los datos experimental de [66] corregidos como en [62]. La curva continua es la velocidad calculada numéricamente para cinética de una reacción con $T_{a}=18500 \mathrm{~K}$ y la curva de trazos corresponde a la velocidad asintótica, $U_{L}^{\infty}$, para esta misma temperatura de activación.

\subsubsection{Modelo de las pérdidas por radiación}

La emisión y la absorción de radiación por las moléculas de un gas son procesos simétricos. Para incluir las pérdidas por radiación en la ecuación de la energía hay que definir previamente la capacidad de emisión/absorción de la radiación térmica por parte de los productos y por la mezcla sin quemar. Esta capacidad de un gas depende del espesor óptico,

$$
\tau=\frac{S}{L_{p}}
$$

donde $S$ es la longitud característica de la región ocupada por el gas y $L_{p}$ es la distancia media de absorción del gas. Si $S \gg L_{p}$, de modo que un rayo tiene que recorrer una distancia $S$ grande comparada con la distancia media de absorción $L_{p}$, toda la energía transportada por el rayo será absorbida por las moléculas del gas. En este caso el gas se 
considera ópticamente grueso. Si por el contrario, $S \ll L_{p}$, el gas es ópticamente delgado; en este caso las moléculas absorben sólo una pequeña parte de la energía de la radiación, que se puede despreciar. Para las mezclas que consideramos, a presión atmosférica, se tiene $L_{p} \sim 1 \mathrm{~m}$ [23]. En el caso de una llama propagándose en un tubo vertical, la mayor parte de la radiación, que los productos de la combustión emiten en todas las direcciones, sólo tiene que atravesar espesores de gas del orden del radio del tubo, por lo que $\tau \ll 1$ y el gas se puede considerar ópticamente delgado. Sólo para los rayos que se propagan hacia arriba podría haber absorción apreciable de la radiación emitida por los productos, ya que en este caso $S \sim L_{p}$. Sin embargo, aguas arriba de la llama la única especie que puede absorber la radiación es el metano, cuya concentración es muy baja. Debido a la baja concentración de metano y al pequeño valor del ángulo sólido correspondiente a la emisión de radiación hacia la parte superior del tubo, se puede despreciar la absorción para todo el gas del tubo, tanto para los productos como para la mezcla sin quemar. Teniendo en cuenta las consideraciones anteriores, las pérdidas por radiación se modelan suponiendo que el gas se comporta como ópticamente delgado. Supondremos, además, que la pared del tubo es totalmente transparente, por las razones que se discuten más adelante. En este caso el calor perdido por la unidad de volumen de gas por unidad de tiempo a causa de la radiación es

$$
L^{*}=4 \sigma K_{p}\left(T^{4}-T_{u}^{4}\right),
$$

donde $\sigma$ es la constante de Stefan-Boltzmann, $K_{p}$ es el coeficiente de absorción medio de Planck y $T_{u}$ es la temperatura ambiente a la que se encuentran tanto el aire fuera del tubo como las paredes del tubo en la zona de ensayo. El término $4 \sigma K_{p} T_{u}^{4}$ de esta ecuación representa, de forma aproximada, la energía recibida del medio que rodea el tubo.

El coeficiente de absorción media de Planck es la suma de los coeficientes de absorción de las especies que componen la mezcla, cada uno de los cuales es proporcional a la presión parcial de esa especie. En la combustión del metano las especies que más radian son el $\mathrm{CO}_{2}, \mathrm{H}_{2} \mathrm{O}, \mathrm{CO}$ y $\mathrm{CH}_{4}$ [24]. Como veremos, las pérdidas por radiación que podrían causar la extinción de la llama se originan en una zona de velocidad baja que hay detrás de un frente de llama muy pobre [52], por lo que, teniendo en cuenta que en estas llamas se quema todo el combustible y que el CO se encuentra únicamente en la zona de reacción, las especies que hay que tener en cuenta en este caso son el dióxido de carbono y el vapor de agua. Por lo tanto admitiremos que

$$
K_{p}=P_{\mathrm{CO}_{2}} K_{\mathrm{CO}_{2}}+P_{\mathrm{H}_{2} \mathrm{O}} K_{\mathrm{H}_{2} \mathrm{O}}
$$

Los coeficientes $K_{\mathrm{CO}_{2}}$ y $K_{\mathrm{H}_{2} \mathrm{O}}$ dependen de las bandas de absorción de cada especie y son funciones de la temperatura. Los valores de $K_{\mathrm{CO}_{2}}$ y $K_{\mathrm{H}_{2} \mathrm{O}}$ que emplearemos son los obtenidos con el modelo SNB (Statistical narrow-band) propuesto por Malkmus [34]. Se ha comprobado que este modelo da resultados más precisos que otros modelos narrow-band para mezclas de $\mathrm{CO}_{2}, \mathrm{H}_{2} \mathrm{O}$ y aire [56]. Ju et al. [24] han calculado los valores de $K_{\mathrm{CO}_{2}}$ y $K_{\mathrm{H}_{2} \mathrm{O}}$ y los han tabulado como funciones de la temperatura, empleando los parámetros necesarios para completar el modelo SNB de Soufiani y Taine [55] para el $\mathrm{CO}_{2}$ y el $\mathrm{H}_{2} \mathrm{O}$. Los valores así calculados se reproducen en la tabla 2.1.

Los cálculos se pueden simplificar si se tiene en cuenta que las difusividades del $\mathrm{CO}_{2}$ y del $\mathrm{H}_{2} \mathrm{O}$ son parecidas, y se hace la aproximación $\mathrm{Le}_{\mathrm{CO}_{2}}=\mathrm{Le}_{\mathrm{H}_{2} \mathrm{O}}$. En estas condiciones, como los ritmos de producción de ambas especies son proporcionales (ver (2.6)), sus 


\begin{tabular}{c|ccc|ccc}
\hline $\mathrm{T}(\mathrm{K})$ & $K_{\mathrm{CO}_{2}}$ & $K_{\mathrm{H}_{2} \mathrm{O}}$ & $K_{\mathrm{CO}}$ & $K_{\mathrm{CO}_{2}} T$ & $K_{\mathrm{H}_{2} \mathrm{O}} T$ & $K_{C O} T$ \\
\hline 300 & 26.04747 & 46.79578 & 0.08534 & 7814.24 & 14038.7 & 25.602 \\
400 & 27.62688 & 27.61953 & 0.32402 & 11050.8 & 11047.8 & 129.608 \\
500 & 30.53680 & 18.51842 & 0.58683 & 15268.4 & 9259.21 & 293.415 \\
600 & 34.42830 & 13.59447 & 4.12013 & 20657.0 & 8156.68 & 2472.08 \\
700 & 33.23986 & 10.12392 & 8.43939 & 23267.9 & 7086.74 & 5907.57 \\
800 & 30.97672 & 7.93460 & 6.97723 & 24781.4 & 6347.68 & 5581.78 \\
900 & 26.80022 & 6.26079 & 5.12998 & 24120.2 & 5634.71 & 4616.98 \\
1000 & 23.12449 & 5.12263 & 4.10991 & 23124.5 & 5122.63 & 4109.91 \\
1100 & 19.25740 & 4.20339 & 3.13242 & 21183.1 & 4623.73 & 3445.66 \\
1300 & 13.52917 & 2.97398 & 1.99050 & 17587.9 & 3866.17 & 2587.65 \\
1500 & 9.59112 & 2.19070 & 1.31217 & 14386.7 & 3286.05 & 1968.26 \\
1700 & 6.95019 & 1.66126 & 0.89445 & 11815.3 & 2824.14 & 1520.57 \\
1900 & 5.14353 & 1.28921 & 0.62820 & 9772.71 & 2449.50 & 1193.58 \\
2100 & 3.88488 & 1.01891 & 0.45299 & 8158.25 & 2139.71 & 951.279 \\
2300 & 2.98017 & 0.81569 & 0.33432 & 6854.39 & 1876.09 & 768.936 \\
2500 & 2.31946 & 0.65969 & 0.25182 & 5798.65 & 1649.22 & 629.550 \\
2700 & 1.90207 & 0.54777 & 0.21137 & 5135.59 & 1478.98 & 570.699 \\
2900 & 1.57858 & 0.45761 & 0.17890 & 4577.88 & 1327.07 & 518.810 \\
\hline
\end{tabular}

Tabla 2.1: Coeficientes de absorción media de Planck para las especies $\mathrm{CO}_{2}, \mathrm{H}_{2} \mathrm{O}$ y $\mathrm{CO}$ calculados con el modelo SNB (statistical narrow-band). Unidades: (atm M) ${ }^{-1}$. Fuente: Ju et al. [24].

fracciones másicas también lo serán: $Y_{\mathrm{CO}_{2}} / s_{\mathrm{CO}_{2}}=Y_{\mathrm{H}_{2} \mathrm{O}} / s_{\mathrm{H}_{2} \mathrm{O}}$, y $P_{\mathrm{H}_{2} \mathrm{O}}=2 P_{\mathrm{CO}_{2}}$. Por otra parte, para expresar las presiones parciales en términos de las fracciones másicas, se pueden despreciar las masas de $\mathrm{CO}_{2}$ y de $\mathrm{H}_{2} \mathrm{O}$ frente a la suma de las masas de $\mathrm{O}_{2}$ y de $\mathrm{N}_{2}$ en la mezcla, ya que estas últimas son mucho mayores para las mezclas pobres. Con esta aproximación, el número de moles total es $n_{T} \simeq n_{\mathrm{O}_{2}}+n_{\mathrm{N}_{2}}$ y las presiones parciales son

$$
\frac{P_{\mathrm{CO}_{2}}}{P} \simeq \frac{Y_{\mathrm{CO}_{2}} / 44}{0.23 / 32+0.77 / 28}=0.655 Y_{\mathrm{CO}_{2}} \quad \text { y } \quad \frac{P_{\mathrm{H}_{2} \mathrm{O}}}{P} \simeq \frac{Y_{\mathrm{H}_{2} \mathrm{O}} / 18}{0.23 / 32+0.77 / 28}=1.6 Y_{\mathrm{H}_{2} \mathrm{O}}
$$

En el cálculo, cuando se usan estas simplificaciones, $Y_{\mathrm{CO}_{2}}=Y_{P}^{*}$ e $Y_{\mathrm{H}_{2} \mathrm{O}}=(44 / 18) Y_{p}^{*}$, donde $Y_{p}^{*}$ es la única fracción másica que se calcula. Suponiendo que los productos cumplen la ecuación de estado de los gases perfectos, la ecuación (2.14) se puede reescribir:

$$
L^{*}=2.62 \sigma R_{g} \rho^{*} Y_{P}^{*} T\left(K_{\mathrm{CO}_{2}}+2 K_{\mathrm{H}_{2} \mathrm{O}}\right)\left(T^{4}-T_{u}^{4}\right),
$$

donde $R_{g}$ es la constante del aire.

Como se ve en la tabla 2.1, el factor $T\left(K_{\mathrm{CO}_{2}}+2 K_{\mathrm{H}_{2} \mathrm{O}}\right)$ tiene sólo una ligera dependencia con la temperatura en el rango de temperaturas típico de los productos de una llama, en el que este factor decrece ligeramente cuando la temperatura aumenta. Aprovechando este 
hecho, el factor se sustituye con su valor $0.25 \mathrm{~K} / \mathrm{Pa} \cdot \mathrm{m}$ correspondiente a una temperatura $T=1300 \mathrm{~K}$. Se ha comprobado que esta aproximación no cambia apreciablemente los resultados obtenidos.

\section{Aproximación de pared transparente}

El tubo empleado para la realización de los experimentos no es perfectamente transparente a la radiación visible e infrarroja emitida por los productos de la combustión, sino que la pared del tubo absorbe y refleja parcialmente esta radiación. La influencia de este intercambio de radiación depende de las propiedades ópticas y térmicas de la pared del tubo, así como de su espesor. A continuación se analiza la influencia de la pared del tubo para comprobar la validez de la hipótesis de tubo totalmente transparente tomada al suponer que la radiación no se refleja en el tubo y que por lo tanto el espesor del gas que atraviesa es mucho más pequeño que la distancia media de absorción del gas.

En el caso en el que la pared del tubo refleje una parte de la radiación de vuelta al interior del tubo, el espesor de gas que atraviesa la radiación emitida es un múltiplo del radio del tubo y se podría dar el caso de absorción total para paredes perfectamente reflectante. Sin embargo, hay que tener en cuenta que en cada reflexión la radiación se atenúa, siendo la atenuación mayor cuanto menor sea la reflectividad de la pared, $\rho_{w}$. Para el caso de un gas a temperatura uniforme encerrado por paredes frías [19], las pérdidas por radiación disminuyen en un factor de orden $K_{p} R^{*} /\left(1-\rho_{w}\right)$ debido a las múltiples reflexiones. El valor de $K_{p} R^{*}$ es muy pequeño, por lo que la disminución de las pérdidas será pequeña, salvo para paredes muy reflectantes, con $\rho_{w}$ cercano a la unidad. El empleo de tubos con paredes transparentes de plexiglas, vidrio o cuarzo permite despreciar la disminución de las pérdidas por radiación debida a las reflexiones en la pared, aunque este efecto se podría tener en cuenta en el modelo reduciendo ligeramente el valor de $K_{p}$. En cualquier caso, a la vista de estas estimaciones, se puede concluir que la hipótesis de paredes perfectamente transparentes es válida para el modelo considerado.

\section{Aproximación de pared fría}

Para obtener una estimación conservativa del aumento de la temperatura de la pared del tubo debido a la radiación de la llama en una región de longitud característica $R^{*}$ alrededor del punto más alto del frente, se puede admitir que: (a) toda la radiación emitida por el gas caliente en esta región, de orden $L_{b}^{*} R^{* 3}$, donde $L_{b}^{*} \sim \sigma K_{p} T_{e q}^{4}$ es el valor característico de $L^{*}$ en el gas quemado, es absorbida en la superficie interna de la pared; y (b) las pérdidas de calor a través de las superficies interna y externa de la pared son despreciables. En el sistema de referencia ligado al frente, la pared se mueve hacia abajo con velocidad $U_{0}^{*}$. El espesor característico de la capa de sólido calentado por conducción desde la superficie interna más caliente de la pared es $b=\operatorname{mín}\left(d_{p}, \sqrt{\lambda_{s} R^{*} / \rho_{s} c_{s} U_{0}^{*}}\right)$, donde $d_{p}$ es el espesor de la pared y $\rho_{s}, c_{s}$ y $\lambda_{s}$ son la densidad, calor específico y conductividad térmica del sólido. El aumento $\Delta T_{p}$ de la temperatura de la pared en esta capa se puede estimar mediante el balance de energía $\rho_{s} c_{s} U_{0}^{*} R^{*} b \Delta T_{p} \sim L_{b}^{*} R^{* 3}$, que da

$$
\frac{\Delta T_{p}}{T_{u}} \sim \frac{\sigma K_{p} T_{e q}^{4} R^{* 2}}{\rho_{s} c_{s} U_{0}^{*} b T_{u}} .
$$


Para el tubo estándar $\left(R^{*}=25.5 \mathrm{~mm}\right)$, con las propiedades térmicas del Plexiglas y $U_{0}^{*}=21 \mathrm{~cm} / \mathrm{s}$, se tiene $\sqrt{\lambda_{s} R^{*} / \rho_{s} c_{s} U_{0}^{*}}=0.11 \mathrm{~mm}$, de modo que, si $d_{p}$ es mayor que este valor, $\Delta T_{p} / T_{u} \sim$ $1.5 \times 10^{-2}$, lo que justifica despreciar el calentamiento de la pared. Del mismo modo, $\Delta T_{p} / T_{u} \sim 5.6 \times 10^{-3}$ para un tubo de cuarzo, y $\Delta T_{p} / T_{u} \sim 3.84 \times 10^{-4}$ para un tubo de aluminio cuya pared tenga un espesor mayor que unos $3 \mathrm{~mm}$. Esta estimación de $\Delta T_{p}$ es para una región de longitud característica $R^{*}$ que se desplaza con la llama. El aumento de temperatura debido a la radiación del gas caliente y a la conducción de calor desde la falda de la llama será mayor aguas debajo de esta región. Aunque este calentamiento no tiene un efecto apreciable sobre la propagación de la llama, es de interés para calcular el tiempo de enfriamiento del tubo, que es el tiempo mínimo que debe transcurrir entre experimentos sucesivos hechos en el mismo tubo.

\subsubsection{Adimensionalización del problema}

En las secciones anteriores se han escrito las ecuaciones de conservación y condiciones de contorno (2.3)-(2.9) que, junto con (2.2), (2.11), (2.14)-(2.17) y la ecuación de estado de los gases perfectos, describen el problema con un modelo cinético de una reacción para describir la llama y un modelo basado en el SNB para evaluar las pérdidas por radiación. Antes de proceder a la resolución numérica, conviene adimensionalizar el problema. Al analizar las ecuaciones se observa que las posibles magnitudes que pueden servir para adimensionalizar dependen de la riqueza de la mezcla: $\gamma, \beta, U_{L}$ y $\delta_{L}$ son funciones de $Y_{u}$. Por ello, para facilitar la comparación de resultados para diferentes riquezas, se usarán los datos del caso de referencia presentando en la sección 2.1.1 para adimensionalizar las ecuaciones. En este caso $U_{L r}=4.63 \mathrm{~cm} / \mathrm{s}$, que se usará para adimensionalizar las velocidades, y $\delta_{L r}=0.43 \mathrm{~mm}$, que se usará para adimensionalizar las distancias. Se debe tener en cuenta que los valores de los parámetros adimensionales $\gamma$ y $\beta$, definidos en el texto encima de (2.12) varían con la concentración de combustible y se pueden calcular a partir de sus valores para el caso de referencia. Así,

$$
\frac{\gamma}{\gamma_{r}}=\frac{Y_{u}}{Y_{u_{r}}} \quad \mathrm{y} \quad \frac{\beta}{\beta_{r}}=\frac{\gamma}{\gamma_{r}}\left(\frac{\gamma_{r}+1}{\gamma+1}\right)^{2}
$$

Una consecuencia de esta adimensionalización es que aparece un parámetro artificial al adimensionalizar el término de producción de energía, que es la relación entre las velocidades asintóticas (2.12) de la llama plana para la riqueza del caso estudiado y la del caso de referencia:

$$
U_{f}=\frac{U_{L}^{\infty}}{U_{L r}^{\infty}}=\left(\frac{\gamma+1}{\gamma_{r}+1}\right)^{(\kappa+3) / 2} \frac{\gamma_{r}}{\gamma} \exp \left[-\frac{\beta}{2} \frac{\gamma+1}{\gamma_{r}+1}\left(1-\frac{\gamma_{r}}{\gamma}\right)\right]
$$

La densidad se escala con $\rho_{u}$ y las fracciones másicas de las especies con $Y_{u}$. La presión y el esfuerzo viscoso se adimensionalizan con $\rho_{u} U_{L r}^{2}$. La temperatura adimensional es $\theta=\left(T-T_{u}\right) /\left(T_{e q}-T_{u}\right)$. En términos de estas variables, las ecuaciones adimensionales 
que describen el problema son:

$$
\begin{aligned}
& \boldsymbol{\nabla} \cdot(\rho \boldsymbol{v})=0, \\
& \rho \boldsymbol{v} \cdot \boldsymbol{\nabla} \boldsymbol{v}=-\boldsymbol{\nabla} p+\rho G \boldsymbol{i}+\boldsymbol{\nabla} \cdot \tau^{\prime}, \\
& \rho \boldsymbol{v} \cdot \boldsymbol{\nabla} \theta=\boldsymbol{\nabla}(\lambda \boldsymbol{\nabla} \theta)+W-L, \\
& \rho \boldsymbol{v} \cdot \boldsymbol{\nabla} Y_{F}=\frac{1}{L e_{F}} \boldsymbol{\nabla} \cdot\left(\lambda \nabla Y_{F}\right)-W, \\
& \rho \boldsymbol{v} \cdot \boldsymbol{\nabla} Y_{P}=\frac{1}{L e_{P}} \boldsymbol{\nabla} \cdot\left(\lambda \nabla Y_{P}\right)+\frac{11}{4} W, \\
& W=\frac{\beta^{2} U_{f}^{2}}{2(\gamma+1)^{\kappa-1} L e_{F}} \rho Y_{F} \exp \left[\beta(\gamma+1) \frac{\theta-1}{1+\gamma \theta}\right], \\
& L=\rho \Sigma Y_{P}\left[(1+\gamma \theta)^{4}-1\right], \\
& \rho(1+\gamma \theta)=1, \quad \lambda=(1+\gamma \theta)^{\kappa}, \\
& r=R: \quad \boldsymbol{v}=U_{0} \boldsymbol{i}, \theta=\frac{\partial Y_{F}}{\partial r}=\frac{\partial Y_{P}}{\partial r}=0, \\
& x \rightarrow-\infty: \quad \boldsymbol{v}=U_{0} \boldsymbol{i}, \theta=0, Y_{F}=1, Y_{P}=0, \\
& x \rightarrow+\infty: \quad \frac{\partial \boldsymbol{v}}{\partial x}=\frac{\partial \theta}{\partial x}=\frac{\partial Y_{F}}{\partial x}=\frac{\partial Y_{P}}{\partial x}=0 .
\end{aligned}
$$

Como se ha adelantado al describir el modelo de las pérdidas por radiación, al poder calcular la radiación sustituyendo la concentración de agua por la concentración de dióxido de carbono multiplicada por un factor, se ha podido eliminar la ecuación correspondiente a la conservación del $\mathrm{H}_{2} \mathrm{O}$. Al final sólo resulta necesario seguir la variación del metano para conocer el término de producción de la energía y la variación del $\mathrm{CO}_{2}$ para conocer las pérdidas por radiación. No resulta necesario seguir los cambios de las demás especies, y su influencia se reduce a un aumento de la masa de gas que hay que calentar.

Los parámetros adimensionales que aparecen en las ecuaciones (2.20-2.30) son

$$
\left.\begin{array}{c}
\gamma=\frac{T_{e q}-T_{u}}{T_{u}}, \quad \beta=\frac{T_{a}\left(T_{e q}-T_{u}\right)}{T_{e q}^{2}}, \quad U_{f}=\frac{U_{L}}{U_{L r}}, \\
G=\frac{g \delta_{L r}}{U_{L r}}, \quad R=\frac{R^{*}}{\delta_{L r}}, \quad \mathrm{Le}_{F}, \quad \mathrm{Le}_{P}, \quad \operatorname{Pr}, \quad \kappa, \\
\Sigma=2.62 \frac{\sigma R_{g} T_{u}^{3} \delta_{L r} Y_{u_{r}}}{c_{p} \gamma_{r} U_{L r}}\left[T\left(K_{C O_{2}}+2 K_{H_{2} O}\right)\right]_{1300 K} \cdot
\end{array}\right\}
$$

Los dos primeros parámetros están dados por (2.18) en función de $Y_{u} / Y_{u r}$ y los valores $\gamma_{r}=4$ y $\beta_{r}=10$ del caso de referencia. El parámetro $U_{f}$ es artificial y se introduce por la razón ya explicada. A no ser que se diga lo contrario, los cálculos se han realizado con los valores $G=2, \mathrm{Le}_{F}=\operatorname{Pr}=1, \kappa=0.75$. El valor $R=60$ corresponde aproximadamente al tubo de inflamabilidad estándar, mientras que $\Sigma \simeq 2 \times 10^{-5}$.

\section{Tratamiento numérico}

Para la resolución numérica del problema, las ecuaciones (2.20) y (2.21) se reemplazan por la formulación equivalente en términos de la función de corriente $[\psi(x, r)]$ y la 
vorticidad $[\omega(x, r)]$, que para un flujo axilsimétrico estacionario están definidas por las igualdades $\rho \boldsymbol{v}=\boldsymbol{\nabla} \wedge\left(r \psi \boldsymbol{e}_{\phi}\right)$ y $\boldsymbol{\nabla} \wedge \boldsymbol{v}=\omega \boldsymbol{e}_{\phi}$, donde $\boldsymbol{e}_{\phi}$ es un vector unitario en la dirección azimutal local. Estas variables satisfacen la ecuación $\mathcal{L} \psi=-\rho r \omega+\nabla \psi \cdot \nabla \ln \rho$ con $\mathcal{L} \psi=\partial^{2} \psi / \partial x^{2}+r \partial\left(r^{-1} \partial \psi / \partial r\right) / \partial r$, que sustituye a la ecuación de continuidad (2.20), y la única componente no trivial de la ecuación que resulta al tomar el rotor de (2.21). A continuación estas ecuaciones, junto con $(2.22)-(2.24)$, se reescriben en términos de las nuevas variables independiente $(\xi, r)$, con $\xi=(x+\nu R) /(h(r)+\nu R)$, donde $\nu$ es una constante ajustable y $h(r)$, con $h(0)=0$, se elige para satisfacer la condición $\theta(\xi=1, r)=\theta_{0}$, al menos en una cierta región en torno al eje del tubo. Las ecuaciones resultantes de discretizan usando diferencias finitas de segundo orden en una malla rectangular no uniforme que cubre el dominio $\left[0, \xi_{\infty}\right] \times[0, R]$ y es más fina alrededor de $\xi=1$, donde está la llama. Valores típicos de los parámetros numéricos son $\nu=1$ y $\xi_{\infty}=3-6$. Las ecuaciones discretizadas se resuelven con un método iterativo pseudo-transitorio, que equivale a añadir derivadas respecto a un tiempo artificial a (2.22)-(2.24) y la ecuación de la vorticidad, y marchar en este tiempo hasta que el resultado se hace estacionario.

\subsection{Resultados}

$\mathrm{Al}$ igual que en otras simulaciones numéricas $[16,52]$ y en los resultados experimentales que se discutirán más adelante, el frente de la llama que se propaga en una mezcla pobre consiste en un casquete aproximadamente hemisférico que se prolonga en una falda alargada (ver figuras 2.3, 2.4 y 2.8). Como ya se ha mencionado, la forma de la parte superior del frente y la velocidad a la que asciende en el tubo son parecidas a las de una burbuja de aire que sube por un tubo lleno de líquido [7].

\subsubsection{Resultados sin pérdidas por radiación}

Se han realizado simulaciones numéricas teniendo en cuenta las pérdidas por radiación y también despreciándolas para comparar los resultados y observar su influencia. En la figura 2.3 se muestran los resultados obtenidos en este último caso, $\Sigma=0$, para valores de la riqueza $\phi=17.39 Y_{u}^{*} /\left(1-Y_{u}^{*}\right)=0.344,0.504,0.538,0.581$. Además se han usado los valores $\operatorname{Le}_{F}=1, R=60$ y $G=2$. Para estos casos los valores del parámetro $U_{f}$ definido en $(2.19)$ son $U_{f}=0.07,0.7,1,1.5[17]$.

Si se observa el proceso que sigue la llama al disminuir la riqueza de la mezcla se ve que en primer lugar la velocidad del gas detrás de la llama disminuye cerca del eje del tubo; en la figura 2.3 se puede ver cómo la separación entre las líneas de corriente (curvas azules) aumenta al disminuir la riqueza (compárense las figuras $2.3 \mathrm{~d}$ y $2.3 \mathrm{c}$ ). Al bajar más la riqueza, figura $2.3 \mathrm{~b}$, se crea una zona de recirculación detrás de la llama, mientras que el espesor de la zona de reacción (curvas rojas) aumenta ligeramente. Cuando la riqueza se hace aún más pequeña, la llama se desplaza al interior de la zona de recirculación y el espesor de la zona de reacción aumenta mucho (figura 2.3a). Esta figura muestra resultados para el valor más pequeño de la riqueza para el que el cálculo numérico converge, que es apreciablemente menor que la riqueza en el límite de inflamabilidad medido experimentalmente.

La figura 2.4 muestra resultados análogos calculados para $R=30$ (tubo de $26 \mathrm{~mm}$ de diámetro). En este caso el cálculo deja de converger para valores de riqueza inferiores 

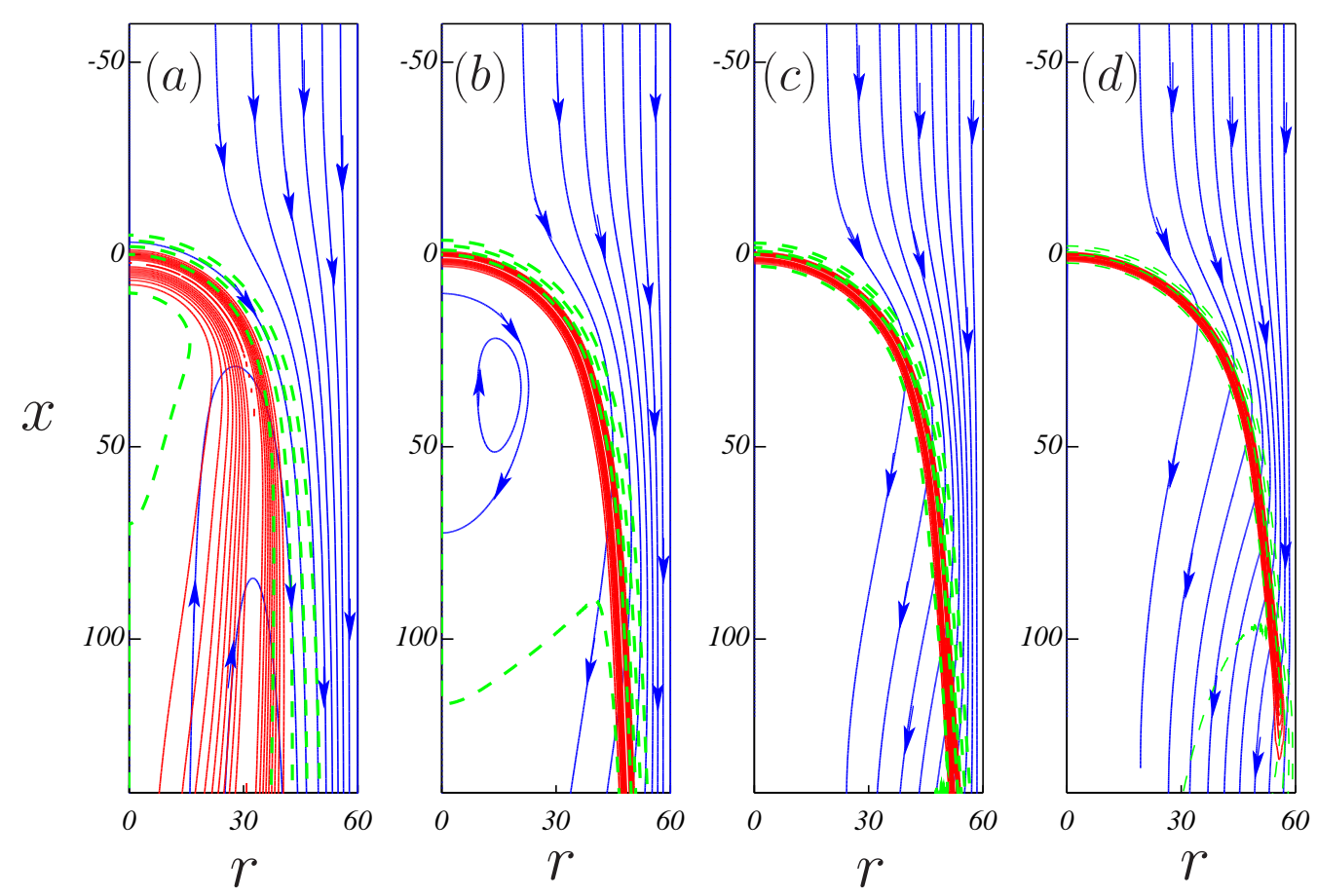

Figura 2.3: Resultados numéricos para $\Sigma=0$ y $R=60$. Se representan contornos de velocidad de reacción $W$ constante (curvas rojas continuas), isotermas (curvas verdes de trazos) y líneas de corriente del flujo relativo al frente de la llama (curvas azules con flechas) para $\phi=0.344(a), 0.504(b), 0.538(c), 0.581(d)$. Los demás parámetros tienen los valores de referencia mencionados bajo la ecuación (2.31).

a $\phi_{\text {lim }} \approx 0.421$ cuando $\operatorname{Le}_{F}=1$. Este valor es parecido al obtenido por [52] en ensayos experimentales en tubos de $24 \mathrm{~mm}$ de diámetro: $\phi_{S T J} \approx 0.486$.

Aunque en los experimentos descritos en los capítulos siguientes se ha usado metano, cuyo número de Lewis es muy próximo a la unidad, también se han realizado cálculos con otros valores de este parámetro, para estudiar su efecto. En la figura 2.5a se puede ver de forma esquemática el comportamiento del frente de la llama en el eje del tubo en función de la riqueza y del número de Lewis. Se han calculado las llamas en un tubo de radio $R=60$ para tres valores de $\operatorname{Le}_{F}: 0.8,0.1$ y 1.2. Para visualizar el tamaño aproximado de la zona de reacción se representan los puntos correspondientes a $W=0.1 W_{\max }$ a ambos lados del valor máximo, $W_{\max }$, que se toma como punto de referencia de las distancias. La riqueza mínima que se consigue $\left(\phi_{\text {lim }}\right)$ disminuye con $\operatorname{Le}_{F}$. En el caso de $\operatorname{Le}_{F}=0.8$, dentro del rango representado en la figura aparece un límite superior, $\phi \approx 0.573$ marcado por círculos negros en la figura, en el que la llama sufre una transición y cambia su forma a forma de tulipa. Esta transición ocurre también para los otros dos valor del número de Lewis, aunque a riqueza mayores que las presentadas en la figura. Se observa que, para una riqueza dada, el comienzo de la reacción (curva roja superior) se adelanta al aumentar el número de Lewis. Las curvas verdes dan la distancia entre el punto donde $W=W_{\max }$ y el punto donde $\theta=0.1$, de forma que la distancia entre la curva roja inferior y la curva verde es una medida del espesor de la llama. Las curvas de puntos azules dan la distancia entre el punto donde $W$ es máximo y el punto de remanso donde $u=0$, que es la frontera 

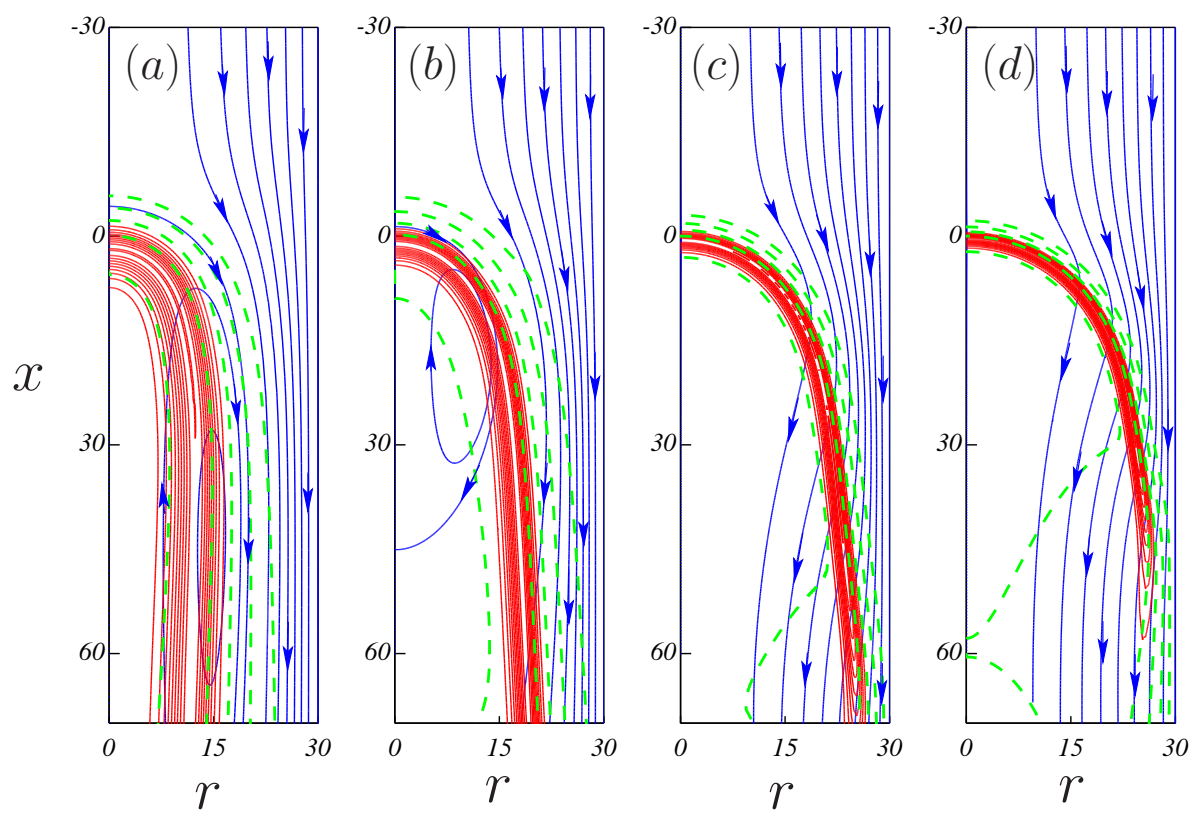

Figura 2.4: Resultados numéricos para $\Sigma=0$ y $R=30$. Se representan contornos de velocidad de reacción $W$ constante (curvas rojas continuas), isotermas (curvas verdes de trazos) y líneas de corriente del flujo relativo al frente de la llama (curvas azules con flechas) para $\phi=0.421(a), 0.474(b), 0.538(c), 0.581(d)$. Los demás parámetros tienen los valores de referencia mencionados bajo la ecuación (2.31).

superior de la zona de recirculación. Como se puede ver, al aumentar la riqueza, la zona de recirculación se aleja de la llama.

El alargamiento (stretch) de la llama se debe principalmente a la velocidad de deformación del flujo de gas fresco inmediatamente delante del frente $(\boldsymbol{n} \cdot \boldsymbol{\nabla} \boldsymbol{v} \cdot \boldsymbol{n}$, siendo $\boldsymbol{n}$ la normal al frente dirigida hacia el gas quemado), cuyo efecto es grande comparado con el efecto de la curvatura del frente $\left(U_{L} \boldsymbol{\nabla} \cdot \boldsymbol{n}\right)[61]$. El cociente $(\boldsymbol{n} \cdot \boldsymbol{\nabla} \boldsymbol{v} \cdot \boldsymbol{n}) /\left(U_{L} \boldsymbol{\nabla} \cdot \boldsymbol{n}\right) \sim U_{0} / U_{L} \gg 1$, teniendo en cuenta que la velocidad de deformación del gas fresco es de orden $U_{0} / R$ y la curvatura del frente es de orden $1 / R$. En el punto más alto del frente, en el eje del tubo, se tiene $-\boldsymbol{n} \cdot \boldsymbol{\nabla} \boldsymbol{v} \cdot \boldsymbol{n}=-\partial u / \partial x$, su valor, que es el máximo de $-\partial u / \partial x$ en el gas frío, se muestra en la figura 2.6a en función de la riqueza para los mismos valores de $\mathrm{Le}_{F}$ de la figura 2.5. En la figura 2.6b se muestra $\beta(\theta-1)$ tras la llama, que es la diferencia entre la temperatura final de combustión y la temperatura adiabática de llama escalada con $\beta^{-1}\left(T_{e q}-T_{u}\right)$. Valores de esta variable de orden unidad cambian apreciablemente la velocidad de combustión respecto a la de la llama plana sin alargamiento, aumentándola si $\beta(\theta-1)>0$ y disminuyéndola si $\beta(\theta-1)<0$, hasta causar la extinción en este segundo caso [64]. Como se ve, la velocidad de alargamiento de la punta de la llama aumenta en todos los casos al disminuir la riqueza. Esto aumenta la temperatura final de combustión e intensifica la llama cuando $\operatorname{Le}_{F}<1$, porque el aumento del flujo difusivo de combustible hacia la zona de reacción causado por el alargamiento es entonces mayor que el aumento del flujo de calor por conducción desde la zona de reacción al gas fresco [64]. Lo contrario ocurre cuando $\mathrm{Le}_{F}>1$, mientras que la temperatura final de combustión no se ve afectada por el alargamiento cuando $\operatorname{Le}_{F}=1$. Estos resultados explican la extinción de la llama 

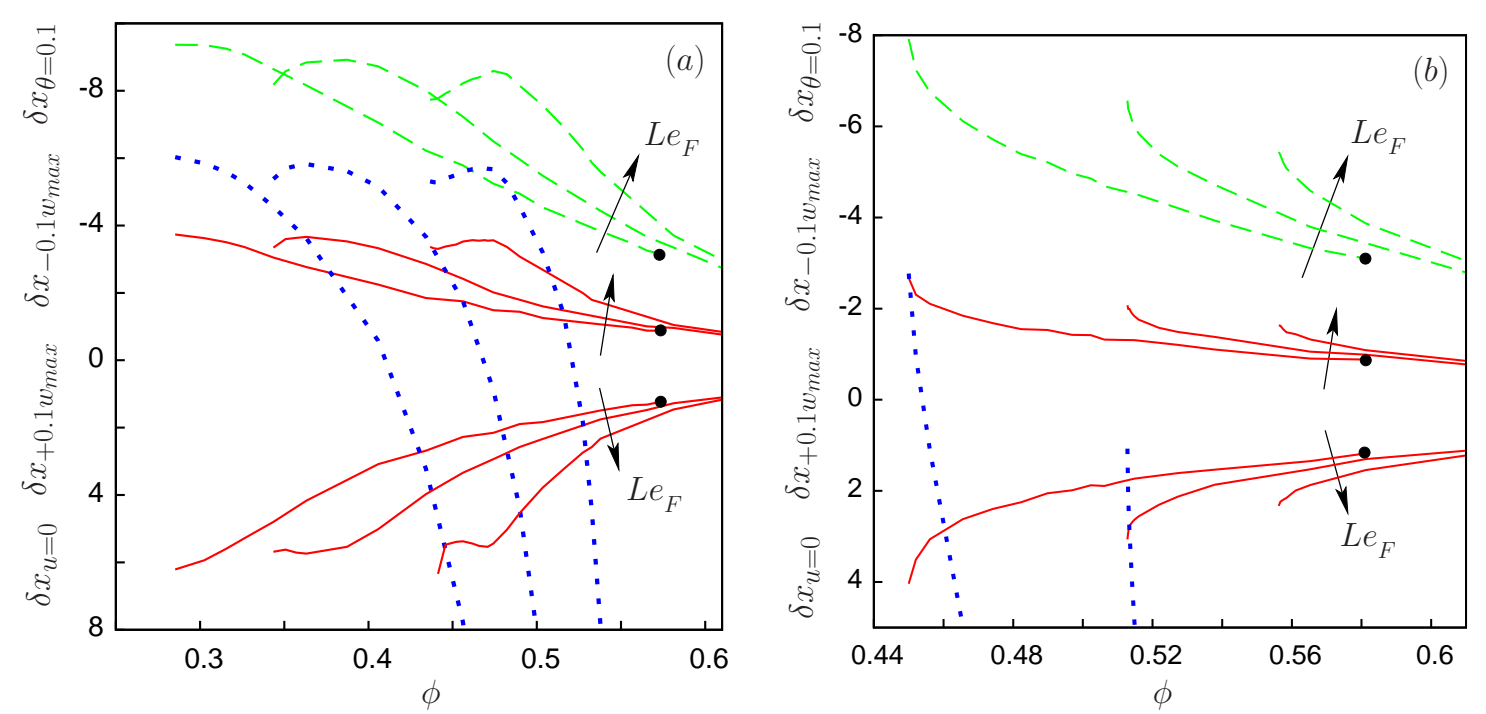

Figura 2.5: Propiedades de la llama en el eje del tubo como funciones de la riqueza. Tomando como origen el punto donde $W$ alcanza su máximo, $W_{\max }$, las curvas rojas muestran las distancias $\delta x_{ \pm 0.1 W_{\max }}$ a los puntos donde $W=0.1 W_{\max }$ a cada lado del máximo. La curva verde de trazos es la distancia desde este origen al punto donde $\theta=0.1$, y la línea azul de puntos es la distancia al punto de remanso donde $u=0$. Los resultados se dan para $\operatorname{Le}_{F}=0.8,1$ y 1.2 , aumentando en la dirección de las flechas. En la figura $(a)$ es $\Sigma=0$ y en la (b) $\Sigma=2 \times 10^{-5}$. Los demás parámetros tienen los valores de referencia mencionados bajo la ecuación (2.31).

cuando $\mathrm{Le}_{F}>1$ a un valor de la riqueza que aumenta con $\mathrm{Le}_{F}$. La extinción para $\mathrm{Le}_{F} \leq 1$ no se puede explicar en términos del alargamiento, sino que depende de la estructura del flujo mostrado en las figuras 2.3a y 2.4a.

Los balances dominantes en el interior de la llama cambian cuando gran parte de la reacción ocurre en la zona de recirculación. En la figura 2.7 se muestran los términos de convección, conducción y reacción de la ecuación (2.22) en el eje del tubo para $\phi=0.406$ y 0.504. La convección no es importante en la región de reacción en el caso de la riqueza más alta, en el que el gas se mueve hacia abajo a través de la zona de reacción. Sin embargo, el término de convección es tan importante como los de conducción y reacción cuando $\phi=0.406$, y es incluso mayor que el de reacción cuando $\phi=0.344$, en cuyo caso el gas se mueve hacia arriba a través de la zona de reacción. Este flujo tiende a confinar el combustible que entra en la zona de recirculación por difusión desde el gas fresco que la rodea.

El aumento de la importancia relativa de la convección al disminuir $\phi$ se puede explicar usando estimaciones de órdenes de magnitud. El número de Zeldovich, $\beta$, es relativamente grande, por lo que las variaciones de temperatura y fracción másica serán pequeñas en la zona de reacción, $\left(Y_{F}, 1-\theta\right)=O\left(\beta^{-1}\right)$. Del balance de conducción y reacción química $\boldsymbol{\nabla} \cdot(\lambda \boldsymbol{\nabla} \theta) \sim W$ se obtiene $\lambda_{b} \beta^{-1} / \delta_{r}^{2} \sim W_{c}$, como para una llama plana sin estiramiento [64]. Aquí $\delta_{r}$ es el espesor característico de la zona de reacción, $\lambda_{b}=(\gamma+1)^{\kappa}$, y $W_{c}=\beta U_{f}^{2} /(\gamma+$ $1)^{\kappa}$, que se obtiene de la ecuación $(2.25)$ con $Y_{F}=O\left(\beta^{-1}\right)$. El valor característico de la velocidad vertical ascendente del gas en la zona de reacción, que denotaremos $u_{c}$, depende 

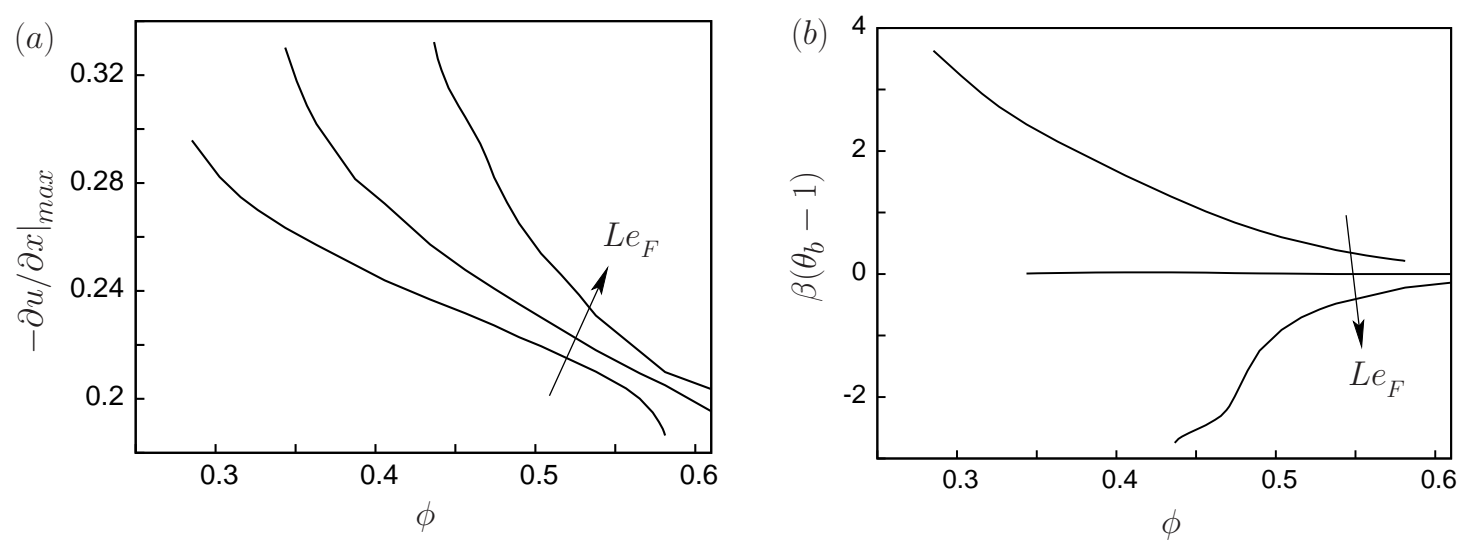

Figura 2.6: (a) Velocidad de deformación del flujo de gas frío en el punto más alto del frente, situado en el eje del tubo. (b) Diferencia entre la temperatura final de combustión y la temperatura adiabática de llama escalada con $\beta^{-1}\left(T_{e q}-T_{u}\right)$.

de las condiciones globales en la región de recirculación. En términos de $u_{c}$, el cociente entre los términos de convección y conducción de la ecuación de la energía en la zona de reacción es

$$
\frac{O[\rho \boldsymbol{v} \cdot \boldsymbol{\nabla} \theta]}{O[\boldsymbol{\nabla} \cdot(\lambda \boldsymbol{\nabla} \theta)]} \sim \frac{\rho_{b} u_{c} \delta_{r}}{\lambda_{b}} \sim \frac{\rho_{b} u_{c}}{\left(\beta \lambda_{b} W_{c}\right)^{1 / 2}}
$$

donde $\rho_{b}=1 /(\gamma+1)$ y se ha usado la estimación $\delta_{r} \sim\left(\lambda_{b} / \beta W_{c}\right)^{1 / 2}$.

$\mathrm{El}$ valor de $W_{c}$ disminuye al disminuir la riqueza, por lo que el cociente (2.32) aumenta. Si este cociente llegase a ser grande, la conducción se haría despreciable en la ecuación de la energía y la difusión se haría despreciable en las ecuaciones de conservación de las especies en la zona de reacción. Sin embargo, un balance convección-reacción no tiene sentido cuando la reacción ocurre en la zona de recirculación, porque la convección no aporta combustible a la zona de reacción. El combustible debe llegar a la zona de reacción por difusión a través de la línea de corriente divisoria. Así pues, estas estimaciones sugieren que deja de haber llama estacionaria en el eje del tubo cuando el cociente (2.32) alcanza un cierto valor crítico de orden unidad. Usando las estimación anterior de $W_{c}$, esto corresponde a un valor límite de $U_{f}$ definido en (2.19) de orden

$$
U_{f_{l i m}}=\frac{u_{c}}{\beta(\gamma+1)}
$$

Esta estimación depende de la velocidad del gas $u_{c}$, que a su vez depende de varios factores. Admitamos que la velocidad del gas en la zona de recirculación es de orden $U_{0}$, con $U_{0} \sim(G R)^{1 / 2}$, aunque los resultados numéricos muestran que es algo más pequeña. Si el espesor de la zona de reacción es mucho menor que el radio del tubo, $\delta_{r} \ll R$, esta zona está cerca del punto de remanso, donde la velocidad es $u_{c} \sim U_{0} \delta_{r} / R$, y por tanto

$$
U_{f_{l i m}}=\frac{(G / R)^{1 / 4}}{\beta(\gamma+1)^{(1-\kappa) / 2}} .
$$




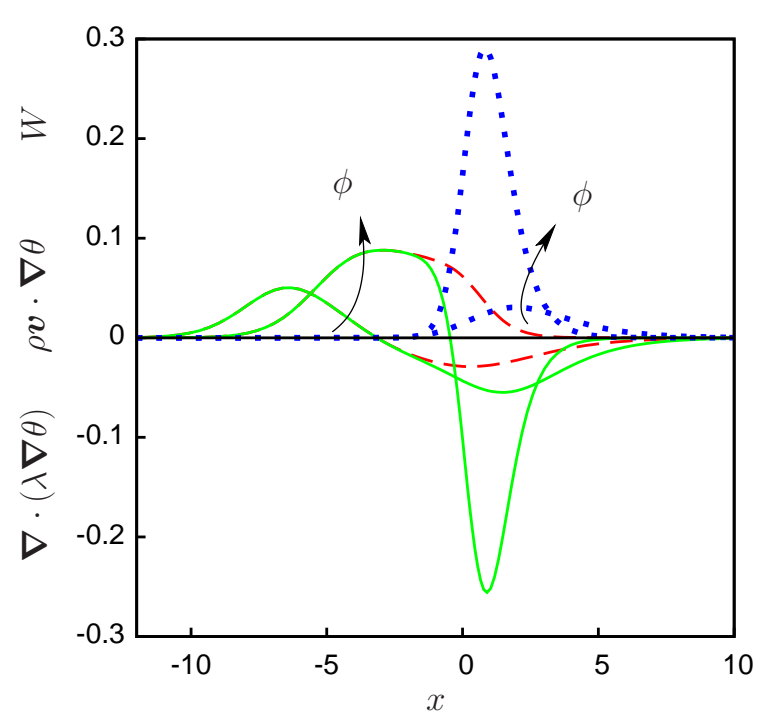

Figura 2.7: Términos de convección (curvas rojas de trazos), conducción (curvas verdes continuas) y reacción (curvas de puntos azules) de la ecuación de la energía (2.22) en el eje del tubo para $\phi=0.406$ y 0.504 y $\Sigma=0$. Los demás parámetros tienen sus valores de referencia.

Si la condición $\delta_{r} \ll R$ no se cumple, como ocurre por ejemplo en las simulaciones con $R=30$ comentadas más arriba (figura $2.4 \mathrm{a}$ ), entonces $u_{c} \sim u_{d}$ y la velocidad límite es

$$
U_{f_{l i m}}=\frac{(G R)^{1 / 2}}{\beta(\gamma+1)} \text {. }
$$

Como se puede observar, las dos estimaciones (2.33) y (2.34) predicen variaciones opuestas de la velocidad límite $U_{f_{l i m}}$ con el radio del tubo. La estimación (2.33) es análoga a los resultados de Buckmaster y Mikolaitis [3] obtenidos con la hipótesis de que la extinción se debe al alargamiento de la llama causado por la velocidad de deformación del gas frío sobre el punto más alto del frente. La estimación (2.34) es similar a la obtenida por Levy [31]

\subsubsection{Influencia de las pérdidas por radiación}

En la figura 2.5b se muestran las misma magnitudes que en la figura 2.5a cuando se tienen en cuenta los efectos de la radiación con $\Sigma=2 \times 10^{-5}$. Como se puede ver, las pérdidas causan la extinción de la llama para un valor de la riqueza que crece con el número de Lewis del combustible $\left(\phi_{\text {lim }}=0.450,0.513\right.$ y 0.556 para $\operatorname{Le}_{F}=0.8,1$ y 1.2 , respectivamente, en un tubo de radio $R=60)$ y está en el rango de los valores experimentales medidos para mezclas de metano/aire en el tubo estándar $\left(\phi_{\text {exp }}=0.507-\right.$ 0.517; ver por ejemplo la referencia [53]).

En la figura 2.8 se muestra la apariencia de la llama límite y el campo fluido para estos tres valores de $\mathrm{Le}_{F}$, y se comparan con los de llamas algo menos pobres, con $\phi=0.581$. Comparando las figuras 2.8 e y $2.3 \mathrm{~d}$ se ve que las pérdidas por radiación apenas afectan a la llama lejos del límite de inflamabilidad, pero la comparación de las figuras $2.8 \mathrm{~b}$ y $2.3 \mathrm{a}$ muestra que el efecto de las pérdidas se hace muy importante al aproximarse a este límite. 
En la figura 2.8c, para $\mathrm{Le}_{F}=1.2$, se ve que las pérdidas causan la extinción de la llama antes de que ésta se acerque a la zona de recirculación. En este caso la combustión en torno al eje del tubo ha sido ya debilitada por el alargamiento debido a la velocidad de deformación del gas frío, de modo que un efecto moderado de las pérdidas basta para provocar la extinción. Por el contrario, en la figura 2.8a, para $\mathrm{Le}_{F}=0.8$, la llama llega a alcanzar el límite de la zona de recirculación antes de extinguirse. En este caso el alargamiento intensifica la combustión, oponiéndose al efecto de las pérdidas de calor y posponiendo la extinción a valores muy pequeños de la riqueza.

$\mathrm{El}$ efecto directo de las pérdidas por radiación en la zona de transporte de la llama da lugar a una disminución de la temperatura final de combustión del orden $\Sigma(\gamma+1)^{3+\kappa}$, y las pérdidas por radiación desde el gas caliente detrás de la llama darían lugar a un flujo de calor desde la llama al gas quemado que causaría variaciones de la temperatura final de combustión de este mismo orden en una llama plana no sometida a alargamiento, para la que el producto $\rho u$ es continuo a través de la llama (Williams [64]). Esta disminución de temperatura es mucho menor que $\beta^{-1}$, y por tanto es insuficiente para extinguir la llama por efectos térmicos. Esto explica la semejanza de los resultados mostrados en las figuras $2.3 \mathrm{~d}$ y $2.8 \mathrm{e}$. Sin embargo, la disminución de la velocidad del gas quemado detrás de la llama, y la posterior aparición de una zona de recirculación cuando se disminuye la riqueza, aumentan drásticamente el efecto de las pérdidas por radiación.

En la figura 2.9a se muestra la variación lo largo del eje del tubo de los términos de convección (curvas de trazos), conducción (curvas continuas) y radiación (curvas de puntos) de la ecuación de la energía (2.22) en el gas quemado para $\operatorname{Le}_{F}=1$ y tres valores de la riqueza. Para la riqueza más alta, $\phi=0.581$, el equilibrio se establece básicamente entre el término de radiación y el término convectivo. Al reducir la riqueza hasta el límite inferior, $\phi=0.513$, cambia la importancia de los términos, ya que la convección se reduce drásticamente y el nuevo equilibrio se establece entre la radiación y la conducción. Si se tiene en cuenta que el tamaño la zona de baja velocidad que se ha creado detrás de la llama es del orden del radio del tubo, la reducción de $\theta$ en esta zona debida a las pérdidas por radiación se puede estimar como $\Delta \theta \sim \Sigma(\gamma+1)^{3-\kappa} R^{2}$, del balance conducción-radiación $\lambda \Delta \theta / R^{2} \sim \rho \Sigma(\gamma+1)^{4}$ con $\rho \approx 1 /(\gamma+1)$ y $\lambda \approx(\gamma+1)^{\kappa}$. Esta disminución de la temperatura adimensional origina un flujo de calor por conducción desde la llama hacia el gas quemado de orden $q_{b}=\mathcal{O}(\lambda \Delta \theta / R)$, que a su vez disminuye la temperatura adimensional final de combustión en una cantidad de este mismo orden (del balance de entalpía a través de la llama; véase Joulin y Clavin [21] y Williams [64]). Como $\beta q_{b}=\mathcal{O}\left[\beta \Sigma(\gamma+1)^{3} R\right]$ es una cantidad de orden unidad para $R=60$ y calores típicos de los demás parámetros, esta estimación muestra que las pérdidas por radiación intensificadas por la presencia de una zona de baja velocidad pueden causar la extinción de la llama.

Para corroborar la influencia de las pérdidas por radiación, en la figura $2.9 \mathrm{~b}$, se representan los valores en el eje del tubo del calor adimensional liberado por la reacción, $\int_{-\infty}^{+\infty} W \mathrm{~d} x$ (curvas continuas), y el flujo de calor por conducción inmediatamente detrás de la llama escalado con el inverso del número de Zeldovich, $-\beta \lambda \partial \theta / \partial x$ (curvas de trazos),

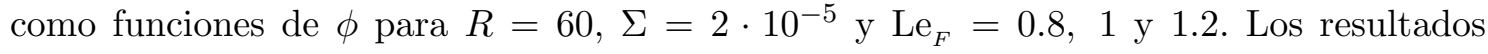
confirman que el flujo de calor desde la llama al gas quemado causado por las pérdidas por radiación sólo toma valores significativos en la proximidad de la extinción.

Cálculos similares para tubos más estrechos muestran que el efecto de las pérdidas por radiación disminuye con $R$, de acuerdo con las estimaciones anteriores. Por ejemplo, 

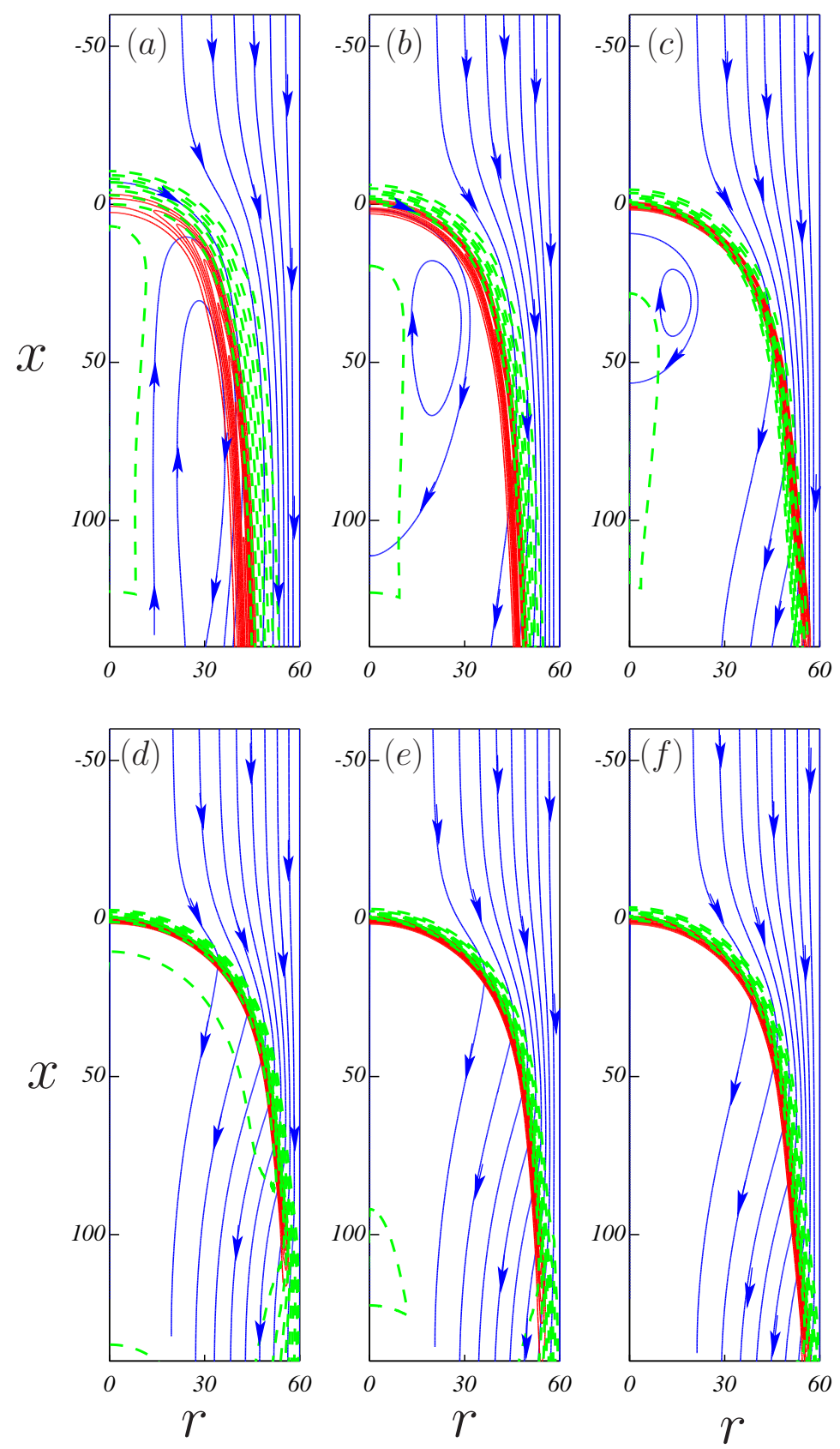

Figura 2.8: Resultados numéricos para $\Sigma=2 \times 10^{-5}$ y $R=60$. Se representan contornos de velocidad de reacción $W$ constante (curvas rojas continuas), isotermas (curvas verdes de trazos) y líneas de corriente del flujo relativo al frente de llama (curvas azules con flechas). Figuras superiores: llamas para riquezas límite para $(a): \operatorname{Le}_{F}=0.8, \phi=0.45$, (b) : $\operatorname{Le}_{F}=1, \phi=0.513$ y $(c): \operatorname{Le}_{F}=1.2, \phi=0.556$. Figuras inferiores: llamas con $\phi=0.581$ y Le $_{F}=0.8(d), 1(e)$ y $\operatorname{Le}_{F}=1.2(f)$. Los demás parámetros tienen los valores de referencia mencionados bajo la ecuación (2.31). 


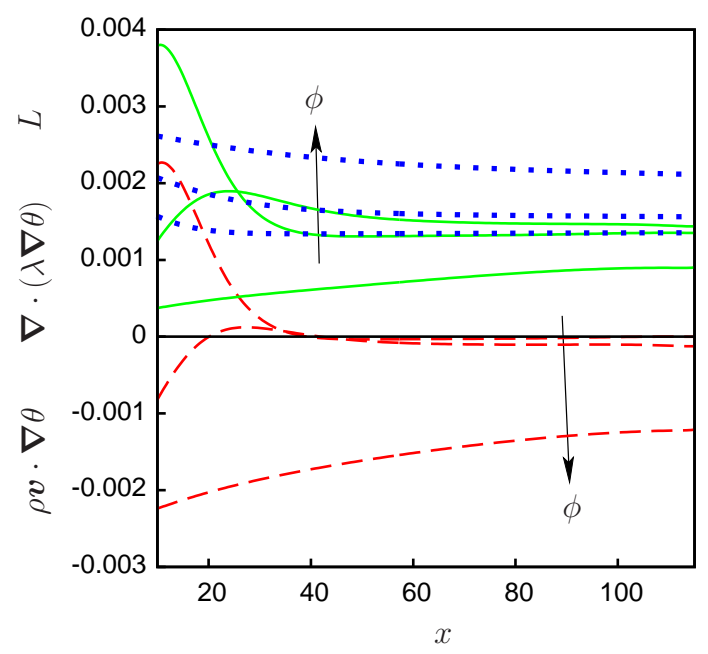

(a)

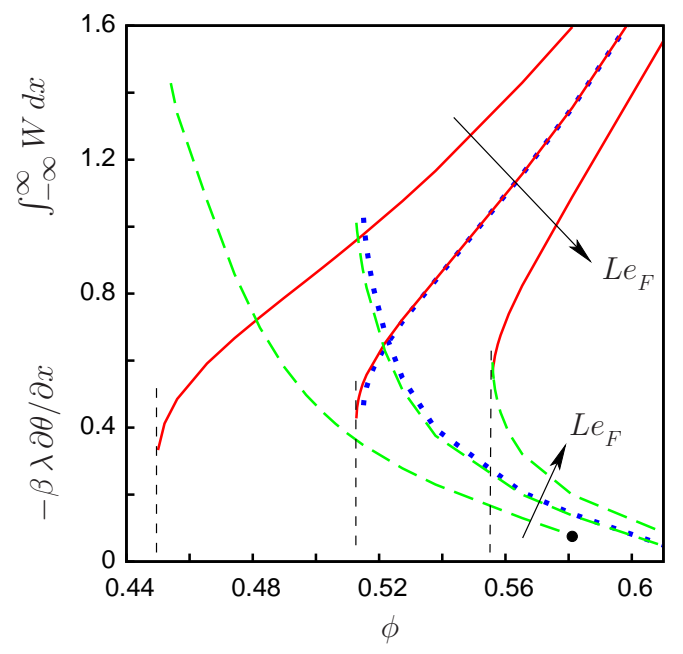

(b)

Figura 2.9: (a) Términos de convección (curvas rojas de trazos), conducción (curvas verdes continuas) y pérdidas por radiación (curvas azules de puntos) de la ecuación de la energía (2.22) en la zona ocupada por los productos de reacción en el eje del tubo para $\operatorname{Le}_{F}=1$ y $\phi=0.513,0.527,0.581$, aumentando según indican las flechas. (b) Valores en el eje del tubo del término de producción integrado a través de la llama, $\int_{-\infty}^{+\infty} W \mathrm{~d} x$ (curvas rojas continuas), y del flujo de calor por conducción hacia los productos quemados, $-\beta \lambda \partial \theta / \partial x$ evaluado en el punto donde $W=0.1 W_{\max }$ (curvas verdes de trazos). Las curvas azules de puntos muestran los mismos resultados para $\mathrm{Le}_{F}=1$ con las fracciones másicas de $\mathrm{CO}_{2}$ y $\mathrm{H}_{2} \mathrm{O}$ calculadas separadamente para tener en cuenta sus diferentes difusividades: $\mathrm{Le}_{\mathrm{CO}_{2}}=1.39$ y $\mathrm{Le}_{\mathrm{H}_{2} \mathrm{O}}=0.83$.

cuando $R=30$ y $\operatorname{Le}_{F}=1$ la extinción ocurre para $\phi_{\text {lim }} \approx 0.448$, con la llama inmersa en la zona de recirculación. La configuración es parecida a la calculada en el apartado anterior sin pérdidas por radiación, y el valor límite de la riqueza no es muy diferente del valor $\phi=0.486$ medido por Shoshin et al. [52] en un tubo de $24 \mathrm{~mm}$.

\subsection{Modelo unidimensional de la llama}

En todos los estudios previos de propagación ascendente de llamas en tubos verticales se ha comprobado que la extinción comienza en el punto más alto de la llama, situado en el eje del tubo. Teniendo en cuenta estas observaciones, se propone un modelo sencillo para describir el comportamiento de la llama cerca del eje del tubo, combinando resultados experimentales con ecuaciones de conservación simplificadas.

El modelo se basa en reemplazar las ecuaciones de conservación de la energía y las 
especies, por las formas simplificadas:

$$
\begin{aligned}
& \rho u \frac{\mathrm{d} \theta}{\mathrm{d} x}=\frac{\mathrm{d}}{\mathrm{d} x}\left(\lambda \frac{\mathrm{d} \theta}{\mathrm{d} x}\right)+\alpha \lambda \frac{\theta_{b}-\theta}{R^{2}}+W-L \\
& \rho u \frac{\mathrm{d} Y_{i}}{\mathrm{~d} x}=\frac{1}{\mathrm{Le}_{i}} \frac{\mathrm{d}}{\mathrm{d} x}\left(\lambda \frac{\mathrm{d} Y_{i}}{\mathrm{~d} x}\right)+s_{i} W, \\
& x \rightarrow-\infty: \quad \theta=0, Y_{i}=Y_{i_{u}} \\
& x \rightarrow+\infty: \quad \frac{\mathrm{d} \theta}{\mathrm{d} x}=\frac{\mathrm{d} Y_{i}}{\mathrm{~d} x}=0
\end{aligned}
$$

que se suponen válidas en el eje del tubo $(r=0)$. La aproximación depende de las siguientes condiciones:

- El radio de curvatura del frente de llama (del orden de $R$ ) es mucho mayor que su espesor (de orden unidad en variables adimensionales), por lo que se han despreciado la difusión radial de las especies y la conducción radial del calor en el interior de la llama.

- Los gradientes de las concentraciones de las especies son pequeños detrás de la llama, por lo que la difusión radial también se desprecia detrás de la llama.

- El efecto de la variación radial de temperatura sin embargo no se puede despreciar detrás de la llama cuando hay pérdidas por radiación. La conducción radial en esta zona se modela escribiendo

$$
\left.\frac{1}{r} \frac{\partial}{\partial r}\left(r \lambda \frac{\partial \theta}{\partial r}\right)\right|_{r=0}=\alpha \lambda \frac{\left(\theta_{b}-\theta\right)}{R^{2}}
$$

donde se introduce el parámetro adimensional indetermiando $\alpha$, cuyo valor se ajusta para que los resultados obtenidos con este modelo coincidan con los resultados del modelo bidimensional descrito en el apartado anterior. Como se puede ver en la figura 2.10a, el mejor acuerdo con el modelo bidimensional se obtiene para $\alpha=15$ en (2.35), que será el valor que se emplee en lo que sigue.

En este modelo simplificado la ecuación de la conservación de la cantidad de movimiento, necesaria para completar la formulación del problema, se sustituye por la incorporación de datos experimentales de la velocidad del gas en el eje del tubo, $u(x)$. La forma de los perfiles de velocidad se discute en el capítulo 5 . Como la velocidad de ascenso de la llama es grande comparada con la velocidad de avance de la llama respecto al gas fresco, la velocidad de este gas relativa al frente de llama disminuye al aproximarse al punto más elevado del frente, alcanzando un mínimo inmediatamente delante de la llama. A continuación, la velocidad del gas aumenta rápidamente, a causa de la expansión térmica en la llama, alcanzando un máximo al final de la zona de reacción, para volver a disminuir y aumentar más lejos aguas abajo, debido a los efectos de la flotabilidad y el flujo del gas que atraviesa la llama más lejos del eje del tubo.

Es preciso determinar la posición de la llama sobre el perfil de velocidad medido. Para ello, procediendo de manera análoga a como se explicó al final del apartado 1.1 para el modelo bidimensional, se comienza eligiendo arbitrariamente un punto $x_{0}$ en la región 

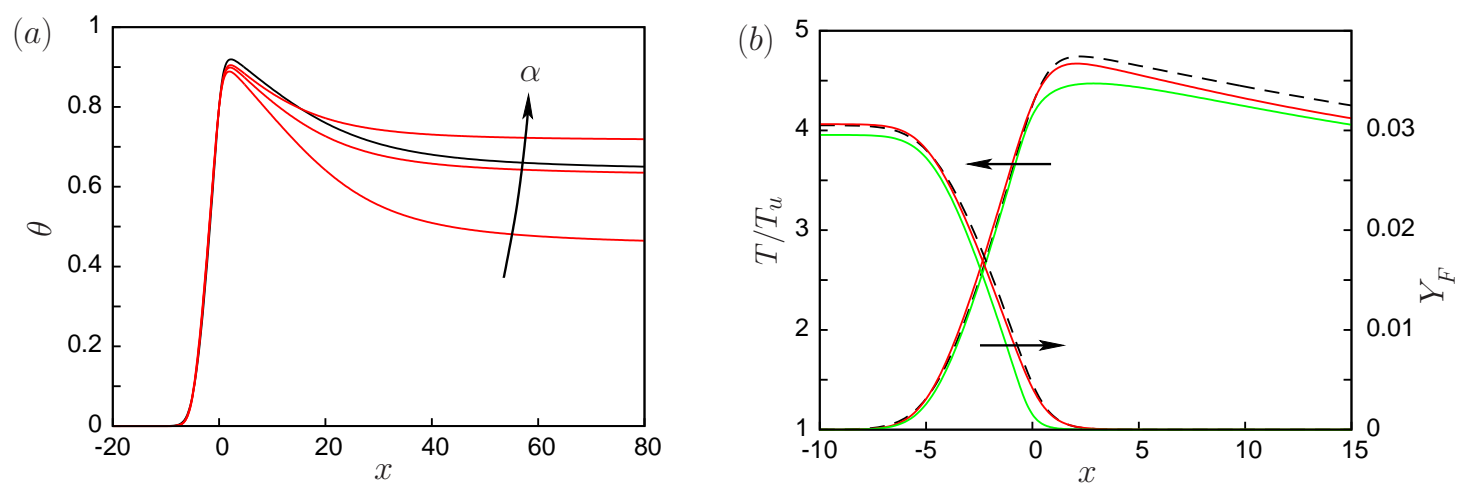

Figura 2.10: (a) Distribuciones de temperatura adimensional $(\theta)$ a lo largo del eje del tubo calculadas con el modelo bidimensional $(2.20)-(2.30)$ para $U_{f}=1.1(\gamma=4.07, \phi=0.541$, $\beta=9.896)$ y los valores de referencia $G=2, R=60, L e_{F}=\operatorname{Pr}=1$ (curva negra), y con el modelo unidimensional y el esquema de una única reacción (curvas rojas, para $\alpha=0,15$ y 30, aumentando en el sentido de la flecha). La distribución de velocidad empleada en el modelo unidireccional es la solución numérica del modelo bidimensional. (b) Comparación de las distribuciones de temperatura y fracción másica de metano obtenidas con el modelo bidimensional (curvas negras de trazos), el modelo unidimensional con una única reacción (curvas rojas), y el modelo unidimensional con el esquema de cuatro reacciones que se introduce más abajo, en el apartado 2.4 (curvas verdes).

del perfil de velocidad entre el mínimo y el máximo mencionados antes, y se impone la condición $\theta=\theta_{0}$, con $\theta_{0}=0.8$, en este punto. Como ahora no hay una variable análoga a $U_{0}$, se trata la riqueza de la mezcla como si fuera un parámetro libre, cuyo valor queda determinado por esta condición y no coincidirá con el valor real del experimento del que se extrajo el perfil de velocidad.

A continuación, se repite este cálculo para diferentes valores de $x_{0}$, hasta conseguir que el producto $\rho u$ varíe suavemente a través de la llama. Este producto es una constante para una llama plana no sometida a alargamiento, y varía suavemente, en una distancia del orden del radio del tubo, para los frentes de llama que se analizan aquí. Pero esta condición no se satisface para cualquier valor de $x_{0}$, sino que una elección arbitraria de este punto conduce a variaciones rápidas de $\rho u$ en una distancia del orden del espesor de la llama. Completado el cálculo y determinado el valor correcto de $x_{0}$, la diferencia entre la riqueza calculada para este caso, digamos $\phi_{\text {num }}$, y su valor real en el experimento es una medida del error introducido por el modelo unidimensional.

\subsection{Modelo cinético de cuatro reacciones}

En el modelo unidimensional resulta sencillo probar esquemas cinéticos más complejos que el de una única reacción de Arrhenius. Por ello se ha optado por usar un esquema cinético reducido de cuatro reacciones del tipo propuesto por Peters y Rogg [45], que describe adecuadamente el comportamiento de las llamas pobres de metano-aire. En simulaciones numéricas empleando estos esquemas se han obtenido resultados con un error pequeño para la velocidad de llama laminar. Aquí, como en Sánchez et al. [49], admitimos 
que $\mathrm{OH}$ es el único radical de sistema $\mathrm{H}_{2}-\mathrm{O}_{2}$, que no está en estado estacionario, y tomamos $\mathrm{CO}, \mathrm{H}_{2}$ y $\mathrm{OH}$ como las tres especies intermedias fuera de estado estacionario. El esquema reducido de cuatro reacciones que usaremos es

$$
\begin{aligned}
\text { I : } & \mathrm{CH}_{4}+2 \mathrm{OH} \rightarrow \mathrm{CO}+\mathrm{H}_{2} \mathrm{O}+2 \mathrm{H}_{2} \\
\text { II }: & \mathrm{H}_{2}+\mathrm{O}_{2} \rightleftharpoons 2 \mathrm{OH} \\
\text { III : } & 2 \mathrm{OH}+\mathrm{H}_{2} \rightleftharpoons 2 \mathrm{H}_{2} \mathrm{O} \\
\mathrm{IV}: & \mathrm{CO}+\mathrm{H}_{2} \mathrm{O} \rightleftharpoons \mathrm{CO}_{2}+\mathrm{H}_{2}
\end{aligned}
$$

con velocidades molares (en variables con dimensiones)

$$
\begin{aligned}
\omega_{\mathrm{I}}^{*} & =\left(k_{1_{1}}[\mathrm{H}]+k_{1_{2}}[\mathrm{OH}]\right)\left[\mathrm{CH}_{4}\right] \\
\omega_{\mathrm{II}}^{*} & =k_{2_{f}}\left[\mathrm{O}_{2}\right][\mathrm{H}]-k_{2_{b}}[\mathrm{O}][\mathrm{OH}] \\
\omega_{\mathrm{III}}^{*} & =\left(k_{3_{f}}\left[\mathrm{O}_{2}\right][\mathrm{H}]-k_{3_{b}}\left[\mathrm{HO}_{2}\right]\right)[\mathrm{M}] \\
\omega_{\mathrm{IV}}^{*} & =k_{4_{f}}[\mathrm{CO}][\mathrm{OH}]-k_{4_{b}}\left[\mathrm{CO}_{2}\right][\mathrm{H}]
\end{aligned}
$$

donde los paréntesis cuadrados indican concentraciones molares de las especies: $[i]=$ $\rho Y_{i} / \mathcal{M}_{i}$, siendo $\mathcal{M}_{i}$ la masa molecular de la especie $i$. La concentración molar del tercer cuerpo es

$$
[\mathrm{M}]=0.6\left[\mathrm{H}_{2}\right]+0.4\left[\mathrm{~N}_{2}\right]+0.44\left[\mathrm{H}_{2} \mathrm{O}\right]+0.4\left[\mathrm{O}_{2}\right]+1.5\left[\mathrm{CO}_{2}\right]+3\left[\mathrm{CH}_{4}\right]+[\mathrm{OTROS}],
$$

y las concentraciones molares de $\mathrm{H}, \mathrm{O}_{\text {y }} \mathrm{HO}_{2}$ que aparecen en las ecuaciones (2.40) están dadas por

$$
\begin{gathered}
{[\mathrm{H}]=K_{1} \frac{\left[\mathrm{H}_{2}\right][\mathrm{OH}]}{\left[\mathrm{H}_{2} \mathrm{O}\right]} \quad[\mathrm{O}]=K_{2} \frac{[\mathrm{OH}]^{2}}{\left[\mathrm{H}_{2} \mathrm{O}\right]}} \\
{\left[\mathrm{H}_{2} \mathrm{O}\right]=\frac{k_{3_{f}}[\mathrm{M}][\mathrm{H}]+k_{5_{b}}\left[\mathrm{H}_{2} \mathrm{O}\right]}{k_{3_{b}}[\mathrm{M}]+k_{5_{f}}[\mathrm{OH}]}\left[\mathrm{O}_{2}\right],}
\end{gathered}
$$

que son aproximaciones a las ecuaciones algebraicas que expresan las condiciones de estado estacionario de estas y otras especies, y de equilibrio parcial de algunas reacciones elementales.

Las constantes de reacciones que aparecen en (2.40) se recogen en la tabla 2.2. Con ligeras modificaciones, los valores de esta tabla son los usados en la referencia [49]. En la misma referencia se detalla el proceso de obtención de las expresiones simplificadas (2.41).

Los valores de los calores de reacción, en $\mathrm{kJ} / \mathrm{mol}$, son

\begin{tabular}{cccc}
\hline$q_{\mathrm{I}}^{*}$ & $q_{\mathrm{II}}^{*}$ & $q_{\mathrm{II}}^{*}$ & $q_{\mathrm{IV}}^{*}$ \\
\hline 356.082 & -78.852 & 562.043 & 41.114 \\
\hline
\end{tabular}

En este esquema el consumo de combustible ocurre en el paso I, un proceso que consume radicales. Estos radicales se generan en el paso II, mientras que el paso III modela la recombinación de los radicales, y el paso IV la oxidación de $\mathrm{CO}$ en $\mathrm{CO}_{2}$. Las especies intermedias que no aparecen en las ecuaciones (2.39) tienen concentraciones pequeñas y su contribución al balance másico se desprecia, por lo que sólo es preciso escribir ecuaciones de transporte para las siete especies $\mathrm{CH}_{4}, \mathrm{O}_{2}, \mathrm{CO}, \mathrm{H}_{2}, \mathrm{OH}, \mathrm{CO}_{2}$ y $\mathrm{H}_{2} \mathrm{O}$, y para la energía. 


\begin{tabular}{cccc}
\hline- & $A$ & $n$ & $T_{a}$ \\
\hline$k_{1_{1}}$ & $1.300 \times 10^{4}$ & 3 & 4042 \\
$k_{1_{2}}$ & $1.600 \times 10^{7}$ & 1.83 & 1395 \\
$k_{2 f}$ & $9.756 \times 10^{13}$ & 0 & 7470 \\
$k_{2_{b}}$ & $1.445 \times 10^{13}$ & 0 & 352 \\
$k_{3 f}$ & $3.535 \times 10^{18}$ & -0.8 & 0 \\
$k_{3 b}$ & $5.058 \times 10^{18}$ & -0.8 & 23578 \\
$k_{4 f}$ & $4.400 \times 10^{6}$ & 1.5 & -373 \\
$k_{4 b}$ & $1.270 \times 10^{9}$ & 1.5 & 11873 \\
$K_{1}$ & 0.2267 & 0 & 7675 \\
$K_{2}$ & $9.660 \times 10^{-2}$ & 0 & 8574.53 \\
$k_{5 f}$ & $2.891 \times 10^{13}$ & 0 & -252.6 \\
$k_{5 b}$ & $3.069 \times 10^{14}$ & 0 & 36088 \\
\hline
\end{tabular}

Tabla 2.2: Constantes de reacción usadas en el esquema de cuatro reacciones. $k_{i}=$ $A_{i} T^{n_{i}} \exp \left(-T_{a_{i}} / T\right)$. Unidades: mol, centímetro cúbico, Kelvin. Fuente: Sánchez et al. [49], con cambios menores.

El cálculo de los flujos difusivos de estas siete especies se simplifica teniendo en cuenta que el nitrógeno es la especie más abundante en cualquier punto del campo fluido. Por ello, se considera una aproximación adecuada emplear la ley de Fick con la difusividad binaria de cada especie en nitrógeno. Con esta aproximación, los números de Lewis son

\begin{tabular}{ccccccc}
\hline $\mathrm{Le}_{\mathrm{CH}_{4}}$ & $\mathrm{Le}_{\mathrm{O}_{2}}$ & $\mathrm{Le}_{\mathrm{CO}_{2}}$ & $\mathrm{Le}_{\mathrm{H}_{2} \mathrm{O}}$ & $\mathrm{Le}_{\mathrm{CO}}$ & $\mathrm{Le}_{\mathrm{H}_{2}}$ & $\mathrm{Le} \mathrm{OH}$ \\
\hline 1 & 1.05 & 1.39 & 0.83 & 1.07 & 0.3 & 0.74 \\
\hline
\end{tabular}

La variación de la conductividad con la temperatura se modela empleando la misma ley potencial que en los apartados anteriores: $\lambda=\left(T / T_{u}\right)^{\kappa}$, con $\kappa=0.75$.

Como se puede comprobar combinando linealmente las ecuaciones de conservación de las especies y la energía, la combinación

$$
\begin{aligned}
c_{p} T+\left(q_{\mathrm{I}}^{*}+2 q_{\mathrm{II}}^{*}+q_{\mathrm{III}}^{*}\right. & \left.+q_{\mathrm{IV}}^{*}\right) \frac{Y_{\mathrm{CH}_{4 u}}}{\mathcal{M}_{\mathrm{CH}_{4}}}+\left(\frac{q_{\mathrm{II}}^{*}}{2}+\frac{q_{\mathrm{III}}^{*}}{2}+q_{\mathrm{IV}}^{*}\right) \frac{Y_{\mathrm{CO}}}{\mathcal{M}_{\mathrm{CO}}}+ \\
& +\frac{q_{\mathrm{II}}^{*}+q_{\mathrm{III}}^{*}}{2} \frac{Y_{\mathrm{H}_{2}}}{\mathcal{M}_{\mathrm{H}_{2}}}+\frac{-q_{\mathrm{II}}^{*}+q_{\mathrm{III}}^{*}}{4} \frac{Y_{\mathrm{OH}}}{\mathcal{M}_{\mathrm{OH}}}
\end{aligned}
$$

satisface una ecuación de transporte sin términos de reacción. El valor de esta combinación es igual en el gas fresco y en el gas quemado. Despreciando las fracciones másicas de $\mathrm{CH}_{4}$, $\mathrm{CO}, \mathrm{H}_{2}$ y $\mathrm{OH}$ en el gas quemado, esta igualdad proporciona un valor aproximado de la temperatura de equilibrio,

$$
c_{p}\left(T_{e q}-T_{u}\right)=\left(q_{\mathrm{I}}^{*}+2 q_{\mathrm{II}}^{*}+q_{\mathrm{III}}^{*}+q_{\mathrm{IV}}^{*}\right) \frac{Y_{\mathrm{CH}_{4 u}}}{\mathcal{M}_{\mathrm{CH}_{4}}},
$$

que se emplea en lo que sigue. Aquí, $Y_{\mathrm{CH}_{4 u}}$ es la fracción másica de metano en el gas fresco (llamado $Y_{u}$ en apartados anteriores). 
El término de producción en la ecuación de la energía (2.35), $W$, se sustituye por

$$
W_{T}=q_{\mathrm{I}} \omega_{\mathrm{I}}+q_{\mathrm{II}} \omega_{\mathrm{II}}+q_{\mathrm{III}} \omega_{\mathrm{III}}+q_{\mathrm{IV}} \omega_{\mathrm{IV}},
$$

donde las velocidades de reacción se han adimensionalizado con el factor $\left(\rho_{u} U_{L_{r}} / \delta_{L_{r}}\right)$. $\left(Y_{\mathrm{CH}_{4 u}} / \mathcal{M}_{\mathrm{CH}_{4 u}}\right)$ y los calores de reacción con $\left(q_{\mathrm{I}}^{*}+2 q_{\mathrm{II}}^{*}+q_{\mathrm{III}}^{*}+q_{\mathrm{IV}}^{*}\right)$.

Los términos de producción en las ecuaciones de conservación para las siete especies cuya evolución debe calcularse son

$$
\begin{array}{cc}
W_{\mathrm{O}_{2}}=-\widetilde{\mathcal{M}}_{\mathrm{O}_{2}} \omega_{\mathrm{II}} \quad W_{\mathrm{CH}_{4}}=-\tilde{\mathcal{M}}_{\mathrm{CH}_{4} \omega_{\mathrm{I}}} \quad W_{\mathrm{CO}_{2}}=\widetilde{\mathcal{M}}_{\mathrm{CO}_{2} \omega_{\mathrm{IV}}} \\
W_{\mathrm{H}_{2}}=\widetilde{\mathcal{M}}_{\mathrm{H}_{2}}\left(2 \omega_{\mathrm{I}}-\omega_{\mathrm{II}}-\omega_{\mathrm{III}}+\omega_{\mathrm{IV}}\right) & W_{\mathrm{H}_{2} \mathrm{O}}=\widetilde{\mathcal{M}}_{\mathrm{O}_{2}}\left(\omega_{\mathrm{I}}-\omega_{\mathrm{IV}}\right) \\
W_{\mathrm{OH}}=\widetilde{\mathcal{M}}_{\mathrm{OH}}\left(-\omega_{\mathrm{I}}+\omega_{\mathrm{II}}-\omega_{\mathrm{III}}\right) & W_{\mathrm{CO}}=\widetilde{\mathcal{M}}_{\mathrm{CO}}\left(\omega_{\mathrm{I}}-\omega_{\mathrm{IV}}\right),
\end{array}
$$

que sustituyen a $s_{i} W$ en las ecuaciones (2.36). Aquí, $\widetilde{\mathcal{M}}_{i}=\mathcal{M}_{i} / \mathcal{M}_{\mathrm{CH}_{4}}$ y, como antes, todas las fracciones másicas se escalan con $Y_{\mathrm{CH}_{4 u}}$.

En la figura 2.11 se compara la velocidad de la llama plana calculada con el esquema (2.39) con la determinada con el mecanismo Gri-Mech 3.0. Como puede verse, ambas velocidades prácticamente coinciden para las llamas pobres de interés en esta tesis.

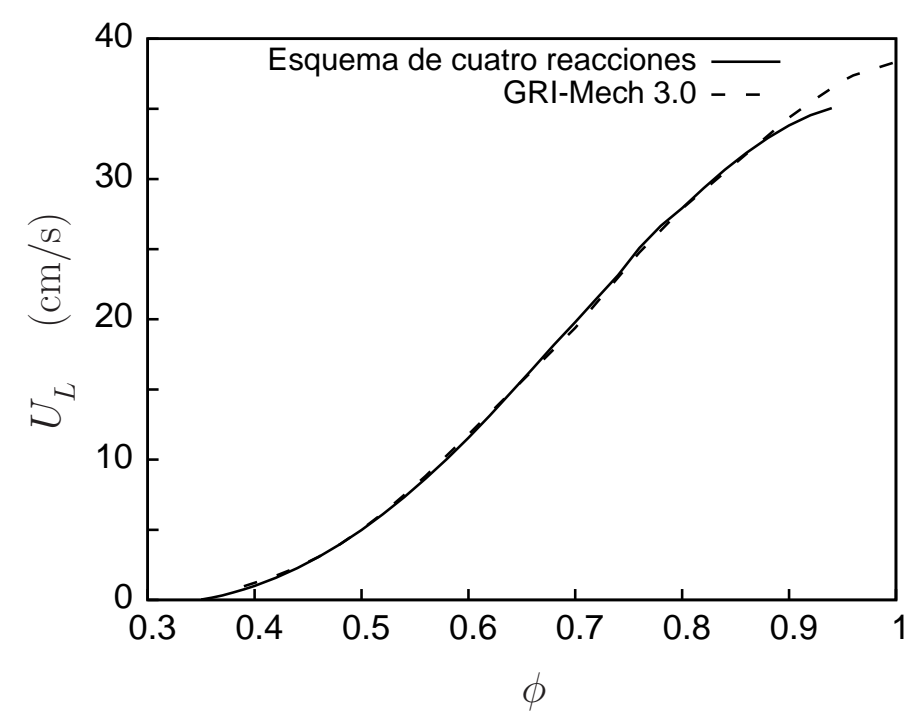

Figura 2.11: Velocidad de la llama plana en función de la riqueza, calculada con el esquema de cuatro reacciones (2.39) (curva continua) y con el mecanismo completo Gri-Mech 3.1 (curva de trazos).

La figura 2.10b incluye comparaciones de los perfiles de temperatura y fracción másica del combustible calculados con el modelo unidimensional y el esquema (2.39) (curvas verdes) con los calculados con este modelo y el esquema de una única reacción (curvas rojas) y con el modelo bidimensional del que se ha extraído el perfil de velocidad necesario para completar el problema (2.35)-(2.38) (curvas negras de trazos). El consumo de combustible es prácticamente igual en los casos en los que se ha usado el esquema cinético de una única reacción. La diferencia en la temperatura para estos dos casos se debe principalmente a la 
aproximación del término de conducción radial explicada en la sección anterior. El esquema cinético de cuatro reacciones muestra una ligera diferencia con los otros dos casos. En particular, se observa que para este caso la riqueza resultante es menor y la consecuencia inmediata es una reducción en el máximo de la temperatura.

También se ha aplicado el modelo unidimensional con el esquema de cuatro reacciones (2.39) y el término de pérdidas por radiación suprimido en la ecuación de la energía (2.35) a los perfiles de velocidad calculados con el modelo bidimensional en ausencia de radiación. En este caso el modelo bidimensional (con el esquema de una única reacción) predice que, con $\mathrm{Le}_{F}=1$, la extinción ocurre para $\phi=0.344$, cuando la llama está ya en la zona de recirculación (ver figuras 2.5a y 2.3a). La predicción del esquema de cuatro reacciones es diferente; la extinción ocurre para $\phi \approx 0.434$. Los perfiles de concentración de seis de las especies cuya evolución se calcula se muestran en la figura 2.12 para varios valores de la riqueza. Como puede verse, las concentraciones de las especies intermedias $\left(\mathrm{OH}, \mathrm{H}_{2}\right.$ y $\mathrm{CO})$ disminuyen drásticamente al acercarse el punto de extinción. La llama soporta peor la corriente inversa que con el esquema de una única reacción. Aparentemente, la ancha región donde ocurre la oxidación del CO es la más afectada, y su fallo se traduce en la extinción de la llama.

\subsection{Conclusiones}

En este capítulo se ha formulado un modelo del ascenso estacionario de un frente de llama axilsimétrico en un tubo vertical que contiene una mezcla pobre. La combustión se ha modelado mediante una reacción global exotérmica irreversible, y las pérdidas de calor por radiación se han tenido en cuenta admitiendo que el gas es ópticamente delgado.

Los resultados numéricos confirman que la forma y velocidad de ascenso de la llama son parecidas a las de una burbuja que asciende en un tubo lleno de líquido. El problema deja de tener solución estacionaria cuando la riqueza de la mezcla disminuye hasta un cierto valor de extinción que depende del radio adimensional del tubo y del número de Lewis del combustible, $\mathrm{Le}_{F}$. En un sistema de referencia ligado a la llama, al disminuir la riqueza a valores próximos al de extinción aparece detrás de la llama una zona de baja velocidad, e incluso recirculación, cuyo tamaño es del orden del radio del tubo y aumenta cuando la riqueza disminuye.

En ausencia de pérdidas por radiación, la extinción se debe a efectos aerodinámicos. Cuando el número de Lewis del combustible es mayor que la unidad, la extinción ocurre a causa del alargamiento ( stretch) de la llama debido a la velocidad de deformación del flujo de gas fresco inmediatamente delante del punto más alto de la llama, en el eje del tubo. Cuando el número de Lewis del combustible es menor que la unidad, la extinción ocurre cuando la mayor parte de la zona de reacción de la llama está en la zona de recirculación, y parece deberse a que la corriente inversa (desde el gas quemado) que existe en esta región limita el aporte de combustible por difusión desde el gas fresco. El valor de la riqueza para el que ocurre la extinción es una función creciente del número de Lewis del combustible. Para el tubo de inflamabilidad estándar, la riqueza de extinción para Le $_{F} \leq 1$ es apreciablemente menor que los valores experimentales que se presentan en los siguientes capítulos. Para un tubo de radio menor $(13 \mathrm{~mm})$ el valor de la riqueza de extinción calculado numéricamente es próximo al obtenido experimentalmente. 

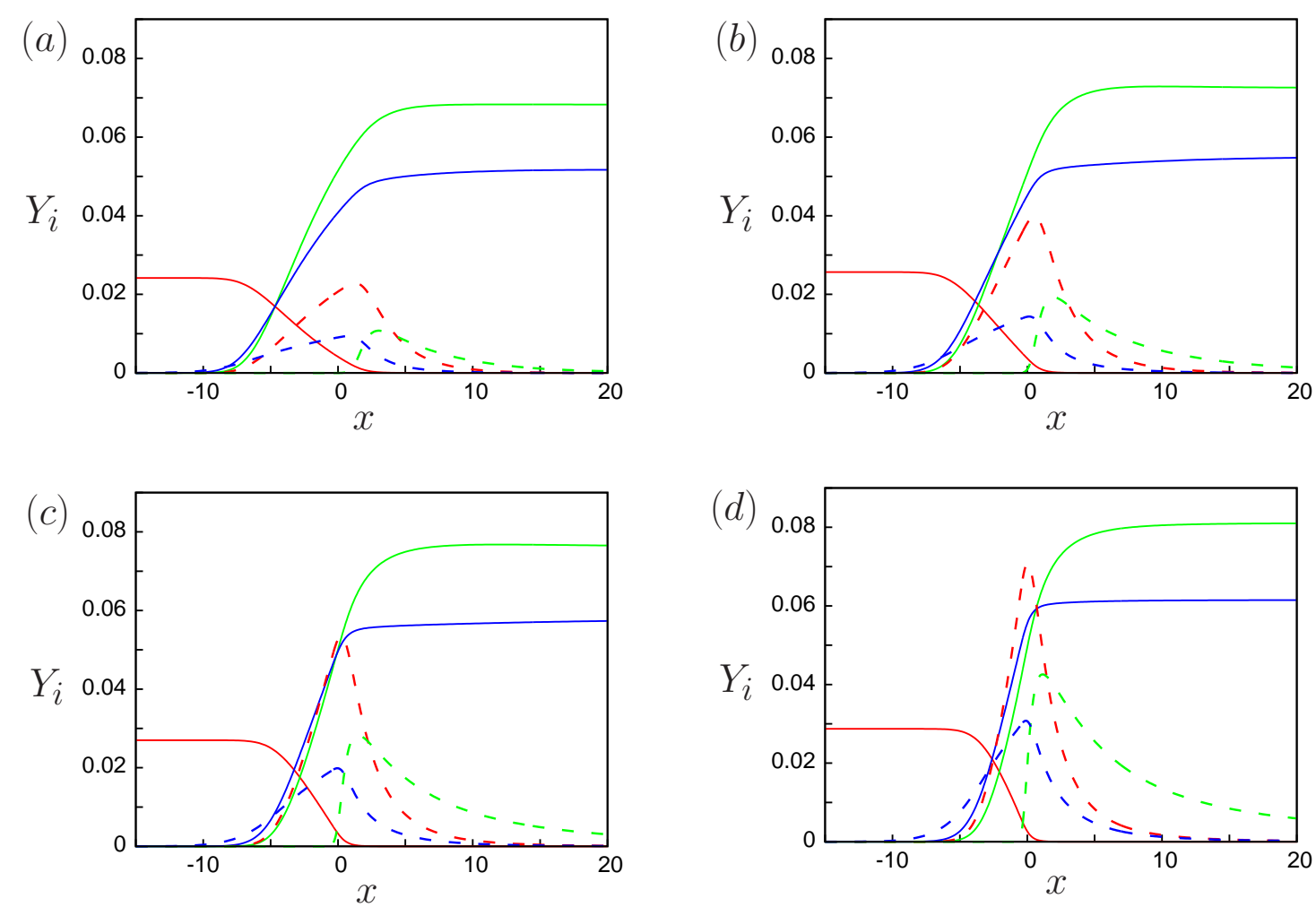

Figura 2.12: Distribuciones de las fracciones másicas de varias especies a lo largo del eje del tubo calculadas sin pérdidas por radiación $(\Sigma=0)$ con el modelo unidimensional, el esquema de cuatro reacciones, y los perfiles de velocidad obtenidos con el modelo bidimensional para $\operatorname{Le}_{F}=1$ y $\phi=0.434(a), 0.474(b), 0.504(c)$, y $0.538(d)$. Los demás parámetros tienen los valores de referencia. Se representan las especies $\mathrm{CH}_{4}$ (curva roja continua), $\mathrm{CO}_{2}$ (verde continua), $\mathrm{H}_{2} \mathrm{O}$ (azul continua), $\mathrm{CO}$ (roja de trazos, multiplicada por 5), $\mathrm{OH}$ (verde de trazos, multiplicada por 50) y $\mathrm{H}_{2}$ (azul de trazos, multiplicada por $500)$. La extinción ocurre aproximadamente para la riqueza del caso ( $a$ ), que es mayor que $\phi_{\text {lim }}$ calculada con el modelo bidimensional (sin pérdidas y con el esquema de una única reacción).

El efecto de las pérdidas por radiación, debidas a las especies $\mathrm{CO}_{2}$ y $\mathrm{H}_{2} \mathrm{O}$, es pequeño lejos de la extinción porque las concentraciones de estas especies son bajas. Sin embargo, el efecto de las pérdidas aumenta mucho al aproximarse a la extinción, debido a la aparición de la zona de baja velocidad mencionada antes, cuya presencia aumenta mucho el tiempo de residencia del gas quemado caliente detrás de la llama. La conducción de calor llega a hacerse importante en esta zona, a pesar de su gran tamaño, y la disminución de temperatura debida a las pérdidas induce un flujo de calor por conducción desde la llama hacia el gas quemado que produce una disminución de la temperatura final de combustión del orden de la temperatura de Frank-Kamenetskii. El valor de la riqueza de extinción calculado numéricamente para mezclas de metano y aire teniendo en cuenta las pérdidas por radiación es similar al valor obtenido experimentalmente en el tubo de inflamabilidad estándar. La importancia de la radiación disminuye cuando disminuye el radio del tubo. 
Se ha introducido un modelo unidimensional simplificado que permite calcular los perfiles de temperatura y concentración de las especies a lo largo del eje del tubo para un perfil de velocidad dado, que debe obtenerse experimentalmente. El modelo se basa en ecuaciones de conservación simplificadas en las que se desprecia la difusión radial de las especies, debido a que el espesor de la llama es pequeño frente al radio del tubo, y la conducción radial de calor detrás de la llama se aproxima mediante un término algebraico con un coeficiente cuyo valor se ajusta para reproducir los resultados del modelo bidimensional descrito antes.

En el marco de este modelo unidimensional, se ha sustituido el esquema de una única reacción irreversible por un esquema reducido más realista de cuatro reacciones. 


\section{Capítulo 3}

\section{Instalación experimental}

\subsection{Tubo de inflamabilidad estándar}

Idealmente, los límites de inflamabilidad de una mezcla entre un combustible y un comburente sólo deben depender de su composición y de sus propiedades termodinámicas. Sin embargo, los resultados experimentales obtenidos por distintos investigadores durante la primera mitad del siglo XX presentan valores de composición muy dispersos para los límites de inflamabilidad de una misma pareja de combustible y comburente. La diferencia entre las instalaciones experimentales usadas, así como la falta de un procedimiento experimental a seguir, parecen ser la causa principal de estas discrepancias. Como se mencionó en el capítulo anterior, estos hechos fueron señalados en un informe técnico de la Oficina de Minas de Estados Unidos (United States Bureau of Mines) realizado por Coward y Jones [6], donde estos autores propusieron utilizar un procedimiento estandarizado para determinar los límites de inflamabilidad

Cuando los límites de inflamabilidad se analizan desde el punto de vista de la seguridad ante explosiones, la capacidad de la llama para propagarse a través de una mezcla, normalmente de gran volumen, debe ser estudiada. En volúmenes muy grandes de mezclas inflamables la zona de combustión tendría inicialmente la forma de un casquete esférico de radio creciente, y los productos de la reacción crearían corrientes de convección. La llama no puede propagarse hacia abajo cuando la velocidad de ascenso de los gases calientes es más grande que la velocidad de la llama respecto al gas, lo que ocurre para llamas cercanas al límite de inflamabilidad. De esta forma, cerca de cada límite hay un rango de riquezas donde puede haber propagación hacia arriba y no hacia abajo. Así que, para la seguridad de procesos industriales, sería más inteligente considerar los límites de propagación hacia arriba como línea de peligro, ya que son más anchos que para el caso de propagación horizontal o hacia abajo de la llama.

En base a las observaciones presentadas en el informe [6] y al consenso de los investigadores posteriores en cuanto al uso de una instalación experimental similar a la utilizada en dicho informe, en nuestro experimento se ha usado como elemento central un tubo vertical de Plexiglas con un diámetro interior de $54 \mathrm{~mm}$, espesor de pared de $3 \mathrm{~mm}$ y una longitud de $1.9 \mathrm{~m}$. Aunque el diámetro de este tubo es entre 3 y $4 \mathrm{~mm}$ mayor que el empleado por otros investigadores, esta diferencia no cambia mucho el límite de inflamabilidad [6]. Además el estudio se centra en el entendimiento de los mecanismos que intervienen en 
la extinción más que en la determinación del valor exacto del límite de inflamabilidad. El Plexiglas es el nombre comercial del polimetilmetacrilato (PMMA), también conocido como cristal acrílico. Al igual que el vidrio, el Plexiglas proporciona un buen acceso óptico para la observación visual de la llama, transmite hasta un $92 \%$ de la luz visible (láminas de $3 \mathrm{~mm}$ de espesor) y filtra la luz ultravioleta para longitudes de onda inferiores a $300 \mathrm{~nm}$. La ventaja principal frente el vidrio es la facilidad para ser mecanizado y taladrado. Ello proporciona mayor versatilidad y menor complejidad para la instalación de instrumentación experimental. Aunque tiene una temperatura de transición vítrea baja (entre 90 y $130{ }^{\circ} \mathrm{C}$ ), la velocidad vertical de propagación del frente de llama es suficientemente rápida (alrededor de $20 \mathrm{~cm} / \mathrm{s}$ ), y los gases calientes tienen un tiempo de residencia suficientemente pequeño, para que la temperatura de la pared no alcance valores tan altos.

Una mezcla se considera inflamable si, al encenderla en el extremo inferior del tubo, la llama es capaz de propagarse hasta su extremo superior. Durante la propagación, el extremo superior del tubo se mantiene cerrado mientras el inferior se abre a la atmósfera, asegurando que la presión dentro del tubo no varía apreciablemente. La zona de estudio es la parte central de tubo, donde la llama alcanza una propagación estable y estacionaria y los efectos de la fuente de ignición pueden ser depreciados. Para mejorar la accesibilidad al interior del tubo, para su limpieza y el oscurecimiento de las paredes, el tubo se divide en 3 secciones. La sección central tiene $40 \mathrm{~cm}$ de longitud, $90 \mathrm{~cm}$ la inferior y $70 \mathrm{~cm}$ la superior. Esta configuración permite además el uso de técnicas que requieran acceso óptico para longitudes de onda ultravioletas, inferiores a los $300 \mathrm{~nm}$, como la técnica LIF (Laser Induced Fluorescence) sin necesidad de cambiar el tubo entero por otro, sino cambiando sólo su sección central por otra de cuarzo.

\section{Estructura rigidizadora}

La unión de las distintas secciones del tubo se realiza mediante bridas fabricadas en el laboratorio. Cada pareja de bridas se une mediante 6 tornillos. Además, se colocan juntas tóricas entre las secciones para asegurar que el tubo sigue siendo estanco a pesar de estar formado por secciones distintas.

La configuración final es bastante rígida, pero es preciso añadir una estructura que mantenga el tubo vertical, facilite la instalación de sensores y además sirva para la fijación de los tubos auxiliares, para aporte de mezcla y evacuación de gases quemados. Para ello se ha fabricado en el laboratorio una jaula construida con perfil de aluminio de $25 \mathrm{~mm}$ (Fasten). La sección en planta de la jaula es un cuadrado de $40 \mathrm{~cm}$ de lado y tiene la altura total es de $170 \mathrm{~cm}$. A la altura de las dos uniones de la sección central del tubo, y en el extremo superior de la jaula, se han situado bases de aglomerado MDF con un orificio de $10 \mathrm{~cm}$ para la instalación del útil de centrado del tubo.

\subsection{Diseño del mezclador de gases}

Para la realización de los experimentos el tubo vertical debe ser llenado con la mezcla de gases deseada. Como las llamas cuyos límites de inflamabilidad se van a estudiar son llamas premezcladas, los gases que constituyen la mezcla deben mezclarse en la proporción seleccionada antes de entrar en el tubo. Para ello el sistema que alimenta la instalación 
experimental debe ser capaz de medir la cantidad de cada gas que compone la mezcla y mezclarlos íntimamente antes de la entrada del tubo.

Para el aporte de aire se ha empleado un compresor que carga un depósito a una presión entre 5 y 9 bar. Los demás gases utilizados para los experimentos son suministrados en botellas individuales de alta presión (alrededor de 200 bar). Por razones de seguridad estas botellas se han almacenado fuera del laboratorio. Para alimentar la instalación experimental con los gases necesarios se han instalado líneas de suministro de gases desde las botellas hasta el interior del laboratorio. En la salida de cada botella se ha conectado un manómetro para poder controlar la presión de los gases en las líneas de suministro.

Antes del primer uso se ha realizado una prueba de estanqueidad de todas las líneas de suministro instaladas para comprobar la ausencia de fugas. Para que el laboratorio siguiera siendo seguro en el caso de fugas posteriores, ya fuera por causa de un escape de gas accidental, el fallo de alguna unión en la línea de suministro o una alta concentración de productos de combustión, el laboratorio ha sido equipado con 4 detectores de concentración de gases con alarma acústica. Estos detectores miden de forma continua la concentración de metano, oxígeno, monóxido y dióxido de carbono en el aire del laboratorio. En caso de detectar que la concentración de algún gas supera los límites de seguridad, se activa la alarma sonora. En la salida de cada línea de suministro dentro del laboratorio se ha instalado una válvula que permite cerrar el paso de los gases que no se estén utilizando. Después de cada válvula se ha añadido un filtro para proteger las electroválvulas que van después.

Una vez el laboratorio ha sido equipado con las líneas de suministro de gases, se ha procedido a la construcción del mezclador de gases, cuya misión es proporcionar la mezcla de gases deseada a partir de los gases individuales. La cantidad de cada gas en la mezcla se controla mediante un controlador de gasto másico. Por su rápida respuesta de ajuste al valor de gasto solicitado y la posibilidad de controlarlo directamente desde el ordenador y sin necesidad de software adicional, se han elegido los controladores de flujo másico Bronkhorst El-Flow (en la tabla 3.1 están recogidas los modelos elegidos para cada gas y sus características principales). Los controladores se han fijado sobre una plancha de acero inoxidable equipada con una fuente de alimentación de corriente continua y tensión de 24 V para alimentarlos. Las salidas de todos los controladores están unidas a la salida del mezclador. Para evitar el paso de un gas a la línea de suministro de otra, a la salida de cada controlador se ha añadido una válvula antirretorno. En la figura 3.1 se presenta el esquema simplificado y una foto del mezclador.

Tabla 3.1: Controladores de flujo másico Bronkhorst El-Flow

\begin{tabular}{|c|c|c|c|}
\hline Gas & Modelo & Rango nominal & Precisión \\
\hline $\mathrm{CH}_{4}$ & F-201CV-5K0 & $0.04-5 l_{n} / \min$ & \\
\hline Aire & F-201AV-50K & $0.4-50 l_{n} / \min$ & \\
\hline $\mathrm{O}_{2}$ & & & \\
$\mathrm{~N}_{2}$ & F-201CV-10K & $0.08-10 l_{n} / \min$ & \\
$\mathrm{CO}_{2}$ & & & \\
\hline
\end{tabular}

$\dagger$ Rd es la lectura del controlador y FS es su rango nominal.

En los experimentos con gases es habitual utilizar volúmenes o caudales para medir la 

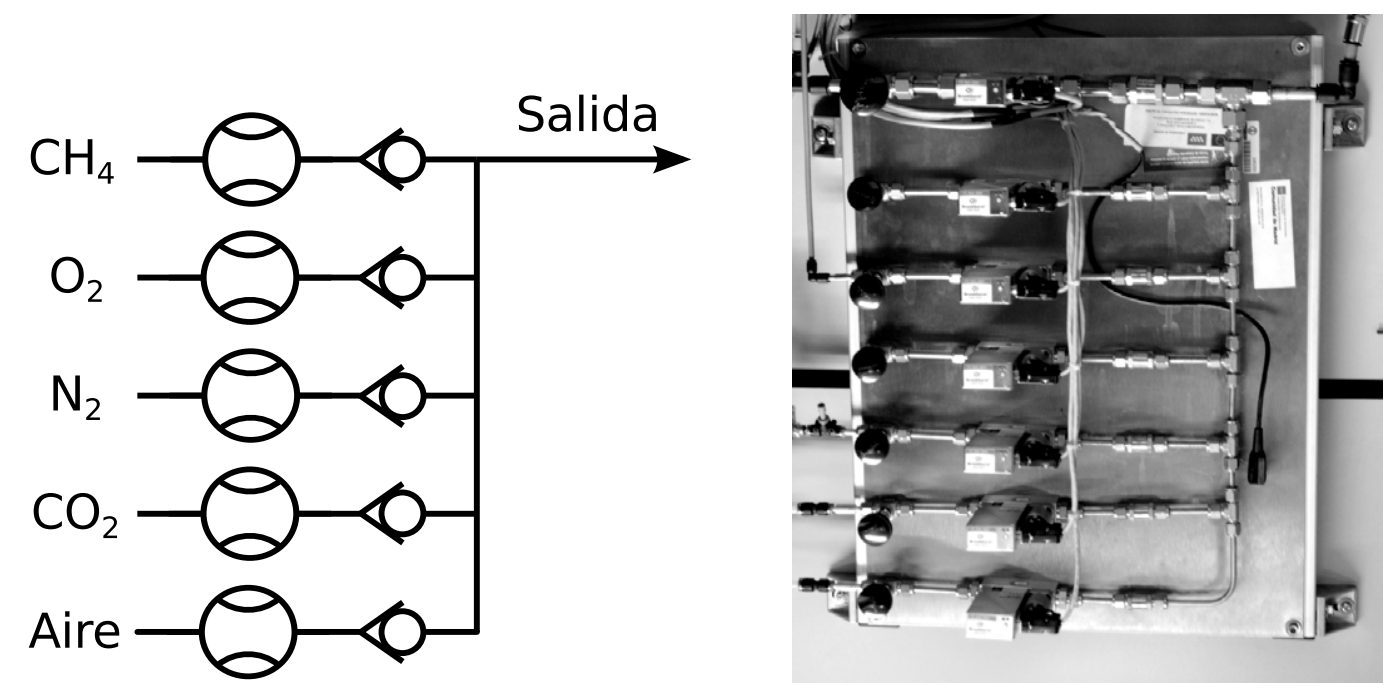

Figura 3.1: Foto y esquema del mezclador de gases

cantidad de gas que se emplea, ya que las cantidades de gas medidas en unidades de masa son muy pequeñas debido a la baja densidad. Para la preparación de mezclas para combustión es útil esta forma de medir por la equivalencia existente entre volúmenes y número de moles de los productos involucrados en la reacción. Los medidores de cantidad de gas basados directamente en la medición de volúmenes de gases y que tengan precisión suficiente suelen ser muy voluminosos y si se quiere medir varios gases ocupan mucho espacio en el laboratorio. Por otro lado las medidas dependen de las condiciones ambientales, ya que el volumen es función de la temperatura y la presión del gas. El empleo de este tipo de medidores añadiría la necesidad de controlar y medir con precisión estos parámetros para cada experimento. Los medidores más compactos están basados en métodos indirectos de medición, como por ejemplo en la transferencia de calor al gas. Para asegurar la precisión de estos medidores la instalación en la línea de gas se debe realizar con cuidado para asegurar la laminaridad del flujo, ya que en caso de tener flujo turbulento la incertidumbre en la medida aumentaría con respecto a la anunciada por el fabricante. Una mejora de estos sensores es la integración de elementos laminarizadores y de medición en un único aparato que permita medir manteniendo los errores dentro de un margen aceptable. Este es el caso de los medidores Bonkhorst El-Flow cuya forma de funcionar se explica a continuación con el objetivo de aclarar sus limitaciones y entender las claves para un uso adecuado.

En la figura 3.2 se presenta un esquema del funcionamiento de estos medidores. El gas se hace pasar primero por un laminarizador para garantizar que el flujo sea laminar. Aguas abajo de este elemento hay un segundo laminarizador que se emplea para generar una caída de presión conocida. Entre los dos laminarizadores hay un orificio que se comunica con la zona aguas abajo del segundo laminarizador a través de un tubo capilar de acero inoxidable. El tubo capilar está rodeado de aire y tiene unidos sus extremos a la carcasa del medidor. Este tubo tiene acoplados a su pared exterior un calentador en la zona central y dos detectores de temperatura resistivos (RTD del inglés de resistance temperature detector) situados simétricamente con respecto a su punto medio. El calentador aporta una cantidad de calor en la zona central del tubo, una parte del cual se emplea en calentar 
el tubo, mientras que otra parte pasa al gas a través de la pared interior del tubo capilar. Si la velocidad del gas en del tubo capilar fuese nula, el perfil de temperaturas de la pared del tubo sería simétrico con respecto al punto medio del tubo y las temperaturas medidas por los dos RTD serían iguales. Cuando pasa gas por el tubo se genera una asimetría en el perfil de temperaturas debido al calor que trasporta el gas desde la parte izquierda a la parte derecha del tubo. En este caso las temperaturas medidas por los sensores son distintas y su diferencia permite determinar el gasto másico de gas que fluye por el tubo capilar. En el apéndice A se profundiza sobre el modelo matemático que permite describir el funcionamiento del sensor.
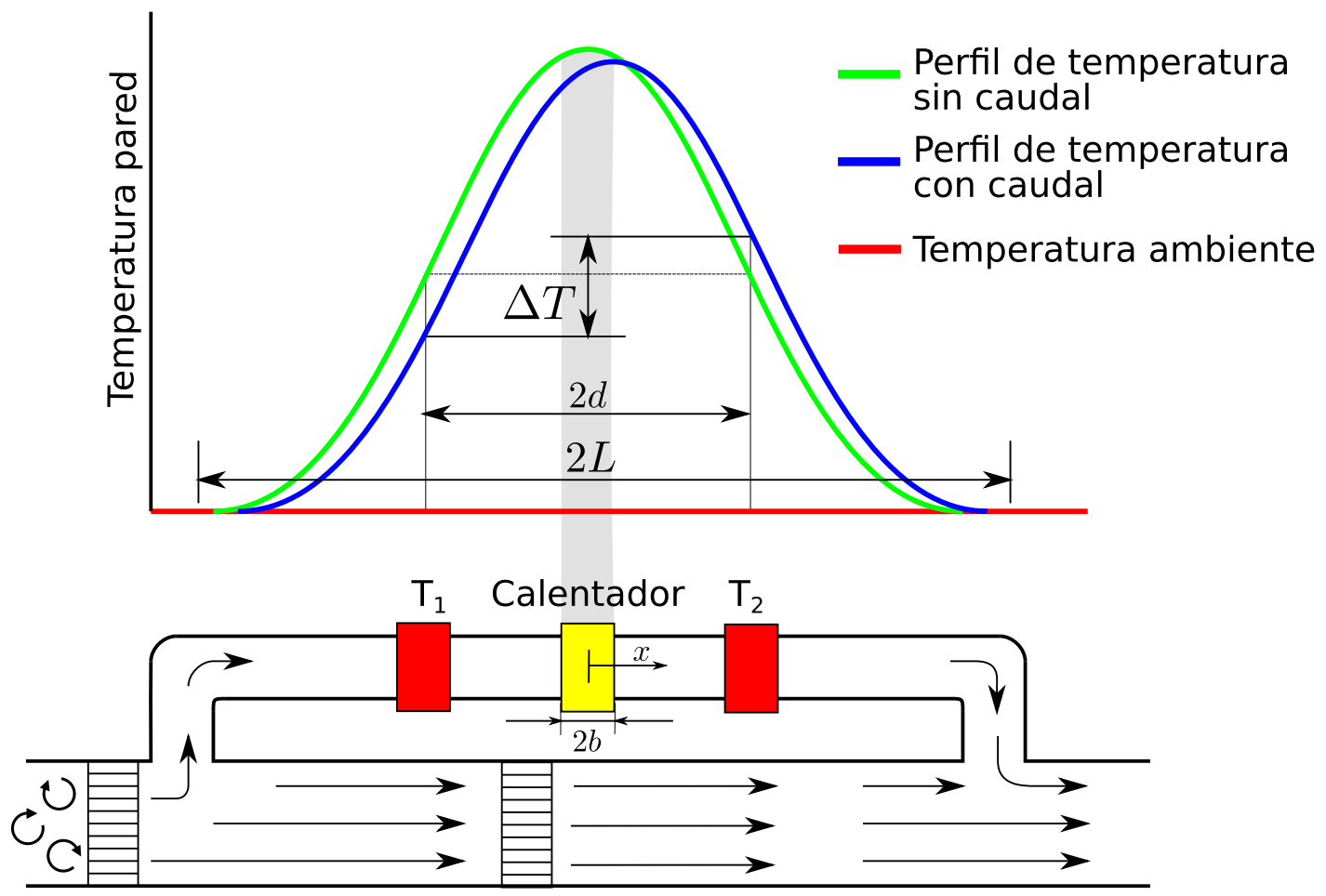

Figura 3.2: Esquema de funcionamiento del controlador de flujo másico El-Flow. El tubo de mayor diámetro es el conducto principal y el de menor diámetro es el tubo capilar. En la parte superior de la figura se representa el perfil de temperatura de la pared en caso de flujo nulo (verde) o distinto de cero (azul). El salto de temperaturas, $\Delta T$, se puede relacionar con el caudal que fluye por el conducto principal.

El controlador está diseñado para que el gasto másico a través del tubo capilar sea proporcional al gasto total que pasa por el canal principal, de tal forma que al transformar la diferencia de temperatura medida en señal se tiene:

$$
V_{\text {signal }}=K c_{p} \dot{m},
$$

donde $V_{\text {signal }}$ es la señal medida por el circuito electrónico del sensor, $c_{p}$ es la capacidad calorífica del gas a presión constante, $\dot{m}$ es el gasto másico y $K$ es una constante.

La proporcionalidad de la señal medida por el controlador con el gasto másico elimina la dependencia de las mediciones con la presión del gas a la entrada del medidor. Además, 
por la forma de funcionar del controlador (ver apéndice A) la señal también es independiente de la temperatura de gas. Estas características proporcionan a los controladores una versatilidad y una facilidad de uso mucho mayores que las de los medidores de caudal volumétrico.

Probablemente, para mantener la noción de consistencia con otros instrumentos, los controladores Bronkhorst El-Flow muestran sus lecturas en unidades del llamado caudal normal o caudal en unidades de volumen normal, que sería el caudal volumétrico real si el gas entrase en el controlador con una densidad correspondiente a condiciones normales, definidas por el fabricante como temperatura de $0^{\circ} \mathrm{C}$ y presión 1 atmósfera. La transformación entre gasto másico y caudal volumétrico se realiza empleando la fórmula:

$$
\dot{V}_{n}=\frac{\dot{m}}{\rho_{n}},
$$

donde $\dot{V}_{n}$ es el caudal y $\rho_{n}$ es la densidad en condiciones normales.

Para obtener el caudal volumétrico en otra condiciones es necesario conocer esta conversión. En el caso de necesitar obtener el valor del flujo másico a partir de las lecturas del controlador, se deben emplear los valores de las densidades del gas en condiciones normales recogidos en la tabla 3.2 .

Tabla 3.2: Densidad y calor específico de los gases empleados en las condiciones normales especificadas por el fabricante: $0^{\circ} \mathrm{C}$ y 1 atm.

\begin{tabular}{|c|c|c|c|}
\hline Nombre & Símbolo & $\rho_{n}\left[\mathrm{~kg} / \mathrm{m}^{3}\right]$ & $c_{p}[\mathrm{~J} /(\mathrm{kg} \cdot \mathrm{K})]$ \\
\hline Aire & Aire & 1.293 & 1010 \\
\hline Dióxido de carbono & $\mathrm{CO}_{2}$ & 1.977 & 892 \\
\hline Metano & $\mathrm{CH}_{4}$ & 0.7175 & 2378 \\
\hline Nitrógeno & $\mathrm{N}_{2}$ & 1.25 & 1043 \\
\hline Oxígeno & $\mathrm{O}_{2}$ & 1.429 & 929 \\
\hline
\end{tabular}

\subsubsection{Riqueza}

La masa de oxidante necesaria para quemar una unidad de masa de combustible es una constante para cada pareja de reactantes. El valor de esta constante está determinado por la reacción global de combustión y las masas moleculares de las especies. Para la pareja de metano-oxígeno la reacción global es

$$
\mathrm{CH}_{4}+2 \mathrm{O}_{2} \rightarrow \mathrm{CO}_{2}+2 \mathrm{H}_{2} \mathrm{O} \text {. }
$$

Como las masas moleculares de combustible y oxidante son 16 y $32 \mathrm{~g} / \mathrm{mol}$ respectivamente y hacen falta dos moléculas de oxidante por cada molécula de combustible, se tiene:

$$
s=\frac{2 \cdot 32}{16}=4 .
$$

La riqueza o relación de equivalencia de una mezcla es el cociente entre la masa de oxidante que haría falta para quemar todo el combustible de la mezcla y la masa de oxidante 
realmente contenida en la mezcla. En términos de las fracciones másicas de combustible y oxidante, $Y_{F}$ y $Y_{O}$, la riqueza de la mezcla es

$$
\phi=\frac{s Y_{F}}{Y_{O}} .
$$

Una mezcla se llama estequiométrica cuando la relación entre la masa de oxidante y masa de combustible que contiene coincide con $s$. Así pues, para una mezcla estequiométrica $\phi=1$. Si $\phi<1$ la mezcla se llama pobre. En una mezcla pobre hay más oxidante del necesario para quemar todo el combustible existente, por lo que cuando se ha consumido todo el combustible queda un resto de oxidante. Si $\phi>1$ la mezcla se llama rica y en su combustión se acaba el oxidante cuando todavía queda un resto de combustible sin quemar.

La relación de equivalencia de una mezcla en función de las medidas de los controladores de combustible y oxidantes usados para formarla es

$$
\phi=\frac{s Y_{F}}{Y_{O}}=\frac{s \cdot \dot{m}_{F}}{\dot{m}_{O}}=s \frac{\rho_{n_{F}} \dot{V}_{n_{F}}}{\rho_{n_{O}} \dot{V}_{n_{O}}}=s \frac{\mathcal{M}_{F}}{\mathcal{M}} \frac{\dot{V}_{n_{F}}}{\dot{V}_{n_{O}}},
$$

donde $\mathcal{M}_{F}$ y $\mathcal{M}_{O}$ son las masas moleculares del combustible y el oxidante. La última igualdad se obtiene usando la ecuación de estado para cada una de las especies $\mathrm{F}$ y $\mathrm{O}$, suponiendo que la mezcla se comporta como una mezcla de gases ideales. Para el caso del metano y el oxígeno,

$$
\phi=2 \frac{\dot{V}_{n_{\mathrm{CH}_{4}}}}{\dot{V}_{n_{\mathrm{O}_{2}}}} .
$$

En la expresión anterior se observa que únicamente con las lecturas de los medidores de oxígeno y metano se puede conocer la relación de equivalencia de la mezcla, aunque ésta contenga también otras especies. Este hecho es importante, ya que muestra que el valor de $\phi$ por sí solo no es suficiente para caracterizar la mezcla, salvo que ésta esté compuesta sólo por oxígeno y metano o metano y aire, ya que la proporción entre nitrógeno y oxígeno en este caso es fija y conocida.

Si se considera el aire como una mezcla únicamente de oxígeno y nitrógeno, por cada unidad de masa de aire se tienen 0.233 unidades de masa de oxígeno y 0.767 de nitrógeno. Por lo que al utilizar la línea de aire comprimido con su propio medidor la relación de equivalencia es

$$
\phi=\frac{s \cdot \dot{m}_{F}}{0.233 \dot{m}_{\text {aire }}}=\frac{s}{0.233} \frac{\mathcal{M}_{F}}{\mathcal{M}_{\text {aire }}} \frac{\dot{V}_{n_{F}}}{\dot{V}_{n_{\text {aire }}}}=9.52 \frac{\dot{V}_{n_{\mathrm{CH}_{4}}}}{\dot{V}_{n_{\text {aire }}}} .
$$

Por la propia definición de la relación de equivalencia ésta sólo depende de la cantidad de metano y oxígeno. En el caso de diluir la mezcla con nitrógeno o cualquier otro gas la relación de equivalencia permanece inalterada. Por ello es muy importante a la hora de comparar los resultados con los obtenidos por otros autores conocer la composición de la mezcla. Incluso en el caso de usar aire puede haber diferencia en el comportamiento de las llamas pobres en función de si se usa aire seco o húmedo. 


\subsubsection{Incertidumbre en la medida de la riqueza}

La riqueza es una parámetro fundamental para describir las mezclas y para estudiar cómo se comportan las llamas en función de su valor. Pero, de la misma manera que ocurre en cualquier medición experimental, el valor obtenido de la riqueza lleva asociada una incertidumbre causada por los errores en las medidas de los caudales de los gases que componen la mezcla.

El error en el valor de la riqueza dada por (3.2) como función de los errores en las medidas de los caudales de metano y oxígeno se obtiene a partir de la siguiente expresión

$$
\mathrm{d}(\ln \phi)=\frac{\partial(\ln \phi)}{\partial\left(\ln \dot{V}_{n_{\mathrm{CH}_{4}}}\right)} \mathrm{d}\left(\ln \dot{V}_{n_{\mathrm{CH}_{4}}}\right)+\frac{\partial(\ln \phi)}{\partial \ln \dot{V}_{n_{\mathrm{O}_{2}}}} \mathrm{~d}\left(\ln \dot{V}_{n_{\mathrm{O}_{2}}}\right)
$$

donde $\partial(\ln \phi) /\left(\partial \ln \dot{V}_{n_{\mathrm{CH}_{4}}}\right)=1$ y $\partial(\ln \phi) /\left(\partial \ln \dot{V}_{n_{\mathrm{O}_{2}}}\right)=-1$. Sustituyendo d $(\ln \phi)$ por $\Delta \phi / \phi$, y análogamente para las otras diferenciales, queda, en el caso más desfavorable en el que los errores se acumulen,

$$
\frac{\Delta \phi}{\phi}=\frac{\Delta \dot{V}_{n_{\mathrm{CH}_{4}}}}{\dot{V}_{n_{\mathrm{CH}_{4}}}}+\frac{\Delta \dot{V}_{n_{\mathrm{O}_{2}}}}{\dot{V}_{n_{\mathrm{O}_{2}}}}
$$

Los errores en las medidas de los caudales están definidos por el fabricante y en el caso de los controladores Bronkhorst EL-Flow corresponden a $0.5 \%$ de la lectura del controlador más el $0.1 \%$ de su rango nominal (ver tabla 3.1).

En el caso de tener un medidor de caudal ideal, el valor que proporciona el medidor es igual al caudal real que se está midiendo. Los caudales medidos con medidores reales, que son imperfectos, se desvían debido a factores aleatorios y a la falta de linealidad en la respuesta del sensor, y generan un error en la medida. Este error es muy difícil de determinar, pero sí se puede estimar y acotar. Al acotar el error, se acepta que no se puede conocer el valor exacto del caudal real, pero que sí se puede asegurar que se encuentra dentro de los límites de error estimados:

$$
\dot{V}_{n}^{\text {real }} \in\left(\dot{V}_{n}^{\text {ideal }}-\Delta \dot{V}_{n}, \dot{V}_{n}^{\text {ideal }}+\Delta \dot{V}_{n}\right) .
$$

La incertidumbre en el valor de la riqueza que se obtiene con los datos de la tabla 3.1 es demasiado grande. Consideremos el siguiente ejemplo. Para el caso del controlador empleado para el metano, en un experimento que usa $0.7 \mathrm{l}_{\mathrm{n}} / \min$ de metano y $2.52 \mathrm{l}_{\mathrm{n}} / \mathrm{min}$ de oxígeno se tiene una riqueza de la mezcla $\phi=0.5556$. El caudal se mide en $\mathrm{l}_{\mathrm{n}} / \mathrm{min}$, donde $l_{n}$ es el volumen de gas en litros a temperatura $0^{\circ} \mathrm{C}$ y presión una atmósfera, y min es un minuto. Los errores asociados a estos medidas, usando los valores de la tabla 3.1 para los controladores, son

$$
\Delta \dot{V}_{n_{\mathrm{CH}_{4}}}=0.0085 \mathrm{l}_{\mathrm{n}} / \mathrm{min} \quad \Delta \dot{V}_{n_{\mathrm{O}_{2}}}=0.0226 \mathrm{l}_{\mathrm{n}} / \mathrm{min} .
$$

Así pues, la riqueza completada con su incertidumbre es

$$
\phi=0.5556 \pm 0.0211,
$$

y, ajustando las cifras significativas de la riqueza a la incertidumbre obtenida, queda

$$
\phi=0.56 \pm 0.02 .
$$


Aunque la acotación del valor de $\phi$ en la ecuación (3.5) es correcta, según estos cálculos sus valores entre 0.54 y 0.58 son indistinguibles entre sí. Sin embargo, para estos valores de la riqueza de la mezcla el comportamiento de la llama es muy distinto, mientras que para las mezclas con $\phi=0.54$ algunas llamas se extinguen dentro del tubo, para $\phi=0.58$ la llama siempre alcanza su extremo superior. Este hecho indica que el error proporcionado por el fabricante es muy conservador, por lo que se pasa a investigar si es posible reducirlo manteniendo el rigor en la exposición de los resultados. Hay dos elementos específicos de las condiciones en que los controladores Bronkhorst se usan en nuestros experimentos que permiten reducir apreciablemente el error de la medida de $\phi$.

Por una parte, el valor $\dot{V}_{n_{O_{2}}}$ del caudal normal de oxígeno se ha mantenido constante en la mayoría de los experimentos, variando el caudal normal de metano para cambiar la riqueza. Esto permite reducir el error en la medida de $\dot{V}_{n_{O_{2}}}$ usando un medidor más preciso, Ritter TG5, cuyo principio de funcionamiento se explica más abajo, para calibrar el controlador Bronkhorst del oxígeno para un valor del caudal normal próximo al valor constante usado en los experimentos. De este modo $\Delta \dot{V}_{n_{O_{2}}} / \dot{V}_{n_{O_{2}}}$ se reduce esencialmente al error relativo del medidor Ritter TG5, que es del $0.5 \%$.

Por otra parte, el caudal normal de metano se ha variado sólamente entre $0.65 \mathrm{l}_{\mathrm{n}} / \mathrm{min}$ y $0.75 \mathrm{l}_{\mathrm{n}} / \mathrm{min}$ en la mayor parte de los experimentos, que es un intervalo pequeño en comparación con el rango completo del controlador Bronkhorst empleado para este gas, que va de 0 a $F=5 \mathrm{l}_{\mathrm{n}} / \mathrm{min}$. Esto permite reducir los errores de las medidas de metano usando hipótesis razonables sobre la curva de respuesta real del aparato.

Admitimos que la medida de $\dot{V}_{n_{C H_{4}}}$ proporcionada por el aparato es, con suficiente aproximación, de la forma $M\left(\dot{V}_{n_{C H_{4}}}\right)$; es decir que únicamente depende del valor de la variable que se trata de medir. La diferencia $\Delta \dot{V}_{n_{C_{H}}}=M\left(\dot{V}_{n_{C_{4}}}\right)-\dot{V}_{n_{C H_{4}}}$ es el error de la medida. Este error es una función desconocida de $\dot{V}_{n_{C H_{4}}}$, acotada por los errores máximos superior e inferior indicados por el fabricante, que en el caso del controlador que usamos son la suma de un error constante y otro proporcional a $\dot{V}_{n_{C H_{4}}}$. El error mayor, correspondiente al fondo de escala del aparato, es $E=0.03 \mathrm{l}_{\mathrm{n}} / \mathrm{min}$. Estos errores máximos se representan por las dos rectas negras de la figura 1.6a, mientras que la curva roja es una representación esquemática de la curva desconocida de error, $\Delta \dot{V}_{n_{C_{H_{4}}}}\left(\dot{V}_{n_{C_{4}}}\right)$. Esta curva esquemática se ha trazado admitiendo que el error es del orden del máximo y varía en cantidades de este orden en el rango completo del aparato. En esta hipótesis, la pendiente de la curva de error en cualquiera de sus puntos será de orden $P=E / F=0.006$.

El intervalo de valores de $\dot{V}_{n_{C_{4}}}$ en que se usa el aparato está delimitado por los dos segmentos verticales en el eje horizontal de la figura 3.4, y se muestra ampliado en la figura 3.4b. En este intervalo reducido, la curva roja se puede aproximar por una recta. $\mathrm{Su}$ ordenada en el punto medio del intervalo, que es el error en la medida del controlador Bronkhorst para $\dot{V}_{n_{C_{4}}}=0.7 \mathrm{l}_{\mathrm{n}} / \mathrm{min}$, se determina con un error de $\pm 0.005 \times 0.7=$ $\pm 3.5 \times 10^{-3} \mathrm{l}_{\mathrm{n}} / \mathrm{min}$ usando una sola vez el medidor Ritter TG5, cuyo error relativo es $0.5 \%$. El orden de la variación de la ordenada de la recta roja entre los extremos del intervalo reducido (de $0.65 \mathrm{l}_{\mathrm{n}} / \mathrm{min}$ a $0.75 \mathrm{l}_{\mathrm{n}} / \mathrm{min}$ ) es $P \times 0.1=6 \times 10^{-4} \mathrm{l}_{\mathrm{n}} / \mathrm{min}$, donde se ha usado la estimación anterior del orden de la pendiente $P$ de la recta. Así pues, sumando ambos errores, puede estimarse que el error en la medida de $\dot{V}_{n_{C_{H_{4}}}}$ del controlador Bronkhorst, incrementada en la diferencia entre las medidas del medidor Ritter TG5 y la del controlador para $\dot{V}_{n_{C H_{4}}}=0.7 \mathrm{l}_{\mathrm{n}} / \mathrm{min}$, es $\pm\left(3.5 \times 10^{-3}+6 \times 10^{-4}\right)= \pm 4.1 \times 10^{-3} \mathrm{l}_{\mathrm{n}} / \mathrm{min}$, 
para medidas de $\dot{V}_{n_{C H_{4}}}$ en el intervalo de $0.65 \mathrm{l}_{\mathrm{n}} / \mathrm{min}$ a $0.75 \mathrm{l} \mathrm{n} / \mathrm{min}$.

E medidor Ritter TG5 mide directamente el caudal de gas y basa su funcionamiento en el desplazamiento de volúmenes. Está compuesto por un tambor dividido en cuatro cámaras cada una de las cuales se comunica con el exterior mediante una ranura en una de sus esquinas (figura 3.3). El tambor se encuentra dentro de una carcasa de plástico y su mitad inferior se encuentra sumergida en un líquido. La entrada de gas, en el centro del aparato, y el tamaño y disposición de las ranuras de salida están diseñadas de tal forma que las cámaras se van llenando de gas secuencialmente, a un ritmo constante y sin ninguna pérdida de gas, y la presión de gas sobre las paredes hace girar al tambor a velocidad constante. El giro del tambor mueve una aguja que marca sobre una escala el volumen de gas que ha pasado a través del medidor, y midiendo el volumen que ha pasado en un intervalo de tiempo dado se obtiene el caudal. El inconveniente de este medidor frente a los Bronkhorst El-Flow es que es dependiente de la temperatura y la presión en el laboratorio, y su lectura de caudal se debe hacer manualmente. La ventaja radica en que su error de $\pm 0.5 \%$ del valor medido es menor, ya que no depende del rango nominal del instrumento, contrariamente a lo que ocurre con los medidores El-Flow.

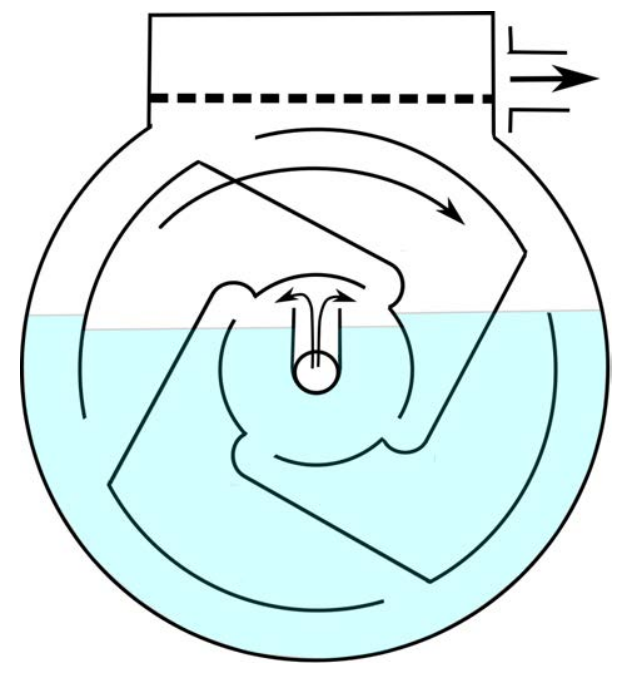

Figura 3.3: Esquema de funcionamiento de los medidores de caudal Ritter TG. El gas entra por el centro del tambor y sale de las cámaras por las ranuras laterales para luego salir del medidor por su parte superior.

\subsection{Encendido de la llama}

Una vez el tubo se ha llenado con la mezcla de interés, ésta debe ser encendida. La fuente de ignición ha de aportar suficiente energía para garantizar la propagación de la llama hasta distancias donde la influencia de la fuente de ignición pueda ser despreciada.

Para el estudio de llamas cercanas a su límite de inflamabilidad se ha empezado usando una llama piloto; por ejemplo una pequeña lámpara de alcohol [6], una pequeña llama de difusión de gas $[6,52]$ o la llama de una cerilla [20]. En estudios posteriores a los de [6] se han incorporado otros métodos de ignición, como la chispa eléctrica $[6,51]$ y la resistencia 


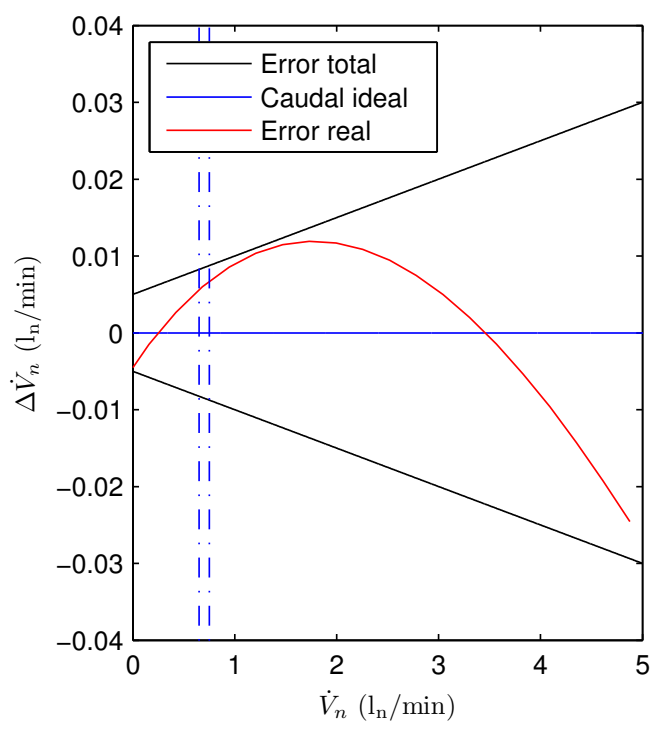

(a) Error del controlador

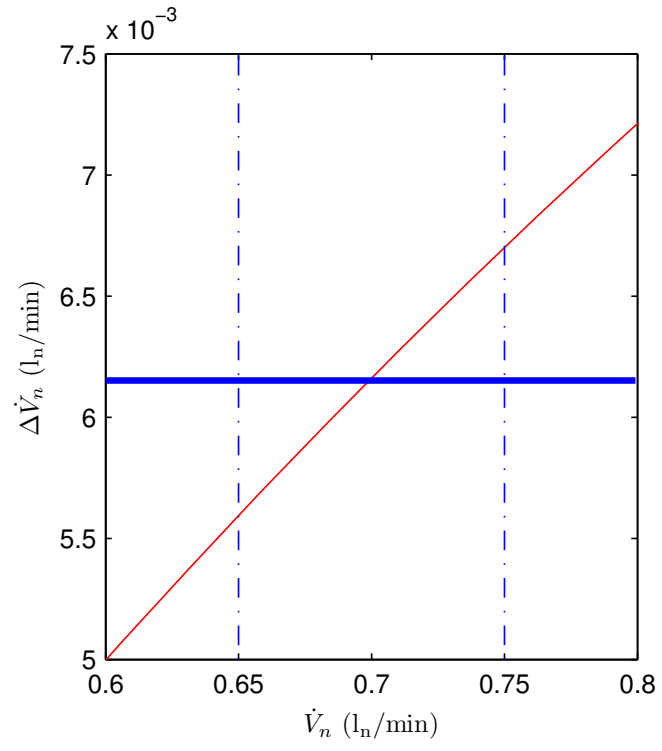

(b) Ampliación a la zona de uso

Figura 3.4: Revisión de la incertidumbre en las medidas de los controladores al reducir su zona de uso a la marcada por las líneas de trazos y puntos.

eléctrica $[20,61]$. En principio no hay ninguna razón destacada para preferir uno de los métodos presentados frente a otros, siempre que se pueda garantizar la independencia de la propagación de la llama de la fuente de ignición; p.ej. Jarosinski et al. [20] emplearon los tres métodos presentados (llama piloto, chispa y resistencia eléctrica) y no detectaron claras ventajas o inconvenientes para ninguno de ellos. De hecho, cuando la riqueza de la mezcla se acerca al valor del límite de inflamabilidad, las perturbaciones y las no uniformidades causadas por la ignición pueden ser suficientes para imposibilitar un encendido adecuado, independientemente del método elegido. Para solucionar este problema de la ignición, Levy [31] propuso enriquecer ligeramente la mezcla que se encuentra en la zona inferior del tubo de inflamabilidad. Esta mezcla enriquecida se enciende adecuadamente usando cualquier método de encendido y proporciona una fuente de ignición consistente y uniforme en todo el ancho del tubo para la mezcla pobre que se encuentra más arriba.

De los tres métodos de ignición se ha elegido el encendido mediante resistencia eléctrica. Se ha comprobado que la ignición es más uniforme usando este método que usando la llama piloto; este hecho también ha sido constatado por von Lavante y Strehlow [61]. Una ventaja importante de la resistencia eléctrica es que se puede controlar de forma remota utilizando un interruptor eléctrico, éste puede ser instalado lejos de la mezcla inflamable y es más seguro que encender manualmente la mezcla usando una llama. Una llama piloto controlada remotamente generaría perturbaciones en la mezcla antes de poder ser encendida. Estas perturbaciones dificultarían la ignición de las mezclas más pobres tal y como apuntó Levy [31]. Si se compara el encendido usando la resistencia eléctrica con el uso de la chispa eléctrica, la ventaja principal reside en el hecho de ser un método de encendido más robusto; las partículas usadas para sembrar la mezcla para las mediciones de PIV se depositan sobre los electrodos que crean la chispa y varían su eficacia, mientras 
que la resistencia eléctrica calienta las partículas que se depositan sobre ella a la misma temperatura que el hilo y su presencia no afecta de manera apreciable el encendido.

La resistencia eléctrica se fabrica en el taller del laboratorio usando hilo de Kanthal de $0.2 \mathrm{~mm}$ de diámetro. Al hilo se le da forma de hélice cilíndrica con un diámetro interior de unos 2-3 mm y longitud entre 10 y $15 \mathrm{~mm}$ (figura 3.5). El Kanthal es una aleación de hierro-cromo-aluminio ( $\mathrm{FeCrAl}$ ) que tiene la propiedad de soportar temperaturas de hasta $1400{ }^{\circ} \mathrm{C}$ manteniendo una gran resistividad eléctrica y tiene una buena resistencia a la oxidación. Se usa una fuente de potencia eléctrica para calentar la resistencia que la alimenta con $30 \mathrm{~W}$ de potencia durante 3 segundos. El procedimiento final del método de ignición se ha establecido después de numerosas pruebas. Primero para decidir la forma óptima de la resistencia y posteriormente para elegir el tiempo de calentamiento de ésta. Se ha observado que cuando la duración del pulso de calentamiento es de 2 segundos, la llama no es capaz de propagarse en algunas mezclas muy pobres a más de unos $30 \mathrm{~cm}$ de la resistencia. Cuando se aumenta la duración del pulso a más de 3 segundos, no se detecta ninguna mejora en el encendido. De hecho, para mezclas muy pobres cercanas al límite de inflamabilidad, se han obtenido mejores encendidos y propagaciones de las llamas enriqueciendo la zona inferior del tubo que aumentando la duración del aporte de calor.
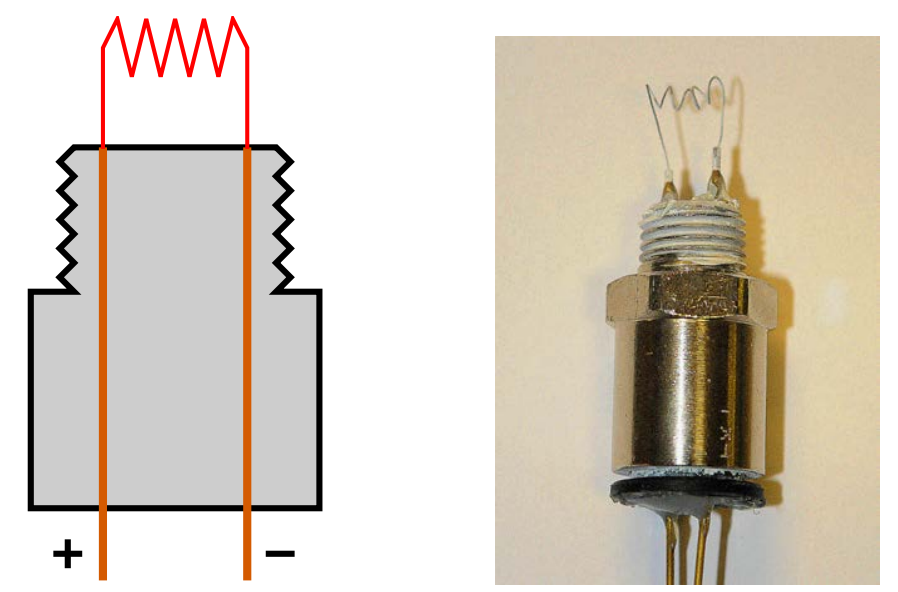

Figura 3.5: Esquema y foto de la resistencia empleada para encender la mezcla montada en un racor de $1 / 4$ " que facilita la instalación en el tubo.

\section{Efecto del encendido en la propagación de la llama}

El encendido de la mezcla juega un papel importante en el posterior comportamiento de la llama. Cuando la riqueza de la mezcla es apreciablemente que el límite de inflamabilidad, el encendido no afecta al desarrollo de la llama. Donde sí se nota la influencia del encendido es cuando la mezcla es muy pobre, cercana al límite inferior de inflamabilidad. De hecho, en estos casos, el encendido puede causar la catalogación como no inflamables de mezclas que sí lo son.

Como se ha observado en estudio anteriores y en los experimentos realizados con la instalación experimental presentada, las llamas muy pobres son muy sensibles a los efectos externos y a las condiciones de realización del experimento. Para evitar que los resultados sean dependientes de estas condiciones, se debe reducir al mínimo su influencia. 


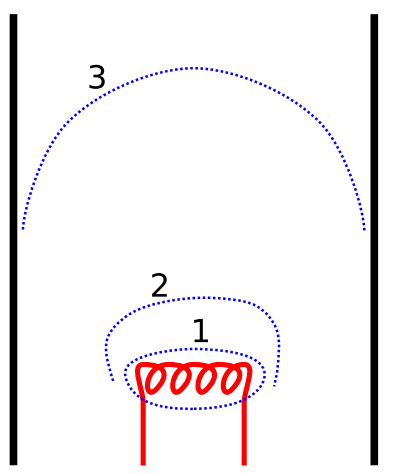

(a) Encendido normal

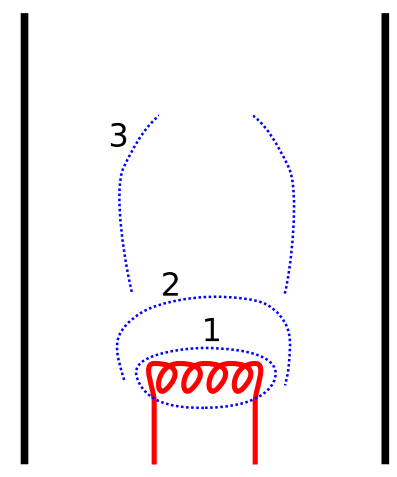

(b) Encendido pobre

Figura 3.6: Representación esquemática del encendido de mezclas con riqueza superior el límite inferior de inflamabilidad (a) y de mezclas con riquezas muy próximas al límite inferior (b).

El encendido de la llama consiste en transferir una gran cantidad de energía a la mezcla, más o menos distribuida en función de la forma de encendido escogido. En el caso de emplear una resistencia eléctrica la energía está mucho más distribuida que en el caso de encendido mediante chispa eléctrica. Este tipo de encendido genera inicialmente una superficie de llama que rodea el cilindro que circunscribe la hélice formada por la resistencia eléctrica, llama 1 en la figura 3.6. En la figura el encendido normal se refiere al encendido de mezclas más ricas que el límite inferior de inflamabilidad, mientras que el encendido pobre se refiere al encendido de mezclas cercanas al límite inferior de inflamabilidad, con riquezas ligeramente inferiores o ligeramente superiores al límite. Una vez creada, esta llama se desplaza hacia arriba empujada por la flotabilidad de los gases calientes generados, dando lugar a la llama 2 (figura 3.6). Estos dos pasos son similares tanto para el encendido normal como para el encendido pobre. El paso siguiente es el que marca la diferencia en el correcto encendido y su efecto sobre la posterior propagación de la llama.

Cuando la concentración de metano es superior al límite de inflamabilidad, la velocidad de la llama plana es suficiente para contrarrestar los movimientos convectivos o las asimetrías creadas en el encendido inicial, de tal forma que la superficie de la llama se amplia rápidamente hasta alcanzar las paredes del tubo y crear una superficie de llama continua que mantiene en su parte inferior los gases calientes generados.

En el caso de encendido de llamas próximas al límite inferior de inflamabilidad, la velocidad de la llama plana es más pequeña y si se crean flujo convectivos demasiado fuertes, la superficie de la llama se rompe y acaba apagándose. Esta extinción en el encendido de la llama puede ocurrir aunque la mezcla sea inflamable, comprobándose que para un misma riqueza la llama a veces se propaga hasta el extremo superior del tubo, mientras que otras veces no es capaz de crear una superficie de llama continua en todo el diámetro del tubo.

La representación de la figura 3.6 es una idealización del encendido basada en la observación del encendido en los experimentos realizados. En el encendido real los primeros dos pasos y la propagación de la llama hasta el paso 3 es mucho más compleja y asimétrica. La corrientes generadas desplazan la superficie de la llama hacia una pared pared del tubo y la extinción ocurre desde cualquier punto de la superficie de la llama, aunque prevalecen 
los punto más altos. Pero la llama 3 para los encendidos normales, figura 3.6a, siempre se consigue.

Para mejorar la consistencia del encendido de las mezclas cercanas al límite de inflamabilidad se ha aprovechado la facilidad de encendido de las mezclas ligeramente más ricas. Por ello, en los caso de mezclas muy pobres, la parte inferior del tubo se ha llenado con una mezcla más rica, cuyo encendido corresponde a la imagen 3.6a. De esta forma, al llegar la llama a la zona donde la mezcla es más pobre el encendido se produce en toda la sección del tubo, evitando la creación de las asimetrías y flujos convectivos que provocaban el apagado de las llamas.

\subsection{Proceso experimental completo}

A continuación se explica de forma esquemática el proceso seguido para la realización de los experimentos.

\section{Montaje del tubo}

El montaje del tubo es un proceso que debe realizarse con frecuencia para garantizar la limpieza interior del tubo. Las partículas de alúmina se depositan sobre las paredes interiores del tubo empeorando la calidad de las imágenes usadas para PIV. Estos efectos se notan en las imágenes tomadas como manchas blancas difuminadas que añaden intensidad parásita.

Como se ha explicado antes, el tubo está compuesto por tres partes que se unen entre ellas mediante bridas fabricadas en el laboratorio. El objetivo principal en el montaje del tubo es asegurar su verticalidad. Para ello se ha instalado una etapa de alineado para cada sección en la jaula rigidizadora. Se regula la inclinación de cada sección del tubo mediante tres tornillos dispuestos a $120^{\circ}$ entre ellos. La inclinación de la sección se controla mediante un nivel de burbuja o digital (figura 3.7).
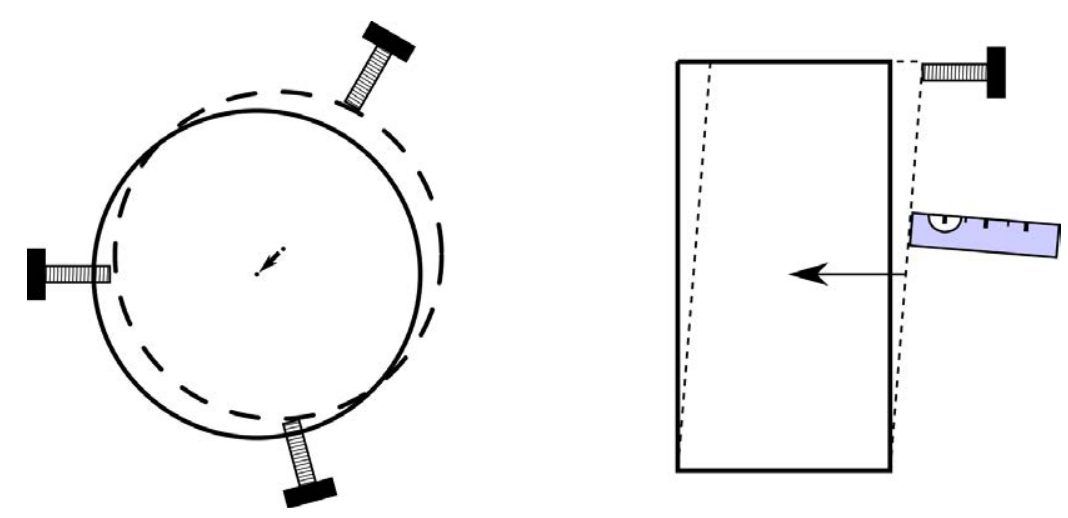

Figura 3.7: Representación esquemática de la alineación de las secciones del tubo con la vertical: Vista en planta (derecha) y vista frontal (izquierda). 


\section{Alineación láser y cámara}

Una vez se tiene el tubo vertical, se procede a la alineación de la cámara del PIV con el láser empleado para iluminar las partículas. La alineación vertical es la más simple, ya que sólo hay que desplazar la cámara hasta que la zona iluminada por el láser esté situada en el encuadre de la cámara. En la figura 3.8 se muestra la situación de la cámara, el tubo y el plano láser en el plano horizontal. Para la alineación, la sección central del tubo se sustituye por una sección igual, con la salvedad de que en las paredes tiene cuatro ranuras a $90^{\circ}$. Dos ranuras marcan la entrada y la salida del plano láser, y las dos restantes la dirección de la cámara que queda perpendicular al plano del láser.

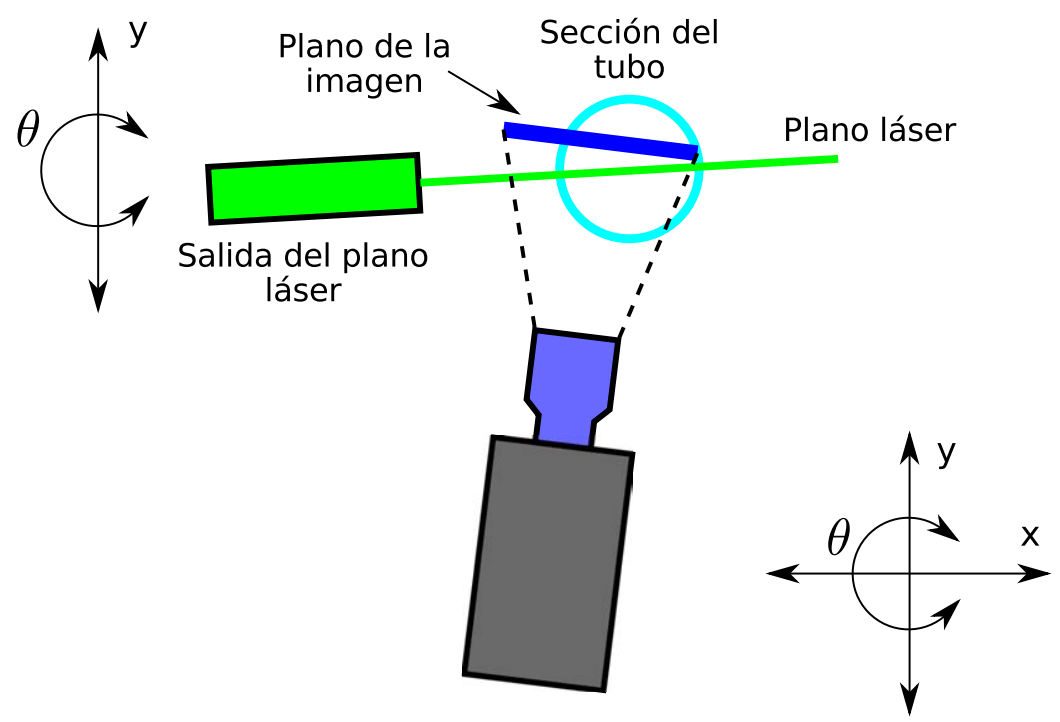

Figura 3.8: Situación del tubo, cámara y plano del láser antes de la alineación visto desde arriba. El cabezal de salida del plano láser sólo tiene control en el eje $y$ y giro alrededor del eje $z$. La cámara puede moverse en el eje $x, y, z$ y alrededor del $z$.

Primero se mueve el láser en el plano hasta que el haz pasa a través de las dos ranuras enfrentadas. De esta forma se asegura que el plano láser pasa por el eje del tubo. En el siguiente paso se alinea el punto medio del láser de la cámara con las otras dos ranuras. La disposición final ideal se muestra en la figura 3.9.

\section{Llenado del tubo}

Un vez elegida la composición de la mezcla, hay que llenar el tubo con ella. Antes de cada experimento el tubo está lleno de gases que deben ser evacuados; aire en el caso del primer experimento de la serie y productos de la combustión para los experimentos posteriores. El gas encerrado en el tubo se evacua a través del extremo inferior del tubo y la mezcla fresca, limpia o sembrada con partículas para el estudio con PIV, se introduce en el tubo por su extremo superior. La mezcla entra perpendicular a la pared del tubo creando vórtices intensos que mezclan rápidamente los gases de la parte superior del tubo. Posteriormente el gas fresco desciende por el tubo y desplaza los gases inicialmente contenidos en el mismo hacia su extremo inferior, por donde son evacuados. 


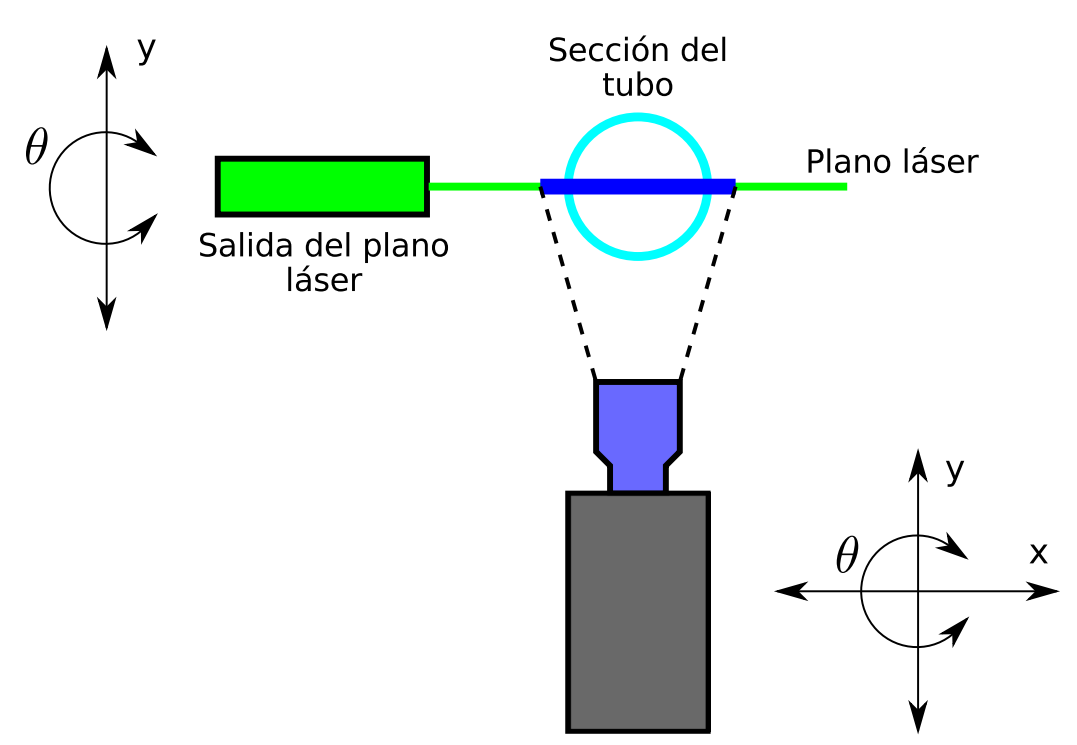

Figura 3.9: Configuración final ideal después de la alineación del tubo, el plano láser y la cámara.

Para asegurar la completa evacuación de los gases se hace pasar por el tubo un volumen de mezcla de unas 10 veces el volumen interior del tubo. No se han observado diferencias si se deja pasar mayor cantidad de mezcla. Otros autores, Jarosinski et al. [20], Shoshin et al. [53], han llegado a la misma conclusión pasando entre 6 y 10 veces el volumen interior del tubo, respectivamente. Para validar este procedimiento de evacuación de los gases del tubo, se han realizado varios ensayos utilizando un medidor de concentración de dióxido de carbono a la salida del tubo, ya que la mezcla fresca no debe contener apenas $\mathrm{CO}_{2}$. Una parte de los gases de salida del tubo han sido extraídos del flujo principal usando una pequeña bomba de aire y se han medido usando el sensor $\mathrm{CO}_{2}$ Engine (SenseAir). Entre la bomba y el sensor se ha instalado un filtro que elimina las partículas de alúmina del gas. Se ha observado que la concentración de $\mathrm{CO}_{2}$ baja rápidamente a medida que se introduce mezcla fresca en el tubo. Cuando se ha pasado un volumen de unas 5 veces el volumen interior del tubo, los niveles de concentración de $\mathrm{CO}_{2}$ son despreciables.

En la figura 3.10 se presenta un esquema de la instalación experimental. El elemento central es el tubo estándar, situado verticalmente. Hay, además, sistemas que permiten controlar la riqueza de la mezcla, la densidad de partículas de sembrado y el enriquecimiento de la mezcla en la zona inferior del tubo. El extremo superior del tubo está siempre cerrado con una tapa que está pegada a él. La mezcla entra al tubo a través de la válvula superior (S). El extremo inferior se abre o se cierra con una tapa movida por un pistón neumático. Esta tapa lleva una junta tórica (O-ring) para asegurar un cierre hermético.

La mezcla, con la composición elegida, sale del mezclador de gases por la electroválvula principal $(\mathrm{P})$, que sirve para cerrar el paso de mezcla en caso de emergencia. Después de esta válvula, la mezcla pasa por el sembrador de partículas que se describe en el capítulo 4. Si no se desea sembrar la mezcla, ésta sólo pasa por el segundo depósito del sembrador (ver figura 4.17). El impactador esquematizado en la figura 3.10 separa las partículas más grandes del flujo principal antes de que pasen al tubo vertical por la válvula S. Mientras se llena el tubo con la mezcla deseada, el extremo inferior del tubo está abierto. Cuando 


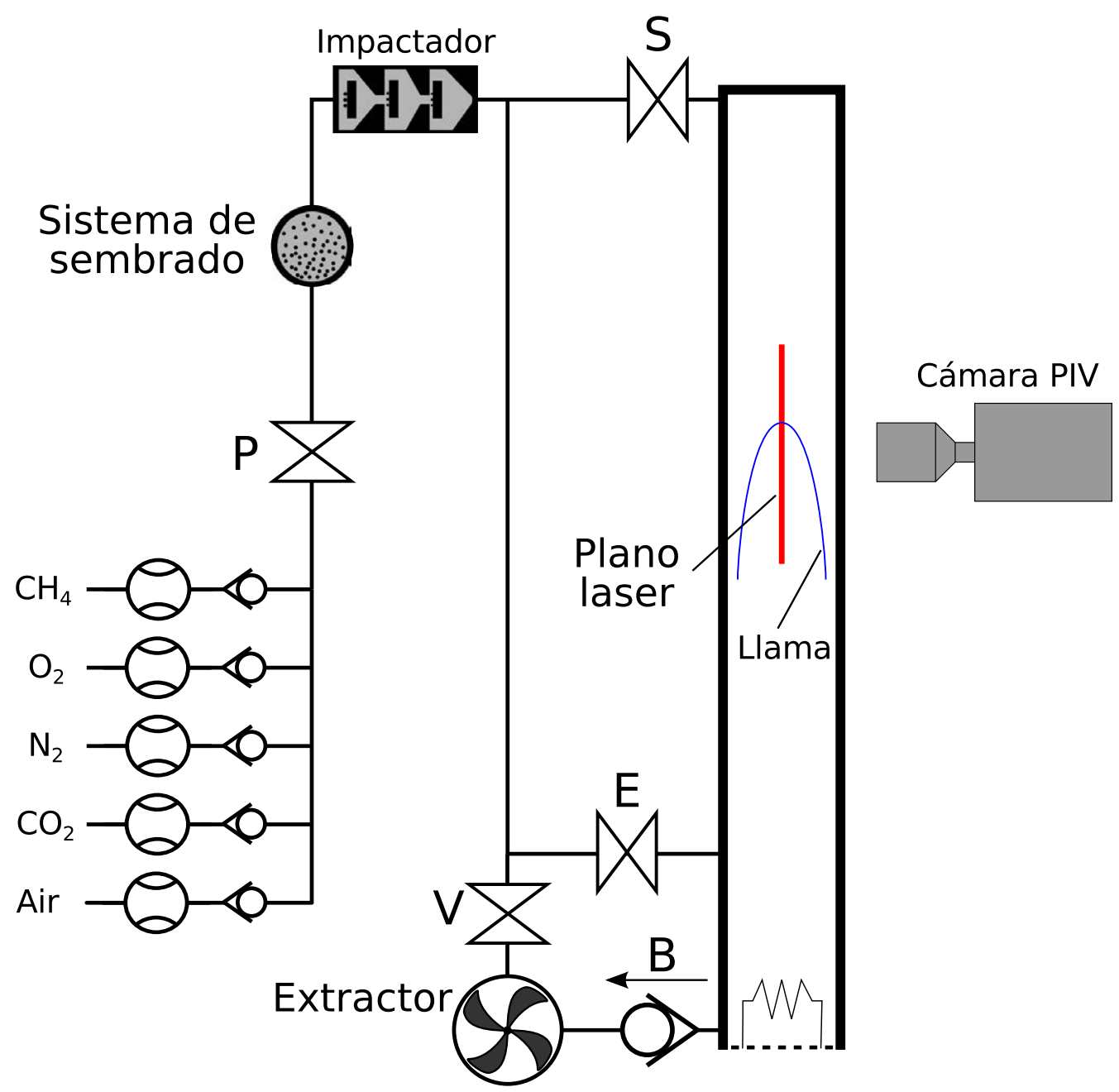

Figura 3.10: Esquema de la instalación experimental.

el tubo se ha llenado con la nueva mezcla, se cierra la válvula S y se cierra la tapa inferior el tubo usando un pistón neumático.

En la parte inferior del tubo se presenta de forma esquemática el circuito secundario para el llenado de la zona inferior del tubo con mezcla enriquecida para favoreces el encendido de la mezcla pobre. Para este proceso, después de llenar el tubo, se abre la válvula $\mathrm{V}$ y se ajusta la nueva riqueza del gas. Después se abre la válvula E y se cierra la V. En este caso la válvula antirretorno B sirve para evacuar el gas introducido en el tubo para enriquecer la zona inferior del tubo. Es importante que esta mezcla esté también sembrada con partículas, ya que en caso contrario se crea una zona de gas con una densidad media menor que la que tiene el gas sembrado con partículas que está más arriba y los gases de la zona inferior ascienden por el tubo en forma de burbuja [58].

Por otro lado, a causa de la presencia de altas concentraciones de partículas, que se depositan por sedimentación sobre los elementos ópticos del equipo de PIV y pueden ser perjudiciales para la salud si no se evacuan a menudo, se ha realizado una mejora en la instalación similar a la implementada por Shoshin et al. [53]. En la parte inferior del 
tubo se ha instalado una línea de evacuación de gases que va directamente al extractor. El control de la línea se hace con una válvula antirretorno (B) que sirve también como válvula de seguridad en caso de sobrepresión en el tubo que puede ser causada al encender la mezcla con la tapa inferior cerrada debido al fallo del pistón neumático. 


\section{Capítulo 4}

\section{Técnicas de medida}

\subsection{Velocidad de subida de la llama}

La resistencia eléctrica cerca del extremo inferior del tubo enciende la mezcla que se encuentra a su alrededor, iniciando una llama que se empieza a propagar de manera irregular en su proximidad. La propagación inicial ocurre en todas las direcciones, hasta que la llama alcanza las paredes del tubo, y después se orienta verticalmente hacia la parte superior del tubo. A una distancia de unos 40-50 cm de la resistencia la llama se estabiliza y toma la forma de un casquete esférico seguido de una falda alargada. La longitud de esta falda no es siempre igual y se ha observado que es mayor cuanto más baja es la riqueza de la mezcla. A una distancia de unos $70 \mathrm{~cm}$ de la resistencia la llama se propaga verticalmente de manera prácticamente estacionaria.

Antes del paso de la llama el gas se encuentra en reposo dentro del tubo y empieza a moverse cuando la llama está suficientemente cerca como para perturbarlo. Para estudiar la evolución del gas a través de la llama es conveniente usar un sistema de referencia ligado a la llama. Para determinar la velocidad de subida de la llama en el tubo se han usado dos métodos distintos: una línea de fotodiodos espaciados una distancia conocida y una cámara de fotos que registra imágenes a intervalos de tiempo conocidos.

\subsubsection{Medición de la velocidad usando una línea de fotodiodos}

El uso de fotodiodos permite determinar los momentos en los que la llama pasa por puntos preestablecidos. Los fotodiodos dan una señal en función de la intensidad de luz que captan, por lo que se ha construido un circuito electrónico para detectar el paso de la llama. De este modo, en vez de la intensidad de luz, se usa una señal TTL como indicador de la presencia de la llama.

Un vez registradas las señales de los fotodiodos, la forma de obtener la velocidad de la llama se representa en el esquema de la figura 4.1, donde, por conveniencia, el tubo vertical se representa horizontalmente.

Para la instalación de los fotodiodos se ha mecanizado un perfil de metacrilato en el que se montan los fotodiodos. Se han taladrado tres agujeros pasantes de diámetro conocido $d$ y una separación $s$. Por el lado exterior del perfil se han taladrado concéntricamente a los taladros anteriores unos agujeros de diámetro de $8 \mathrm{~mm}$ y profundidad $3 \mathrm{~mm}$, que coinciden con las dimensiones del encapsulado TO5 de los fotodiodos empleados. Para 


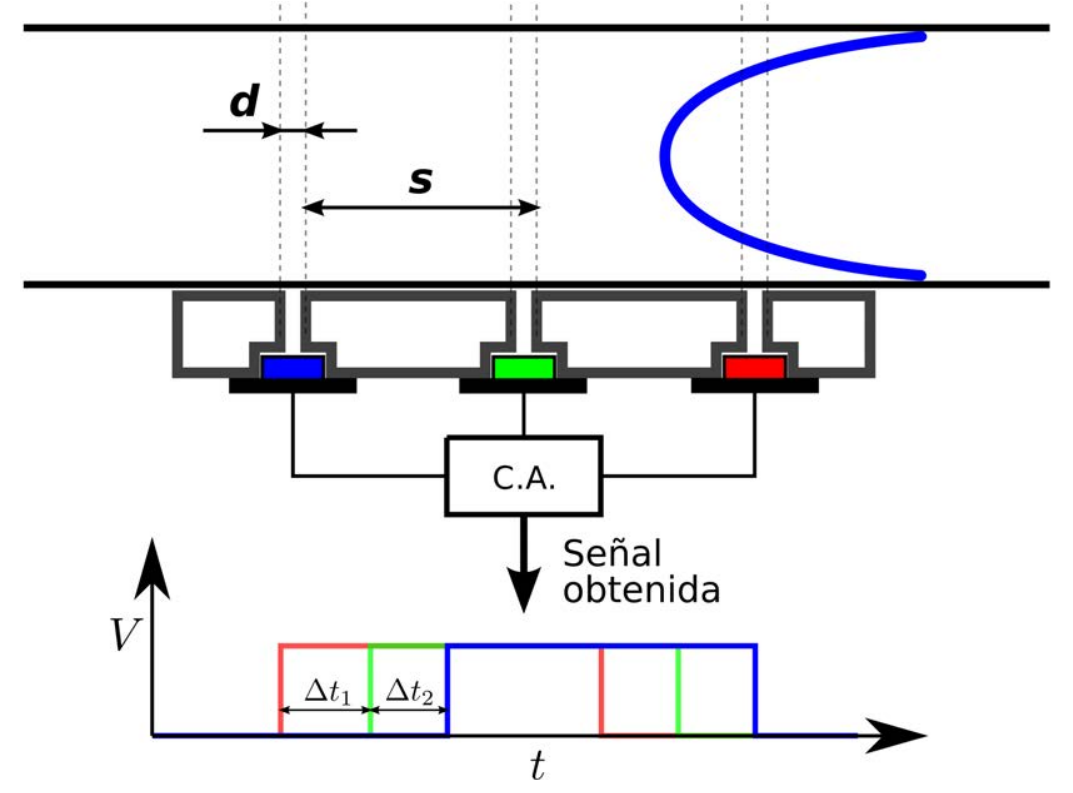

Figura 4.1: Esquema de funcionamiento de la línea de fotodiodos.

el uso de la línea de fotodiodos el perfil se une al tubo y se fija mediante unas bandas elásticas ancladas a sus extremos. Los taladros de diámetro $d$ fijan el ángulo de visión de los fotodiodos y permiten una detección más precisa del frente. Cuando la llama cruza el campo de visión de un fotodiodo, la señal que se genera es amplificada en el circuito amplificador (C.A. en la figura 4.1) de tal forma que en cuanto supera un umbral mínimo, se genera una señal de $5 \mathrm{~V}$. La señal generada dura mientras haya llama en el campo de visión del fotodiodo, lo que incluye el tiempo de paso de la falda, sin embargo, para nuestros propósitos importa sólo el frente de subida inicial. Cuando el frente de llama llega al segundo fotodiodo y cruza su campo de visión, se genera una nueva señal que es a su vez amplificada. Lo mismo ocurre para el tercer fotodiodo.

Una vez se han registrado las tres señales, la información del frente de subida de cada una de ellas establece la posición del frente de llama y los tiempos $\Delta t$ transcurridos entre cada pareja de señales. La velocidad de subida es $U=s / \Delta t$.

Idealmente, la señal que indica la presencia de la llama es generada en el momento en el que el punto más alto de la misma entra en el campo de visión de cada fotodiodo. Con una velocidad de subida constante, serán además iguales los tiempos que tarda la llama en recorrer la distancia que separa cada pareja de fotodiodos.

Los resultados experimentales registrados muestran variaciones entre las dos velocidades registradas por el paso de la llama frente a los tres fotodiodos empleados. Mientras que para las llamas más ricas estas variaciones no son importantes, sí lo son en el caso de las llamas muy pobres, cuya intensidad luminosa es menor. Los resultados se deben a diferencias entre las sensibilidades de los fotodiodos. Aunque las sensibilidades son parecidas, las diferencias se hacen apreciables a causa de la alta amplificación que requiere la señal. Se ha observado que si para una cierta configuración se tiene $\Delta t_{1}<\Delta t_{2}$, al intercambiar las posiciones de los fotodiodos 2 y 3 , pasa a ser $\Delta t_{1}>\Delta t_{2}$. Este error se ha reducido al máximo instalando potenciómetros que se ajustan para obtener la misma 
señal amplificada de todos los sensores para una incidencia lumínica dada.

Por otra parte, los fotodiodos no detectan el punto más alto de llama cuando su luminosidad es muy débil, sino sólo su lateral. Esto causa dificultades en el caso de llamas no simétricas que oscilan a través del tubo, y es de hecho el mayor inconveniente del método.

\subsubsection{Medición de la velocidad usando imágenes fotográficas}

Otra forma de calcular la velocidad de subida del frente de llama es registrando su posición en instantes de tiempo conocidos mediante una cámara fotográfica, cuyo sensor está formado por millones de pequeños fotodiodos. La cámara se mantiene fija y tiene un campo de visión amplio, de tal forma que la llama se mantiene en el campo de visión de la cámara en varias fotografías consecutivas.

Para este caso es necesario tener una escala para relacionar la distancia real recorrida por la llama con los píxeles recorridos en la imagen. Para ello se utiliza un papel milimetrado que se coloca en coincidiendo con el eje del tubo. Como se va a medir la distancia recorrida por la punta de la llama, la distorsión del tubo sobre las escala en los laterales del plano no es importante; sólo interesa la escala en el eje del tubo.

Inicialmente se ha utilizado una cámara réflex, Nikon D300, cuyos disparos se han controlado externamente. El modo de alta velocidad de la cámara sólo admite una adquisición de 8 imágenes por segundo ( $8 \mathrm{fps}$ ) y añade la indeterminación del momento exacto de disparo, ya que la aplicación principal de la cámara no es la fotografía en entornos científicos. Se ha añadido el disparador externo de la cámara con una modificación que permite controlar su disparo mediante señales TTL, uniendo las terminales interiores usando un relé de estado sólido $(S S R)$ de tal forma que la unión se realiza al pasar la señal obtenida del generador de señales. La cámara realiza la fotos en instantes de tiempo equiespaciados y de estas fotos se extrae la posición de la llama.

La cámara réflex tiene limitaciones importantes para esta aplicación, ya que a la baja cadencia de imágenes se le añade la baja intensificación del sensor para reducir el ruido fotográfico. Para evitar estas limitaciones, se ha sustituido la cámara réflex por una cámara de velocidad mayor Basler Ace acA1920-155uc, que tiene una resolución menor, pero permite grabar hasta 150 fps. A diferencia de la réflex, esta cámara está orientada a usos en entorno científico y los tiempos de disparo están controlados y son fijos. La limitación de velocidad de grabación viene impuesta por la capacidad de trasferencia de datos por la conexión USB de la cámara. Para usar la resolución total, la velocidad máxima admitida por la conexión permite grabar a $100 \mathrm{fps}$.

Para extraer la posición de la llama en cada imagen, éstas con tratados utilizado la herramienta de tratamiento de imágenes de Matlab (Image Processing Toolbox). Las imágenes digitales monocromo se tratan como matrices cuyos elementos contienen el nivel de intensidad de cada píxel, con valores entre 0 (negro) y 255 (blanco) para las imágenes de 8 bits. El tamaño de la matriz es igual a la resolución del sensor de la cámara, $4288 \times 2848$ píxeles para la cámara réflex y $1920 \times 1200$ píxeles para la USB. Las fotos tomadas con estas cámaras son en color y cada imagen se compone de tres matrices que corresponden a las intensidades de cada color primario: rojo, verde y azul (abreviatura en inglés: RGB). El color de cada píxel corresponde a una combinación de los niveles del mismo píxel en las tres matrices. 
Las mezclas con riqueza inferior a la riqueza estequiométrica, generan llamas que emiten luz en la banda del color azul. Esta propiedad facilita la detección de la llama, ya que las matriz correspondiente al canal azul (B) tendrá niveles de intensidad mayores que los otros dos canales. Las llamas muy pobres, ensayadas en nuestros experimentos, conllevan algunas dificultades debidas a su baja luminosidad y su movimiento en el sistema de referencia ligado a la cámara. Para reducir el efecto de la borrosidad de la llama causado por su movimiento, se reduce el tiempo de exposición, pero es necesario usar un valor de compromiso para tener suficiente cantidad de luz captada por el sensor debido la baja luminosidad de la llama. El valor usado ha sido de unos $5 \mathrm{~ms}$, tiempo en el que la llama recorre una distancia de aproximadamente un milímetro. Como la posición de la llama se necesita para medir su velocidad, el efecto de este movimiento durante la exposición se mitiga al medir desplazamiento relativos entre dos imágenes.

Los niveles de intensidad del canal azul en una línea vertical en el centro de la fotografía de una llama (donde está situado el punto más alto de la llama) se representa en la imagen izquierda de la figura 4.2. El nivel máximo de intensidad que se puede registrar con estas imágenes es 255, pero, como se puede ver, el máximo nivel de luz en la llama sólo alcanza la décima parte de este máximo. La llama está situada en las proximidades del píxel 100, pero su posición no es fácilmente detectables a causa del alto nivel de ruido. Para el caso de las fotos tomadas con la cámara réflex, la detección del frente se realiza manualmente, ya que sólo se debe detectar el frente en 5-6 imágenes. Para las imágenes grabadas con la cámara Basler, que son entre 30-50 para cada experimento, se ha desarrollado un código cuyo algoritmo de detección se detalla a continuación.
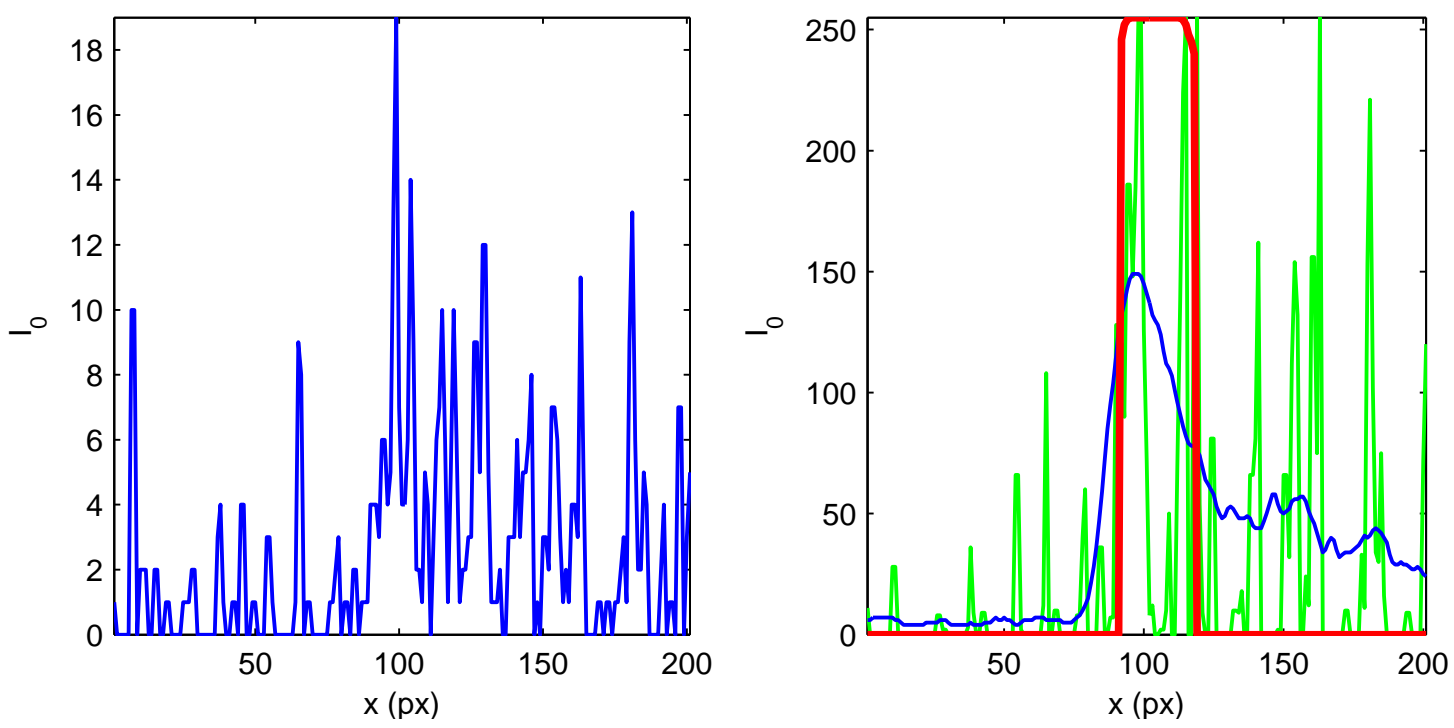

Figura 4.2: Perfiles de intensidad de los píxeles involucrados en el proceso de detección del frente de la llama. Primero se amplia el rango dinámico de la imagen orginal (verde) para después aplicar un filtro de suavizado media (azul). El resultado final (rojo) es la posición de la llama. 


\section{Algoritmo de detección de la llama}

El algoritmo de detección se desarrolla a partir del perfil de intensidad típico en las imágenes registradas. Como se puede ver en la imagen izquierda de la figura 4.2, delante de la llama hay muchos píxeles con niveles de intensidad comparables a los píxeles que hay en la llama. Este ruido se debe principalmente a usar el sensor ajustado a su nivel máximo sensibilidad para compensar la baja luminosidad de la llama. Al analizar las imágenes de la zona delante de la llama, se ha observado que el ruido correspondiente a algunos píxeles se manifiesta en un único canal, el píxel tiene sólo uno de los colores primarios. Este ruido se reduce transformando las tres matrices de la imagen a una matriz en escala de grises, empleando para cada uno de sus píxeles la combinación lineal $\mathrm{M}=2.99 \mathrm{R}+0.587 \mathrm{G}+0.114 \mathrm{~B}$, donde $\mathrm{M}$ es el píxel de la nueva matriz monocromo, mientras que $\mathrm{R}, \mathrm{G}$ y $\mathrm{B}$ corresponden al valor del píxel en los canales de cada color primario. Esta nueva matriz, con menor ruido delante de la llama, se emplea para amplificar el canal azul de la imagen, multiplicando cada elemento de la matriz con el correspondiente del canal azul. Este tipo de amplificación aumenta tanto el ruido como la señal, aunque al emplear ala matriz $\mathrm{M}$, se amplifica la señal de la llama en mayor grado. La matriz amplificada resultante tiene su máximo valor por debajo del valor máximo disponible, 255, por lo que se amplia su rango dinámico. El $1 \%$ de los píxeles de mayor valor se igualan a 255 , mientras que el $1 \%$ con menor valor se iguala a 0 . El perfil resultante se muestra en la figura 4.2 (perfil verde).

La gran cantidad de ruido y la amplificación de la imagen mantienen el perfil de intensidades de los píxeles discontinuo (ver figura 4.2). El suavizado de esta imagen (la matriz obtenida al amplificar el canal azul de la imagen original) se realiza empleando un filtro medio. Se ha escogido un filtro cuyo funcionamiento consiste en atribuir a cada píxel de la imagen el valor medio de las intensidades de los píxeles que se encuentran a su alrededor en un disco con radio 9 píxeles. Este filtrado es muy efectivo en las zona de fondo negro de la imagen. El perfil de intensidades en el medio de la imagen después de este filtrado se muestra con el perfil azul en la imagen derecha de la figura 4.2.

Dependiendo de la calidad de la imagen, puede ser necesario aplicar varias veces el filtro medio junto a la amplificación del canal azul. Después se establece un nivel de intensidad de corte, típicamente un valor superior a 200, de tal forma que todos los píxeles de mayor valor se igualan a 255, mientras que los de menor valor se igualan a 0 . El perfil resultante se presenta en rojo en la figura 4.2, que es similar a una función de salto escalón. El frente se subida del perfil es la posición del frente de la llama.

\section{Validación de la detección del frente}

El proceso de detección de la llama comienza con la primera imagen de la figura 4.3. El canal azul de esta imagen ha sido amplificado para mejorar la visualización de la imagen. El algoritmo explicado más arriba consigue una buena detección de la parte exterior de la llama, mientras que la parte inferior carece de interés para medir la velocidad de subida de la llama. En la imagen central se muestra el resultado final del proceso. El punto más alto de la llama se determina buscando el elemento de la matriz no nulo con menor número de fila (contando las filas de arriba hacia abajo). La gran dependencia del resultado con los reflejos en el tubo y la baja luminosidad de la llama requieren una validación ad hoc de las posiciones calculadas. Esta comprobación se realiza mostrando en pantalla la fotografía de la llama y una línea horizontal (en rojo para mejorar su contraste) que marca la posición 
del punto más alto de la llama. Si se observa que la barra no determina correctamente esta posición, se rechaza el resultado y se cambia el algoritmo, añadiendo o eliminando un paso de amplificación/filtrado medio de la imagen. Los errores de la velocidad medida empleando este método se discuten en el apartado 5.2.2.

Para estos cálculos se ha considerado despreciable el efecto del ángulo que forma el eje del objetivo de la cámara con el punto más alto de la llama, ver apéndice B para más detalles.

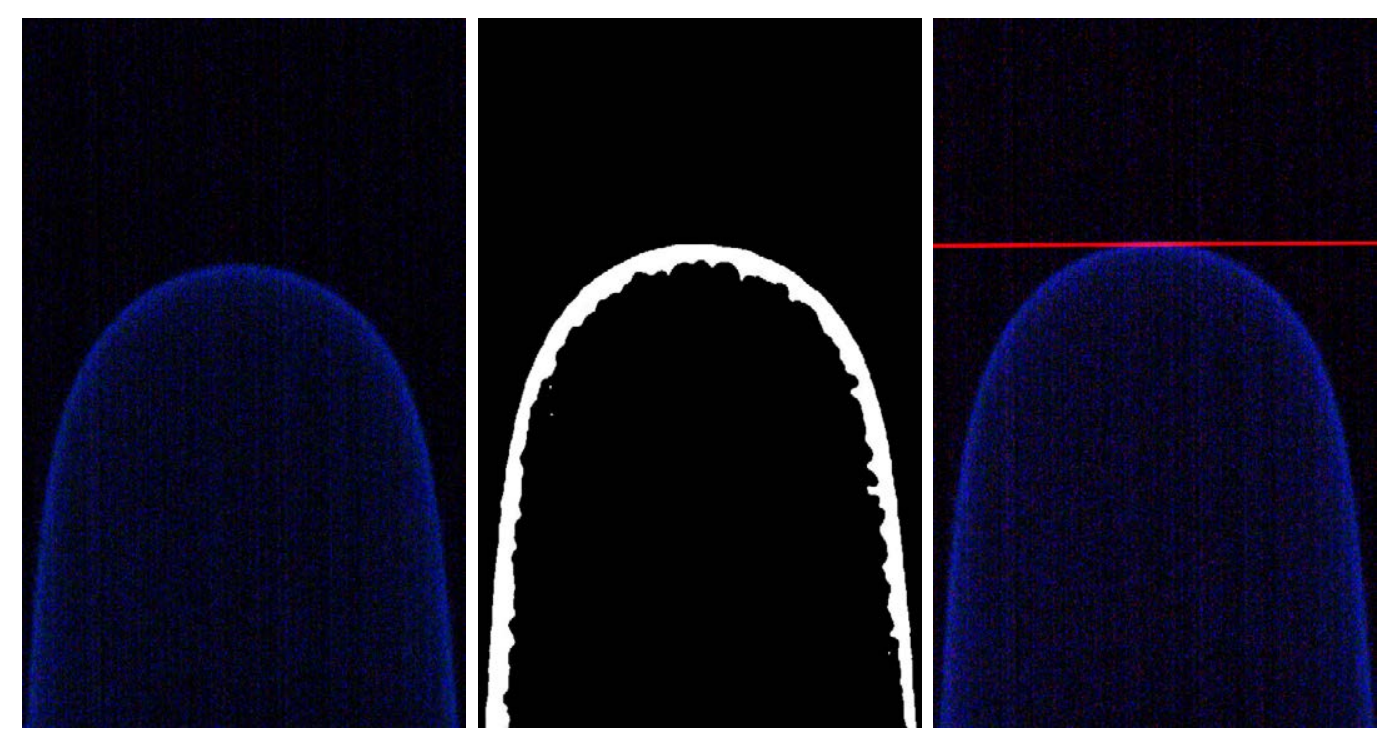

Figura 4.3: Detección del frente de la llama. La primera imagen por la izquierda es la foto de la llama, la imagen del centro es la imagen que se obtiene al tratar la foto de la llama con el algoritmo expuesto. La imagen de la derecha es la foto de la llama con la línea roja que indica la posición del frente.

\subsection{Particle Image Velocimetry (PIV). Introducción.}

El movimiento inducido en el gas por la propagación de la llama no se puede observar directamente, por lo que no es posible medir la velocidad del gas de la misma manera en que se ha medido la velocidad del frente de llama. La velocidad del gas debe determinarse indirectamente sembrando la mezcla con partículas trazadoras y midiendo la velocidad de éstas. La técnica, llamada PIV (del inglés Particle Image Velocimetry), es bien conocida y muy utilizada. Sin embargo, para su correcta aplicación es preciso considerar una serie de factores, unos de carácter general y otros específicos de nuestro experimento, en el que la presencia de la lama ocasiona un gradiente de temperatura muy fuerte en una región localizada.

Los factores a considerar son de dos tipos. Unos tiene que ver con la extracción del campo de velocidad de las partículas a partir de imágenes fotográficas, y otros con la propia dinámica de las partículas, que en general no sigue estrictamente el movimiento del gas cuya velocidad se quiere medir.

Los primeros se discuten en el apartado 4.3, que se centra en las condiciones de densidad 
y uniformidad del sembrado y de resolución de las imágenes de las partículas, así como en el efecto que tiene sobre todo esto la expansión térmica del gas en la llama. En esta apartado se supone que las partículas siguen fielmente el movimiento del gas.

Lo segundos factores relativos a la dinámica de las partículas, se discuten en el apartado 4.4. En un flujo isotermo, las partículas únicamente siguen el movimiento del gas si son suficientemente pequeñas para poder despreciar los efectos de su inercia y de la sedimentación. Si el número de Reynolds del movimiento de las partículas respecto al gas es pequeño, estos efectos se pueden estimar como sigue:

- La velocidad de sedimentación de una partícula es $v_{s}=m_{p} g / c_{f}$, donde $m_{p}$ es la masa de la partícula y $c_{f}$ es el coeficiente de fricción de Stokes, $c_{f}=6 \pi \mu_{g} a$, siendo $\mu_{g}$ la viscosidad del gas y a el radio de la esfera equivalente de Stokes, cuya resistencia es igual a la de la partícula. Esta velocidad debe ser pequeña frente a la velocidad característica del gas.

- El número de Stokes es el cociente $t_{s} / t_{g}$ entre el tiempo característico de adaptación de la partícula, $t_{s}=m_{p} / c_{f}$, y el tiempo característico del gas, que se define más adelante. El número de Stokes debe ser pequeño para que las partículas puedan seguir al gas.

Por otra parte, para asegurar que las partículas dispersen eficazmente la luz, su tamaño mínimo debe ser algo mayor que la longitud de onda de la radiación empleada para iluminarlas, pero típicamente existe un rango de tamaños en el que se satisfacen tanto esta limitación como las dos condiciones anteriores.

El problema se complica cuando en el flujo hay fuertes gradientes de temperatura. Las partículas en el interior de la llama están sometidas a una fuerza adicional, de termoforesis, proporcional al gradiente local de temperatura y tanto mayor cuanto menor sea el tamaño de las partículas. Como veremos, esta fuerza tiene un efecto local importante en nuestro problema para partículas de tamaño inferior a unas pocas micras, lo cual supone una limitación al empleo de la técnica de PIV para medir la velocidad del gas en el interior de la llama.

\subsection{PIV I - Densidad de sembrado y resolución. Efecto de la expansión térmica.}

\subsubsection{Elementos de la técnica. Ventanas de interrogación y correlaciones cruzadas}

En el caso ideal de partículas que sigan fielmente el movimiento del gas, la velocidad local del gas sería igual a la velocidad de las partículas marcadoras. Para calcular esta velocidad bastaría con conocer dos posiciones de una partícula, $\boldsymbol{x}_{1}$ y $\boldsymbol{x}_{2}$, en dos instantes de tiempo, $t_{1}$ y $t_{2}$. La velocidad de la partícula se podría calcular fácilmente:

$$
\boldsymbol{v}=\frac{\boldsymbol{x}_{2}-\boldsymbol{x}_{1}}{t_{2}-t_{1}}=\frac{\Delta \boldsymbol{x}}{\Delta t},
$$

donde $\Delta \boldsymbol{x}$ es la distancia recorrida por la partícula en el tiempo $\Delta t$. 
Las posiciones de las partículas se pueden registrar mediante imágenes fotográficas que se utilizan posteriormente para calcular la velocidad, siendo $\Delta t$ el tiempo transcurrido entre la toma de dos imágenes consecutivas. Con una densidad de partículas baja se podría identificar la posición de cada partícula en cada una de las imágenes, pero cuando el número de partículas es grande esto ya no es posible, y hay que aplicar algoritmos específicos para identificar el movimiento de las partículas. A continuación se presenta de manera sucinta el funcionamiento de esta técnica. Una explicación en profundidad de los distintos tipos de PIV y de los algoritmos empleados se puede encontrar en [47].

La utilización de fotografías de las partículas limita la posibilidad del estudio a un plano, ya que en la proyección de la imagen de cada partícula sobre el sensor de la cámara se pierde la información de su posición sobre el eje normal al sensor. En el caso de una llama subiendo en un tubo vertical el movimiento es axilsimétrico, por lo que las partículas fluidas que están inicialmente en un plano que contiene el eje del tubo permanecen en él. Para poder medir la velocidad del fluido solamente en ese plano, las partículas que se encuentren en el resto del tubo no deben aparecer en las imágenes, lo cual se consigue iluminando el flujo con un haz láser plano que pasa por el eje del tubo. En estas condiciones las partículas que están fuera del haz no se iluminan y no se ven en las imágenes.

Idealmente, en un experimento empleando PIV se obtendrían dos imágenes como las presentadas en la figura 4.4. Normalmente la densidad de partículas es mucho mayor que la indicada en las imágenes y no habría forma de identificar la posición de una misma partícula en las dos imágenes. En la figura 4.4 sin embargo, es fácil ver cuál ha sido el movimiento del fluido, ya que todas las partículas en la imagen de la derecha (correspondiente al instante $t_{0}+\Delta t$ ) tienen el mismo desplazamiento con respecto a sus posiciones en la imagen de la izquierda (correspondiente al instante $t_{0}$ ).

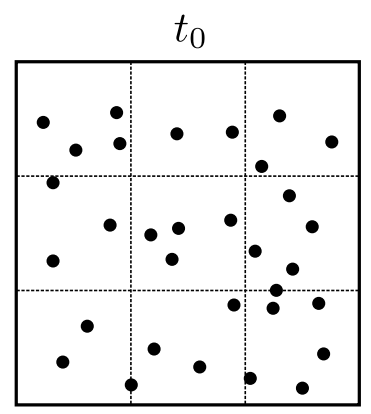

Imagen 1

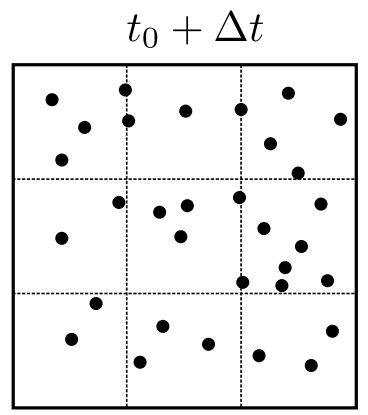

Imagen 2

Figura 4.4: Imágenes ideales para la utilización de PIV

Matemáticamente una imagen se puede representar como un mapa de intensidad, $I=I(x, y)$, donde para cada pareja de valores $x$ e $y$ está definido un valor de $I$. Si las imágenes son digitales, los valores de $(x, y)$ son discretos y se refieren a la posición del píxel correspondiente en el sensor de la cámara. En el caso presentado en la figura 4.4 se tendrían las imágenes $I_{1}(x, y)$ e $I_{2}(x, y)$. Para aumentar el número de valores de velocidad que se van a calcular las imágenes se dividen en ventanas de interrogación más pequeñas, de tamaño $\Delta x \times \Delta y$, y se calcula la correlación cruzada en el centro de cada ventana, $\left(x_{i}, y_{j}\right)$, dada por: 


$$
R_{I I}\left(x_{i}, y_{j} ; \delta x, \delta y\right)=\int_{-\Delta x / 2}^{\Delta x / 2} \int_{-\Delta y / 2}^{\Delta y / 2} I_{1}\left(x_{i}+\xi, y_{j}+\eta\right) I_{2}\left(x_{i}+\xi+\delta x, y_{j}+\eta+\delta y\right) d \eta d \xi
$$

Cada ventana de interrogación dentro de la imagen $I_{1}$ tendrá asociada una matriz de valores de correlación cruzada $R_{I I}$ que se calcula empleando la ecuación (4.1) con diferentes parejas de valores $(\delta x, \delta y)$. En la figura 4.5 se representa $R_{I I}$ como función de $(\delta x, \delta y)$. La posición del máximo de esta función representa el desplazamiento medio más probable de las partículas de la imagen $I_{1}$ durante el tiempo $\Delta t$ :

$$
\Delta \boldsymbol{x}_{m}\left(x_{i}, y_{j}\right)=\left.(\delta x, \delta y)\right|_{\max \left(R_{I I}\right)}
$$

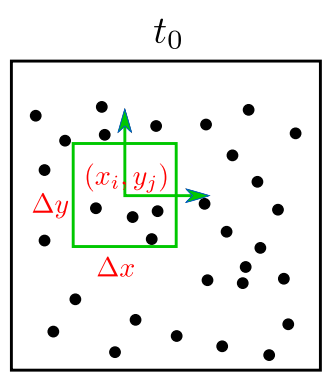

Imagen 1

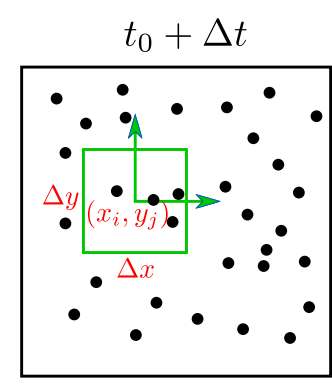

Imagen 2

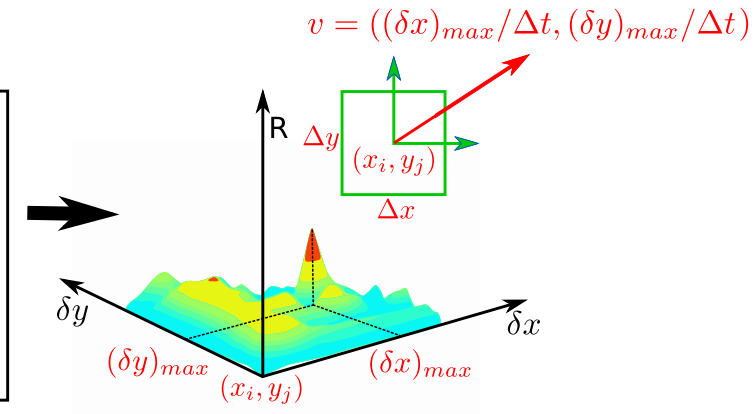

Figura 4.5: Esquema del proceso de correlación cruzada usado en el algoritmo de PIV

Teniendo el desplazamiento medio más probable de las partículas en cada ventana de interrogación se puede calcular la velocidad media de estas partículas conociendo el tiempo que transcurre entre las dos imágenes:

$$
\boldsymbol{v}_{m}\left(x_{i}, y_{j}\right)=\frac{\Delta \boldsymbol{x}_{m}\left(x_{i}, y_{j}\right)}{\Delta t}
$$

donde $\left(x_{i}, y_{j}\right)$ son las posiciones de los centros de las distintas ventanas de interrogación dentro de la imagen. En esta sencilla expresión se puede observar una limitación importante del método: la velocidad obtenida con PIV es la velocidad media de las partículas dentro de cada ventana de interrogación. Se podría pensar que la solución es reducir el tamaño de las ventanas de interrogación, pero existe un límite determinado por la cantidad de señal disponible. A medida que se reduce el tamaño de la ventana, aumenta el ruido y el máximo de la correlación se difumina.

\section{Influencia de las pérdidas de pares}

Como se puede ver en la figura 4.5, la función $R_{I I}$ está definida para cualquier pareja de valores de $(\delta x, \delta y)$ y toma valores entre cero y su máximo, $R_{I I_{\max }}$. De cara a la evaluación del desplazamiento de las partículas, todos los valores distintos de $R_{I I_{\max }}$ no aportan información y se consideran ruido, mientras que el valor $R_{I I_{\max }}$ se considera señal. La 
relación señal-ruido (SNR: signal to noise ratio) ${ }^{1}$ mide la calidad de la señal obtenida de la correlación. Cuanto mayor sea el valor SNR, mayor será el nivel confianza de la estimación del desplazamiento de las partículas de la ventana de interrogación.

La fiabilidad de los resultados obtenidos empleando PIV depende en gran medida del comportamiento de los pares, que es un término empleado en la literatura para definir la pareja de imágenes de una partícula en las dos fotografías tomadas en el proceso. El valor máximo de $R_{I I}$ calculado usando la ecuación (4.1) se obtiene al desplazar la imagen $\mathrm{I}_{2}$ a la posición en la que el máximo número de pares se superpone. Un concepto importante en el tratamiento de los errores del PIV es la pérdida de pares, que se refiere al hecho de que la imagen de una partícula en una de las fotos no exista en la otra. Esto puede ocurrir en los dos sentidos; que la partícula esté en la ventana de interrogación de la primera imagen y no esté en la segunda o al revés, que esté en la segunda y no en la primera imagen. Un caso típico de pérdida de pares se da cuando se estudia un flujo con una componente de velocidad perpendicular al plano láser. En esta situación, si una partícula se encuentra inicialmente cerca del borde de la banda iluminada por el láser, es posible que después del tiempo $\Delta t$ esté fuera de esta banda y su imagen no aparezca en la segunda fotografía. Estas situaciones se denominan pérdidas de pares fuera de plano (out-of-plane pair losses). La pérdida de estas partículas se puede reducir bajando el tiempo $\Delta t$ entre imágenes. La otra posibilidad es que la pérdida de pares ocurra dentro de la banda iluminada por el láser, debido a que una partícula que aparece en la primera imagen se sale de ventana de interrogación en la segunda imagen, o a que entre y aparezca en la ventana de interrogación en la segunda imagen, mientras que se encontraba fuera de ella en la primera. Estos casos se denominan pérdidas de pares en el plano (in-plane pair losses). El efecto que genera la pérdida de pares en el cálculo de la correlación es una reducción de su valor para el desplazamiento real de las partículas en la ventana. Si la pérdida de pares es muy grande, es posible que el valor máximo de la correlación se sitúe en una posición distinta del desplazamiento más probable de las partículas, y el vector de desplazamiento sería erróneo. De esta forma la pérdida de pares, tanto en el plano como fuera de él, introduce errores en los vectores de velocidad medida.

Para comprobar cómo afecta la pérdida de pares a la velocidad calculada empleando la correlación (4.1), se toma una ventana de interrogación de $4 \times 4$ píxeles y se colocan 5 partículas, cuya posición inicial se muestra en la figura 4.6 para el caso A, donde, idealmente, cada una de las partículas sólo ocupa un píxel. El fluido sembrado con estas partículas se considera que se mueve con velocidad horizontal uniforme $u=1 \mathrm{px} / \mathrm{s}^{2}$. Las partículas siguen fielmente al fluido, por lo que cada partícula se desplaza 1 px por cada segundo de tal forma que las dos partículas situadas más a la derecha en $t=0$ salen de la ventana de interrogación para $t=2 \mathrm{~s}$. Al hacer la correlación de dos ventanas de interrogación de lado $4 \mathrm{px}$, se obtiene una matriz de correlación de $7 \times 7$ elementos, que contienen los valores de $R_{I I}$ para cada desplazamiento $(\delta x, \delta y)$. El elemento $(4,4)$ de esta matriz, corresponde a $(\delta x, \delta y)=(0,0)$. En los gráficos inferiores de la figura 4.6 las barras muestran el valor máximo de $R_{I I}$ en la columna correspondiente a cada $\delta x$, y el número situado encima de cada barra indica la posición $\delta y$ de este máximo dentro de la columna. $\mathrm{Al}$ realizar la correlación de la imagen A con ella misma, el valor máximo de la correlación

\footnotetext{
${ }^{1}$ Para su cálculo se emplea la fórmula $\mathrm{SNR}=1-m / M$, donde $M$ es el máximo de $R_{I I}$ y $m$ es el valor máximo inmediatamente anterior a $M$. SNR toma valores entre 0 y 1 , ver referencias $[26,65]$.

${ }^{2}$ Se emplea px como abreviatura de píxel.
} 
está en $(\delta x, \delta y)_{R_{\max }}=(0,0)$. En la correlación de la imagen B con la imagen A cambian los valores de la matriz $R_{I I}$, y el máximo se sitúa en $(\delta x, \delta y)_{R_{\max }}=(1,0)$. La velocidad en este caso está bien calculada: $u=1 \mathrm{px} / \mathrm{s}$. Si se hace la correlación de la imagen C con la imagen A, el máximo aparece en $(\delta x, \delta y)_{R_{\max }}=(2,0)$, por lo que $\boldsymbol{v}=(1,0) \mathrm{px} / \mathrm{s}$. Se ha calculado correctamente el vector, pero el valor $R_{I_{\max }}$ ha disminuido a consecuencia de la pérdida de pares. El valor de SNR para las correlaciones AA y BA es 0.6, mientras que para CA es 0.33 .
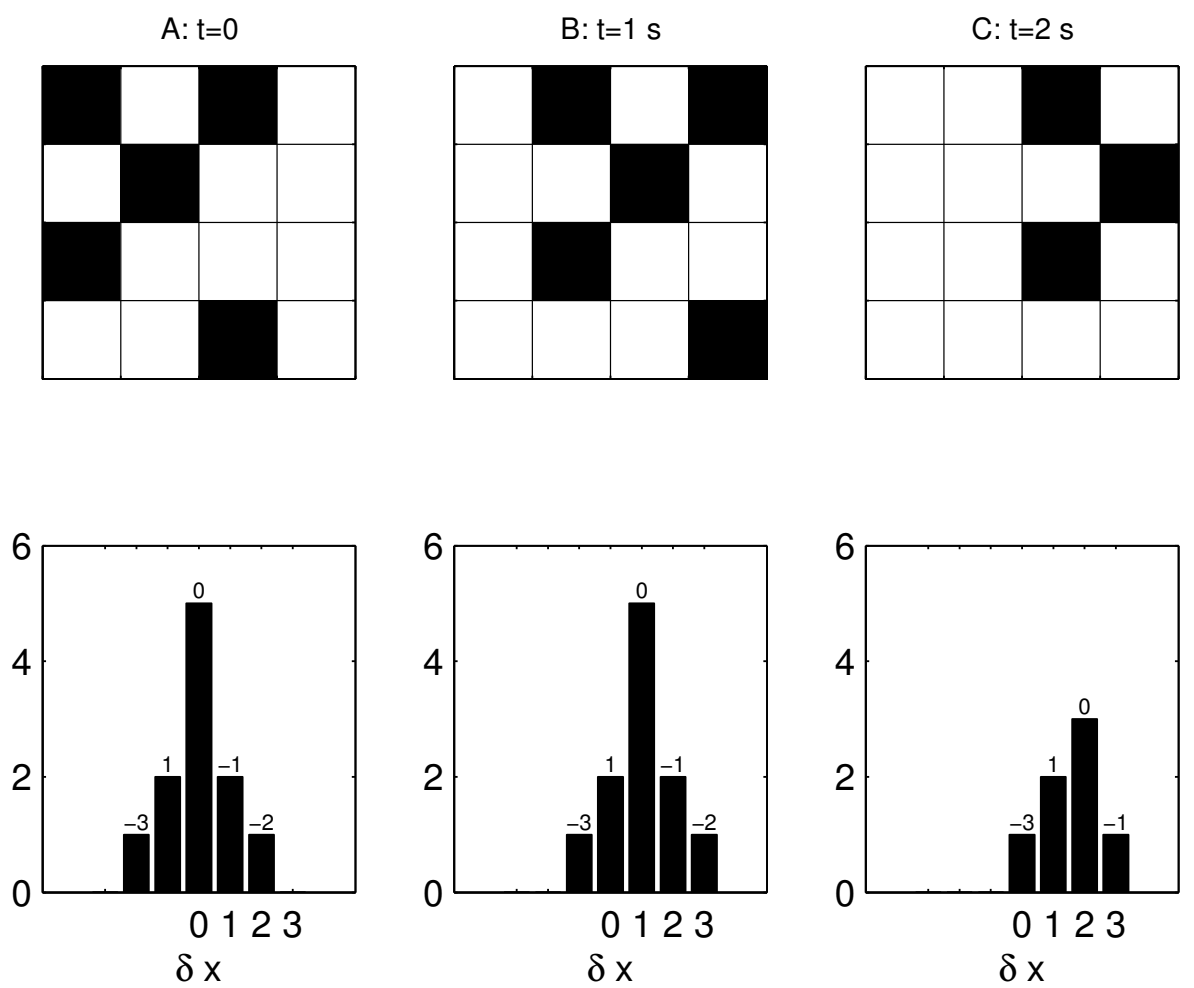

Figura 4.6: Fila superior: Posiciones de las partículas que se mueven con el fluido a una velocidad de $1 \mathrm{px} / \mathrm{s}$ sin entrada de partículas nuevas. Fila inferior: Las barras muestran el valor máximo de $R_{I I}$ en la columna $\delta x$ y el número situado encima de las barras la posición $\delta y$ del máximo dentro de la columna.

En un flujo real también hay partículas a la izquierda de la ventana de interrogación, por lo que la evolución será más parecida a la de la figura 4.7. Mientras algunas partículas salen por la derecha de la ventana de interrogación, otras nuevas entran por su izquierda, de tal forma que la pérdida de pares es mayor. Al hacer la correlación BA en este caso, el máximo se sitúa en la misma posición que antes: $(\delta x, \delta y)_{R_{\max }}=(1,0)$, pero el valor de SNR se reduce hasta 0.2 a causa del valor de la correlación en la posición $(0,1)$, que se aproxima al valor máximo de la correlación. Este cambio en la matriz $R_{I I}$ está causado por la aparición de las dos nuevas partículas por la izquierda de la ventana de interrogación, que añaden señal a la correlación. En el paso $\mathrm{C}$ se pierden los pares de la derecha y el máximo ahora se sitúa en $(\delta x, \delta y)_{R_{\max }}=(1,1)$ dando una velocidad $\boldsymbol{v}=(1 / \sqrt{2}, 1 / \sqrt{2})$. El valor SNR para esta correlación es 0.25 . 
$A: t=0$

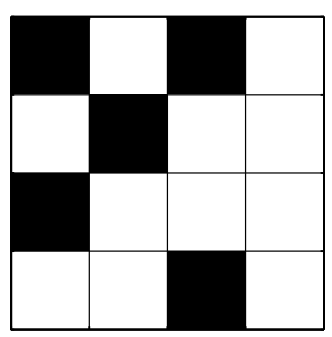

$B: t=1 s$

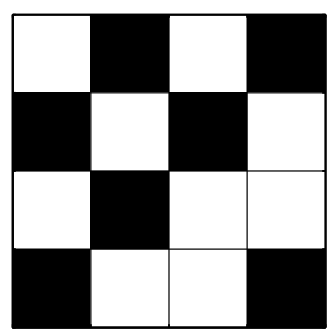

$\mathrm{C}: \mathrm{t}=2 \mathrm{~s}$

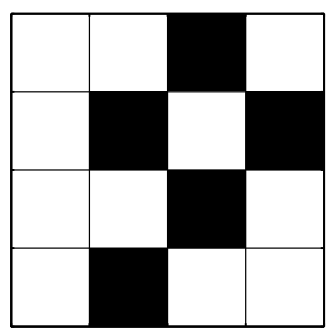

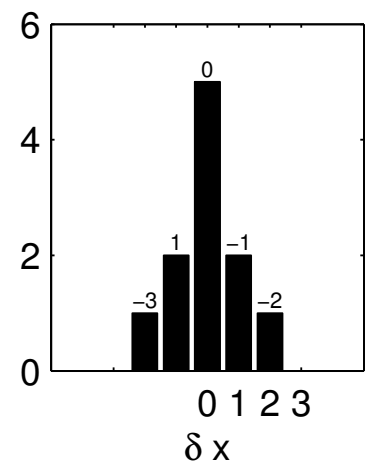
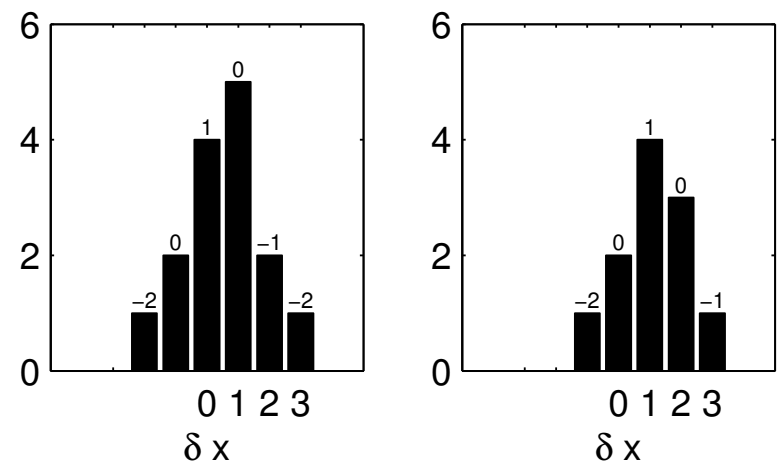

Figura 4.7: Fila superior: Posiciones de las partículas que se mueven con el fluido a una velocidad de $1 \mathrm{px} / \mathrm{s}$ con entrada de partículas nuevas. Fila inferior: Las barras muestran el valor máximo de $R_{I I}$ en la columna $\delta x$ y el número situado encima de las barras la posición $\delta y$ del máximo dentro de la columna.

En estos dos casos tan sencillos se ha podido observar la influencia de la pérdida de pares en la velocidad estimada y en la relación señal-ruido. Resulta evidente que su influencia es menor cuanto mayor sea el número de pares que se mantienen en las dos imágenes. Mantener el máximo número de pares en las dos imágenes aumentará el valor de SNR y mejorará la fiabilidad de la estimación de la velocidad.

Como se ha comentado anteriormente, el error introducido por la pérdida de pares se reduce aumentando la cantidad de pares disponibles, de tal forma que la pérdida o ganancia de señal de correlación a causa de la salida o entrada partículas sea pequeña frente a la señal de los pares que se mantienen. Un modo de aumentar el número de pares disponibles en las dos imágenes es aumentar el tamaño de la ventana de interrogación (aumentar la densidad de partículas es también una opción en caso de que sea posible). Esta solución, sin embargo, acarrea inconvenientes cuando se pretende medir flujos más complejos que una corriente uniforme, debido a la variación de la velocidad con la distancia dentro de la ventana de interrogación. Supongamos que hay un gradiente de velocidad que da lugar a un aumento apreciable de velocidad en la ventana en la dirección de la propia velocidad. Entonces las partículas más rápidas se habrán salido de la ventana de interrogación en la segunda imagen, por lo que la pérdida de pares en este caso ocasiona una sobre-representación de las partículas más lentas, otorgándoles un mayor peso en el 
cálculo de $R_{I I}$. El gradiente de velocidad infravalora la velocidad media de las partículas de la ventana de interrogación [27]. El efecto es el mismo cuando el gradiente de velocidad tiene sentido contrario, como puede verse considerando la invariancia del proceso ante inversiones del tiempo y la velocidad.

\subsubsection{Aplicación a nuestro experimento}

La técnica de PIV se utiliza con frecuencia en multitud de problemas, lo que ha dado lugar a un extenso conocimiento de sus posibilidades y limitaciones, y a continuas mejoras. Este conocimiento se ha traducido en recomendaciones de carácter general para mejorar los resultados obtenidos que, en lo que se refiere a los efectos del sembrado discutidos antes, son las siguientes:

1. El número mínimo de pares disponibles debe ser mayor de 5 [47].

2. El tamaño óptimo de las partículas es de dos píxeles [47]. Este parámetro está muy condicionado por las particularidades del experimento.

3. El desplazamiento máximo de las partículas entre las dos imágenes debe ser menor que la mitad del tamaño de la ventana de interrogación. El valor recomendado de este desplazamiento es de un cuarto de la ventana de interrogación [27, 47]

\section{Efectos de la resolución y la densidad de sembrado}

En lo que sigue analizaremos los efectos de la densidad de sembrado y la resolución de las imágenes (y el tamaño de las ventanas de interrogación) en presencia del gradiente de temperatura debido a la llama. Para este estudio usaremos imágenes sintéticas generadas a partir de los campos axilsimétricos de velocidad calculados mediante el modelo bidimensional introducido en el capítulo 2. Las imágenes serán procesadas con un software de PIV de uno general, el PIVLab desarrollado por Thielicke y Stamhuis [60] para ser usado en Matlab, con una configuración simple para calcular directamente el máximo de la correlación cruzada en ventanas de interrogación fijas y contiguas de $32 \times 32$ píxeles y sin desplazamiento ni deformación de estas ventanas.

Para generar las imágenes se calculan las trayectorias de partículas puntuales inyectadas continuamente, con una distribución uniforme, a una distancia $R$ por encima del punto más alto de la llama. Se inyectan $n_{0} \pi R^{2} U_{0}$ partículas por unidad de tiempo, donde $n_{0}$ es la densidad numérica deseada en el gas fresco. Cada partícula sigue al gas, de modo que su posición en el sistema de referencia ligado a la llama satisface $\mathrm{d} \boldsymbol{x}_{p} / \mathrm{d} t=\boldsymbol{v}(\boldsymbol{x})$, donde $\boldsymbol{v}(\boldsymbol{x})$ es el campo de velocidad calculado para $\phi=0.557$. El haz plano de láser se modela con una distribución de intensidad gaussiana, con una anchura de $2 \mathrm{~mm}$ alrededor de un plano que contiene al eje del tubo. Para el cálculo de las imágenes se asigna a cada partícula una sección eficaz de dispersión tal que su imagen cubre 2-5 píxeles. La concentración de partículas en el dominio de cálculo, que es el mismo que en las simulaciones del capítulo 2, se estabiliza al cabo de un cierto tiempo desde el inicio de la inyección, y el flujo de partículas que sale por la parte inferior del dominio se hace igual al flujo inyectado por la parte superior. Tras alcanzar este estado estacionario se genera un cierto número de parejas de imágenes, típicamente 10. El intervalo de tiempo $\Delta t$ entre las imágenes de una pareja se ha tomado igual a $0.5 \mathrm{~ms}$, si bien se han probado también otros valores entre 
0.2 y $2 \mathrm{~ms}$, que pueden resultar más apropiados para satisfacer la recomendación 3 del apartado anterior con las resoluciones más extremas que se han empleado. (Al aumentar la resolución de las imágenes sin cambiar el tamaño en píxeles de las ventanas de interrogación disminuye la fracción del campo fluido correspondiente a cada ventana y el tiempo de residencia de las partículas en ella). El intervalo de tiempo entre parejas de imágenes es mayor, de 0.2 segundos.

Para generar las imágenes se superpone sobre el dominio de cálculo una red de $N_{x} \times$ $N_{r}$ celdas cuadradas, que modela el sensor de una cámara, y se distribuye la intensidad dispersada por cada partícula, que depende de su distancia al centro del haz, sobre estas celdas en proporción al área de cada una cubierta por la imagen de la partícula. Se han generado imágenes sintéticas con tres densidades numéricas de partículas, $n_{0}=10,20 \mathrm{y}$ $100 \mathrm{~mm}^{-3}$, empleando en cada caso tres resoluciones diferentes, $N_{x} \times N_{r}=1200 \times 1000$ $(1 \mathrm{Mpx}), 2400 \times 2000(5 \mathrm{Mpx})$ y $4800 \times 4000(20 \mathrm{Mpx})$.

En la figura 4.8 se muestra una imagen típica con $n_{0}=20 \mathrm{~mm}^{-3}$. En ella se aprecian claramente dos regiones, la que se encuentra encima de la llama, con una densidad de partículas alta y uniforma, y la que se encuentra debajo, con una densidad también aproximadamente uniforme, pero mucho menor que la anterior, a causa de la expansión térmica del gas en la llama. Entre las dos regiones hay una zona de transición, cuyo espesor es el de la llama. En las tres ampliaciones de la derecha de la figura 4.8, que muestran ventanas de $64 \times 64$ píxeles de la imagen original, se aprecia mejor la variación de densidad. Una consecuencia de la disminución de densidad a través de la llama es la necesidad de emplear una densidad de sembrado alta cuando se quiere medir la velocidad del gas quemado. En el apartado 4.5 se explica cómo se realiza el sembrado en los experimentos.

Para analizar los efectos de la resolución de las imágenes y la densidad de sembrado, se representan en la figura 4.9 los perfiles de velocidad obtenidos a lo largo del eje del tubo, que son de especial interés porque se emplean en el modelo unidimensional descrito en las secciones 2.3 y 2.4 .

En todos los gráficos de la figura 4.9, el perfil de velocidad obtenido en la simulación numérica bidimensional se representa por una curva negra de trazos, mientras que las curvas continuas representan los perfiles calculados con el software de PIV aplicado a las imágenes de $1 \mathrm{Mpx}$ (curvas rojas), $5 \mathrm{Mpx}$ (verdes) y $20 \mathrm{Mpx}$ (azules). Las curvas rojas discontinuas muestran cómo los resultados de las imágenes de 1 Mpx pueden mejorar empleando tratamientos sofisticados disponibles en este software particular, tales como el desplazamiento y la deformación de las ventanas de interrogación en función de la velocidad medida. Estas curvas no se discuten en lo que sigue porque tales mejoras no son el propósito de este apartado. Los gráficos de la derecha de la figura 4.9 muestran toda la extensión del campo fluido cubierto por las imágenes, mientras que los de la derecha son ampliaciones de la región que contiene la llama. La distancia se mide desde el borde superior de las imágenes. La densidad de sembrado crece de arriba abajo.

En el gráfico superior izquierdo se observa cómo la baja densidad de partículas afecta a las velocidades medidas detrás de la llama (curva azul). Este comportamiento se debe a que, para la resolución de $20 \mathrm{Mpx}$, las ventanas de interrogación de 32 píxeles son muy pequeñas y contienen pocos pares, haciendo que la posición del máximo de la correlación sea impredecible. La misma configuración, sin embargo, permite obtener resultados óptimos para el caso de máxima densidad empleada (gráfico inferior izquierdo). La zona de aceleración del gas causada por la expansión térmica, ampliada en las tres imágenes 

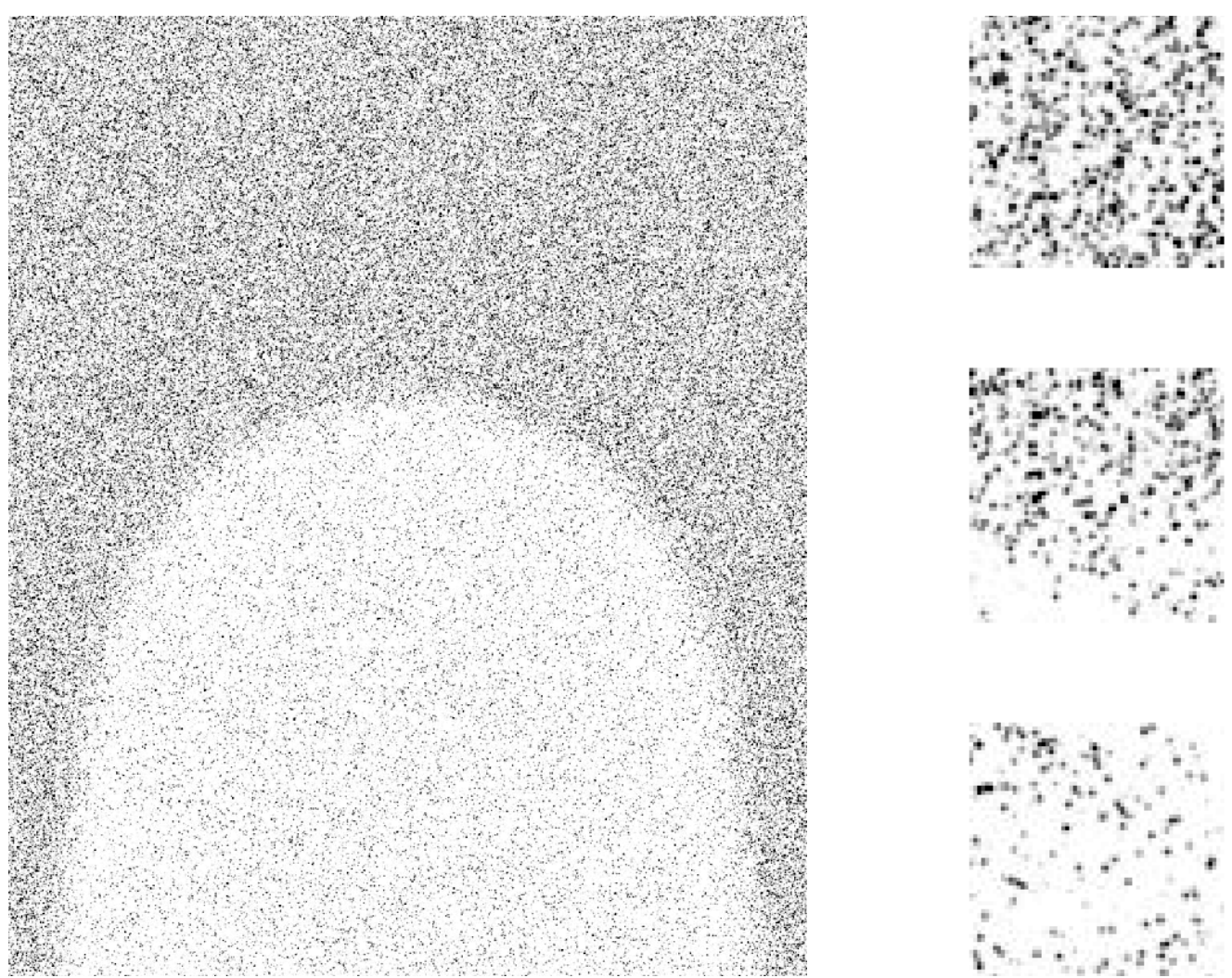

Figura 4.8: Imagen sintética generada para aplicar PIV (se muestra el negativo de la imagen para mejorar la visualización). A la derecha se presentan 3 muestras de $64 \times 64$ píxeles para exponer las diferencias de la densidad en la imagen: la densidad de partículas aguas arriba de la llama (imagen superior), en la zona de la llama (imagen del medio) y detrás de la llama (imagen inferior).

de la derecha, se resuelve bien con la resolución de 20 Mpx y densidades de 20 y 100 partículas $/ \mathrm{mm}^{3}$. Sin embargo, para $n_{0}=10$, la velocidad en la parte final de la zona de aceleración no se calcula correctamente, a causa de la baja densidad de partículas.

En los casos de menos resolución espacial (curvas rojas continuas), las ventanas de interrogación no son pequeñas comparadas con la distancia (el espesor de la llama) en la que aumenta la velocidad. En estos casos la velocidad medida se aparta del valor real (curvas negras de trazos) y tiende a un cierto promedio de las velocidades de las partículas dentro de la ventana. El efecto es muy marcado en torno a los extremos de la velocidad inmediatamente delante y detrás de la llama, pero puede observarse también en torno al mínimo de la velocidad detrás de la llama (visible en los gráficos de la izquierda de la figura 4.9). Descontando las pérdidas de pares en la zona de expansión del gas, el máximo de la correlación se obtiene para un desplazamiento $(\delta x, \delta y)$ correspondiente en una velocidad media de las partículas en la ventana de interrogación. Pero no todas las partes de la ventana tienen el mismo peso en este promedio, porque la expansión térmica causa variaciones en la densidad de partículas dentro de la ventana. El efecto es específico de los problemas con fuertes gradientes de temperatura. En nuestro caso, la densidad de partículas decrece en la misma dirección en la que crece la velocidad, por lo que cabe 

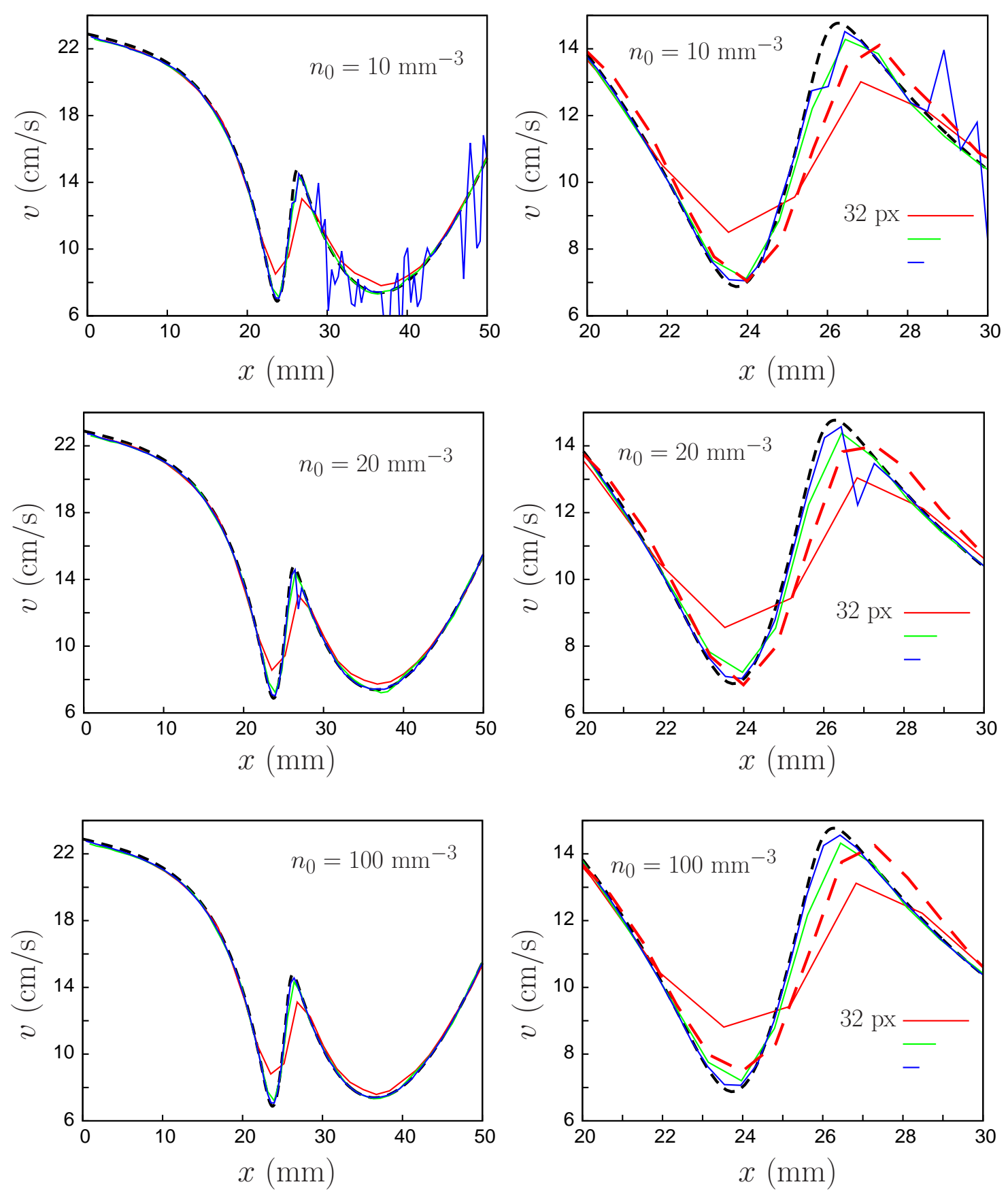

Figura 4.9: Resultados PIV en el eje del tubo a partir de imágenes sintéticas para distintas resoluciones de imagen: $1 \mathrm{Mpx}$ (rojo), $5 \mathrm{Mpx}$ (verde) y $20 \mathrm{Mpx}$ (azul). La velocidad real del cálculo numérico es la línea negra de trazos. 
esperar que el nuevo efecto refuerce el de la pérdida de pares debido a las variaciones de velocidad, aumentando el sesgo de los resultados hacia las velocidades menores.

Las velocidades obtenidas con las imágenes de $5 \mathrm{Mpx}$ (curvas verdes) son más precisas. Por una parte, las ventanas son suficientemente grandes para contener un número de partículas suficiente para calcular la velocidad detrás de la llama, y por otra son suficientemente pequeñas para ajustarse a las variaciones del perfil de velocidad en la zona de la llama sin que aparezcan fuertes variaciones de velocidad y concentración de partículas en su interior.

Se debe tener en cuenta que en los cálculos anteriores las ventanas de interrogación se han colocado en la imagen de forma contigua y que la posición de la velocidad medida está en el centro de la ventana. En función de la posición del centro de la primera ventana las velocidades se medirán en unos puntos o en otros. Además la resolución espacial conseguida de esta manera es baja. Se puede incrementar la resolución situando los centros de las ventanas a una distancia inferior a su tamaño, de forma que se solapen y compartan algunos pares de partículas. El solapamiento no es necesario para medidas en zonas con gradiente de velocidad pequeño (el perfil de velocidad delante de la llama en las imágenes de la izquierda de la figura 4.9). Cuando el gradiente de velocidad es alto, como en la zona de aceleración de la llama (imágenes de la derecha de la figura 4.9), el solapamiento mejora la resolución del perfil de velocidad; ver figura 4.10. Los efectos de la resolución de las imágenes sigue observándose, pero el solapamiento añade resolución espacial y mejora las medidas. Cuando los centros de las ventanas coinciden para distintos solapamientos, la velocidad medida también coincide, como era de esperar al aplicarse la correlación a la misma región de la imagen. Para las imágenes de $5 \mathrm{Mpx}$, un solapamiento del $88 \%$ (separación entre los centros de las ventanas de 4 px) muestra un error causado por la reducción de la densidad de partículas a la salida de la llama.
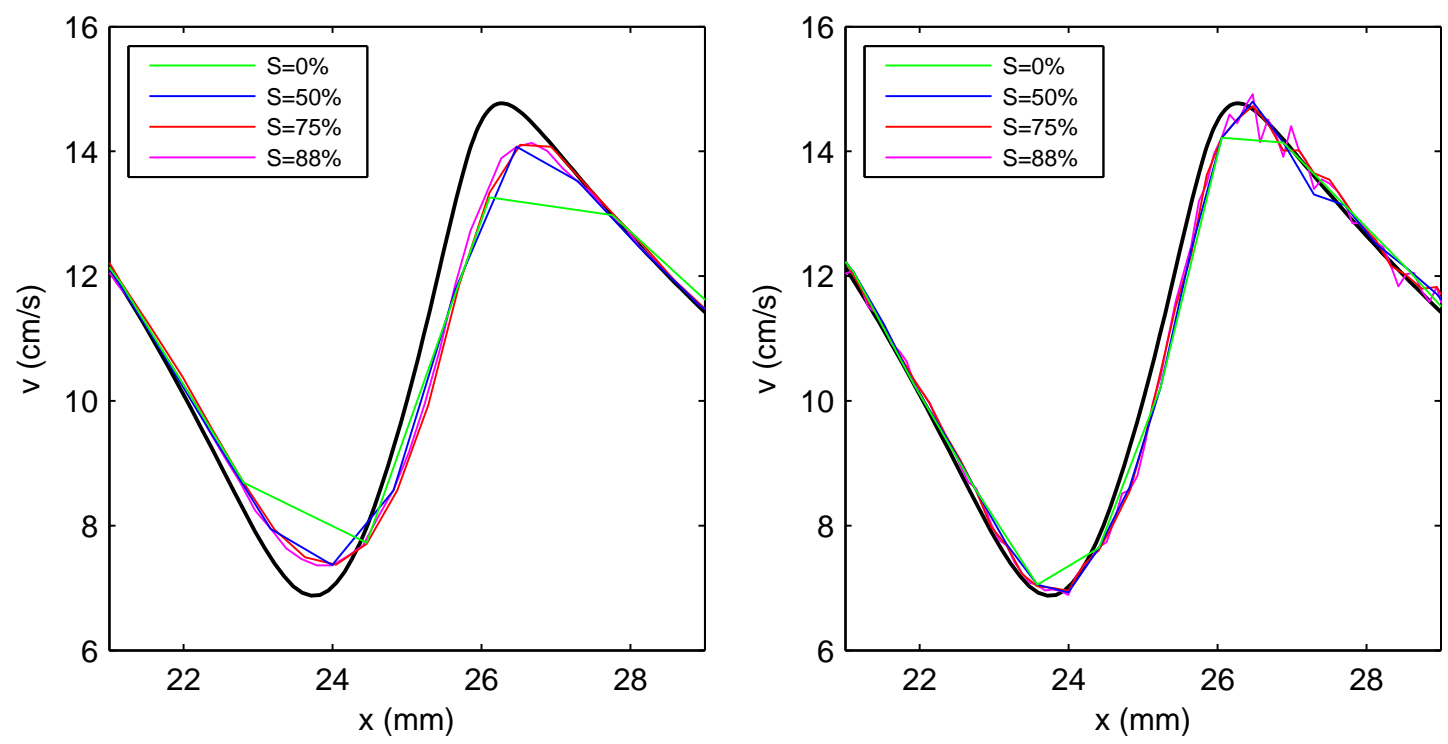

Figura 4.10: Efecto del solapamiento en la precisión de las medidas con PIV. La imagen de la izquierda es para fotografías de 1 megapíxel y la de la derecha para 5 megapíxeles.

Examinando los errores relativos entre la velocidad medida y la numérica, se comprueba 
que un solapamiento superior al $75 \%$ no reduce de manera significativa el error, mientras que el aumento del solapamiento del $50 \%$ al $75 \%$ sí lo hace, sobre todo en torno al mínimo de velocidad antes de la llama. En la figura 4.11 se muestran los errores calculados usando la fórmula

$$
\varepsilon_{r_{i}}=\frac{V_{n_{i}}-V_{m_{i}}}{V_{n_{i}}} \cdot 100,
$$

donde $V_{n_{i}}$ es la velocidad numérica y $V_{m_{i}}$ es la velocidad medida en el punto $i$. Las velocidades en los puntos donde no hay medidas se han obtenido interpolando linealmente. El aumento de la resolución reduce en gran medida el error cerca de la zona de mínima velocidad. En la región de expansión del gas el error también se reduce, pero la velocidad medida sigue siendo un $7-8 \%$ inferior a la velocidad real. Éste es un error de sesgo y se debe principalmente al alto gradiente de velocidad, tal y como se ha comentado en el apartado anterior.

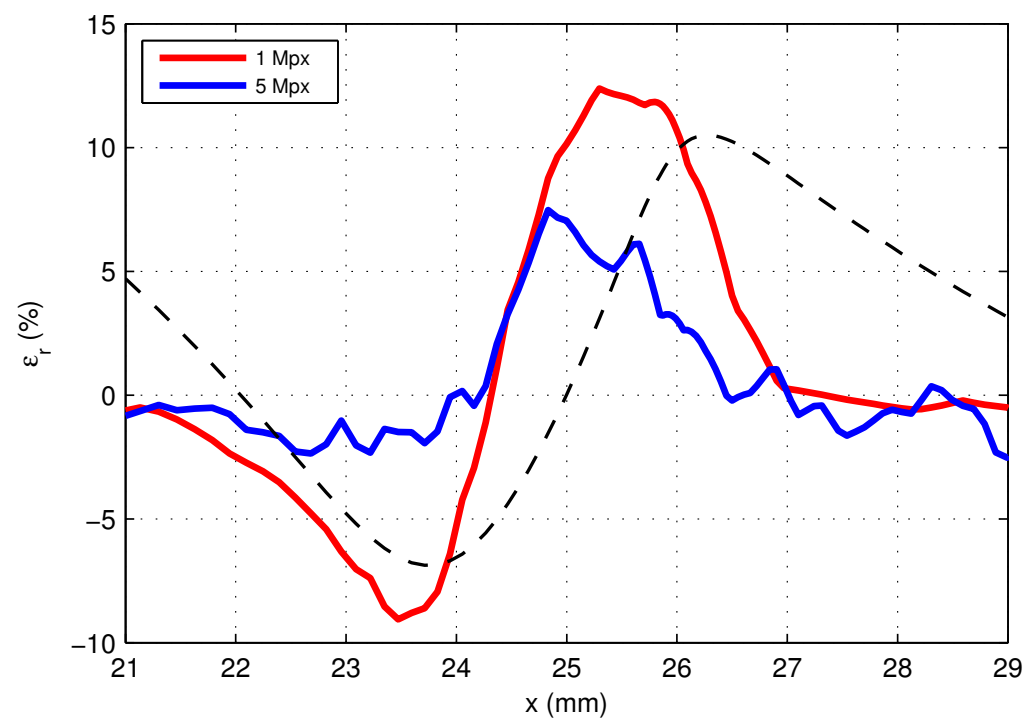

Figura 4.11: Error relativo de la velocidad medida con respecto a la real. Al aumentar la resolución disminuye el error. En la zona de aceleración de la llama el error de sesgo causado por el gradiente de velocidad tiene un máximo.

\subsection{PIV II - Dinámica de las partículas.}

\subsubsection{Partículas sólidas en un flujo isotermo}

Las partículas usadas como trazadores para realizar las medidas con PIV son sólidas y tiene necesariamente una densidad mucho mayor que la del gas. Estas partículas sólo pueden seguir aproximadamente el movimiento del gas si son muy pequeñas. Supondremos que la distancia media entre las partículas es mucho mayor que su tamaño, por lo que la interacción directa entre partículas es despreciable, y que el número de Reynolds del movimiento relativo de las partículas respecto al gas es pequeño. En estas condiciones son aplicables los resultados de Maxey y Riley [38] para la fuerza ejercida por el gas 
sobre una partícula, al menos para un flujo localmente isotermo. Además, los efectos de la masa añadida y de la fuerza sobre una partícula debida a la aceleración del gas se pueden despreciar debido al pequeño valor de la relación entre la masa de gas desplazada por una partícula y la masa de la partícula. La ecuación del movimiento de una partícula esférica de radio $a$ se reduce a

$$
m_{p} \frac{d \boldsymbol{v}_{p}}{d t}=\underbrace{m_{p} \boldsymbol{g}}_{\boldsymbol{F}_{g}}-\underbrace{6 \pi \mu a\left(\boldsymbol{v}_{p}-\boldsymbol{v}\right)}_{\boldsymbol{F}_{v}}-\underbrace{6 \pi \mu a^{2} \int_{t_{0}}^{t} \frac{\mathrm{d}\left(\boldsymbol{v}_{p}-\boldsymbol{v}\right)}{\mathrm{d} \tau} \frac{\mathrm{d} \tau}{\sqrt{\pi \nu(t-\tau)}}}_{\boldsymbol{F}_{B}},
$$

donde $m_{p}$ y $\boldsymbol{v}_{p}$ son la masa y la velocidad de la partícula, y $\nu$ y $\boldsymbol{v}$ son la viscosidad cinemática y la velocidad del gas. Los términos del segundo miembro son la fuerza de flotabilidad, que se ha sustituido por el peso de la partícula, la resistencia de Stokes y la fuerza de Basset. La importancia de ésta última depende de las condiciones del flujo. En función del tiempo característico de variación de la velocidad relativa, $t_{g}$, el cociente entre la fuerza de Basset y la resistencia de Stokes es $B=\sqrt{a^{2} / \nu t_{g}}$. En un sistema de referencia ligado a la llama, el tiempo característico más corto es el tiempo de residencia del gas en la llama, de orden $\delta_{f} / \gamma U_{L}$, donde $\delta_{f}$ es el espesor de la llama. Usando este tiempo en lugar de $t_{g}$, se obtiene

$$
B=\sqrt{\frac{\gamma U_{L} \delta_{f}}{\nu}} \frac{a}{\delta_{f}}
$$

donde el primer factor es de orden unidad y el segundo es pequeño para las partículas usadas, del orden de la micra. En un sistema de referencia ligado al tubo, que es el que se usa para medir la velocidad, el menor tiempo característico es más corto, del orden de $\delta_{f} / U_{0}$. Sin embargo, el cociente B sigue siendo pequeño. A la vista de esta estimación se desprecia la fuerza de Basset en (4.2).

$\mathrm{El}$ efecto de las otras dos fuerzas se puede describir como sigue:

- La gravedad origina velocidades del orden de la velocidad de sedimentación

$$
v_{s}=\frac{2}{9} \frac{\rho_{p} a^{2}}{\mu} g
$$

que se obtiene del balance entre el peso de la partícula y la resistencia de Stokes.

- El balance entre la resistencia de Stokes y la inercia de la partícula,

$$
\frac{2}{9} \frac{\rho_{p} a^{2}}{\mu} \frac{\mathrm{d} \boldsymbol{v}_{p}}{\mathrm{~d} d}=-\left(\boldsymbol{v}_{p}-\boldsymbol{v}\right)
$$

permite estimar el tiempo característico de adaptación de la velocidad de la partícula a la velocidad del gas, $t_{s}=2 \rho_{p} a^{2} / 9 \mu$. La partícula sigue el movimiento del gas si el tiempo característico de variación de su velocidad en la posición de la partícula es grande frente a $t_{s}$. Al depender de las partículas para medir la velocidad del gas, éstas hacen el papel de un filtro pasabajos con una frecuencia de corte $f_{c}=1 / t_{s}$.

La tabla 4.1 muestra los valores de $t_{s} / t_{g}$, usando como $t_{g}$ el mismo tiempo característico que en la estimación (4.3) de la fuerza de Basset, y la velocidad de sedimentación dada por (4.4) para varios valores del radio de las partículas. 


\begin{tabular}{ccc}
\hline$a(\mu m)$ & $\tau / t_{c}$ & $v_{s}(\mathrm{~cm} / \mathrm{s})$ \\
\hline 0.5 & $2.2 \times 10^{-3}$ & 0.022 \\
1 & $9 \times 10^{-3}$ & 0.09 \\
2.5 & $5.6 \times 10^{-2}$ & 0.56 \\
5 & 0.22 & 2.2 \\
\hline
\end{tabular}

Tabla 4.1: Tiempos característicos de repuesta y velocidades de sedimentación de las partículas de alúmina para distintos radios.

Como se puede ver, la condición $t_{s} / t_{g} \ll 1$ se cumple para partículas de hasta $2.5 \mu \mathrm{m}$ de radio, que adaptan su movimiento al del gas con rapidez suficiente para las medidas de PIV (ver figura 4.12a). Sin embargo, la velocidad de sedimentación de estas partículas es $v_{s}=0.56 \mathrm{~cm} / \mathrm{s}$, que es comparable a la velocidad del gas en el interior de la llama, del orden de $\gamma U_{L}$. La condición de que la velocidad de sedimentación sea pequeña comparada con la velocidad del gas en nuestro experimento limita el radio de las partículas a valores inferiores a una micra (ver figura 4.12b).
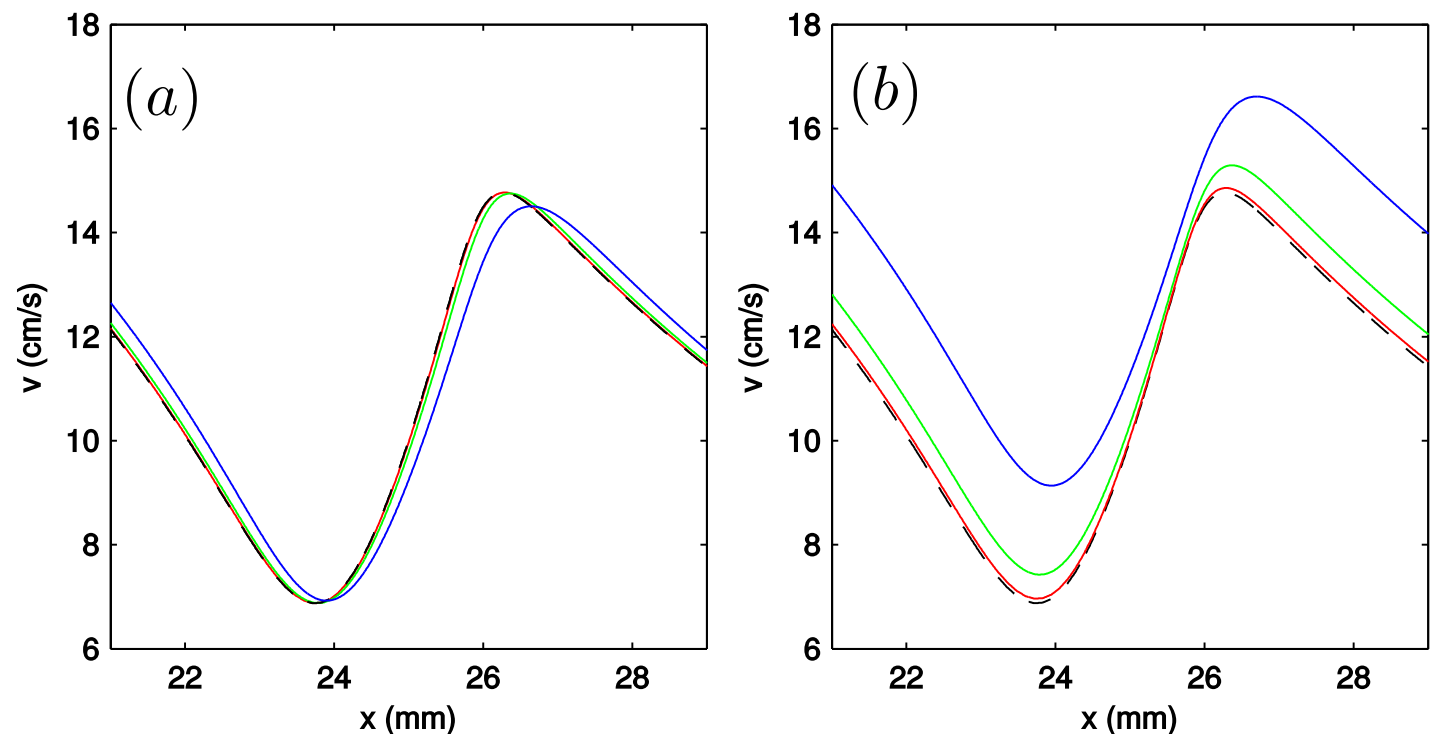

Figura 4.12: Influencia del tamaño de las partículas en su capacidad de seguir el movimiento del gas sin gravedad (a) y con gravedad (b). Leyenda: $a=1 \mu \mathrm{m}$ (curva roja), $2.5 \mu \mathrm{m}$ (curva verde) y $5 \mu \mathrm{m}$ (curva azul). La curva negra a trazos es el velocidad del gas en el eje del tubo calculado con el modelo bidimensional para $\phi=0.546$ (ver apartado 2.1).

\subsubsection{Termoforesis}

El fenómeno de la termoforesis ocurre cuando una partícula muy pequeña, de tamaño comparable al camino libre medio de las moléculas del gas, se encuentra en una región del campo fluido donde $\nabla T \neq 0$. En estas condiciones, las moléculas del gas que chocan con la partícula le transfieren una cantidad de movimiento neta no nula, que la empuja en el 
sentido contrario a $\boldsymbol{\nabla} T$, hacia las zona de baja temperatura [28]. La fuerza de termoforesis que actúa sobre una partícula de radio $a$ es

$$
\boldsymbol{F}_{T P}=-\mu \nu a f_{T P} \nabla \ln T
$$

donde $\nu=\mu / \rho$, y $\rho, T$ y $\mu$ son la densidad, temperatura y viscosidad del gas. El factor $f_{T P}$ es una función del número de Knudsen y el cociente de las conductividades térmicas del gas y la partículas $\Lambda=\lambda_{g} / \lambda_{p}$. El número de Knudsen es el cociente entre el camino libre medio de las moléculas del gas y el radio de la partícula: $\mathrm{Kn}=l / a$, donde $l=2 \mu / \rho c$ con $c=\sqrt{8 R_{g} T / \pi}$. Usaremos la correlación propuesta por Talbot et al. [59]:

$$
f_{T P}=\frac{12 C_{s}\left(\Lambda+C_{t} \mathrm{Kn}\right)}{\left(1+3 C_{m} \mathrm{Kn}\right)\left(1+2 \Lambda+2 C_{t} \mathrm{Kn}\right)},
$$

donde $C_{m}=1.14, C_{t}=2.18$ y $C_{s}=1.17$.

Como ya se ha visto en el apartado anterior, cuando la densidad de la partícula es mucho mayor que la del gas y que el número de Reynolds del movimiento de la partícula relativo al gas es pequeño, la fuerza más importante que actúa sobre la partícula debida a este movimiento relativo es la resistencia de Stokes. Para partículas cuyo tamaño no sea mucho mayor que el camino libre medio de las moléculas del gas, la expresión de la fuerza de Stokes usada en (4.2) debe corregirse y toma la forma

$$
\boldsymbol{F}_{v}=-\frac{6 \pi \mu a}{f_{C}(\mathrm{Kn})}\left(\boldsymbol{v}_{p}-\boldsymbol{v}\right),
$$

donde $f_{C}(\mathrm{Kn})$ es el factor de Cunningham, que corrige la ley de Stokes para valores no pequeños del número de Knudsen. Este factor está dado por

$$
f_{C}(\mathrm{Kn})=1+\mathrm{Kn}\left[A+B \exp \left(-\frac{C}{\mathrm{Kn}}\right)\right],
$$

donde $A=1.12, B=0.41$ y $C=0.88$ [40].

Teniendo en cuenta además la fuerza gravitatoria que actúa sobre la partícula, su ecuación de movimiento es

$$
m_{p} \frac{\mathrm{d} \boldsymbol{v}_{p}}{\mathrm{~d} t}=\boldsymbol{F}_{v}+\boldsymbol{F}_{T P}+m_{p} \boldsymbol{g}, \quad \frac{\mathrm{d} \boldsymbol{x}_{p}}{\mathrm{~d} t}=\boldsymbol{v}_{p},
$$

donde $\boldsymbol{x}_{p}$ y $\boldsymbol{v}_{p}$ con la posición y velocidad de la partícula, $m_{p}=\frac{4}{3} \pi a^{3} \rho_{p}$ es su masa, y $\boldsymbol{g}$ es la aceleración de la gravedad.

Los efectos de la gravedad y de la inercia de la partícula, proporcionales a su masa, son despreciables para partículas muy pequeñas, para las que (4.9) se reduce al equilibrio de fuerzas $\boldsymbol{F}_{v}+\boldsymbol{F}_{T P}=0$. Esta ecuación simplificada permite determinar la diferencia entre la velocidad de la partícula y la del gas debida a la termoforesis:

$$
\boldsymbol{v}_{T P} \equiv \boldsymbol{v}_{p}-\boldsymbol{v}=-\nu \alpha_{T P} \nabla \ln T \quad \text { con } \quad \alpha_{T P}=\frac{f_{T P} f_{C}}{6 \pi} .
$$

El factor $\alpha_{T P}$ se muestra en la figura 4.13a como función de la temperatura del gas para partículas de alúmina de varios tamaños. Se han usado los valores $\rho_{p}=4000 \mathrm{~kg} / \mathrm{m}^{3}$, $\lambda_{p}=30 \mathrm{~W} / \mathrm{m} \cdot \mathrm{K} \mathrm{y} \mu / \mu_{u}=\left(T / T_{u}\right)^{\kappa}, \operatorname{con} \kappa=0.75, T_{u}=300 \mathrm{~K}$ y $\mu_{u}=1.78 \times 10^{-5} \mathrm{~kg} / \mathrm{m} \cdot \mathrm{s}$. El factor $\alpha_{T P}$ tiende a $(A+B)\left(C_{s} / C_{m}\right) / 3 \pi=0.55$ cuando $\mathrm{Kn} \rightarrow \infty$, y a $12 C_{s} \Lambda /(1+2 \Lambda)$ cuando $\mathrm{Kn} \rightarrow 0$. Este último valor es muy pequeño porque $\Lambda \ll 1$ para partículas de alúmina. El número de Knudsen de una partícula de $1 \mu \mathrm{m}$ de radio crece desde $6.28 \times 10^{-2}$ a 0.47 cuando la temperatura del gas aumenta desde $300 \mathrm{~K}$ a $1500 \mathrm{~K}$. 

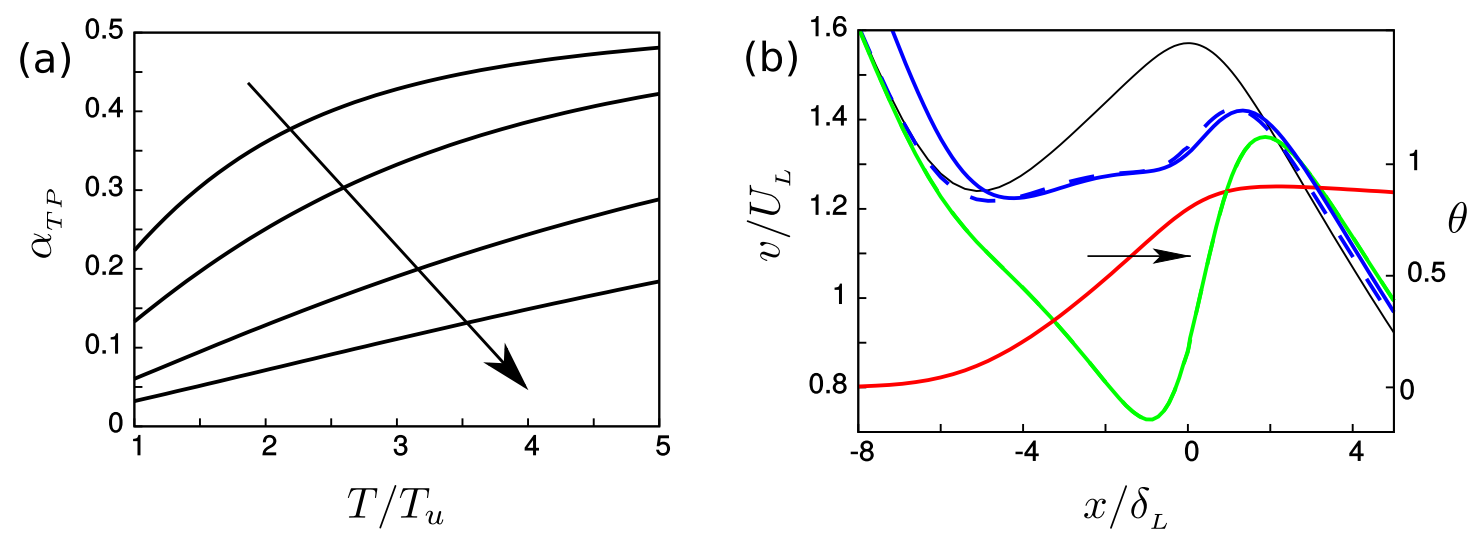

Figura 4.13: (a) Valores del coeficiente $\alpha_{T P}$ para distintas temperaturas entre 300 y 1500 $\mathrm{K}$ y para radios de partículas de 1, 2, 5 y 10 micras con valores crecientes según indica la flecha. (b) Perfil de velocidad (negro) y temperatura (rojo) en el eje del tubo para $\phi=0.546$ calculados en al sección 2.1. Perfiles de velocidad calculados usando la ecuación (4.9) para $a=1 \mu \mathrm{m}$ (verde) y $a=5 \mu \mathrm{m}$ (azul). La línea azul a trazos corresponde la partícula de 5 micras usando la ecuación (4.10).

\subsubsection{Efecto de la termoforesis en el interior de la llama}

En la región de transporte de la llama $\nabla T \sim 1 / \delta_{f}$, donde $\delta_{f}$ es el espesor de la llama, del orden $\delta_{f} \sim \nu / \gamma U_{L}$ en términos de la velocidad de la llama plana $U_{L}$ (Williams [64]). Así pues $v_{T P} \sim \nu \alpha_{T P} / \delta_{f} \sim \alpha_{T P} \gamma U_{L}$. La velocidad de las partículas difiere apreciablemente de la del gas cuando $\alpha_{T P}=\mathcal{O}(1)$, lo cual ocurre en rangos de tamaños de partícula y temperatura del gas típicos de los experimentos (ver figura 4.13a).

En la figura 4.13b se muestran los perfiles de velocidad y temperatura del gas a lo largo del eje del tubo (curvas negras y roja) calculados con el modelo bidimensional del apartado 2.1 para $\phi=0.546$. Las curvas verde y azul son las velocidades de partículas de radios $a=1 \mu \mathrm{m}$ y $5 \mu \mathrm{m}$ calculados resolviendo la ecuación (4.9), reescrita en la forma $m_{p} v_{p} \mathrm{~d} v_{p} / \mathrm{d} x=F_{v}+F_{T P}+m_{p} g$, donde $F_{v}$ y $F_{T P}$ son los valores de las fuerzas de resistencia aerodinámica y termoforesis para una partícula que se mueva a lo largo del eje, con la condición $v_{p}=U_{0}+f_{C} g / 6 \pi \mu a$ para $x \rightarrow-\infty$. Como se ve, el efecto de la termoforesis es importante para ambas partículas dentro de la llama, donde $F_{T P}<0$ y el movimiento de las partículas se ve retardado respecto al del gas. El efecto es mayor para las partículas más pequeñas $(1 \mu \mathrm{m})$, cuya velocidad decrece apreciablemente por debajo de la velocidad mínima del gas, delante de la llama, y dista de alcanzar su máximo inmediatamente detrás. Los efectos de la gravedad y la inercia son pequeños para estas partículas; la curva verde es indistinguible de la que se obtiene con la ecuación simplificada $F_{v}+F_{T P}=0$. Las partículas mayores $(5 \mu \mathrm{m})$ son algo menos afectadas por la termoforesis, pero los efectos de la gravedad y la inercia no son despreciables. Esta partículas se mueven más deprisa que el gas delante de la llama, y no son capaces de seguir la fuerte aceleración del gas debida a la expansión térmica en el interior de la misma. La curva azul de trazos muestra la velocidad obtenida del balance $F_{v}+F_{T P}=0$ para partículas de $5 \mu \mathrm{m}$, que como se ve difiere de la velocidad real de estas partículas.

Estos resultados ponen de manifiesto las importantes limitaciones que la termoforesis 
impone al emplear la técnica PIV, pues indica que no existe un rango de tamaños de partículas que sigan fielmente el movimiento del gas en el interior de la llama.

\subsubsection{Corrección de la deriva de la velocidad causada por la termoforesis}

Las medidas de PIV proporcionan el campo de velocidades de las partículas marcadoras, en lugar de la velocidad del gas que se desea medir. Si los efectos de la gravedad y la inercia de las partículas son despreciables, la diferencia entre ambas velocidades se debe íntegramente a la termoforesis y está dada por $\boldsymbol{v}_{T P}$ en (4.10). El error de las medidas de PIV se podría corregir si $\boldsymbol{v}_{T P}$ si pudiera evaluar, y esto depende de dos factores: el tamaño de las partículas responsables de la señal en las imágenes de PIV y la distribución de temperatura del gas.

En los experimentos se han empleado partículas de alúmina (Metalograf) de tres diámetros nominales: $0.3 \mu \mathrm{m}, 1 \mu \mathrm{m}$ y $5 \mu \mathrm{m}$. Las distribuciones de tamaños de las partículas detrás del impactador, que completa el sistema de sembrado descrito en al apartado siguiente, se han medido con un analizador de movilidad diferencial (TSI SMPS3938) y con un instrumento basado en la difracción de las luz láser (Malvern Spraytec), así como a partir de micrografías obtenidas en un microscopio electrónico de barrido. Estas medidas muestran distribuciones de tamaños bastante anchas, que tienen un máximo para un diámetro algo menor que el valor nominal indicado por el fabricante y se extienden hasta las decenas de nanómetros, si bien estas partículas tan pequeñas apenas dispersan luz y su presencia no debería afectar a las medidas de PIV. Las micrografías también muestran aglomerados globulares de decenas de partículas, con diámetros del orden del diámetro nominal y algunos aglomerados más grandes cuando se suprime el impactador. Las partículas de diámetro nominal $0.3 \mu \mathrm{m}$ fueron descartadas por ser malos dispersores, ya que gran parte de la población está en el rango de dispersión de Rayleigh, en el que la intensidad de la radiación dispersada decrece como la sexta potencia del diámetro de la partícula escalado con la longitud de onda de la radiación [2].

La contribución de las partículas de cada tamaño a las imágenes de PIV está determinada por el producto de la función de distribución de tamaños de la población y la sección eficaz de dispersión de las partículas. En el rango de tamaños de interés, el primer factor es una función decreciente del tamaño mientras que el segundo es una función creciente. El resultado es que la contribución tiene un máximo para partículas de alrededor de $2 \mu \mathrm{m}$. En lo que sigue supondremos, como primera aproximación, que la contribución de estas partículas es dominante.

La temperatura del gas tampoco se puede medir en nuestro experimento. En ausencia de esta información usaremos un procedimiento que permite calcular aproximadamente la temperatura usando formas simplificadas de las ecuaciones de conservación de la energía y las especies. En el eje del tubo, donde aplicaremos el procedimiento, estas ecuaciones son las del modelo unidimensional del apartado 2.3, pero en principio el mismo procedimiento es válido para otras secciones del frente de llama, una vez que se ha identificado la normal local al frente. Estas ecuaciones simplificadas requieren como dato de entrada la velocidad del gas, que debe proceder de las medidas experimentales de PIV. Sin embargo, como la velocidad correcta no se conoce de antemano, ya que las medidas proporcionan únicamente la velocidad de las partículas, se aplica un método iterativo que va corrigiendo sucesivamente la velocidad medida y la distribución de temperatura aproximada en la que 
se basa la corrección de la velocidad.

El método iterativo consiste en lo siguiente. El perfil de velocidad medido, que denotaremos $u_{m}(x)$, se usa en lugar de $u(x)$ en las ecuaciones (2.35) y (2.36). Con esta velocidad se calcula el perfil de temperatura resolviendo el problema unidimensional como se indicó en la sección 2.3. Esta distribución se emplea para calcular la deriva termoforética $u_{T P}(x)$, dada por la única componente no nula de (4.10) en el eje del tubo, y con ello se obtiene un perfil corregido de velocidad del gas: $u(x)=u_{m}(x)-u_{T P}(x)$. Este perfil se lleva de nuevo a las ecuaciones (2.35) y (2.36), y se repite el cálculo hasta que el perfil de velocidad converge [41].

Como comprobación de la convergencia, la figura 4.14a muestra el resultado de aplicar el método iterativo usando como perfil $u_{m}(x)$ de partida el representado por la curva verde de la figura $4.13 \mathrm{~b}$, correspondiente a partículas de radio $a=1 \mu \mathrm{m}$, mientras que la velocidad real del gas está dada por la curva negra de esta figura. Ambas curvas se repiten en la figura 4.14a como curva 0 y curva de trazos, respectivamente, mientras que las curvas 1 a 5 son los resultados de las sucesivas iteraciones. Como se ve, la velocidad corregida del gas prácticamente coincide con la velocidad real después de seis iteraciones.
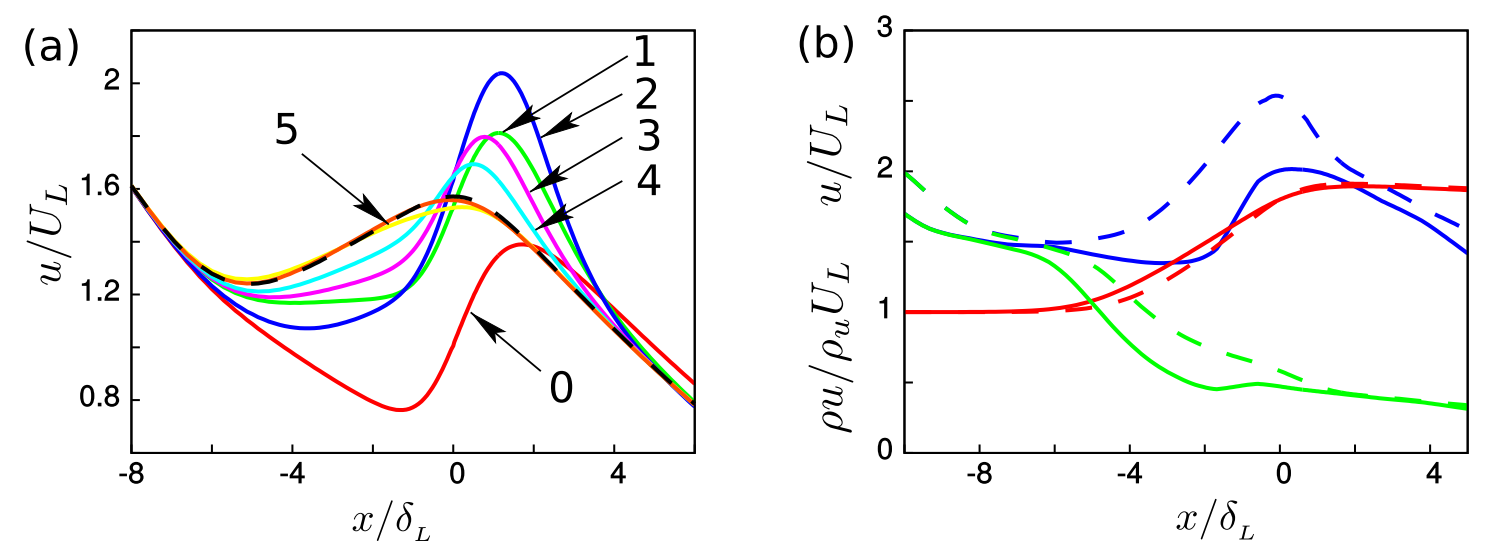

Figura 4.14: (a) Proceso iterativo para la corrección de la velocidad medida con PIV. La curva 0 es la velocidad no corregida y la curva de trazos es la velocidad real del gas. Las curva 1-5 son los resultados de sucesivas iteraciones. El resultado prácticamente coincide con la velocidad real del gas al cabo de seis iteraciones. (b) Aplicación del proceso iterativo a un perfil de velocidad medido con PIV. La curva azul continua es la velocidad medida y la curva azul de trazos la velocidad corregida. Las curvas rojas continua y de trazos son los perfiles de temperatura calculados con el modelo unidimensional para estas velocidades, mientras que las curvas verdes corresponden al flujo másico $\rho u$.

La figura 4.14b muestra el resultado de aplicar la corrección a un perfil de velocidad real medido con PIV para $\phi=0.54$. La curva azul continua es la velocidad medida y la curva azul de trazos la velocidad corregida. Las curvas rojas continua y de trazos son los perfiles de temperatura calculados con el modelo unidimensional para las velocidades medida y corregida, respectivamente. Por último, las curvas verdes son los perfiles correspondientes del flujo másico, $\rho u$. El método converge al cabo de cuatro iteraciones. Como puede verse, la magnitud de la corrección es apreciable en el interior de la llama, y el perfil corregido del flujo másico es más suave que el perfil no corregido. 


\subsection{Sembrado de partículas}

\subsubsection{Lecho fluidizado}

Tanto las consideraciones teóricas como la experiencia obtenida en la realización de los experimentos con PIV aconsejan usar una densidad de partículas lo más homogénea posible. El hecho de que aparezcan gradientes de concentración causadas por el tipo de flujo en el gas, no exime de la preparación de condiciones iniciales lo más cercanas a las ideales posible.

En el caso de sembrar gases los problemas de homogeneidad se hacen más patentes, ya que se necesita un sistema que sea capaz no solo de suministrar continuamente partículas al flujo de gas, sino también de s de manera homogénea en la mezcla. La elección del sembrador depende de las partículas empleadas, aunque la forma más habitual de generar partículas sólidas para el sembrado de una gas es mediante un lecho fluidizado, que consiste en una nube de partículas a través de la que se hace circular el gas. El gas, a su paso por este lecho, arrastra una parte de las partículas. Aunque visualmente es una manera sencilla de crear un aerosol, a la hora de emplearlo las complicaciones son varias por las distintas variables que se han de controlar, como por ejemplo el caudal de aire y la densidad de partículas deseada.

Los primeros ensayos se han realizado empleando un lecho fluidizado muy sencillo situado sobre una base porosa por la que se hacía pasar el gas. Este método funciona bien durante un cierto tiempo, pero después se forman unos canales en el lecho y se reduce drásticamente la cantidad partículas que arrastra el gas. Se ha observado que este método funciona mejor con partículas de magnesia que con partículas de alúmina, ya que estas últimas tienen tendencia a compactarse. Sin embargo, como ya se ha comentado, la magnesia no soporta las temperaturas de la llama, por lo que la densidad de estas partículas detrás de la llama se reduce mucho.

Otro tipo de sembradores habituales de partículas sólidas en gas son los sembradores ciclónicos. Normalmente tienen la ventaja de obtener una densidad más uniforme de sembrado que los lechos fluidizado. Al probar este sistema para sembrar la mezcla se ha observado que la densidad de partículas era muy baja para poder aplicar PIV . Se ha intentado mejorar este sistema añadiendo en la base un agitador magnético, pero debido a la tendencia de las partículas de alúmina a compactarse este método tampoco funcionaba, porque el agitador se trababa. Se ha intentado solucionar el problema sustituyendo el imán del agitador por un ventilador acoplado a un motor. El ventilador tiene más fuerza de giro que el imán, pero acababa por compactar todas las partículas, por lo que no iban al aire. Para este caso en concreto el sembrado ciclónico ha resultado ser inútil.

Tras el intento fallido del sembrador ciclónico se ha intentado mejorar el primer sembrador, cuya mayor limitación se debía a la formación de canales de paso con el tiempo. Se ha intentado evitar esta limitación creando una corriente transversal a estos canales, cambiando la aportación de gas. En vez de inyectarlo a través de una base porosa, se ha pasado a inyectarlo a través de un tubo de diámetro interior de $4 \mathrm{~mm}$ que descarga cerca de la pared de un cilindro. Esta configuración crea una corriente fuerte en las paredes del cilindro que rompe los canales. También con esta configuración la eficacia del sembrado se reducía con el paso del tiempo, ya que aunque se rompen los posibles canales verticales, se crean otros en dirección azimutal dentro del cilindro. Finalmente se ha añadido un 

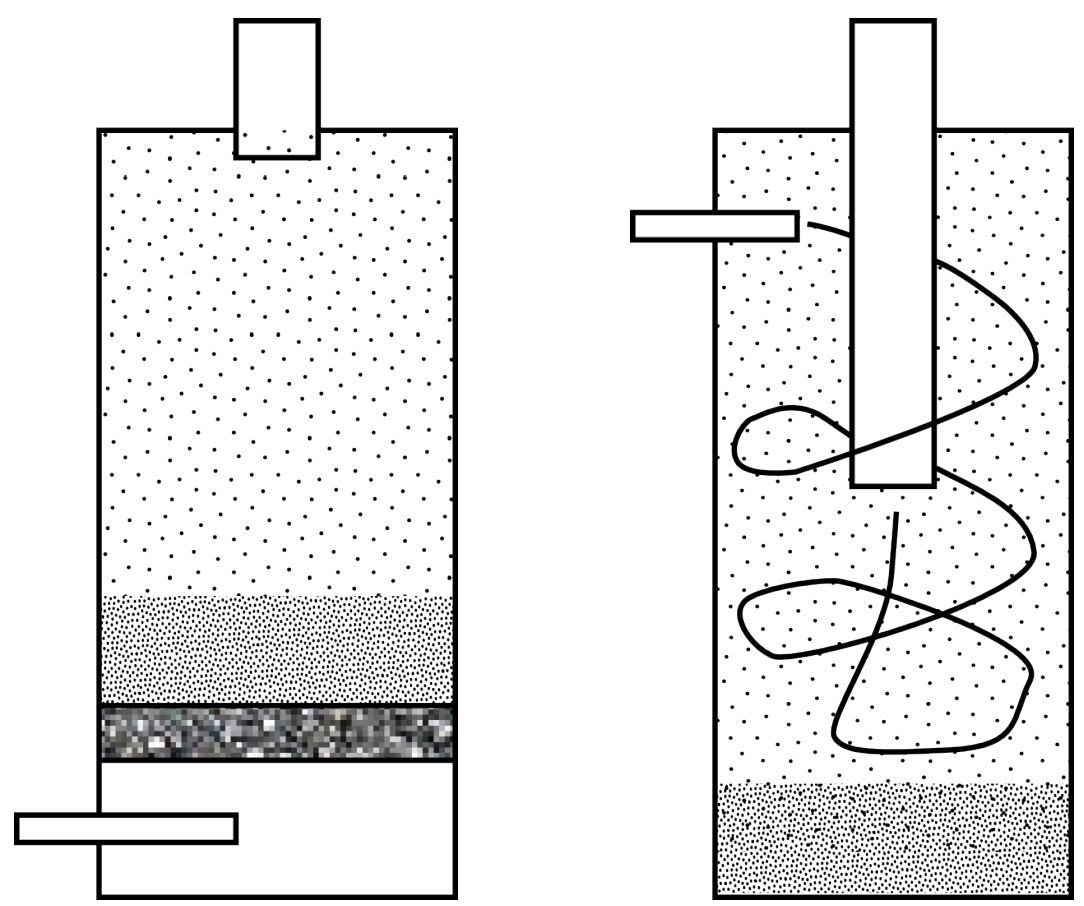

Figura 4.15: Sembradores de lecho fluidizado con base porosa (izquierda) y con ciclón (derecha)

agitador que golpea las paredes del cilindro con una frecuencia aproximada de $1 \mathrm{~Hz}$. El golpe remueve el lecho fluido y los canales que se forman, aportando de forma continua partículas al gas. Con esta configuración se obtiene una densidad muy alta de partículas por lo que se necesita un control final sobre ésta. Para ello, se ha añadido un depósito cilíndrico a la salida del lecho fluidizado, de tal forma que solo una parte ajustable de la mezcla pasa por el lecho mientras que el resto pasa sólo por el segundo depósito (ver figura 4.16), lo cual permite ajustar la densidad final de partículas en el gas.

Esta configuración ha sido la adoptada finalmente y permite ajustar la densidad de manera bastante controlada. El ajuste se hace de forma manual y con control visual, que se realiza encendiendo el láser y visualizando en el monitor las imágenes de la cámara del PIV mientras se está llenando el tubo. Los resultados conseguidos dependen de la experiencia que se va adquiriendo con el tiempo en este experimento concreto.

La línea principal de mezcla tiene un caudal constante. Antes de llegar al sembrador se divide en dos líneas secundarias, la primera va al lecho fluidizado y la segunda al ajustador de densidad. La línea del ajustador de densidad tiene una válvula de ajuste manual que permite variar el caudal que circula por la línea. La línea del lecho fluidizado tiene una válvula con dos posiciones: abierta o cerrada. Al comienzo del llenado del tubo no pasa caudal por el lecho fluidizado, sólo por el ajustador de densidad. En estas condiciones las partículas que entran en el tubo son muy pocas. Cuando se quiere empezar a sembrar la mezcla se abre la válvula del lecho fluidizado. En esta configuración, debido a un estrangulamiento instalado en la línea del lecho fluidizado, el caudal que pasa por éste es pequeño en comparación con el que pasa por el ajustador de densidad. A partir de este momento se empieza a cerrar la válvula de la línea del ajustador de densidad, aumentando 


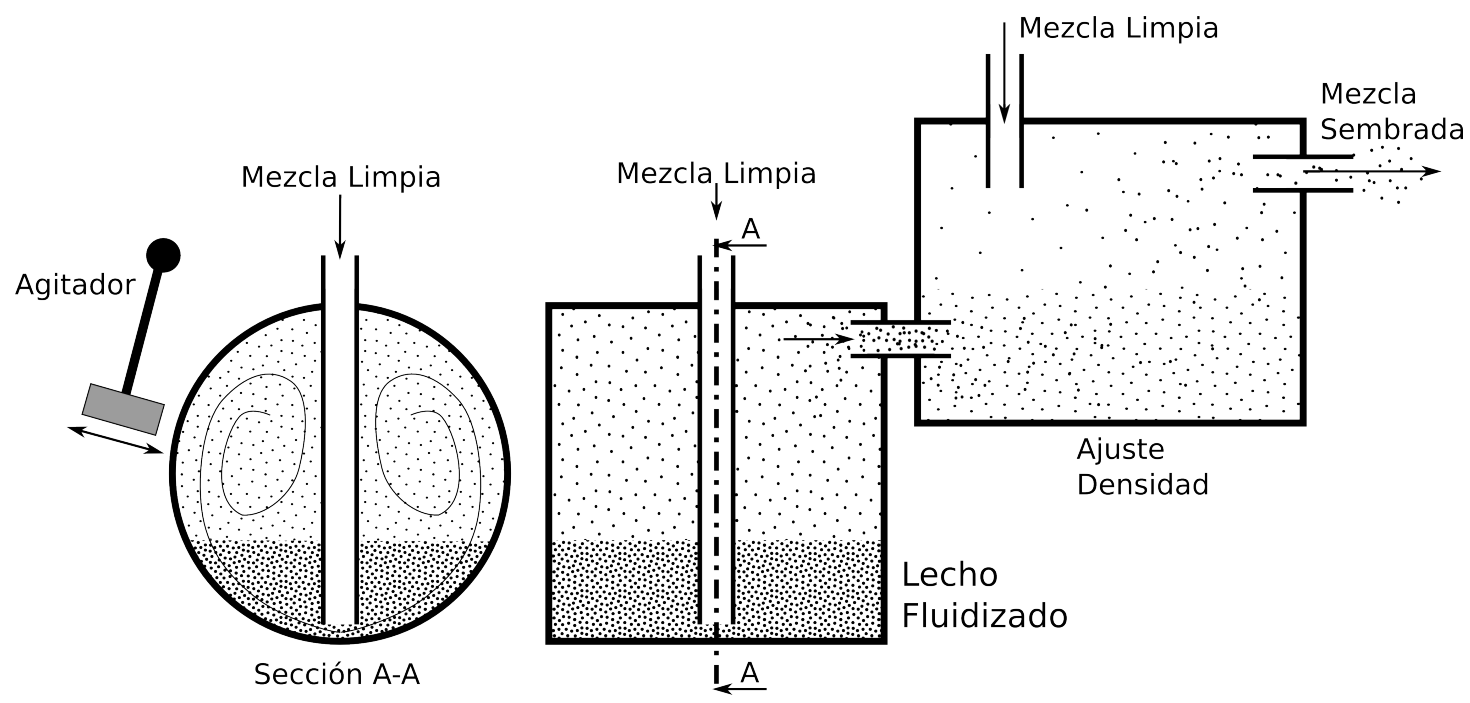

Figura 4.16: Representación esquemática del sistema de sembrado. Se divide en una etapa inicial de lecho fluidizado y posteriormente se añade una cámara para ajustar la densidad de partículas. El paso de mezcla a las dos cámaras se ajusta mediante un sistema de by-pass.

el caudal que pasa por el lecho fluidizado, ya que la suma de los dos caudales es constante. Durante este proceso, el láser está encendido y en la pantalla del ordenador se puede ver en tiempo real la densidad de partículas dentro del tubo. Realmente existe un retardo entre la densidad de partículas observadas y la que sale del sembrador, que se debe a que la parte superior del tubo se va llenando de la nueva mezcla. Esta limitación implica que el ajuste de la densidad se debe hacer de forma continua y sin cambios bruscos. Cuando se alcanza la densidad deseada se deja pasar el tiempo suficiente para llenar todo el tubo de ensayo con la misma densidad de partículas y se cierra la válvula principal (ver apartado 3.4 para los detalles del llenado del tubo).

Normalmente, una vez se ajusta la posición de la válvula de la línea del ajustador de densidad, se suele mantener fija durante unos 5 experimentos y sólo necesita ligeros ajustes para acomodar la densidad a las condiciones buscadas en cada experimento.

\subsubsection{Impactador}

La fiabilidad de los resultados obtenidos mediante PIV se basa en la capacidad de las partículas para seguir el movimiento del gas. Tal y como se ha visto en el análisis de la ecuación (4.2), esta capacidad está muy condicionada por el tamaño de las partículas. Las partículas grandes tienen una velocidad de sedimentación alta, y además su inercia no les permite adecuar su velocidad a la del gas (ver figura 4.12). Como ya se ha comentado, este hecho se ve reforzado al emplear partículas sólidas para sembrar gases, ya que su relación de densidades es del orden de $10^{3}$.

Aunque se elija una distribución de partículas de tamaño muy pequeño, el sembrador no puede garantizar que éstas no se aglomeren formando partículas mucho mayores que el valor nominal. A veces estos aglomerados pueden superar en un orden de magnitud el tamaño nominal de las partículas. Debido al sistema de sembrado elegido, no se puede 


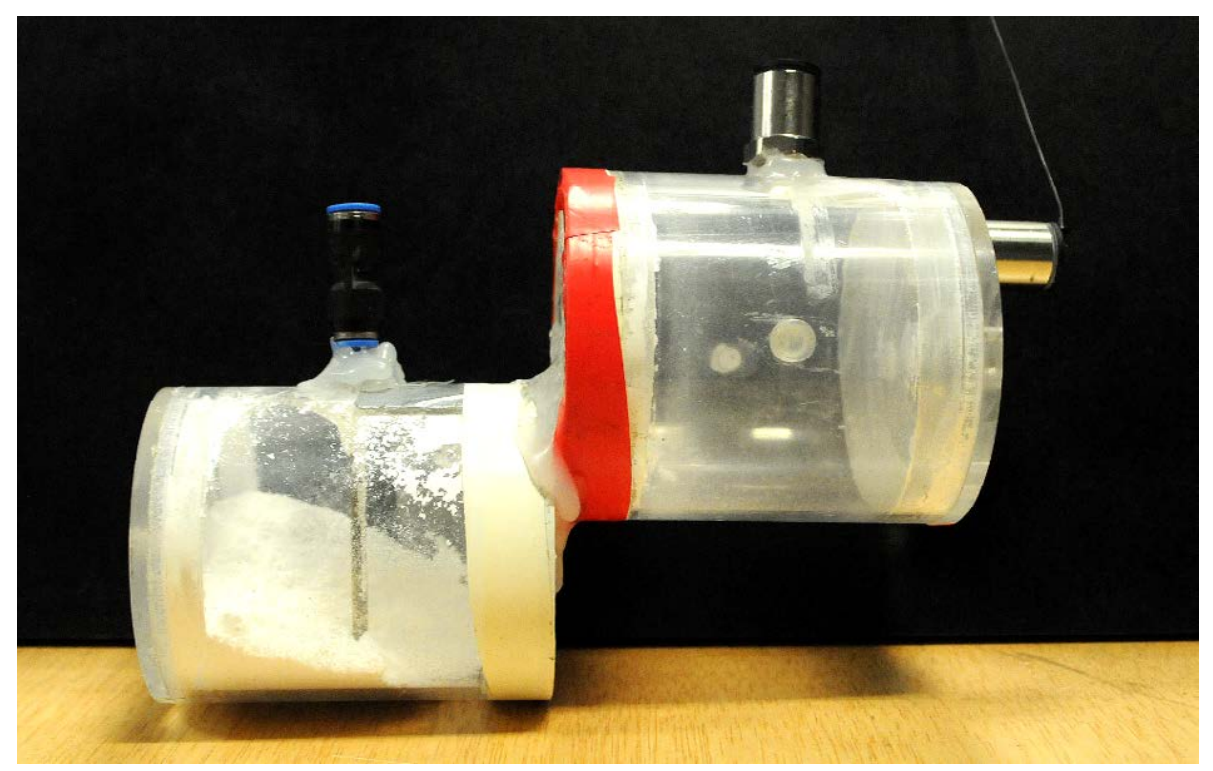

Figura 4.17: Fotografía del sistema de sembrado. El depósito de la derecha es el lecho fluidizado y el de la izquierda se usa para ajustar la densidad de partículas. El paso de mezcla a las dos cámaras se ajusta mediante un sistema de by - pass.

evitar este efecto, pero sí se puede intentar evitar que los aglomerados y las partículas más grandes en general lleguen al tubo de ensayo. Para ello, en la entrada del tubo se ha instalado un impactador.

El impactador es un colector de partículas de tipo inercial. Su principio de funcionamiento se basa en la aceleración del gas que transporta las partículas a la salida de una boquilla enfrentada a una placa fija. Las partículas más grandes, que tienen mayor inercia, no adaptan suficientemente rápido su trayectoria a la del gas, por lo que impactan en la placa. Idealmente todas estas partículas son retenidas la placa, por lo que a la salida del impactador el gas sólo lleva las partículas más pequeñas. En el caso real hay partículas que rebotan y están presentes en la salida, aunque en concentración menor que en la entrada. El impactador que se ha diseñado para esta instalación experimental no tiene en cuenta el rebote de las partículas, ya que su presencia no es crítica para el desarrollo del experimento.

En la figura 4.18 se presenta el esquema de una etapa típica de un impactador. Las partículas al atravesar la boquilla siguen las líneas de corriente del gas, pero al acercarse a la placa de impacto se desvían de ellas de manera brusca. Las partículas con menor inercia adaptan su trayectoria al gas y salen de la etapa. No ocurre lo mismo con las partículas más grandes. Los parámetros que describen la etapa son el diámetro de la boquilla (W), que será también el diámetro del chorro de salida, la longitud de la boquilla (T) y la separación entre la salida de la boquilla y la placa de impacto (S). Para el diseño adecuado del impactador es necesario elegir correctamente las dimensiones que caracterizan el impactador y para ello se ha seguido el proceso explicado en [15], donde también se explica cómo reducir el impacto del rebote de las partículas en el caso de tener una concentración mayor de la admisible a la salida.

Antes de presentar las ecuaciones usadas para el cálculo definiremos dos tamaños 


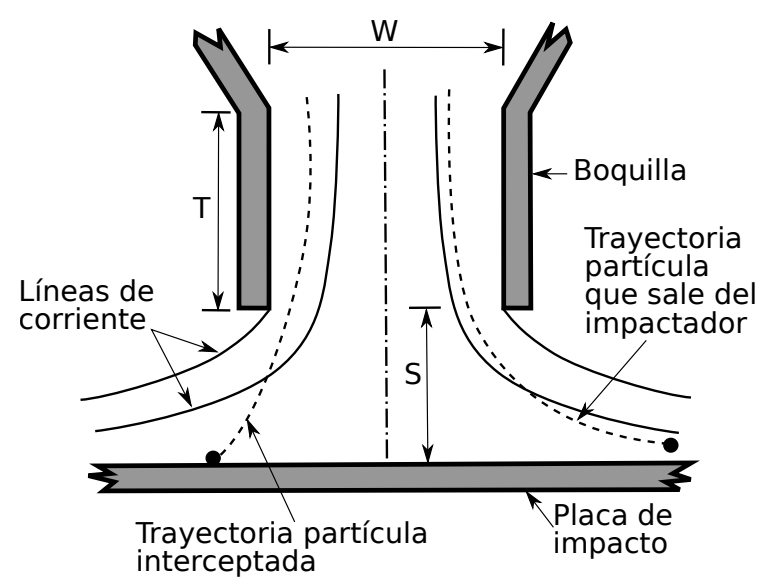

Figura 4.18: Esquema de una etapa del impactador. Las líneas continuas son las líneas de corriente del fluido y las discontinuas son la trayectoria de las partículas.

empleados en el desarrollo de la teoría de los impactadores: el radio de Stokes y el radio aerodinámico $^{1}$. El radio de Stokes es muy importante para el caso de emplear partículas de sembrado que no son perfectamente esféricas. Se define la esfera equivalente de Stokes, como la esfera que teniendo la misma densidad que la partícula tiene la misma velocidad de sedimentación. El radio de esta esfera es el radio de Stokes, $a_{s}$. El radio aerodinámico es el radio de la esfera con densidad $\rho_{a}=1000 \mathrm{~kg} / \mathrm{m}^{3}$ que tiene la misma velocidad de sedimentación que la partícula. Este radio es útil para la obtención de gráficos y desarrollos teóricos independientes de las partículas empleadas. En la figura 4.19 se puede ver las relaciones entre los tamaños definidos.

Cada etapa de un impactador se puede describir por una curva de eficiencia, que muestra la capacidad de la etapa ya diseñada de sustraer del flujo las partículas de cada tamaño. La figura 4.20 muestra la forma típica de una de estas curvas. La curva de eficiencia ideal sería un salto escalón en el mínimo radio de las partículas que se desea eliminar. La curva real siempre tiene una pendiente finita. El valor de la eficiencia está determinado por el porcentaje de partículas que es capaz de atrapar la etapa. Esta curva permite definir el radio mediano, $a_{50}$, que es el radio de las partículas que el impactador es capaz de atrapar en un $50 \%$.

En el funcionamiento del impactador el movimiento de la partícula está determinado por la fuerza viscosa del fluido sobre la partícula y la inercia de ésta. Un parámetro importante para el diseño del impactador es el número de Stokes definido más arriba. Para el impactador, donde se conoce la velocidad inicial de la partícula, $V$, el número de Stokes se puede interpretar como el cociente entre la distancia, $D_{d}$, que recorrería una partícula antes de detenerse en un gas en reposo y el radio del chorro de gas $(W / 2)$ [35]. Como puede verse resolviendo la ecuación (4.2) con $\boldsymbol{g}=\boldsymbol{v}=0$ y empleando la corrección de Cunningham para la fuerza de Stokes, la distancia $D_{d}$ es

$$
D_{d}=t_{s} \cdot V=\frac{2}{9} \frac{\rho_{p} a_{s}^{2} f_{C}}{\mu} V
$$

\footnotetext{
${ }^{1}$ Aunque en la literatura sobre impactadores es más habitual encontrar los diámetros equivalente que los radios, usaremos éstos últimos por consistencia con los apartados anteriores.
} 


\section{Partícula irregular}

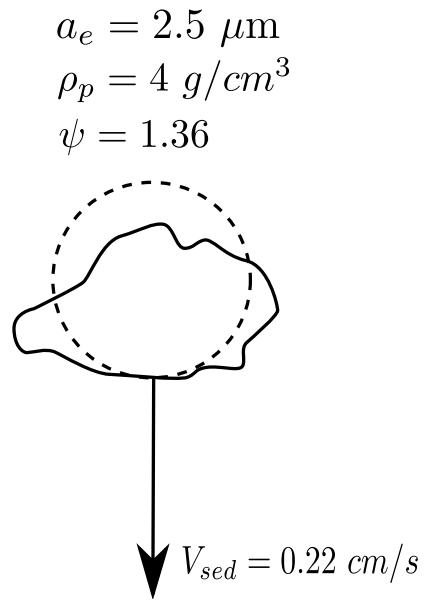

\section{Esfera equivalente de Stokes}

$$
\begin{aligned}
a_{s} & =2.15 \mu \mathrm{m} \\
\rho_{p} & =4 \mathrm{~g} / \mathrm{cm}^{3}
\end{aligned}
$$

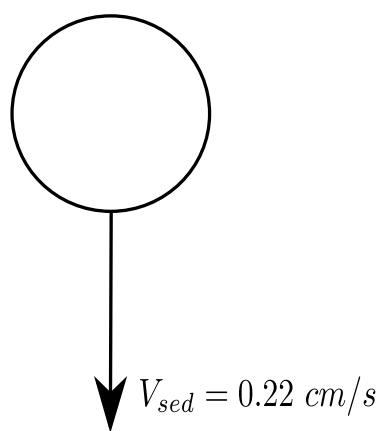

\section{Esfera equivalente aerodinámica}

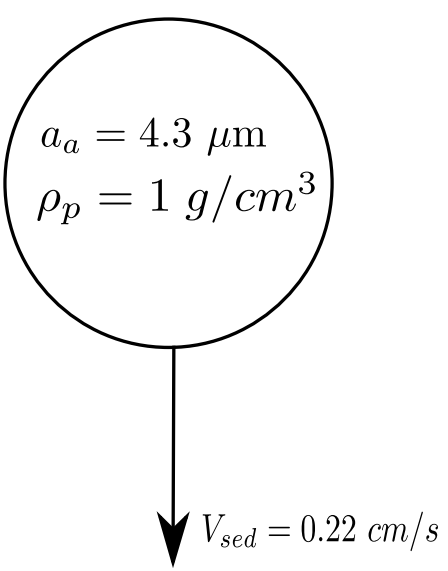

Figura 4.19: Forma real de la partícula (izquierda),esfera equivalente de Stokes para esta partícula (centro) y esfera aerodinámica equivalente (derecha) [18].

por lo que el número de Stokes es

$$
\mathrm{St}=\frac{D_{d}}{W / 2}=\frac{4}{9} \frac{\rho_{p} a_{s}^{2} f_{C} V}{\mu W}
$$

donde $V$ coincide con la velocidad del gas en el chorro. Esta velocidad se calcula fácilmente a partir del caudal de gas total, $Q$, que pasa por la boquilla:

$$
V=\frac{4 Q}{\pi W^{2}}
$$

El número de Stokes (4.11) se define de la misma forma para las esferas equivalentes aerodinámicas, sustituyendo $\rho_{p}$ por $\rho_{a}$ y $a_{s}$ por $a_{a}$. Como se ha comentado al explicar los tipos de esferas equivalentes, tomar como referencia el radio aerodinámico permite obtener curvas de eficiencia independientes del tipo de partícula elegida.

Uno de los usos más importantes del número de Stokes es para la predicción del radio de corte, $a_{50}$. Las curvas de eficiencia de los impactadores que tengan geometría parecidas, pero con distinto diámetro de la boquilla o distinto caudal, coinciden si se representan como función de St. El radio de corte $a_{50}$ corresponde a un único número de Stokes, llamado el Stokes crítico, $\mathrm{St}_{50}$. El valor del número de Stokes crítico es aproximadamente el mismo para diferentes etapas del impactador que tengan geometría similar, y puede ser empleado para predecir la actuación del impactador. Para los impactadores con boquillas cilíndricas se tiene $\mathrm{St} \simeq 0.24$ [46].

Utilizando el número de Stokes crítico se puede calcular el diámetro de la boquilla necesario para tener un radio de corte dado. Si cada etapa tiene una única boquilla de descarga contra la placa de impacto, su diámetro será 


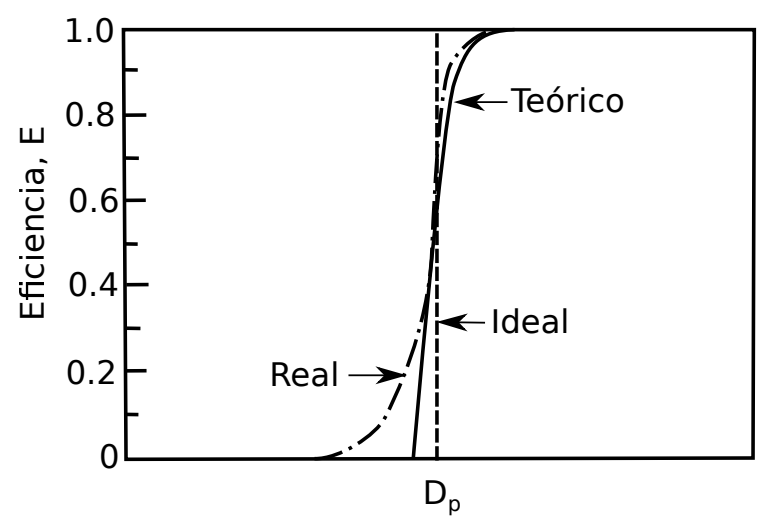

Figura 4.20: Curva de eficiencia ideal, real [46] y teórica [35] de una etapa de un impactador.

$$
W=\left(\frac{16}{9 \pi} \frac{\rho_{p} a_{50}^{2} f_{C} Q}{\mu \mathrm{St}_{50}}\right)^{\frac{1}{3}}
$$

Como se puede observar en la ecuación (4.12), una vez se ha elegido la geometría del impactador, el producto del caudal por el diámetro al cuadrado debe permanecer fijo. Por ello si se aumentara de manera notable el caudal a través del impactador, el diámetro de corte disminuiría. Debido a la forma en la que se ha diseñado el experimento, no hay grandes variaciones de caudal al llenar el tubo, por lo que el diámetro de corte es siempre cercano al elegido en el diseño. Otros factores, como $f_{C}$ y $\mu$, dependen de la presión y la temperatura respectivamente. En este caso tampoco hay variaciones importantes en las condiciones ambientales que afecten al diámetro de corte de manera notable.

El parámetro que puede echarse en falta en la ecuación (4.12) es la distancia $S$ entre la boquilla y la placa de impacto. Se ha observado que el radio crítico $a_{50}$ depende fuertemente de esta distancia cuando la relación $S / W$ es menor de 0.5. Sin embargo, tanto el $\mathrm{St}_{50}$ como la forma de la curva de eficiencia se hacen independientes de $S / W$ cuando el valor de este cociente es mayor que 0.5 [35]. Para definir la geometría actual se ha empleado el valor mínimo recomendado para el diseño de un impactador cilíndrico; $S / W=1$ [36].

Finalmente es preciso hacer una comprobación más para asegurar que la curva de eficiencia del impactador diseñado es parecido a la curva ideal. Para ello hay que calcular el número de Reynolds en la boquilla,

$$
\operatorname{Re}=\frac{\rho V W}{\mu}=\frac{4 \rho Q}{\pi \mu W} .
$$

Para que el impactador funcione correctamente el valor Re debe ser superior a 100, pero para asegurar un mejor funcionamiento se recomienda $\operatorname{Re}>500$, ver figura 4.21.

El número de Reynolds en el chorro del impactador diseñado, con $W=6 \mathrm{~mm}$ y caudal de $Q \approx 10 \mathrm{l} / \mathrm{min}$, es aproximadamente igual a 3000. Empleando la figura 4.21 se obtiene para este impactador $\mathrm{St}_{50} \approx 0.18$, que para la densidad de la alúmina da un radio de la esfera equivalente de Stokes $a_{s} \approx 1 \mu \mathrm{m}$. Este impactador reduce la cantidad de partículas con radio mayor a una micra en la mezcla sembrada y elimina la mayoría de los aglomerados globulares grandes observados con el microscopio electrónico de barrido. 


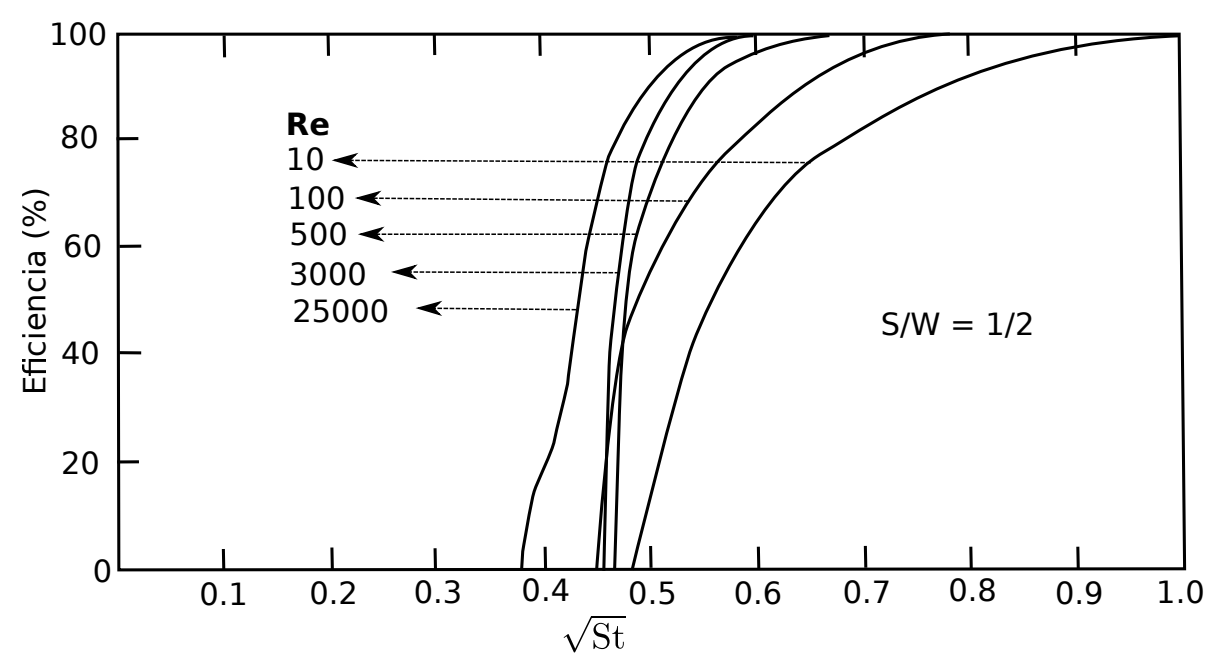

Figura 4.21: Curvas de eficiencia de un impactador en función del número de Reynolds y del tamaño de la partícula. Fuente: Marple y Liu [35].

\subsection{Conclusiones}

En este capítulo se han explicado las técnicas de medida empleadas para estudiar la evolución de la llama. Su velocidad de ascenso dentro del tubo se ha medido empleando dos métodos distintos: a partir de las señales de una línea de fotodiodos equiespaciados a lo largo de la pared del tubo que detectan la posición de la llama cuando pasa frente a ellos, y a partir de fotografías del frente de llama tomadas a intervalos de tiempo conocidos. La ventaja de la línea de fotodiodos es que su señal se puede amplificar y posibilita la detección de llamas débiles. Sus desventajas principales son que esta amplificación es susceptible de proporcionar falsos positivos en la detección de la llama, y que la resolución temporal de las medidas es limitada.

Para tomar fotografías de la llama se han utilizado dos cámaras, una réflex, Nikon D300, y una cámara USB, Basler Ace. La cámara réflex tiene un sensor con mayor resolución que la Basler, pero ésta última tiene una frecuencia de adquisición de imágenes mucho mayor, que permite registrar varias imágenes durante la extinción de una llama.

El cálculo de la velocidad de la llama se ha realizado empleando las herramientas de tratamiento de imágenes de Matlab. La detección de la llama se realiza aislando el canal azul de las imágenes en color y aplicándole distintos filtros para reducir el ruido y amplificar la luminosidad registrada de la llama.

La velocidad del gas alrededor de la llama se mide de empleando la técnica de PIV. Se han analizado los factores que causan errores en las medidas separándolos en dos grupos: los relacionados con la uniformidad del sembrado y la resolución de las imágenes, y los relacionados con la dinámica de las partículas. En ambos casos el estudio se particulariza para las condiciones de nuestro experimento, donde la presencia de la llama hace inaplicables algunos resultados establecidos para esta técnica.

La presencia de la llama provoca la expansión térmica del gas que la atraviesa y genera una zona detrás de la llama cuya densidad de partículas es menor que delante de la misma. La expansión térmica también causa gradientes de velocidad de las partículas dentro de 
las ventanas de interrogación empleadas por el algoritmo de PIV. Estos efectos introducen errores importantes en las medidas de PIV a través de la llama. Se ha comprobado que estos errores se pueden reducir aumentando la resolución de las imágenes y empleando técnicas avanzadas del algoritmo de PIV, tales como la deformación, el desplazamiento y el solapamiento de las ventanas de interrogación.

La presencia de la llama también afecta al movimiento de las partículas usadas para sembrar el gas. Estas partículas experimentan al atravesar la llama la fuerza de termoforesis generada por el alto gradiente térmico en la llama y que empuja a las partículas hacia el gas frío. Esta fuerza es importante cuando el tamaño de las partículas es comparable al camino libre medio de las moléculas del gas, siendo éste el caso de nuestro experimento. Se ha propuesto un procedimiento para corregir la deriva de la velocidad de las partículas causada por la termoforesis, empleando para el cálculo de la temperatura del gas el modelo unidimensional explicado en el capítulo 2.

Finalmente se detalla el sistema de sembrado necesario para poder emplear la técnica PIV. La dispersión de las partículas se realiza usando un lecho fluidizado provisto de un agitador que golpea su pared para evitar la formación de canales de paso del gas en el lecho fluidizado, que reducen drásticamente la cantidad de partículas que arrastra el gas. A la salida del lecho fluidizado se ha situado un impactador que limita el tamaño máximo de las partículas atrapando las partículas con radios superiores a una micra. 


\section{Capítulo 5}

\section{Resultados experimentales}

\subsection{Comportamiento de la llama}

Los resultados más sencillos de obtener con la instalación experimental presentada son los relacionados con la inflamabilidad de la mezcla y el comportamiento de la llama durante la propagación vertical. Para estudiar la inflamabilidad de la mezcla es suficiente con la observación visual de la propagación de la llama: si ésta es capaz de propagarse desde el extremo inferior del tubo hasta el extremo superior sin extinguirse, la mezcla es inflamable. Las llamas de mezclas muy pobres son muy sensibles a los factores externos por lo que el valor de la riqueza que se obtiene en el límite de inflamabilidad tiene asociado un error aleatorio que se suma a los errores de los equipos empleados para medir la cantidad de cada gas en la mezcla.

La mera observación de la llama permite saber si la mezcla está cerca de su límite de inflamabilidad o si se trata de una mezcla algo más rica. Durante la propagación de la llama ésta tiene forma de campana, un casquete esférico en la parte superior seguido de una falda cuya longitud varía con la riqueza. Esta longitud aumenta cuando la riqueza baja y disminuye cuando la riqueza aumenta, ver figura 5.1.

$\mathrm{Al}$ ser la densidad de la mezcla sin quemar que se encuentra por encima del frente de la llama mayor que la densidad de los gases calientes que se encuentran detrás de la llama, los gases calientes son empujados hacia arriba. Esta misma fenomenología se observa en el ascenso de una burbuja de aire dentro de una columna de líquido (burbuja de Taylor $[7])$. Aunque la relación entre las densidades del líquido y del aire $\left(\rho_{\text {liq }} / \rho_{\text {aire }} \sim 1000\right)$ es mucho mayor que la relación entre las densidades de la mezcla sin quemar y de los gases calientes $\left(\rho_{\text {mezcla }} / \rho_{\text {calientes }} \sim 5\right)$, las velocidades de propagación vertical de la burbuja de aire y del frente de llama son muy parecidas.

En los experimentos realizados se ha observado que tras un corto transitorio después del encendido, explicado en la sección 3.3, la llama se propaga de manera estacionaria hasta el extremo superior del tubo, siempre y cuando la mezcla sea inflamable. La llama no varía su forma y guarda su simetría axial durante toda la propagación.

En la figura 5.2 se puede ver una sucesión de fotografías de una llama tomadas cada 20 milisegundos, la velocidad de muestreo de la cámara ha sido de 50 imágenes por segundo. En las distintas fotografías se observa que la llama mantiene la simetría de revolución y que el espacio recorrido entre dos fotografías consecutivas es el mismo. La pendiente de la 


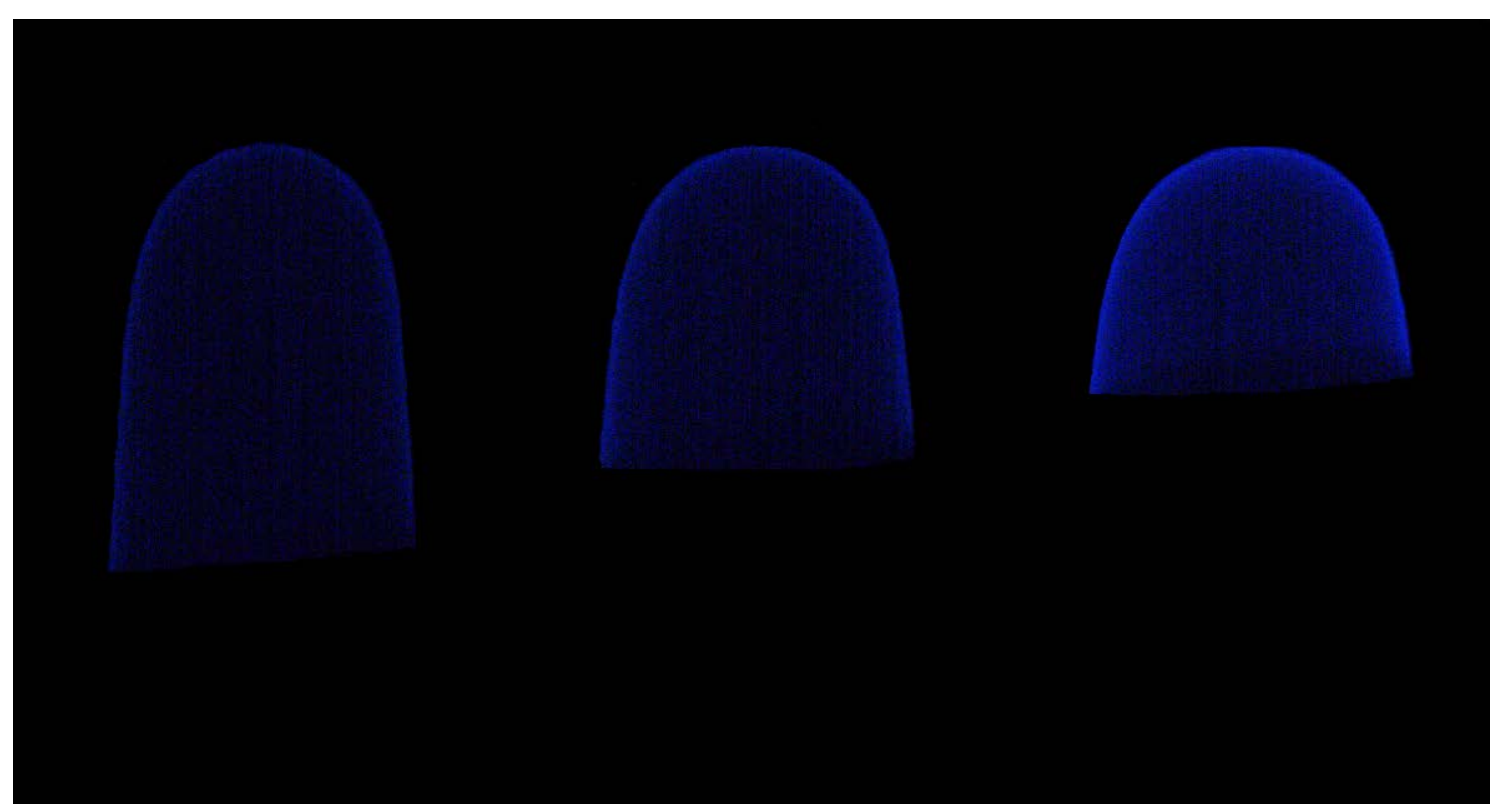

Figura 5.1: Comparación de la longitud de la falda de la llama entre tres casos con distinta riqueza. La riqueza aumenta de izquierda a derecha y los tres experimentos han sido realizados en el mismo día bajo las mismas condiciones. También se puede apreciar como aumenta la luminosidad de la llama al aumentar la riqueza.

recta resultante al unir la punta de la llama en cada imagen da la velocidad de propagación de la llama y, como se puede observar, es la misma a lo largo de todo el recorrido. En este caso en concreto el recorrido es de unos $40 \mathrm{~cm}$ que es el campo de visión de la cámara. Igualmente se ha comprobado que la propagación estacionaria se da en todo el tubo salvo en la cercanía de los dos extremos.

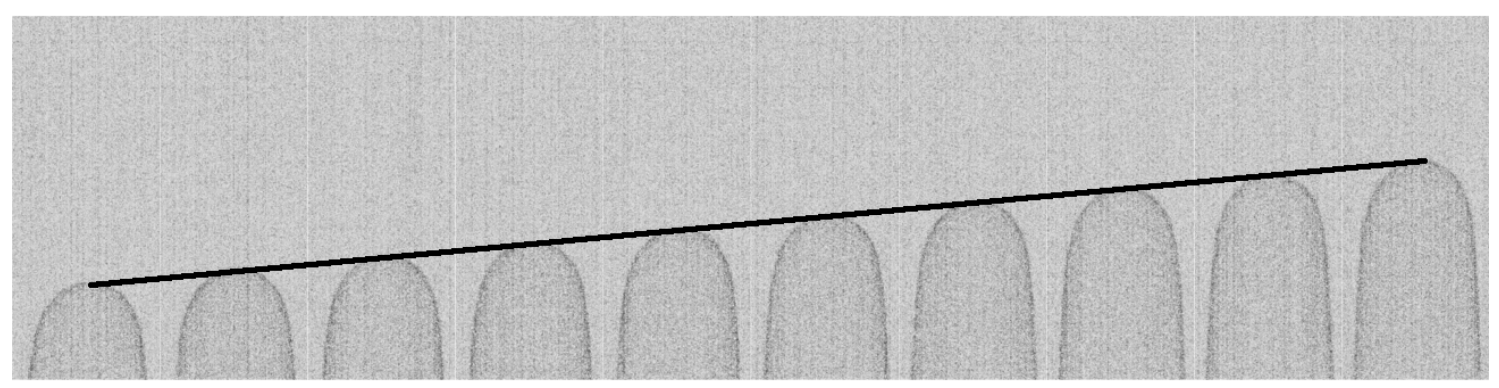

Figura 5.2: Propagación de la llama.

\section{Extinción}

Cuando la riqueza de la mezcla es ligeramente inferior al límite de inflamabilidad, la llama tiene, durante una cierta etapa inicial, la misma forma y comportamiento que para mezclas inflamables. Sin embargo estas llamas se apagan antes de alcanzar el extremo 
superior del tubo. Visualmente la extinción de la llama es fácil de observar, pero el estudio en detalle de este proceso es complicado. La llama se extingue dentro del tubo, pero la altura a la que lo hace es impredecible. Si se disminuye aún más la riqueza de la mezcla, no se llega a formar la llama y el frente de llama generado por la resistencia eléctrica se apaga rápidamente. Para evitar una extinción prematura de la llama, se enriquece la mezcla en la zona inferior del tubo. De esta forma la llama no se apaga debido a las perturbaciones generadas en el encendido (explicación detallada en la sección 3.3). Aunque de esta forma se evita una extinción prematura de la llama, la posición exacta de la extinción dentro del tubo sigue siendo aleatoria (dentro de un rango comprendido entre los 70 y $130 \mathrm{~cm}$ de distancia de la resistencia), dificultando un estudio detallado del proceso de extinción.

En algunos casos sí se ha conseguido captar la extinción de la llama en vídeo, consiguiendo que la llama se apagara en el campo de visión de la cámara. La observación de las extinciones grabadas coinciden con los resultados expuestos por otros autores [31, 51, 61]: la llama empieza a apagarse en la punta y la extinción se va propagando hacia los laterales.

La propagación previa de la llama no presenta ningún indicio de su futura extinción. Al igual que las llamas con riquezas ligeramente mayores, estas llamas se propagan verticalmente de forma estacionaria hasta que, en un momento dado, se rompe la continuidad del frente de la llama en la punta, entendiendo como frente de llama la quimioluminiscencia registrada por la cámara (ver figura 5.5). A partir de este momento la reconstrucción virtual del frente de llama, que se obtiene uniendo el la llama aún activa en la falda mediante un casquete hemisférico, cambia su comportamiento y deja de desplazarse a la misma velocidad que lo hacía antes de comenzar a apagarse.

En la figura 5.3 se puede ver una sucesión de imágenes que corresponden a la extinción de una llama. En los primeros fotogramas la llama tiene velocidad constante; se puede observar que su punta se encuentra en una recta cuya pendiente da la velocidad de propagación de la llama. En el momento en el que la punta se despega de la recta (cuarta imagen desde la derecha) la extinción ha comenzado.

Si se sigue la evolución de la punta de la llama de cerca durante la extinción (figura 5.5) se puede observar que al principio, al igual que ocurre con la velocidad de propagación, no hay ningún indicio de la próxima extinción de la llama. El frente de la llama se ve continuo y la intensidad luminosa de llama no varía a lo largo del frente. A partir del fotograma 6 la intensidad de la llama empieza a disminuir y en el fotograma 12 el frente de la llama deja de ser continuo. Estas observaciones no aportan más información sobre los mecanismos responsables de la extinción y, aunque no habían sido registradas debido a limitaciones técnicas, habían sido apuntadas por Levy [31].

Los experimentos empleando la técnica Schlieren $[13,31]$ han mostrado que la extinción no afecta inmediatamente a la propagación de la burbuja de gases calientes. De hecho, una vez se apaga la llama la burbuja de gas caliente sigue avanzando con la misma velocidad y forma durante unos $15 \mathrm{~cm}$.

\subsection{Velocidad de ascenso de la llama}

El estudio del comportamiento de la llama es muy importante para determinar cuáles son los límites de inflamabilidad de la mezcla, pero la información conseguida en estos experimentos es muy escasa para poder explicar en profundidad las causas de la extinción 


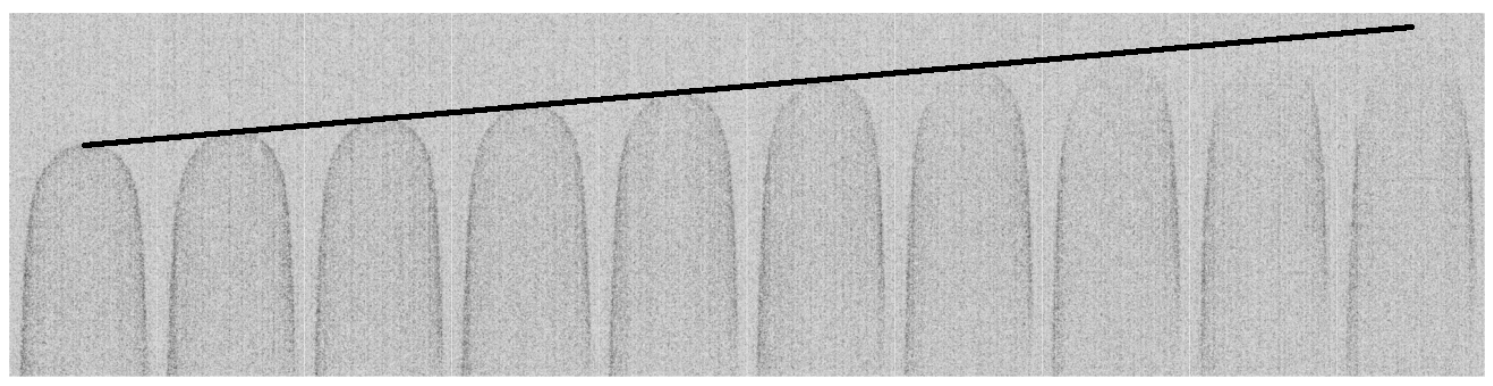

Figura 5.3: Evolución de la llama antes de extinguirse. Tiene una velocidad de propagación vertical constante y empieza a apagarse en la punta de la llama. La fotos son el negativo del canal azul amplificado.

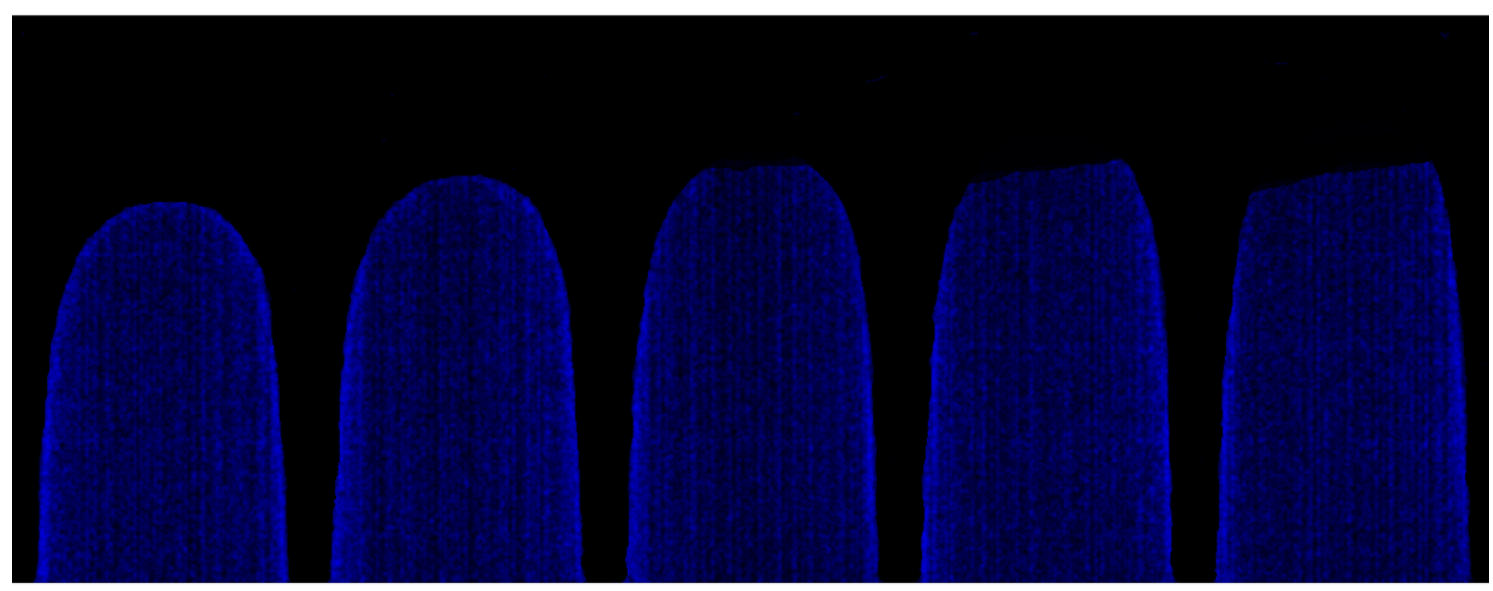

Figura 5.4: Evolución de la llama antes de extinguirse. Tiene una velocidad de propagación vertical constante y empieza a apagarse en la punta de la llama.

de las llamas.Tanto más cuanto que la extinción ocurre en tiempos muy cortos (en la secuencia de la figura 5.5 en menos de $100 \mathrm{~ms}$ ) y el desarrollo previo de la llama no arroja ningún indicio de su futura extinción.

Al igual que en otros estudios recientes [13, 51-53], el empleo de la técnica de PIV para medir la velocidad del gas tanto por delante como por detrás de la llama se vuelve imprescindible para estudiar el efecto del alargamiento de la llama o el de las pérdidas por radiación en la zona de baja velocidad que se encuentra detrás del frente de llama.

Para medir la velocidad vertical del frente de llama, en los primeros experimentos se ha empleado una línea de fotodiodos cuyo pico de sensibilidad se encuentra cerca de la longitud de onda correspondiente al color azul, ver sección 4.1.1. Se han empleado tres fotodiodos separados por una distancia de $2 \mathrm{~cm}$ entre cada pareja. Se ha diseñado y fabricado un circuito amplificador que amplifica la señal de los fotodiodos y convierte la señal resultante de la presencia de la llama en una función salto escalón. El tiempo transcurrido entre dos escalones consecutivos, $\Delta t$, que corresponde a la señal medida para dos fotodiodos consecutivos, permite calcular la velocidad de ascenso de la llama: 


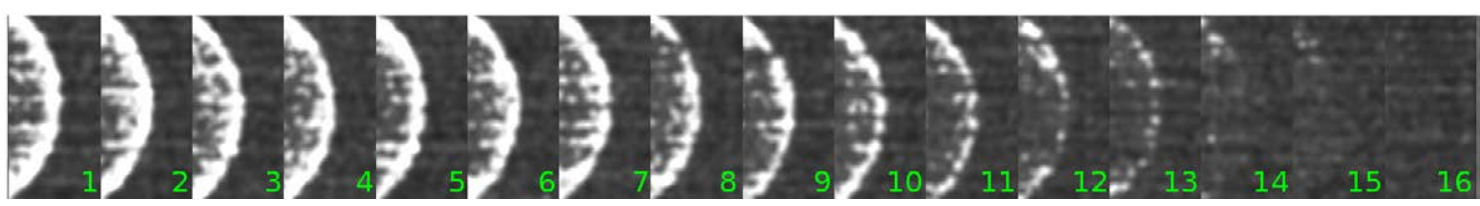

Figura 5.5: Evolución de la llama antes de extinguirse. Tiene una velocidad de propagación vertical constante y empieza a apagarse en la punta de la llama.

$$
U_{0}=\frac{d}{\Delta t},
$$

donde $d$ es la distancia que hay entre dos fotodiodos consecutivos en la línea y $U_{0}$ es la velocidad de ascenso de la llama dentro del tubo.

La señal se ha medido empleando un equipo de adquisición de datos, Yokogawa WE7000, equipado con una tarjeta de adquisición de 8 canales, Yokogawa WE7173. Se han empleado 3 canales y se ha usado una frecuencia de adquisición de 1000 muestras por segundo, el máximo que permite la tarjeta para mediciones en directo (live recording), por lo que la resolución temporal mínima ha sido

$$
\Delta t_{r}=1 \mathrm{~ms}
$$

Esta resolución temporal limita el valor de la velocidad que se puede medir con esta distribución de los fotodiodos si se busca contener el error de la medición. El error absoluto en el cálculo de la velocidad se puede calcular de la siguiente manera:

$$
E_{a}=\frac{d}{\Delta t}-\frac{d}{\Delta t+\Delta t_{r}}=\frac{d}{\Delta t}\left(\frac{\Delta t_{r}}{\Delta t+\Delta t_{r}}\right)=U_{0}\left(\frac{\Delta t_{r}}{\Delta t+\Delta t_{r}}\right) .
$$

Empleando la ecuación (5.1) se puede calcular el valor del error relativo:

$$
e_{r}=\frac{\Delta t_{r}}{\Delta t_{r}+\frac{d}{U_{0}}} .
$$

Como se puede apreciar en la ecuación (5.2), el error relativo impuesto por la resolución temporal del equipo de adquisición de datos depende únicamente de la velocidad vertical de la llama que se quiere medir y de la distancia entre los fotodiodos, ya que $\Delta t_{r}$ es fijo. En este caso, a la vista de las mediciones obtenidas por otros autores, se espera que la velocidad sea de unos $20 \mathrm{~cm} / \mathrm{s}$. Empleando la ecuación (5.2), el error relativo de esta medida sería del orden de $1 \%$ de la velocidad de subida de la llama. Sin tener que cambiar el equipo de adquisición de datos, se podría mejorar el error aumentando la distancia entre los fotodiodos, pero se perdería la información local de llama, ya que se pretende conocer la velocidad en el momento en que la llama pasa por delante de la cámara de PIV, y el campo de visión de esta cámara es del orden del diámetro del tubo, algo mayor que la distancia entre el primer y el último fotodiodo.

En la figura 5.6 se muestra una porción de la señal registrada a la salida del circuito amplificador al pasar una llama por delante de la línea de fotodiodos. Los fotodiodos han sido colocados en orden rojo, verde y azul (estos colores sólo hacen referencia a la 
forma de representar los datos y nada tienen que ver con la banda de sensibilidad de los fotodiodos). Se ha programado un código en Matlab que detecta la posición del salto escalón en la cadena de datos (mucho más larga que lo representado en la figura 5.6, ya que la adquisición de datos comienza antes de encender la llama y se registra la señal hasta que la llama alcanza el extremo superior del tubo, unos 10 segundos después) y proporciona el valor del tiempo correspondiente a la activación de cada diodo. En este caso, los tres tiempo consecutivos medidos son:

$$
t_{1}=1.383 \mathrm{~s} \quad t_{2}=1.47 \mathrm{~s} \quad t_{3}=1.558 \mathrm{~s} .
$$

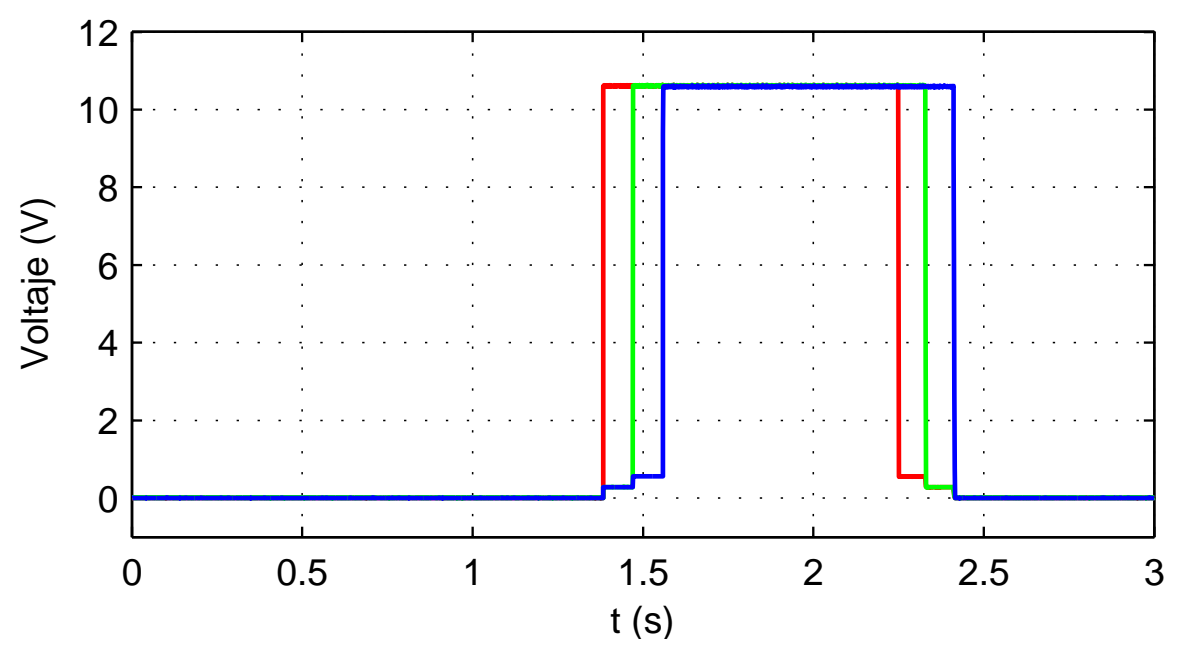

Figura 5.6: Señal medida a la salida del circuito amplificador de la línea de fotodiodos.

Conociendo los tiempo de paso de la llama por delante de los detectores se puede calcular el tiempo que tarda la llama en desplazarse los $2 \mathrm{~cm}$ que separan cada pareja de fotodiodos:

$$
\Delta t_{1}=87 \mathrm{~ms} \quad \Delta t_{2}=88 \mathrm{~ms} .
$$

La llama se desplaza con velocidad constante por lo que, idealmente, se tendría que cumplir la igualdad $\Delta t_{1}=\Delta t_{2}$. En este caso esta afirmación se podría dar por válida, ya que la pequeña diferencia entre los dos tiempos puede ser debida al equipo de adquisición, cuya resolución temporal es de $\Delta t_{r}=1 \mathrm{~ms}$ o $\Delta t_{1}-\Delta t_{2}=\Delta t_{r}$.

Las dos velocidades medidas en este caso, correspondiente a la propagación de una llama con riqueza relativa $\phi=0.534$, son

$$
U_{1}=22.988 \mathrm{~cm} / \mathrm{s} \quad U_{2}=22.727 \mathrm{~cm} / \mathrm{s} .
$$

El error relativo es

$$
e_{r}=\frac{U_{1}-U_{2}}{U_{2}} \cdot 100=1.15 \% \text {. }
$$

Como se puede comprobar, el error es moderado y se puede esperar que el sistema de medición adoptado aporte datos fiables. Sin embargo, hay que tener en cuenta el hecho de 
que estos datos corresponden a un experimento de los cientos que se han hecho. Que en este caso las dos velocidades medidas sean muy parecidas, no implica que sean veraces. Para ello hay que analizar los demás casos y comprobar los valores que se obtienen, así como las fuentes de error que pueden influir en la medición. Este experimento se ha elegido como muestra de que, aún teniendo una respuesta perfecta de la línea de fotodiodos, existe un error mínimo que no se podrá reducir.

\subsubsection{Efecto de la sensibilidad de los fotodiodos}

El caso presentado más arriba requiere una buena preparación del sistema de medida, sobre todo en la corrección de las diferentes sensibilidades de los tres fotodiodos y la corrección del efecto de variación del valor de las resistencias usadas en el circuito. Esta corrección se ha hecho exponiendo los fotodiodos a la misma fuente de luz y corrigiendo su respuesta mediante unas resistencias variables añadidas al circuito. Se ha comprobado que la salida del circuito amplificador es muy sensible a bajas intensidades de luz, siendo esta propiedad muy necesaria debido a la poca luminosidad de las llamas pobres. La sensibilidad de los fotodiodos no sólo depende de su fabricación, sino también de la colocación física de éstos. Se deben tener en cuenta los siguientes efectos:

Distancia a la fuente de luz: la posición ideal del fotodiodo es en la misma pared del tubo, pero aún así la forma de la llama implica que, a medida que ésta se mueve por delante del fotodiodo, la distancia del frente de llama a la superficie receptora de luz varía. La punta de la llama se encontraría a la distancia de un radio del tubo (27 mm más el espesor de la pared del tubo) y la falda estaría a unos pocos milímetros del fotodiodo. Se tiene que buscar que el circuito amplificador sea capaz de detectar la punta de la llama aumentando la sensibilidad.

Campo de visión: el campo de visión de los fotodiodos es muy amplio, lo cual introduce incertidumbre en la posición de la fuente de la luz que se detecta. Se ha añadido un tubo esbelto que limita angularmente la región cuya radiación alcanza al fotodiodo. Esta decisión aumenta la distancia del fotodiodo a la fuente de luz, pero es necesaria para reducir la incertidumbre.

Reflejos: los reflejos en las paredes del tubo pueden dar falsos positivos, sobre todo teniendo una amplificación tan alta de la señal.

Fotodiodo defectuoso: este tipo de errores se deben a una sensibilidad anormalmente baja del fotodiodo. Introduce valores de $\Delta t$ muy altos.

A continuación se explicarán con más detalle los errores que pueden aparecer debido a las causas antes expuestas empleando los esquemas de la figura 5.7. En estos esquemas se representa el primer fotodiodo de la línea y su posición relativa con respecto a la llama y al tubo. Se discute el error generado suponiendo que el fotodiodo siguiente de la línea detecta la llama de manera ideal.

Cuando la sensibilidad del primer fotodiodo no está bien ajustada, en este caso al máximo, se da el caso del esquema 5.7a. Estos errores de detección son muy habituales en las llamas de mezclas muy pobres con intensidad luminosa muy baja. Al llegar la punta de la llama a la zona de detección del fotodiodo, en un instante $t_{1}^{i d}$, su distancia a éste es 


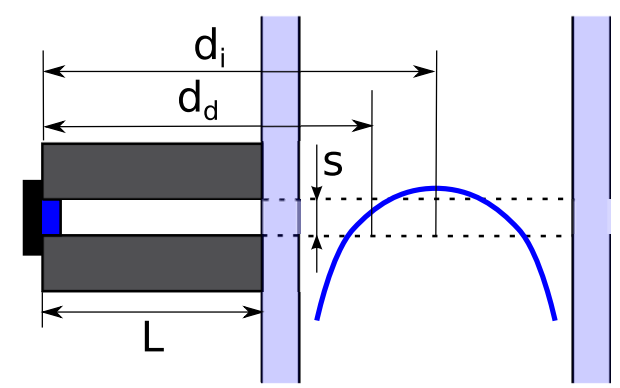

(a) Distancia de detección.

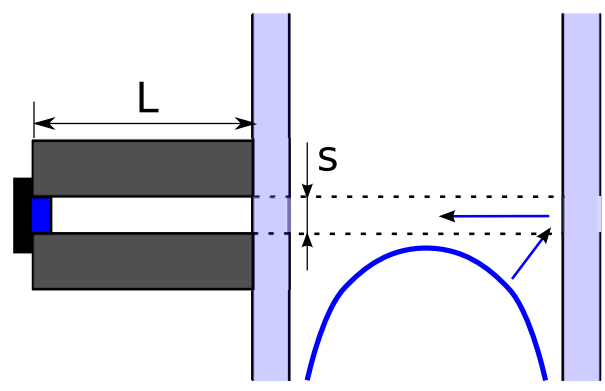

(b) Reflejos en la pared.

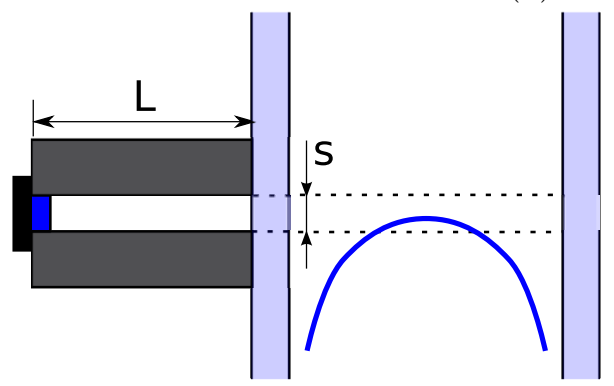

(c) Campo de visión.

Figura 5.7: Esquema de las posibles situaciones que pueden generar error en la detección de la posición exacta de la llama con respecto al fotodiodo. El fotodiodio está situado a una distancia $L$ de la pared del tubo para reducir su ángulo de visión.

$d_{i}$. Sin embargo, por falta de sensibilidad, la llama sigue subiendo sin ser detectada hasta un instante $t_{1}>t_{1}^{i d}$, cuando el frente de la llama está a una distancia $d_{d}$ del fotodiodo y el circuito genera el salto escalón. El tiempo de detección es mayor que el ideal porque la detección ocurre más tarde, $\left(t_{1}>t_{1}^{i d}\right)$. Admitiendo que el segundo fotodiodo funciona de manera ideal, el tiempo entre las dos señales será más pequeño que el real que tarda la llama en recorrer la distancia $d$ que separa los dos fotodiodos. El valor de $\Delta t_{1}$ más pequeño que el real hace que la velocidad medida sea mayor que la real. Este tipo de errores sobrevalora el valor de la velocidad.

En caso de que el error se deba a los reflejos, ocurre al contrario. La llama es detectada antes de llegar al campo de visión del fotodiodo; ver figura 5.7b. Es más probable que esto ocurra para llamas más ricas, cuya intensidad luminosa es suficiente para generar reflejos capaces de excitar al fotodiodo. El tiempo de detección en este caso es anterior al ideal, por lo que $t_{1}<t_{1}^{i d}$. Este tipo de errores infravaloran el valor de la velocidad medida.

Los errores causados por la distancia de detección y por los reflejos en la pared suelen ser errores detectables, ya que los valores de la velocidad medida en estos casos son anormalmente altos o bajos. No ocurre lo mismo para los errores debidos al campo de visión del fotodiodo. En este caso se desconoce la posición de la punta de la llama dentro del campo de visión del fotodiodo en el momento de la detección. La indeterminación de esta posición se puede reducir disminuyendo el radio del tubo añadido entre el fotodiodo y la pared, pero a costa de disminuir la señal recibida de la llama. El error introducido por esta incertidumbre se puede cuantificar. El valor máximo absoluto en este caso corresponde a la detección de la llama en el límite del campo de visión con respecto a una detección 


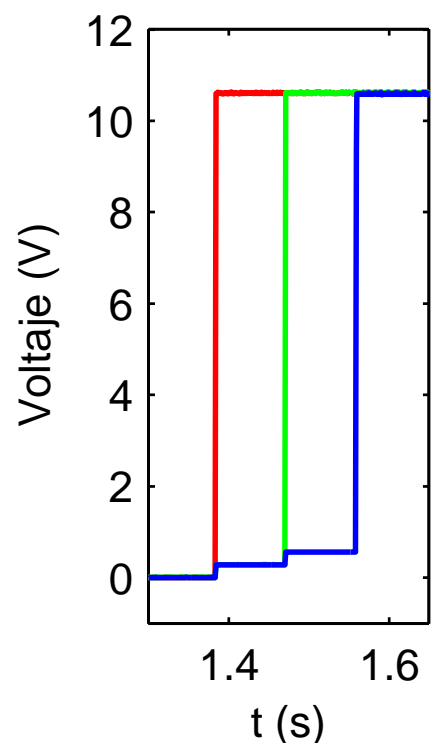

(a) Detección ideal

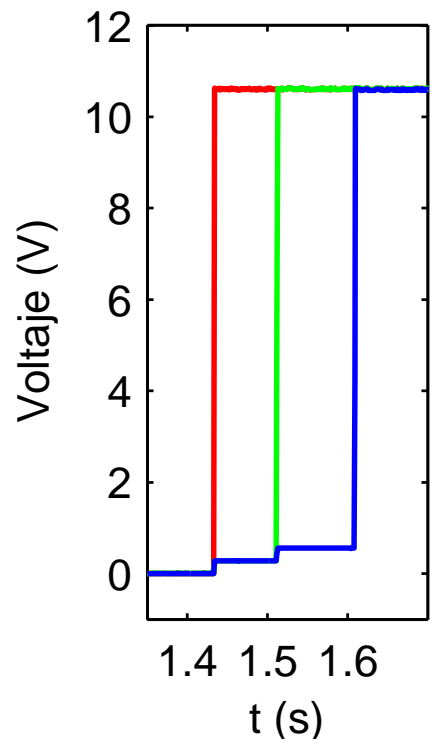

(b) Fotodiodo II adelantado

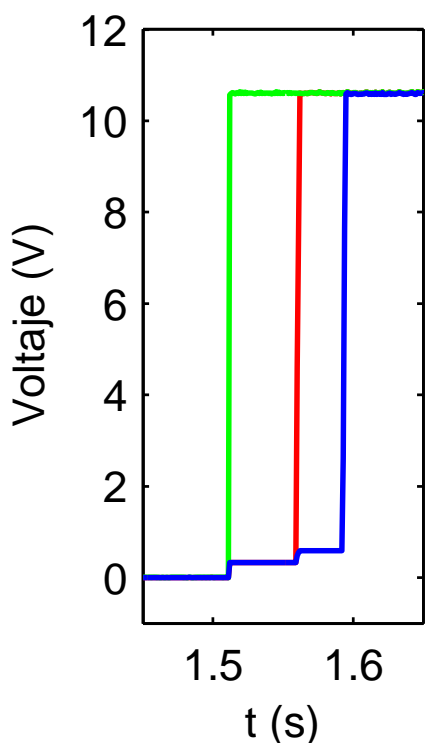

(c) Fotodiodo I defectuoso

Figura 5.8: Casos de señales registradas con los fotodiodos.

perfecta:

$$
E_{a}=\frac{d+s / 2}{\Delta t}-\frac{d-s / 2}{\Delta t}=\frac{s}{\Delta t} .
$$

Empleando la ecuación (5.1) se obtiene el error relativo

$$
e_{r}=\frac{s / \Delta t}{d / \Delta t}=\frac{s}{d} .
$$

Los primeros intentos de medir la velocidad se han hecho añadiendo a los fotodiodos tubos de $2 \mathrm{~mm}$ de diámetro, pero esto reduce demasiado la luz que llega al sensor. Al aumentar el valor de $s$ a $3 \mathrm{~mm}$ se empezó a medir de forma consistente. El error en este caso es de $\pm 7.5 \%$, un valor alto, pero que es muy conservador, ya que la llama se suele detectar con mayor probabilidad en el centro del campo de visión del fotodiodo que en sus extremos.

En algunos de los experimentos realizados se han registrado señales como las representadas en la figura 5.8c. Este tipo de situaciones ocurren cuando un fotodiodo resulta defectuoso de fábrica o se ha estropeado durante su uso. El primer fotodiodo necesita mucha más señal para detectar la llama, por lo que la detecta tarde, incluso después de que la llama haya sido detectada por el segundo fotodiodo de la línea, resultando que $\Delta t_{1}<0$. Aunque estos errores son fácilmente detectables por dar lugar a velocidades negativas, se reducen a la mitad los datos de los experimentos realizados en esta situación.

En la figura 5.9 se han recopilado las velocidades medidas en distintos experimentos empleando los fotodiodos. Los resultados que se muestran no son los datos en bruto, sino que se han filtrado los valores de velocidad demasiado grandes y los correspondientes a experimentos realizados de forma incorrecta. Una de las razones para descartar los 
datos de algunos experimentos ha sido no haber esperado un tiempo suficiente entre dos experimentos consecutivos. Cuando el tiempo de espera es bajo, normalmente inferior 5 minutos, se ha observado que la velocidad de la llama aumenta con cada experimento. En estos casos el valor de la velocidad superaba el límite máximo esperado de $7.5 \%$ de error relativo con respecto al valor medio de la velocidad, por lo que se descartó que estos valores anómalos se debieran al sistema de medida.

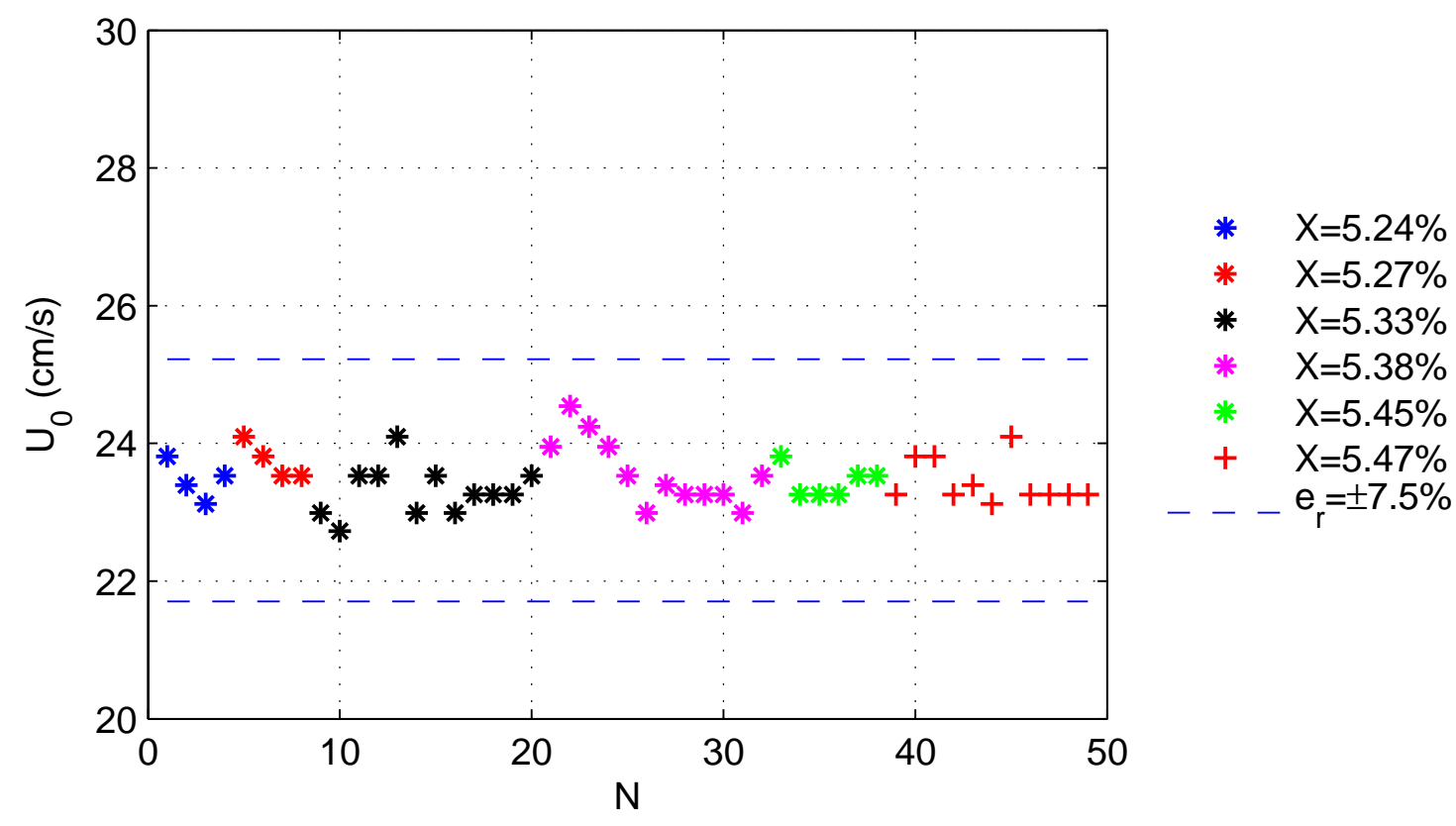

Figura 5.9: Representación gráfica de las velocidades de ascenso de la llama afectadas por la temperatura de las paredes. Los distintos símbolos de la figura corresponden a distintas fracciones volumétrica de metano en la mezcla ensayada. $\mathrm{N}$ es el número de orden del experimento después de ordenar los experimentos considerados válidos según valores crecientes de la fracción volumétrica de metano.

En la figura 5.9 se presentan las velocidades medidas en función de la fracción volumétrica de metano en la mezcla. Se muestra el valor de cada experimento por separado para que se pueda observar mejor cómo el valor medio de la velocidad no varía de forma apreciable con la riqueza de la mezcla para riquezas cercanas al límite de inflamabilidad. En estos experimentos el valor $X=5.24 \%$ corresponde al valor mínimo de la concentración de metano para que se han obtenido mezclas inflamables. En términos de relación de equivalencia se tendría $\phi=0.525$. Aunque se aprecia cierta variación en las velocidades medidas, éstas no guardan relación con la riqueza, por lo que los datos obtenidos refuerzan la afirmación de que la velocidad vertical de la llama dentro del tubo es independiente de la riqueza de la mezcla.

Si se agrupan los datos para cada riqueza, figura 5.10a, se puede observar la dispersión de los resultados. En la figura $5.10 \mathrm{~b}$ se presentan los valores medios de la velocidad para cada riqueza y las barras de error representan la desviación típica de los resultados para cada caso, valores que se recogen en la tabla 5.1. Se ha tenido en cuenta que el error mínimo de la medida es de $1 \%$ por lo que el valor de la velocidad media, $\bar{U}_{0}$, tiene sólo 3 


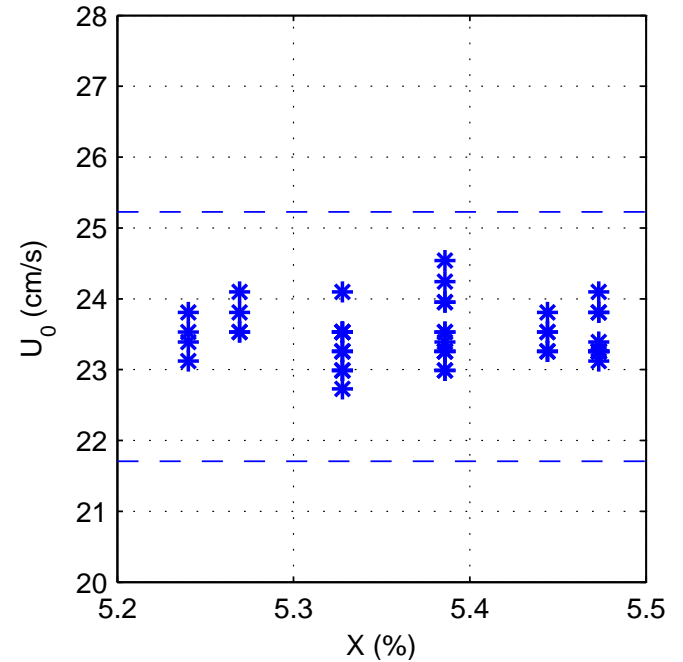

(a)

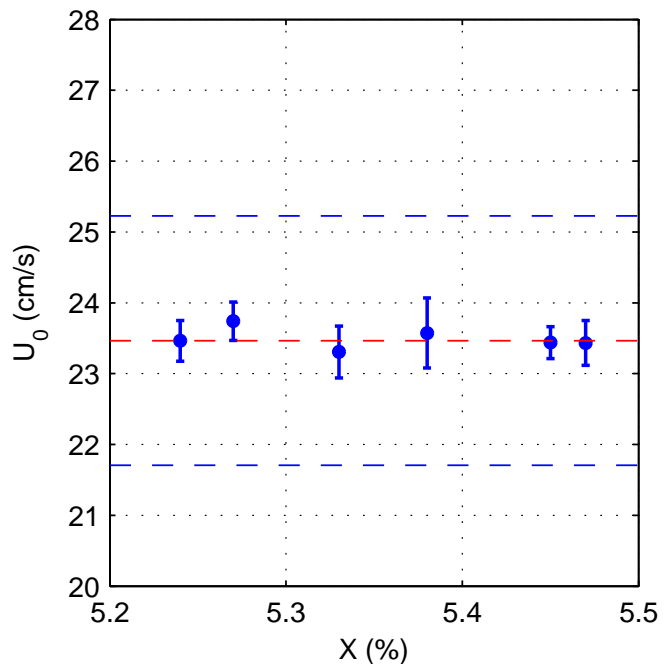

(b)

Figura 5.10: Valores de la velocidad de ascenso de la llama medida para cada riqueza mediante fotodiodos (a) y sus valores medios y desviaciones típicas para cada caso.

cifras significativas. La desviación típica calculada sólo afecta a la última cifra significativa de la velocidad. En términos de error relativo la desviación típica obtenida, $\sigma$, está entre el doble y cuádruple del mínimo valor de error esperado para este sistema, pero es mucho menor que el límite máximo estimado de $\pm 7.5 \%$ que, como ya se ha mencionado, era un valor del error muy conservativo.

Tabla 5.1: Valores medios de la velocidad y desviaciones típicas para las medidas con fotodiodos.

\begin{tabular}{|c|c|c|c|c|c|c|}
\hline$X(\%)$ & 5.24 & 5.27 & 5.33 & 5.38 & 5.45 & 5.47 \\
\hline $\bar{U}_{0}(\mathrm{~cm} / \mathrm{s})$ & 23.5 & 23.7 & 23.3 & 23.6 & 23.4 & 23.4 \\
\hline$\sigma(\mathrm{cm} / \mathrm{s})$ & \pm 0.3 & \pm 0.3 & \pm 0.4 & \pm 0.5 & \pm 0.2 & \pm 0.3 \\
\hline$e_{r}(\%)$ & \pm 1.2 & \pm 1.1 & \pm 1.6 & \pm 2.1 & \pm 1.0 & \pm 1.4 \\
\hline
\end{tabular}

En las figuras 5.9 y 5.10 se han representado también los límites de error máximo estimado, $\pm 7.5 \%$ del valor medio de todas las velocidades. Los datos se encuentran dentro de este intervalo. Aunque en la figura 5.10a se aprecia bastante dispersión de los datos, este hecho se puede deber tanto al sistema de medida como a la aleatoriedad de los experimentos. Para poder discernir el origen de estas variaciones se ha medido la velocidad de la llama empleando fotografías del movimientos de la llama, tal y como se ha explicado en la sección 4.1.2.

\subsubsection{Errores en la medición de la velocidad empleando imágenes fo- tográficas}

En la sección anterior se han presentado los resultados obtenidos al medir la velocidad vertical de la llama empleando una línea de fotodiodos. La desviación de las mediciones es 
superior al mínimo error estimado, pero mucho menor que el error máximo posible para este sistema de medición. El análisis de estos resultados muestra dos posibles escenarios:

1. Las variaciones de la velocidad de la llama para una riqueza dada son reales y se deben a variaciones de las condiciones de realización cada experimento. En este caso habría que intentar reducir las variaciones en las condiciones entre experimentos consecutivos, buscar las causas que influyen en la velocidad de la llama y, algo muy importante a la hora de analizar los datos, tener presente que la velocidad media calculada no es válida para el estudio de una llama en concreto, sino que el análisis debe basarse en la velocidad medida en ese caso.

2. Las variaciones de la velocidad de la llama para una riqueza dada no son reales y aparecen debido al sistema de medida empleado y sus errores asociados. En este caso la velocidad de la llama debe ser la misma para cada riqueza, pero los errores aleatorios en la medición muestran variaciones inexistentes. Habría que analizar si la precisión de esta forma de medir es suficiente para considerar fiables las mediciones.

Para poder conocer a qué caso de los dos presentados más arriba corresponden los datos obtenidos, se ha procedido a medir la velocidad de la llama mediante otro método que usa imágenes fotográficas de la evolución de la llama. Si se consigue grabar el movimiento de la llama conociendo el tiempo que media entre imágenes consecutivas, y se puede medir la distancia recorrida por la llama en ese tiempo, entonces se podrá calcular la velocidad media de la llama en ese intervalo. En la figura 5.2 se muestra la evolución estacionaria de la llama en varias fotografía consecutivas. El objetivo es poder medir el valor de la pendiente de la recta que une la punta de la llama en las diferentes imágenes. El empleo de un método de medición de la velocidad alternativo al de la línea de fotodiodos abre las siguientes posibilidades. Se pueden:

1. Obtener las mismas velocidades que usando la línea de fotodiodos y con un error de medida parecido. En este caso se confirmarían los datos obtenidos, aunque no se podría afirmar cuál es el origen de la dispersión de las velocidades.

2. Obtener las mismas velocidades que usando la línea de fotodiodos, pero con un error de medida más pequeño. En este caso se confirmarían los datos obtenidos y, además, se podría constatar que hay parámetros en el desarrollo del experimento que afectan a la velocidad de la llama.

3. Obtener velocidades distintas que usando la línea de fotodiodos. En este caso sería necesario recurrir a un tercer método de medición para descartar uno de los dos métodos empleados.

Es necesario estimar el error del nuevo sistema de medida para saber si se dan las condiciones 1 o 2 , ya que el 3 ha sido descartado en las primeras pruebas al obtener velocidades parecidas a las obtenidas con la línea de fotodiodos.

Sa ha usado una cámara réflex Nikon D300, que permite tomar imágenes a 5 o 6 FPS. Se ha ajustado la sensibilidad del sensor de la cámara al máximo para poder usar un tiempo de exposición reducido. Para que las llamas con baja luminosidad se vieran con suficiente claridad en las imágenes, después de varias pruebas se ha ajustado el tiempo 
de exposición a $5 \mathrm{~ms}$, un compromiso entre capturar suficiente intensidad de la imagen y evitar un frente de llama demasiado difuminado, a causa de su movimiento. Las imágenes se han tomado a la máxima resolución que permite la cámara, 12 megapíxeles. El campo de visión de la cámara se ha ajustado para poder obtener 5 imágenes útiles de la llama, intentando que la punta de la llama no estuviera demasiado cerca de los márgenes de las fotos. Este ajuste corresponde a unos $30 \mathrm{~cm}$ de longitud del tubo, y la escala resulta ser de unos $70 \mu \mathrm{m} / \mathrm{px}$ o $14 \mathrm{px} / \mathrm{mm}$. Estos valores no son fijos para todos los experimentos, ya que en algunos casos se puede disminuir el número de imágenes reduciendo el campo de visión de la cámara, para aumentar la resolución. Cada batería de experimentos tiene su propia escala por lo que cada vez que se calcula la velocidad hay que usar la escala correspondiente a ese experimento.

En la figura 5.11 se ha dibujado un esquema del posible error en la detección de la llama, que es necesario para poder estimar los errores en las medidas de la velocidad. Se ha observado que en las fotos se aprecia un espesor de la llama, e. Este espesor es la suma del espesor real de la zona luminosa de la llama más un espesor virtual generado por el desplazamiento de la llama durante el tiempo de la exposición de la foto. En el caso de una detección perfecta de la distancia $d_{r}$ recorrida por el frente de llama en el tiempo $\Delta t$ que hay entre las dos imágenes, se tendría la velocidad real:

$$
U_{0}^{r}=\frac{d_{r}}{\Delta t} .
$$

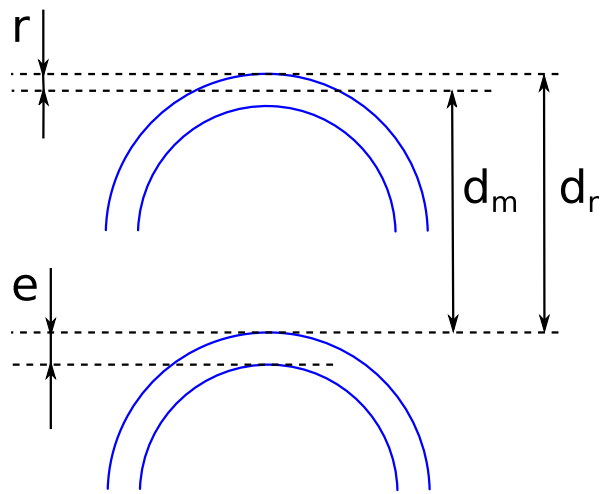

Figura 5.11: Esquema de la resolución en la detección.

En realidad existe una incertidumbre $r$ en la detección, y la distancia medida, $d_{m}$, será distinta de la real. La velocidad medida sería

$$
U_{0}^{m}=\frac{d_{m}}{\Delta t} .
$$

Los errores absoluto y relativo en este caso son

$$
\begin{aligned}
& E_{a}=U_{0}^{r}-U_{0}^{m}=\frac{r}{\Delta t}, \\
& \varepsilon_{r}= \pm \frac{E_{a}}{U_{0}^{m}}= \pm \frac{r}{d_{m}} .
\end{aligned}
$$


Para poder calcular el error relativo de las medidas es necesario estimar el valor de $r$. En el caso de emplear las imágenes de la cámara réflex, la detección del frente se realiza manualmente. Teniendo en cuenta que en las imágenes tomadas los niveles de intensidad que delimitan el espesor de la llama son muy pronunciados y fácilmente distinguibles a simple vista, el espesor se puede asimilar a una división en una escala de un medidor analógico. En este caso el error en la detección sería el mismo que el error de lectura de un medidor analógico que es igual a la mitad de la división:

$$
r=\frac{e}{2} .
$$

Se ha medido el espesor de las llamas en las fotos y normalmente es de unos 40 píxeles, dependiendo de la distancia de la cámara al tubo y del tiempo de exposición. La distancia recorrida en píxeles será igual al producto entre el tiempo transcurrido entre imágenes, la velocidad de la llama y la escala $s_{p}$ :

$$
\varepsilon_{r}= \pm \frac{e / 2}{\Delta t U_{0}^{m} s_{p}}= \pm \frac{40 / 2}{0.2 \cdot 235 \cdot 14}= \pm 3 \% .
$$

$\mathrm{Al}$ igual que para el caso de la línea de fotodiodos, este error es un límite máximo para la configuración expuesta. En realidad al realizar la detección del frente manualmente la incertidumbre será menor que la mitad del espesor y el error será inferior al $3 \%$. Cada experimento permite calcular entre 3 y 5 velocidades de la llama mientras ésta recorre los $30 \mathrm{~cm}$ del tubo que aparecen en las imágenes. Si se calcula la desviación típica de cada experimento se observa que su valor suele estar por debajo del $3 \%$, figura 5.12a. Además, si se dibuja el histograma de estos errores, figura $5.12 \mathrm{~b}$, se observa que la mayoría de los experimentos tienen un error inferior al $2 \%$.

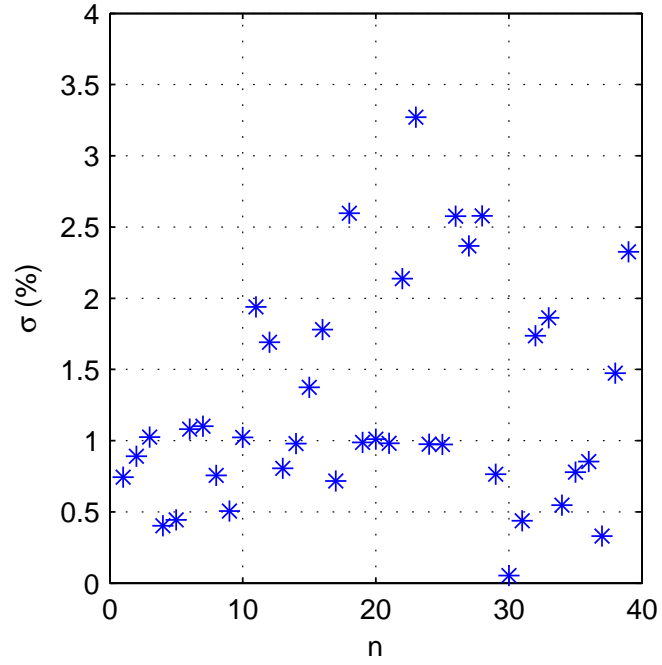

(a) Errores para reflex

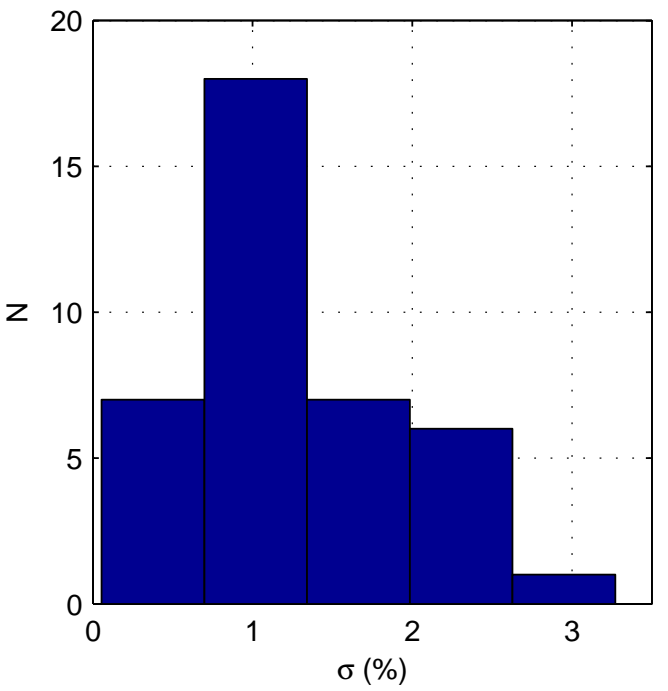

(b) Histograma de errores

Figura 5.12: Valores de la velocidad de subida de la llama medida para cada riqueza mediante fotografías. 
La medición de la velocidad vertical de la llama usando la cámara reflex tiene un error menor que empleando la línea de fotodiodos, pero la velocidad medida no es local, ni corresponde al momento exacto en el que se dispara el láser PIV, sino que es una media de la velocidad a lo largo de unos $5 \mathrm{~cm}$. En el caso de la línea de fotodiodos esta media corresponde a un recorrido de $2 \mathrm{~cm}$. La pequeña dispersión en las velocidades medidas apuntan a que la velocidad no varía a lo largo del tubo, al menos no lo hace mientras la llama se encuentra en el campo de visión de la cámara, pero convendría usar una cámara más rápida para confirmar esta aseveración. Otra razón de peso para usar una cámara rápida es poder capturar la extinción de la llama, que ocurre en menos tiempo que el que transcurre entre dos imágenes tomadas a 5 FPS. Por ejemplo, para la evolución de la llama durante la extinción presentada en las figuras 5.3 y 5.5 .

Por estas razones hemos recurrido a usar una cámara Basler Ace acA1920-155uc. La máxima velocidad a la que puede grabar esta cámara manteniendo la máxima resolución es de 150 FPS, aunque es difícil alcanzar este máximo por la limitación en el ancho de banda de la transmisión de las imágenes, que depende de la longitud del cable USB que une cámara y ordenador. Las grabaciones se han realizado a 60 y 100 FPS para evitar fallos en la conexión de la cámara, ya que el aumento de la velocidad de grabación provocaba un error que hacía que la cámara dejara de grabar, perdiendo los datos correspondientes a un experimento. Se ha aprovechado la resolución máxima de la cámara, de 5 megapíxeles, para ajustar el campo de visión de la cámara a $15 \mathrm{~cm}$ de longitud de tubo. La escala resultante ha sido de $60 \mu \mathrm{m} / \mathrm{px}$ o $16 \mathrm{px} / \mathrm{mm}$.

Para estimar el error en las medidas realizadas con la cámara USB se sigue el mismo razonamiento que para el caso de la cámara réflex, por lo que se puede proceder como en la ecuación (5.4). En este caso varía la escala y el valor de $\Delta t$, que se puede sustituir por

$$
\Delta t=\frac{1}{F P S} .
$$

El código programado en Matlab para detectar el frente de la llama (explicado en la sección 4.1.2) permite al usuario interrumpir la ejecución del programa y reajustar algunos parámetros en caso de que la posición detectada no coincida con el frente de la llama en la imagen. En este caso el valor de $r$ es el mismo que cuando la detección se hace manualmente y es $r=e / 2$, donde $e$ es el espesor de la llama. Normalmente en estas imágenes el valor de $e$ ha sido de unos 20 píxeles. Las imágenes se suavizan dentro del código aplicando un filtro que reemplaza cada píxel por la media de las intensidades de los píxeles que se sitúan en un disco de radio 9 píxeles. Esta configuración hace que el frente suavizado de la llama varíe su intensidad desde el mínimo hasta el máximo en unos 19 píxeles. La detección del frente se ha hecho de tal forma que el límite de detección se sitúa como máximo a unos 5 píxeles del valor máximo de intensidad. Si las imágenes son de buena calidad y sin fuentes externas de luz, esta condición se cumple en las mediciones y se puede estimar la incertidumbre en la detección del frente de llama $r$ en esos 5 píxeles. Por lo tanto el error relativo será

$$
\varepsilon_{r}= \pm \frac{r \cdot F P S}{s_{p} U_{0}^{m}}= \pm \frac{5 \cdot 30}{16 \cdot 235}= \pm 4 \%,
$$

algo mayor que usando la cámara réflex. 
En la ecuación (5.5) se puede ver que el error es directamente proporcional a la velocidad de grabación, en FPS. Esto se debe a que la distancia recorrida por la llama es más pequeña cuando mayor es la velocidad de grabación, mientras que la incertidumbre es siempre la misma. Una velocidad de 30 FPS permite limitar el error al $\pm 4 \%$. Realmente la llama se sigue grabando a 60 o 100 FPS, pero para el cálculo de velocidad se usa una de cada dos o de cada tres imágenes. Se puede comprobar esta influencia analizando los datos de un experimento en concreto, cuyas variaciones de velocidad dentro del campo de visión de la cámara se han representado en la figure 5.13. En esta figura se muestran tres casos: usando todas, usando la mitad y usando la tercera parte de las imágenes disponibles para el cálculo de la velocidad. Se observa que usar las imágenes correspondientes a grabar a 30 FPS permite limitar las variaciones de la velocidad por debajo del $\pm 4 \%$, tal y como se ha estimado anteriormente. Se podrían reducir algo más las variaciones usando 15 FPS, pero se perderían también la mitad de las velocidades medidas. Para el caso en el que se usan todas las imágenes, FPS $=60$, las variación duplica su valor hasta $\pm 8 \%$.

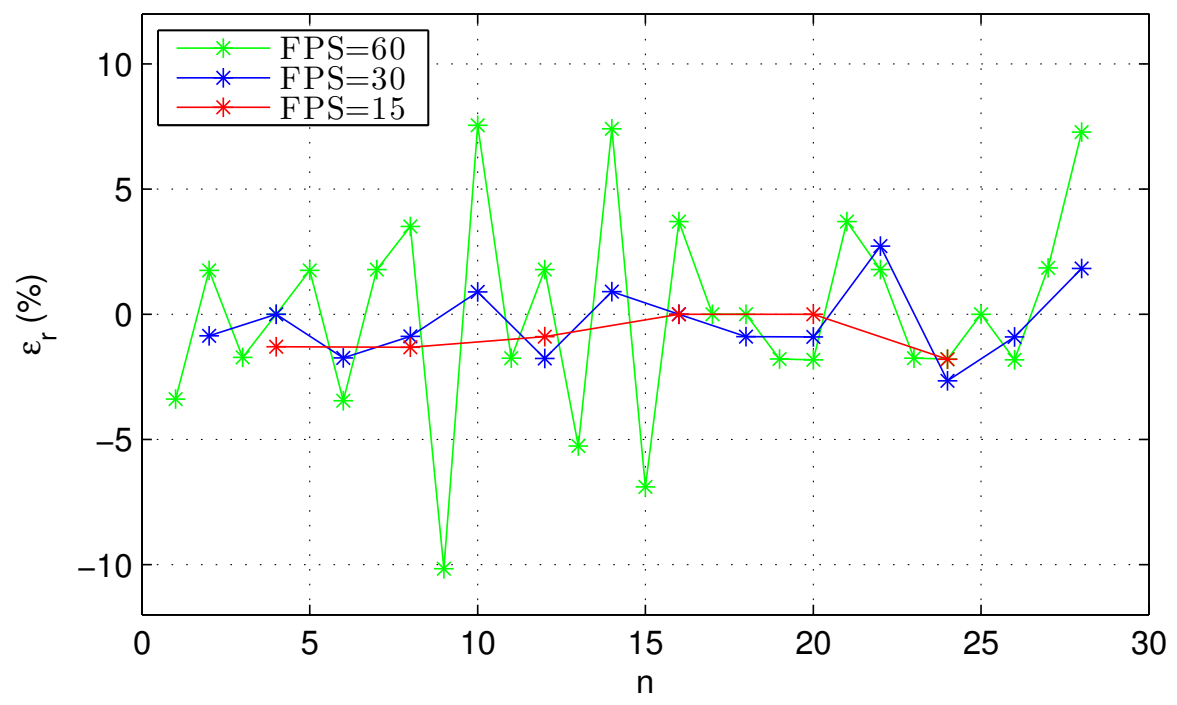

Figura 5.13: Influencia de FPS en el error.

Si se examinan los resultados de velocidad media y desviación típica de este experimento, tabla 5.2, se puede comprobar que la velocidad media no varía con el número de velocidades calculadas. Este comportamiento es una constatación más de que la velocidad de la llama es constante en la sección media del tubo, y por lo tanto su propagación se puede considerar estacionaria. También se puede ver que la desviación típica de la velocidad no se puede reducir indefinidamente; en este caso llega a un límite del $\pm 1.7 \%$, muy cercano al $\pm 1.8 \%$ correspondiente a 30 FPS.

En la figura 5.14a se muestran las desviaciones típicas de las velocidades de todos los experimentos en los que se ha usado la cámara USB para medir la velocidad. Se puede observar que gran parte de los experimentos tienen la desviación típica de su velocidad por debajo del $\pm 4 \%$. Los últimos experimentos tienen la peculiaridad de que en ellos se han grabado las llamas mientras el láser infrarrojo del PIV estaba en funcionamiento. En estos casos hay una mayor dificultad para detectar el frente de la llama de forma 
Tabla 5.2: Influencia de las FPS en el error de la velocidad medida.

\begin{tabular}{|c|c|c|c|c|}
\hline FPS & $\mathrm{N}$ & $\bar{U}_{0}(\mathrm{~cm} / \mathrm{s})$ & $\sigma(\mathrm{cm} / \mathrm{s})$ & $\sigma(\%)$ \\
\hline 60 & 30 & 23.26 & \pm 0.73 & \pm 3.1 \\
\hline 30 & 15 & 23.26 & \pm 0.41 & \pm 1.8 \\
\hline 15 & 7 & 23.28 & \pm 0.4 & \pm 1.7 \\
\hline 10 & 5 & 23.26 & \pm 0.41 & \pm 1.7 \\
\hline
\end{tabular}

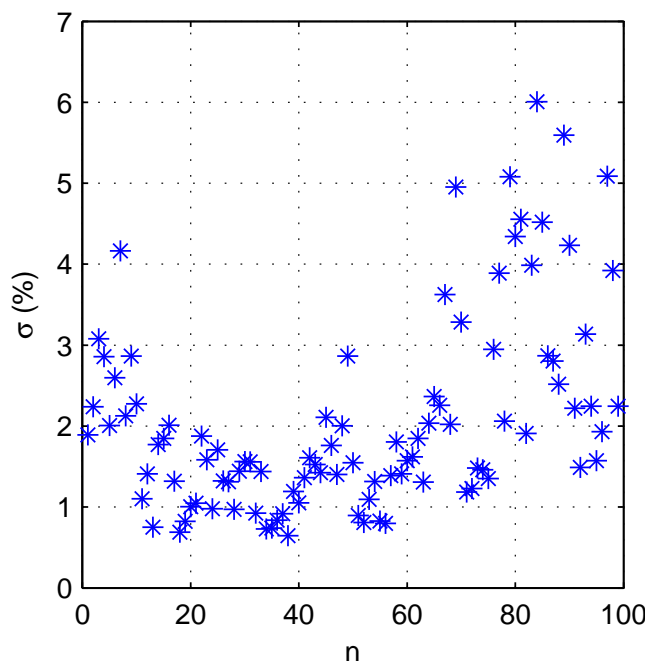

(a) Errores para reflex

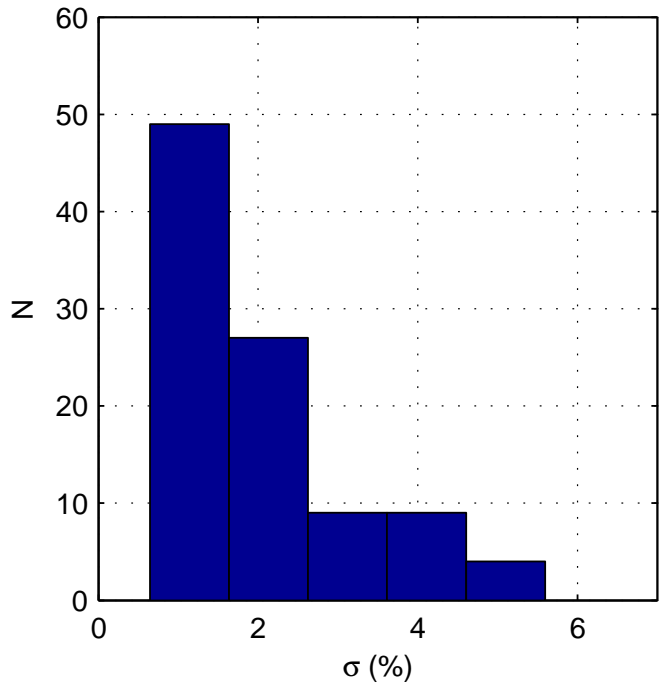

(b) Histograma de errores

Figura 5.14: Errores en la velocidad para mediciones con USB.

automática, por lo que se ha recurrido en los peores casos a la detección de la llama de forma manual. Mientras el ruido y fuentes de luz externa afectan mucho a la detección mediante algoritmos, el ojo humano filtra de una manera muy intuitiva la información. Por contra, en estos casos aumenta el valor de $r$ hasta $e / 2$, que es de unos 10 píxeles. El máximo error en estos casos es del $\pm 8 \%$. Aún teniendo en cuenta estos datos, en el histograma de las desviaciones típicas de la figura 5.14b se comprueba que la mayoría de las medidas tienen la desviación típica inferior al $\pm 2 \%$.

\subsubsection{Velocidad de la llama en función de la riqueza}

En la figura 5.15 se presentan todas las velocidades medidas con los tres métodos empleados. Se puede observar que la dispersión de los resultados no es demasiado grande, aunque aumenta para las riquezas más bajas. Las llamas para estas riquezas son más inestables y por esos sus resultados presentan mayor dispersión. Además, al estudiar el comportamiento de las llamas con riquezas próximas al límite de inflamabilidad, se ha conseguido mayor cantidad de datos para las riquezas más bajas.

Para analizar cómo se comporta la llama al variar ligeramente la riqueza de la mezcla, se han realizado experimentos con una resolución mínima de $\phi$ de 0.002. Para analizar la dependencia del comportamiento de la llama con la riqueza es necesario que la separación 


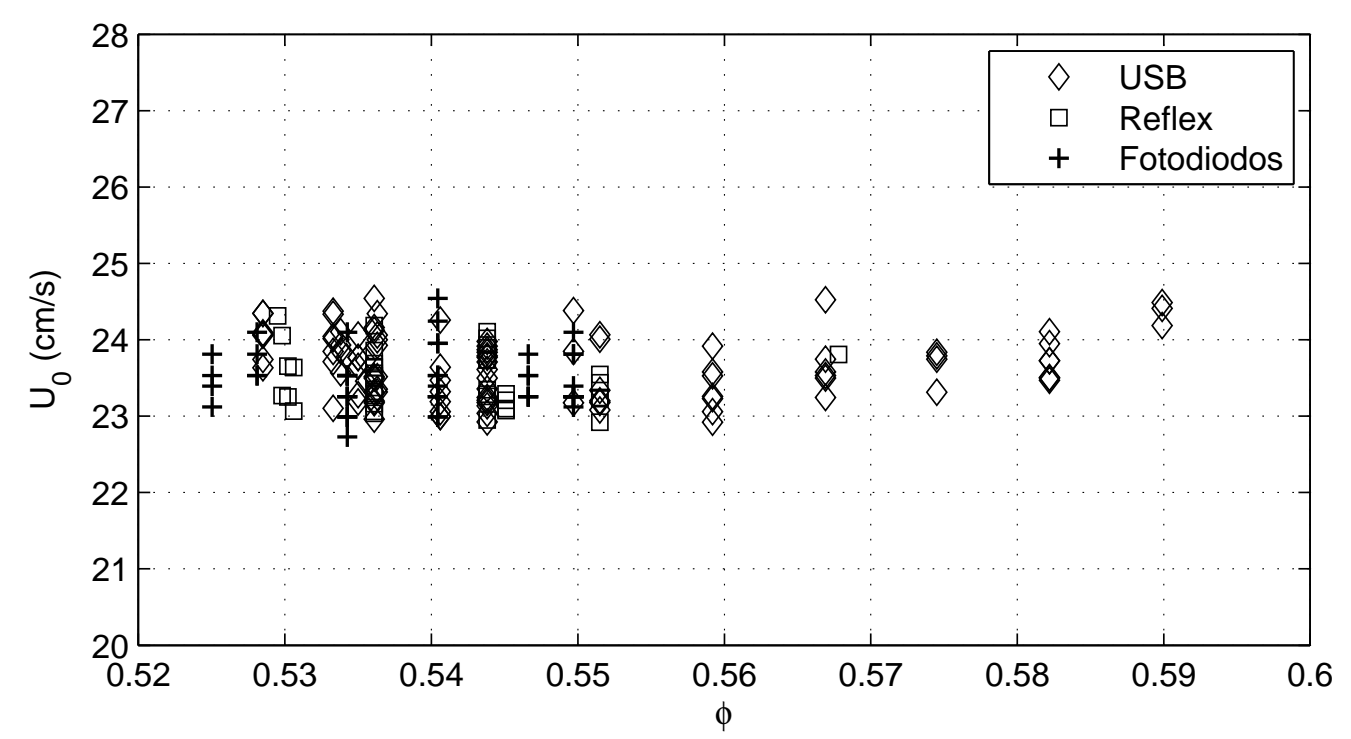

Figura 5.15: Velocidades medidas representadas en función de la riqueza de la mezcla.

entre los distintos valores de $\phi$ sea mayor que la incertidumbre de su medida. En la sección 3.2.2 se ha visto que el valor de la incertidumbre en la determinación del valor de $\phi$ es de aproximadamente \pm 0.004 . A la vista de esta incertidumbre se considera que para representar el valor de la riqueza es adecuado emplear sólo 2 cifras significativas, especialmente, teniendo en cuenta que lo que se estudia es cómo varía el comportamiento de la llama con la riqueza, y no cuál es la riqueza exacta a la que se obtiene un comportamiento dado, como la extinción. En la figura 5.16 se agrupan las velocidades para cada valor de la riqueza con dos cifras significativas. Se presentan las medias para cada $\phi$ acompañadas de las desviaciones típicas representadas con una barra vertical. La barra horizontal muestra la incertidumbre en el valor de la riqueza.

Como se puede observar en la figura 5.16, la velocidad vertical de la llama es prácticamente constante para riquezas cercanas al límite inferior de inflamabilidad. En este caso el límite se considera que es $\phi=0.53$, aunque lleva asociada una incertidumbre de \pm 0.004 . En el rango entre $\phi=0.53$ y 0.58 las variaciones de la velocidad están dentro de los errores experimentales, por lo que se puede considerar válida la hipótesis de que la velocidad no varía con la riqueza. Además el valor de la velocidad medida es muy parecido a la velocidad de ascenso de una burbuja de aire dentro de un tubo lleno de líquido. Esta observación ha sido remarcada en la mayoría de los estudios experimentales sobre la extinción de llamas con propagación ascendente en tubos verticales [20,31, 50-52, 61]. La velocidad de una burbuja de gas ascendiendo dentro de un tubo lleno de líquido, también llamada burbuja de Taylor, sólo depende de la gravedad y del radio del tubo. Davies y Taylor [7] propusieron emplear para el cálculo de la velocidad de siguiente fórmula:

$$
U_{D T}=0.464 \sqrt{g R},
$$

donde $g$ es la aceleración de la gravedad y $R$ es el radio del tubo que contiene el líquido. Para el tubo usado en nuestros experimentos, $R=27 \mathrm{~mm}$, la velocidad de subida de la 
burbuja es

$$
U_{D T}=23.88 \mathrm{~cm} / \mathrm{s}
$$

Otros investigadores que han estudiado el movimiento de burbujas de aire en líquidos han obtenido fórmulas cuyos resultados se parecen más a los resultados de experimentos realizados en tubos de 3 a $8 \mathrm{~cm}$ de diámetro:

$$
\begin{aligned}
\text { Dumitrescu [11] : } & 0.496 \sqrt{g R}=25.5 \mathrm{~cm} / \mathrm{s} \\
\text { Collins [5] : } & 0.486 \sqrt{g R}=25 \mathrm{~cm} / \mathrm{s}
\end{aligned}
$$

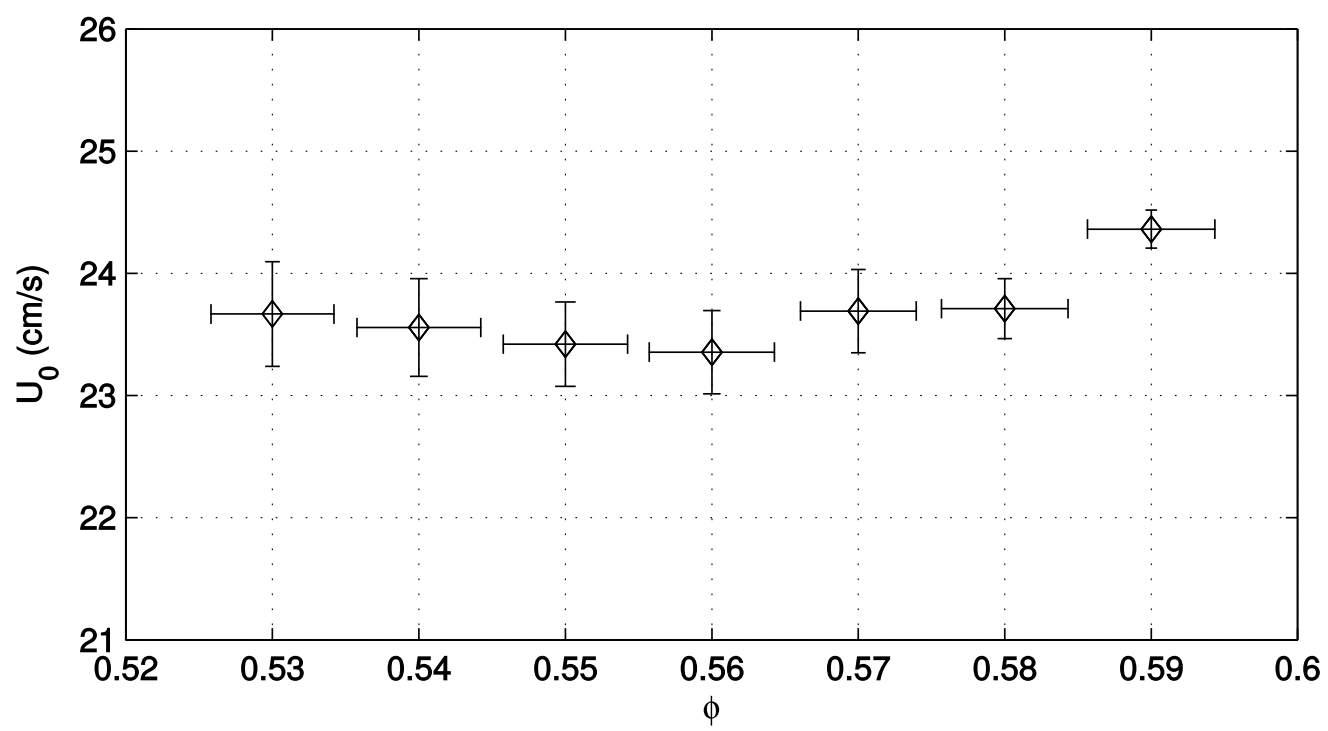

Figura 5.16: Velocidades medias y errores de medida de la velocidad y de la riqueza.

La velocidad que más se ajusta a los resultados experimentales obtenidos para la llama es la que se calcula con la fórmula propuesta en [7]. Como se puede ver en la figura 5.17, ésta sobrevalora la velocidad de subida de la llama. Pero hay que tener en cuenta que para obtener la ecuación (5.6) se ha supuesto $\rho_{l} / \rho_{a} \ll 1$, donde $\rho_{l}$ es la densidad del líquido y $\rho_{a}$ es la densidad del aire. Para mejorar el cálculo de la velocidad cuando las dos densidades son comparables, se puede emplear la corrección propuesta por Bychkov y Liberman [4]:

$$
U_{D T}\left(T_{b}\right)=0.464 \sqrt{\left(1-\frac{T_{u}}{T_{b}}\right) g R},
$$

donde $T_{u}$ es la temperatura del gas fuera de la burbuja y $T_{b}$ es la temperatura del gas dentro de la burbuja. En este caso la velocidad corresponde a una burbuja de aire caliente que asciende dentro de un tubo lleno de aire frío, sin intercambiado de calor ni masa a través la frontera de la burbuja.

Se han considerado los valores de $T_{b}$ correspondientes a los productos de combustión de una mezcla de aire con metano con los valores de $\phi$ del experimento. Se ha supuesto que se quema todo el combustible y que los productos finales están en equilibrio y no hay pérdidas de calor. El cálculo del estado de equilibrio se ha realizado usando el programa 


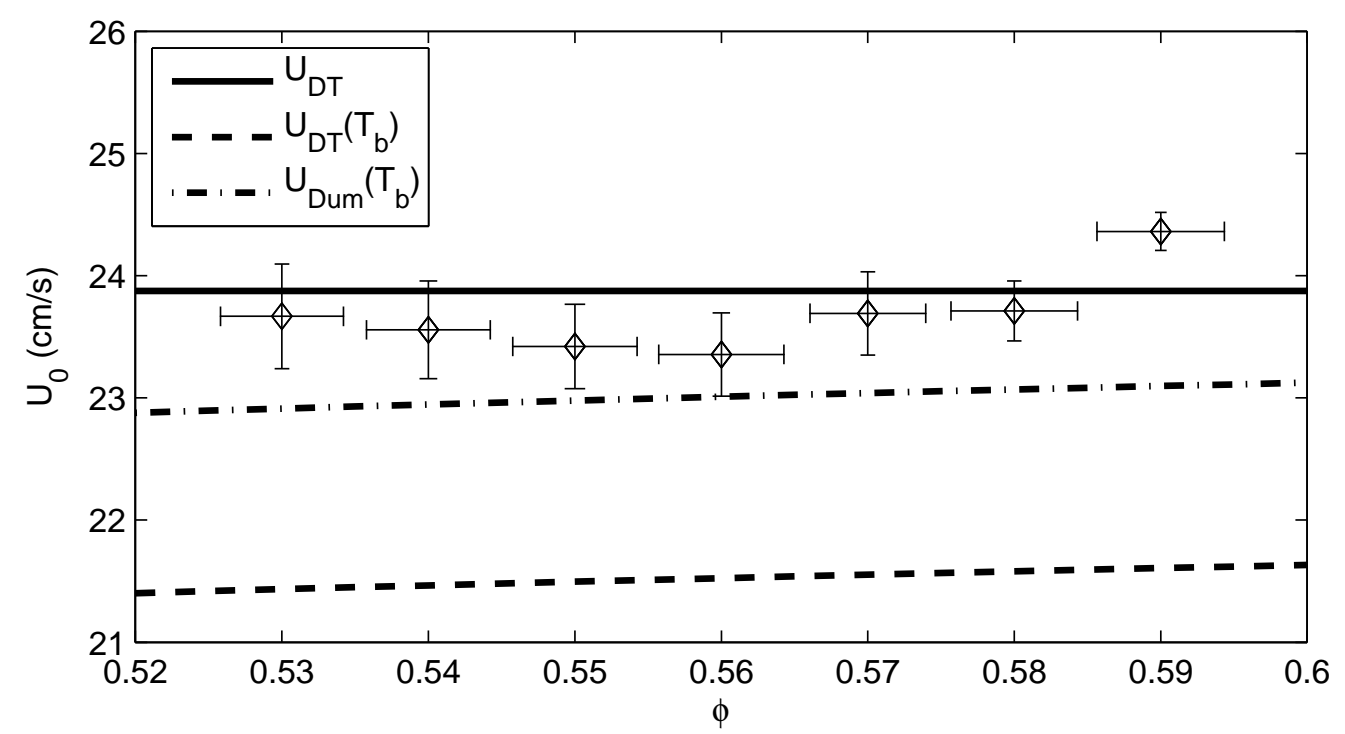

Figura 5.17: Semejanza de la velocidad de ascenso de la llama con los casos de burbujas de aire en líquido y de aire caliente en aire frío. La curva continua corresponde a la ecuación (5.6) y la curva de trazos a la misma ecuación añadiendo el factor $1-T_{u} / T_{b}$ dentro de la raíz. La curva de línead y puntos muestra los valores obtenidos usando la ecuación (5.8).

CEA (Chemical Equilibrium with Applications) [39]. Al usar la corrección por la expansión térmica finita propuesta por Bychkov y Liberman [4], añadiendo el término $\sqrt{1-T_{u} / T_{b}}$ a las ecuaciones (5.6) y (5.7), la fórmula que más se acerca a los resultados experimentales es la obtenida por Dumitrescu [11]:

$$
U_{\text {Dum }}\left(T_{b}\right)=0.496 \sqrt{\left(1-\frac{T_{u}}{T_{b}}\right) g R} .
$$

No se pretende usar estas fórmulas para describir el movimiento de la llama, ya que, a diferencia de las burbujas, la frontera de la llama es permeable y la masa que la atraviesa varía con la riqueza. Sin embargo, la semejanza entre la velocidad de las llamas y las burbujas pone de manifiesto que el mecanismo que genera su movimiento es en ambos casos la fuerza de flotabilidad.

\subsection{Campo de velocidades}

El movimiento del gas fresco encima de la llama provoca cambios en la presión de orden

$$
\Delta p_{u} \sim \rho_{u} U_{0}^{2},
$$

donde $\rho_{u}$ es la densidad del gas y $U_{0}$ es la velocidad de ascenso de la llama (ver figura $5.16)$.

Las variaciones de presión detrás de la llama se pueden estimar como $\Delta p_{b} \sim \rho_{b} u_{c}^{2}$, donde $u_{c}$ es la velocidad característica del gas detrás de la llama, en sistema de referencia que asciende con ella. Se pueden dar dos situaciones: 
1. Que $u_{c}$ sea del orden de $U_{0}$, en cuyo caso

$$
\frac{\Delta p_{b}}{\Delta p_{u}} \sim \frac{\rho_{b} U_{0}^{2}}{\rho_{u} U_{0}^{2}} \ll 1,
$$

ya que la expansión térmica impone la relación de densidades $\rho_{b} / \rho_{u} \ll 1$.

2. Que $u_{c}$ sea del orden $u_{f}\left(\rho_{u} / \rho_{b}\right)$, en cuyo caso

$$
\frac{\Delta p_{b}}{\Delta p_{u}} \sim \frac{\rho_{u}}{\rho_{b}}\left(\frac{u_{f}}{U_{0}}\right)^{2} .
$$

Para mezclas muy pobres, se tiene $u_{f} / U_{0} \sim 1 / 5$ (ver figura 2.11), por lo que en este caso también se cumple

$$
\frac{\Delta p_{b}}{\Delta p_{u}} \ll 1 .
$$

La condición $\Delta p_{b} \ll \Delta p_{u}$, junto con la condición de que la velocidad de avance de la llama respecto al gas fresco es pequeña frente a $U_{0}$, implican que el flujo del gas fresco delante de la llama es similar al de un fluido delante de una burbuja ocupada por otro fluido de densidad mucho menor. La pequeña diferencia entre los dos flujos se debe al gasto másico a través de la llama, que en el caso de una burbuja es nulo.

Los resultados experimentales obtenidos con PIV apoyan esta conclusión. De igual modo, son similares a los resultados publicados por otros autores [52, 53], y también a los resultados numéricos obtenidos con el modelo bidimensional de la llama (ver capítulo 2). En un sistema de referencia ligado a la llama, el campo de velocidades en el tubo se puede separar en cuatro regiones, (ver figura 5.18):

1. La región lejos aguas arriba del frente de llama, a distancias mayores que el radio del tubo, donde no llega la perturbación debida a la presencia de la llama. En esta región la velocidad es uniforme y constante, con el valor $U_{0}$ medido en la sección anterior.

2. Una región delante de la llama con tamaño del orden del radio del tubo. En esta región el gas se frena a causa de la limitación de gasto másico a través de la llama.

3. La zona de la llama, donde el gas sufre una importante aceleración a causa de la expansión térmica. El tamaño de esta zona es comparable al espesor de la zona de transporte de la llama, $\delta_{f}$.

4. La región detrás de la llama, donde la configuración del flujo es muy dependiente de la riqueza de la mezcla.

Las dos primeras regiones son similares a las correspondientes regiones delante de una burbuja. Como se puede ver en la figura 5.18, se puede considerar que la primera región comienza en $x \approx-2 \mathrm{~cm}$ y se extiende hasta el extremo superior del tubo, que en el sistema de referencia ligado a la llama se mueve hacia la llama con velocidad $U_{0}$. Todo el gas que se encuentra en esta región se mueve con la misma velocidad, $U_{0}$, que puede ser distinta para cada caso, pero cuyo valor está en el rango $23-24 \mathrm{~cm} / \mathrm{s}$ (ver figura 5.16). 


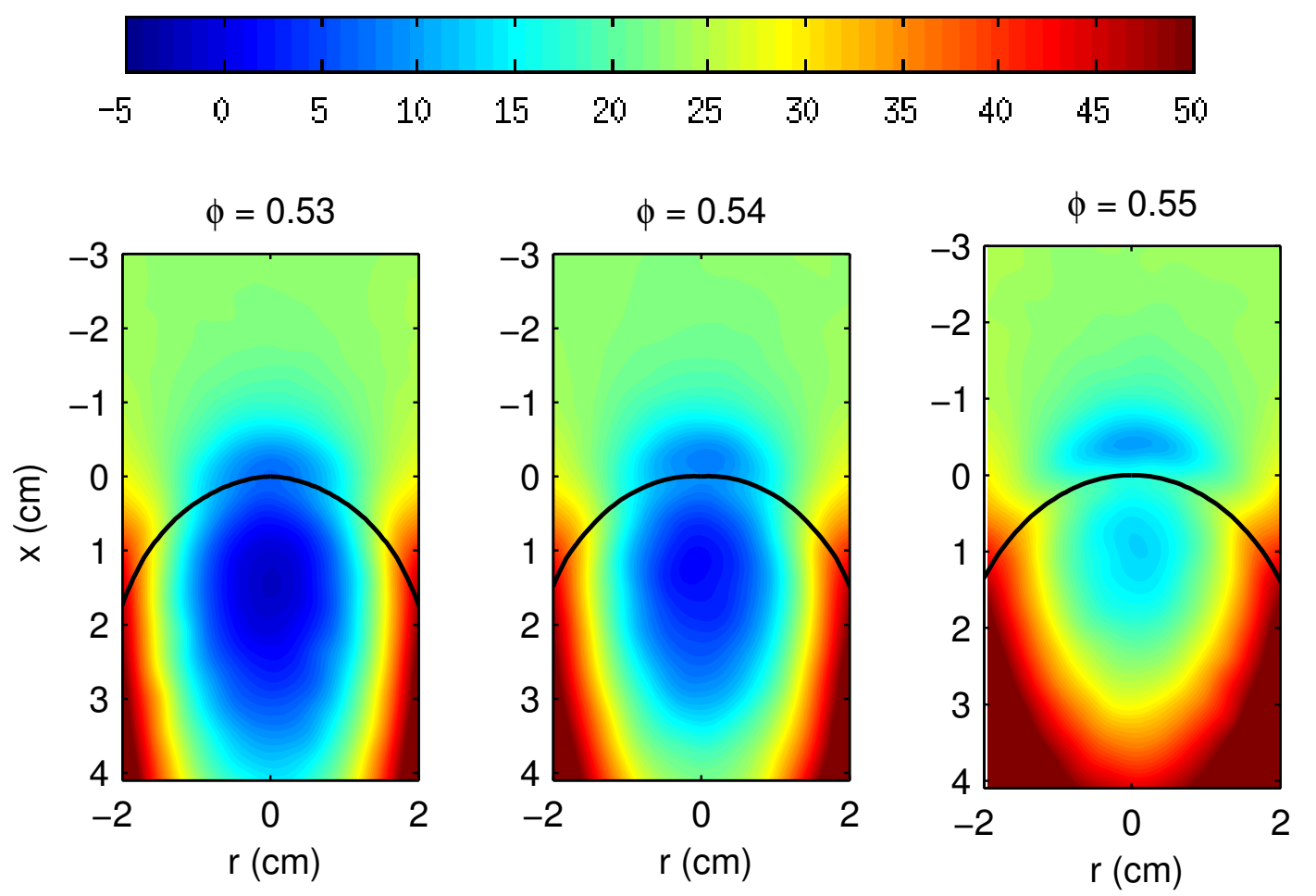

Figura 5.18: Mapa de los valores de la velocidad vertical del gas alrededor de la llama representada por la línea negra. La escala de color está en $\mathrm{cm} / \mathrm{s}$.

A una distancia de la llama del orden del radio del tubo, $x \approx-2 \mathrm{~cm}$, los vectores de velocidad medida comienzan a mostrar una componente radial no nula, mientras que la componente vertical comienza a disminuir de valor (ver figura 5.19). A partir de $x \approx-1$ $\mathrm{cm}$ este efecto se aprecia en la separación creciente entre las líneas de corriente, sobre todo en la zona central del tubo (figura 5.19). Al llegar al frente de llama, representado por la línea negra en las figuras 5.18, 5.19, 5.21, 5.22 y 5.24 (que en realidad está situada cerca del final de la zona de expansión térmica), una parte del gas atraviesa el frente y aumenta el valor de la componente de la velocidad normal a la superficie de la llama, curvando las líneas de corriente hacia el eje del tubo. El gas que no se consume en la parte central de la llama es desviado hacia las paredes del tubo y se consume en la falda de la llama. La masa de mezcla que se consume por unidad de superficie de llama disminuye al disminuir la riqueza. Este fenómeno aumenta la cantidad de mezcla desviada hacia las paredes del tubo y provoca un aumento de la longitud de la falda de la llama (ver figura 5.20). Este comportamiento se puede observar en las fotografías de la figura 5.1.

La mezcla que viene desde el infinito con velocidad $U_{0}$ se quema completamente en la llama, si se desprecia la cantidad de mezcla que puede quedar sin quemar en la proximidad de la pared del tubo. Teniendo en cuenta la forma de la llama y que su longitud, $L_{f}$, se mide desde su punto superior hasta el punto más bajo de la falda, su superficie se puede aproximar por la de un cilindro de radio $R$ y longitud $L_{f}$. Suponiendo que la velocidad del gas fresco normal a la superficie de la llama es del orden de la velocidad de la llama 
plana, $U_{L}$, se tiene

$$
\rho U_{0} \pi R^{2} \sim \rho U_{L} 2 \pi R L_{f}
$$

Por lo tanto se puede estimar la longitud de la llama como

$$
\frac{L_{f}}{R} \sim \frac{U_{0}}{2 U_{L}} .
$$

La velocidad $U_{L}$ crece con la riqueza, mientras que, como se ha visto en la sección anterior, la velocidad $U_{0}$ es prácticamente constante para las riquezas cercanas al límite de inflamabilidad. De esta forma, la longitud de la falda debe disminuir al aumentar la riqueza. En la figura 5.20 se ha dibujado el valor de $U_{0} / U_{L}$, usando una aproximación lineal para los valores de $U_{L}$ (ver figura 2.11) en el intervalo $\phi=0.5-0.6$. Como se puede ver, se cumple la estimación cualitativa (5.10).
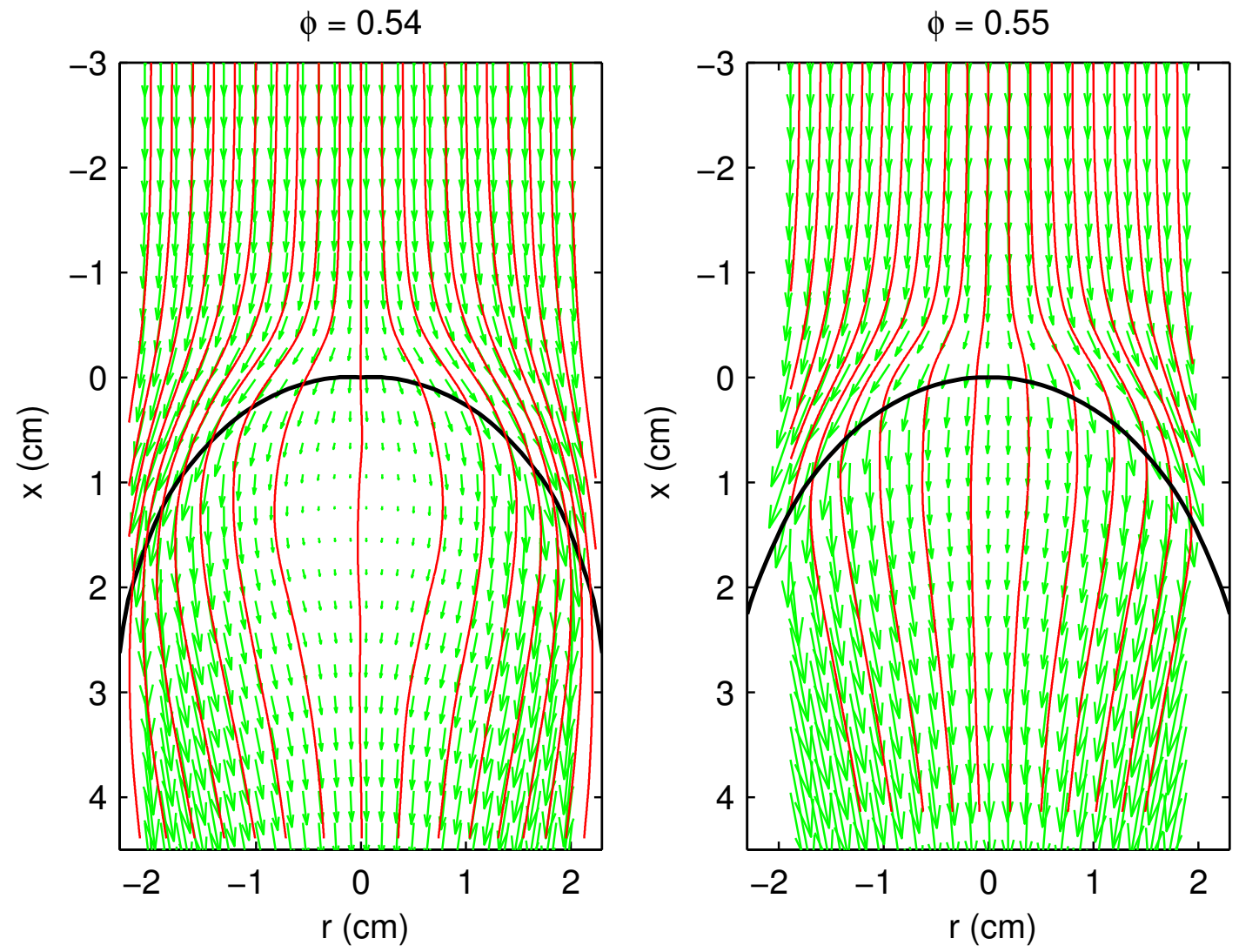

Figura 5.19: Vectores de velocidad (flechas verdes) y líneas de corriente (líneas rojas) del gas en su movimiento estacionario alrededor de la llama. La línea negra representa el frente de llama.

Mientras que la configuración del flujo delante de la llama es poco dependiente de la riqueza, siempre con valores cercanos al límite inferior de inflamabilidad, los cambios del flujo detrás de la llama son muy pronunciados. Debido a la fuerza de flotabilidad, el gas que se acelera a través de la llama a causa de la expansión térmica se decelera detrás de 


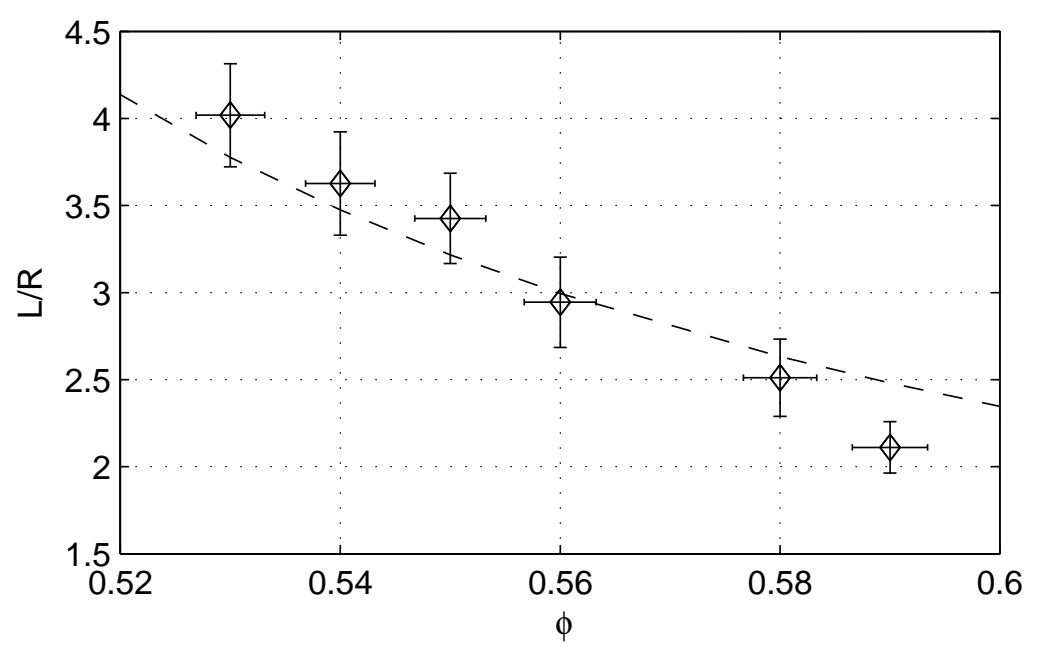

Figura 5.20: Dependencia de la longitud de la llama con la riqueza de la mezcla. La longitud se mide en el eje del tubo desde el punto más alto del frente hasta el punto más bajo de la llama. La línea de trazos es la relación $U_{0} / U_{L}$ empleando una aproximación lineal en el intervalo $\phi=0.5-0.6$ para $U_{L}$ (figura 2.11) y la velocidad vertical se toma constante: $U_{0}=23 \mathrm{~cm} / \mathrm{s}$.

la misma. La consecuencia de este efecto es la aparición de una región de baja velocidad detrás de la llama. A medida que se disminuye la riqueza de la mezcla, el tamaño de esta zona aumenta, mientras que la velocidad mínima que alcanza el gas en esta región disminuye. Para riquezas altas, lejos del límites de inflamabilidad, la expansión térmica acelera los productos de la reacción con mucha intensidad, y la fuerza de flotabilidad no es capaz de decelerarlos en distancias del orden del radio del tubo. En la figura 5.21 se presenta el campo de velocidades alrededor de la llama y la velocidad del gas en el eje del tubo para $\phi=0.66$. La velocidad de ascenso de la llama en el tubo es en este caso $U_{0}=40$ $\mathrm{cm} / \mathrm{s}$, casi el doble que la medida para valores de $\phi$ entre 0.53 y 0.58 . Este hecho indica que el ascenso en la llama no está gobernado por la flotabilidad de los gases calientes, sino por la velocidad a la que la llama consume la mezcla. En estos casos tampoco se cumple la condición de que la forma de la llama y su velocidad de subida sean similares a las de una burbuja, ya que $U_{L} \approx 20 \mathrm{~cm} / \mathrm{s}$, y al emplear la ecuación (5.9) se tiene $\Delta p_{b} \sim \Delta p_{u}$.

La velocidad de la llama respecto al gas fresco disminuye cuando disminuye la riqueza, lo cual aumenta la importancia relativa de la flotabilidad. De esta forma la velocidad de los productos, que para $\phi=0.66$ es muy alta, disminuye. Cuando el efecto dominante en el movimiento vertical de la llama es la flotabilidad de los gases calientes, la velocidad de subida de la llama no varía apenas con la riqueza de la mezcla. Se ha observado que esto ocurre para riqueza inferiores a $\phi=0.58$ (ver figura 5.16). En estos casos el valor mínimo de la velocidad de los gases detrás de la llama, que se da en el eje del tubo, es inferior a la velocidad de subida $U_{0}$.

Cuando la riqueza se aproxima al límite inferior de inflamabilidad, $\phi=0.53-0.55$, se detecta claramente una región de baja velocidad detrás de la llama, con velocidades inferiores a $0.5 U_{0}$. En la figura 5.22 se presentan los vectores de velocidad del gas para riquezas $\phi=0.54$ y 0.55 . Para la riqueza más baja se aprecia que hay una zona detrás de 

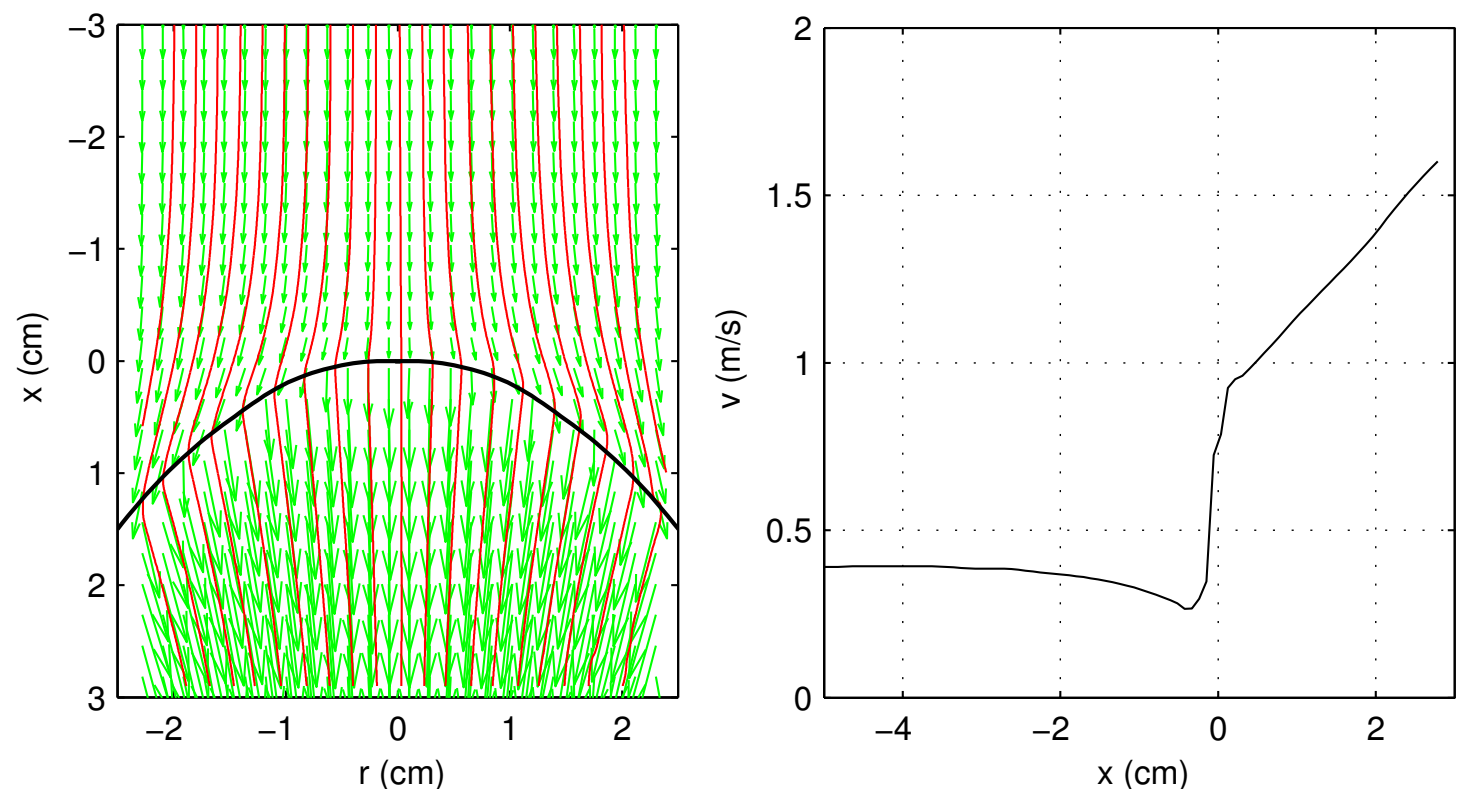

Figura 5.21: Campo de velocidades y líneas de corriente (izquierda), y perfil de velocidad en el eje del tubo (derecha) con $U_{0}=40 \mathrm{~cm} / \mathrm{s}$ para riqueza de la mezcla mucho más rica que el límite de inflamabilidad: $\phi=0.66$.

la llama donde los vectores de velocidad son claramente menores que los vectores que hay en los laterales y en la zona baja de la imagen. Aunque no se aprecia en la imagen, ocurre lo mismo para la riqueza más alta. En el campo de vectores para la riqueza $\phi=0.54$ se han marcado con un contorno rojo los puntos donde $|\boldsymbol{v}|=6 \mathrm{~cm} / \mathrm{s}$, y la velocidad es menor en los puntos del interior del contorno. Para $\phi=0.55$ no hay ningún punto detrás de la llama que cumpla la condición $|\boldsymbol{v}| \leq 0.6 \mathrm{~cm} / \mathrm{s}$.

La configuración del flujo detrás de la llama no es la misma en todos los experimentos, aunque la riqueza de la mezcla sea la misma. Estas variaciones se manifiestan sobre todo para $\phi=0.54$, donde la zona marcada en rojo en la figura 5.22 varía su tamaño. El comportamiento del flujo detrás de la llama para riquezas cercanas al límite de inflamabilidad es muy sensible a pequeñas variaciones de la riqueza y a otros muchos factores que es difícil controlar en el experimento. Tal como se ha explicado en el capítulo 3, las electroválvulas usadas para medir los gastos másicos de los gases empleados para preparar la mezcla no permiten medir con exactitud la riqueza con una resolución inferior a 0.01. Además, para un riqueza calculada dada, el valor de la riqueza real puede variar dentro del intervalo de incertidumbre, que se ha estimado como $\Delta \phi= \pm 0.004$. Este error intrínseco del montaje experimental puede ser la causa de las variaciones de la velocidad de los productos para una riqueza dada.

En nuestros resultados experimentales el valor mínimo de la riqueza para la que la mezcla se puede considerar inflamable es $\phi=0.53$. Para este valor, al igual que para $\phi=$ 0.54, la velocidad mínima medida detrás de la llama varía de un experimento a otro, aunque la riqueza medida no varíe. Cuando la riqueza se acerca al límite inferior de inflamabilidad, la velocidad mínima alcanzada detrás de la llama se hace muy pequeña. Normalmente su valor está entre 0.5 y $2 \mathrm{~cm} / \mathrm{s}$, aunque en algunos casos se hace negativa, formándose una 

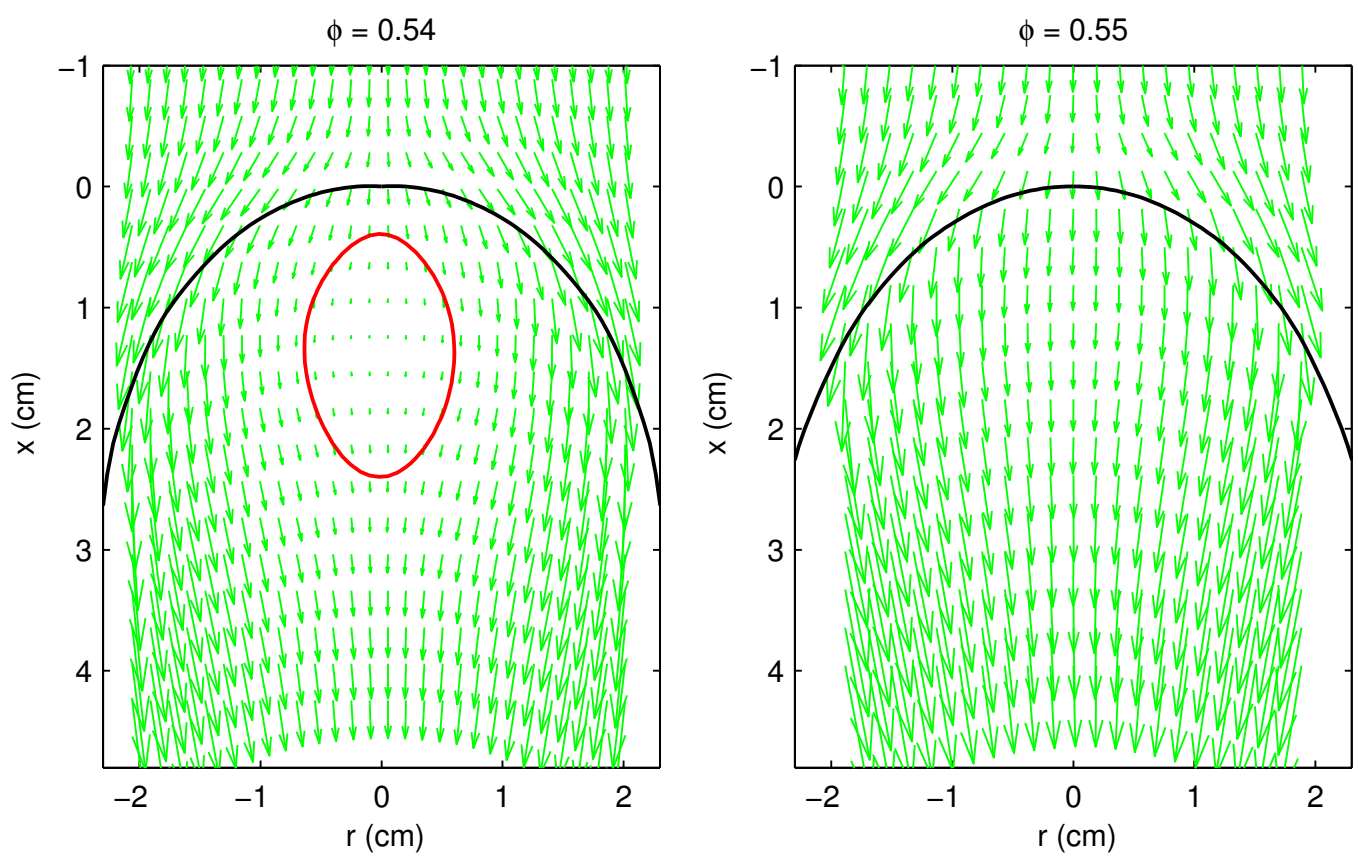

Figura 5.22: Vectores de la velocidad del gas para riquezas cercanas al límite inferior de inflamabilidad. El círculo rojo marca la zona para la que la velocidad del gas cumple la condición $|\boldsymbol{v}| \leq 6 \mathrm{~cm} / \mathrm{s}$.

zona de recirculación detrás de la llama. En la figura 5.23 se presentan varios perfiles de velocidad en el eje del tubo para las riquezas $\phi=0.53,0.54$ y 0.55 . Mientras que el perfil de velocidad para $\phi=0.55$ se diferencia claramente por su velocidad mínima elevada detrás de la llama, las velocidades mínimas para las riquezas $\phi=0.53$ y 0.54 son menores y muy similares. También se representa en la imagen la velocidad obtenida por Shoshin et al. [53] para las mezclas cercanas al límite inferior de inflamabilidad. Como se puede apreciar, este perfil de velocidad es muy similar a los obtenidos en nuestros experimentos.

Para la riqueza $\phi=0.53$ se han medido campos de velocidad con velocidad mínima negativa detrás de la llama. En estos casos se genera una zona de recirculación de los gases detrás de la llama y la zona de baja velocidad, $|\boldsymbol{v}| \leq 6 \mathrm{~cm} / \mathrm{s}$, es mayor que la de la figura 5.22 , y se acerca al frente de la llama (ver figura 5.24).

\subsubsection{Extinción}

Una mezcla se considera inflamable si la llama es capaz de propagarse desde el extremo inferior del tubo de inflamabilidad estándar hasta su extremo superior [6]. Dependiendo de las condiciones experimentales, del tipo de encendido y de la incertidumbre en la medida de la riqueza, puede darse la extinción de una llama en principio inflamable. En los experimentos realizados, las llamas siempre se apagan para $\phi=0.52$, mientras que para $\phi=0.53$ se dan distintas situaciones:

- Extinción de la llama muy cerca de la zona de ignición. 


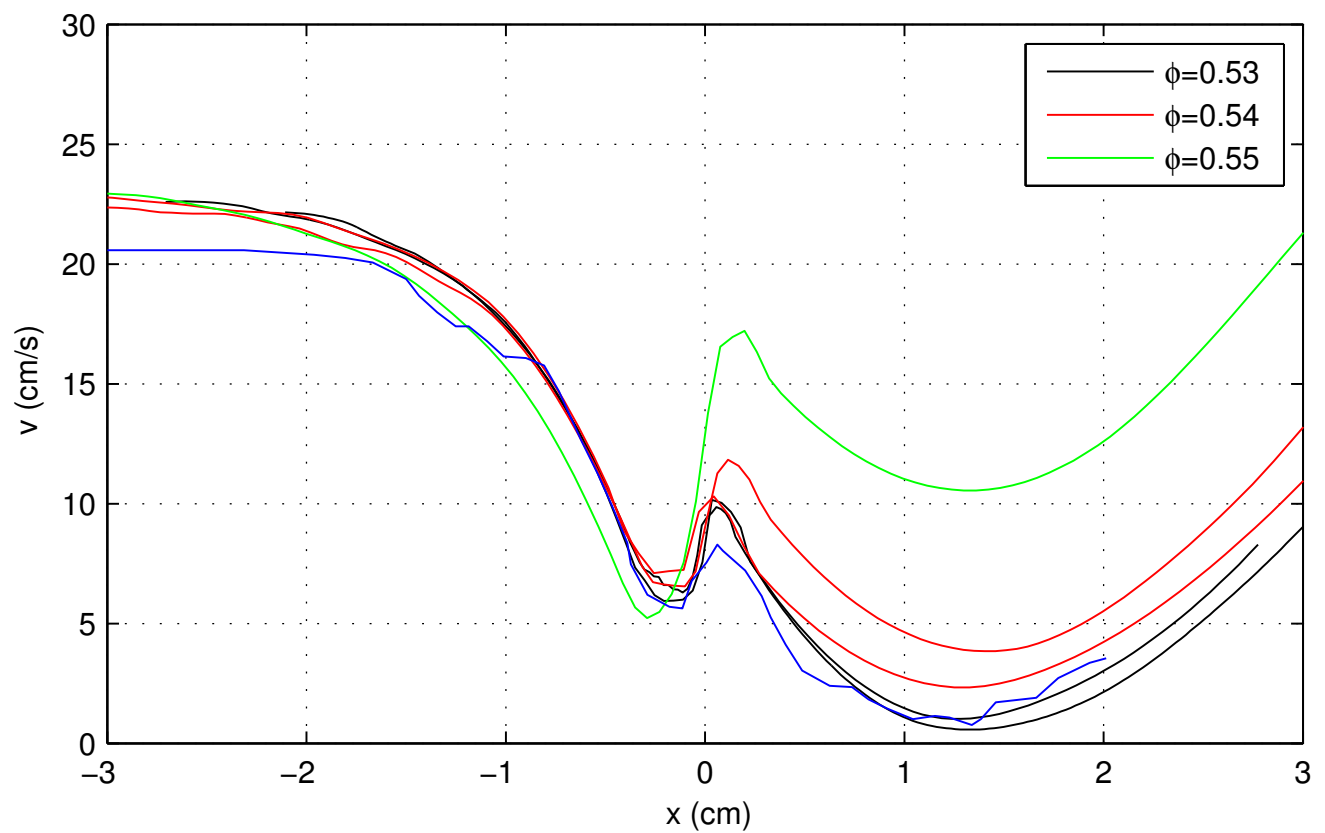

Figura 5.23: Perfiles de velocidad del gas en el eje del tubo para $\phi=0.53$ (negro), 0.54 (rojo) y 0.55 (verde). En azul se ha dibujado la velocidad obtenida por Shoshin et al. [53] en condiciones similares a nuestros experimentos.

- Extinción de la llama en la zona media del tubo, siempre a una distancia inferior a $140 \mathrm{~cm}$ de la fuente de ignición.

- Propagación de la llama hasta el extremo superior del tubo.

La extinción que ocurre cerca de la zona de ignición de la mezcla, explicada en el apartado 3.3, no se estudia porque en estos casos aún no se ha alcanzado el régimen estacionario de propagación. Cuando la extinción se da en la zona media del tubo, ésta ocurre en una posición indeterminada, mientras que la posición de la cámara del PIV es fija. Además, para conseguir una resolución espacial adecuada para medir la velocidad a través de la llama, la región que se graba es pequeña. Por ello es muy poco probable conseguir captar el momento de la extinción en las imágenes del PIV. Sí se han obtenido datos para llamas que se extinguen antes de pasar por la región de encuadre de la cámara o después.

En la figura 5.25 se muestran los perfiles de velocidad en el eje del tubo para distintos experimentos realizados con la misma riqueza: $\phi=0.53$. Los dos perfiles superiores corresponden a experimentos en los que la llama es visible con la cámara de fotos antes y después del disparo del láser. El perfil inferior corresponde a una llama que es visible $100 \mathrm{~ms}$ antes del disparo del láser, pero que se ha extinguido $100 \mathrm{~ms}$ después. Al analizar las imágenes de PIV se observa una zona sin partículas en la zona de expansión de los gases, un claro indicador de que la llama se ha apagado y no hay flujo másico a través de la frontera entre el gas frío y el gas caliente. Como se puede ver en la figura 5.25, el gas no sufre ninguna aceleración en la zona donde debería estar la llama. 

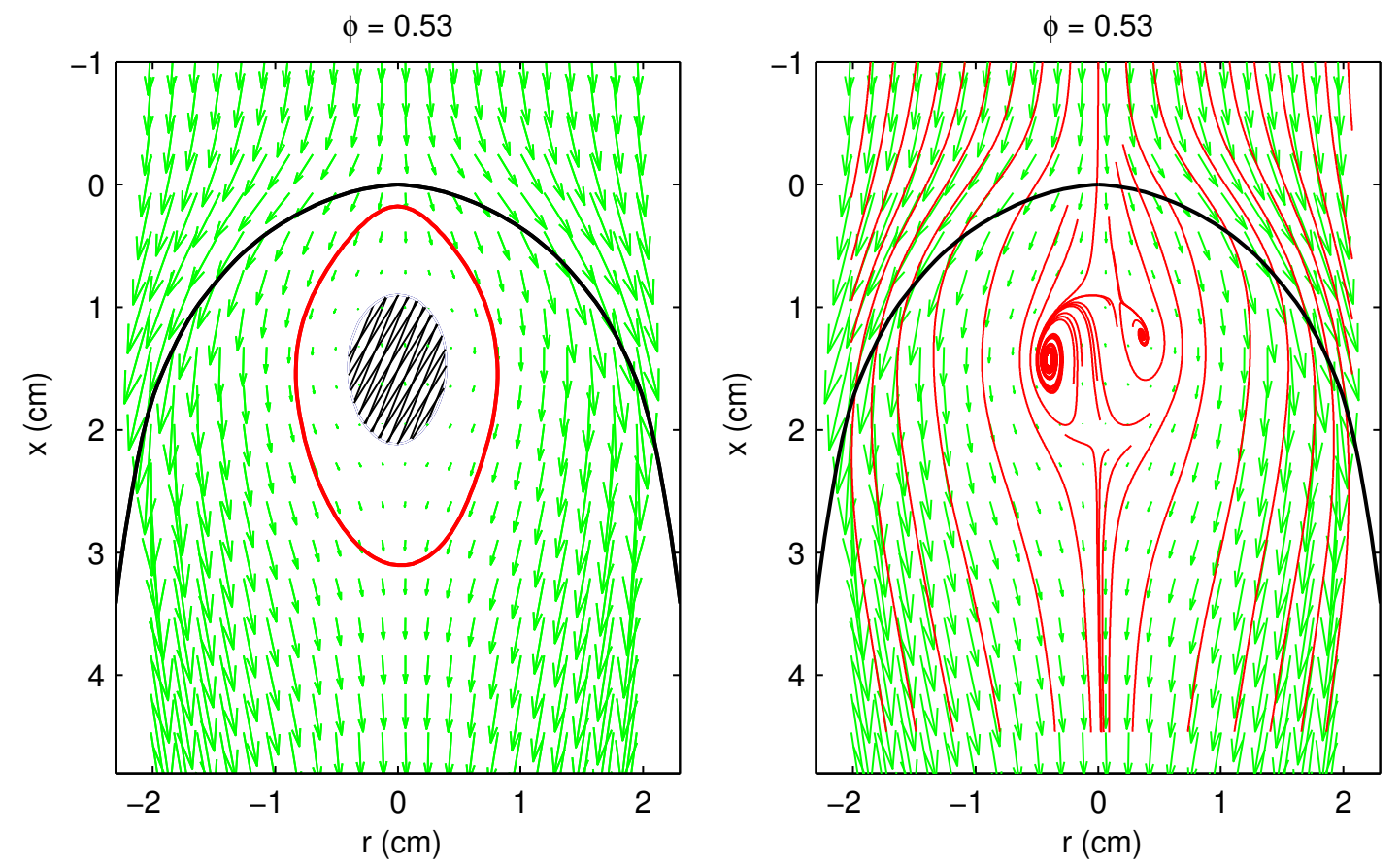

Figura 5.24: Vectores de velocidad y líneas de corriente para $\phi=0.53$ con presencia de recirculación. En la imagen de la izquierda se marca con el círculo rojo la zona donde $|\boldsymbol{v}| \leq 6 \mathrm{~cm} / \mathrm{s}$ y la zona rayada marca la zona de recirculación, donde $u \leq 0$.

Cuando una llama se extingue, la burbuja de gas caliente que se encuentra debajo del frente de llama sigue ascendiendo y recorre una distancia del orden de $4-5$ diámetros del tubo a la misma velocidad que antes de extinguirse la llama [31]. La extinción comienza en el punto más alto de la llama y se va propagando hacia los laterales. En este proceso, el gas que se quema en los laterales de la llama alimenta con productos calientes el interior de la burbuja.

\subsection{Pérdidas por radiación}

Los resultados numéricos del capítulo 2 para el esquema de una reacción global única ponen de manifiesto la importancia de las pérdidas de energía por radiación, debidas principalmente a los productos de la reacción $\mathrm{CO}_{2}$ y $\mathrm{H}_{2} \mathrm{O}$. Las temperaturas máximas calculadas aplicando el modelo unidimensional a los perfiles de velocidad medidos para las riquezas $\phi=0.53$ y 0.54 son $T_{b}=4.57 T_{u}$ y $4.86 T_{u}$, respectivamente. Estos valores difieren de la correspondiente temperatura adiabática de llama $\left(T_{e q}=5.12 T_{u}\right.$ y $\left.5.19 T_{u}\right)$ en cantidades del orden de la temperatura de Frank-Kamenetskii, $T_{e q}^{2} / T_{a}$, que es $0.42 T_{u}$ para $\phi=0.53$. Claramente la llama en este caso está próxima a la extinción; el valor $\phi=0.53$ es cercano al límite de inflamabilidad medido en nuestro experimento. Queda por aclarar si la extinción es causada por la escasez de radicales debida al predominio de las reacciones de recombinación cuando la temperatura baja como consecuencia de las pérdidas de calor o, por el contrario, este efecto de la cinética química real sólo entra en 


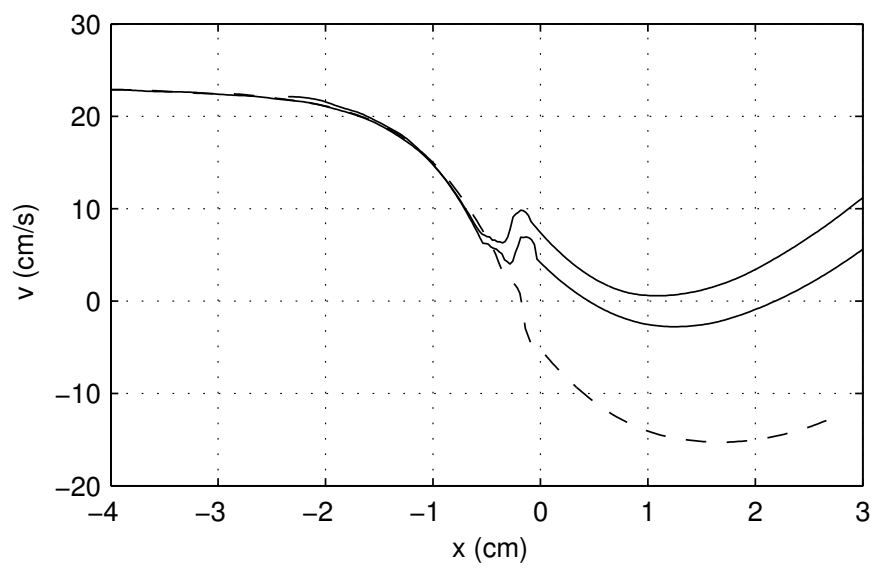

Figura 5.25: Perfiles de velocidad en el eje del tubo para $\phi=0.53$. El perfil a trazos corresponde a una llama apagada.

juego en las etapas finales de la extinción, cuando las pérdidas de calor ya han hecho a la llama térmicamente inviable.

Como se ha comentado antes, las pérdidas por radiación son insuficientes para provocar la extinción de una llama plana no sometida a alargamiento, porque las concentraciones de $\mathrm{CO}_{2}$ y $\mathrm{H}_{2} \mathrm{O}$ son muy pequeñas. Actuando sobre una llama plana, estas pérdidas disminuirían la temperatura final de combustión en una cantidad $\delta T=O\left[\lambda_{b} L_{b} /\left(\rho_{u} c_{p} u_{f}\right)^{2}\right]$, donde $\lambda_{b}$ y $L_{b}$ son la conductividad térmica del gas y el término de pérdidas, definido en el capítulo (2), evaluados en el gas quemado $\left(T=T_{b}, Y_{\mathrm{CO}_{2}}=(11 / 4) Y_{\mathrm{CH}_{4 u}}\right.$, $\left.Y_{\mathrm{H}_{2} \mathrm{O}}=(9 / 4) Y_{\mathrm{CH}_{4 u}}\right)$ y $u_{f}$ es la velocidad de la llama plana (Williams [64]). Con $u_{f}$ del orden de la velocidad de la llama adiabática y $T_{b} \approx T_{e q}$, resulta $\delta T /\left(T_{b}-T_{u}\right)=O\left(2.5 \times 10^{-2}\right)$, que es demasiado pequeño para extinguir la llama.

La intensificación del efecto de la radiación cerca del límite de inflamabilidad se debe a la aparición de una zona de baja velocidad detrás de la llama, encontrada por primera vez en los experimentos de Shoshin y Jarosinski [51] y Shoshin et al. [53]. La figura 5.26 muestra los términos de convección, conducción y radiación de la ecuación de la energía evaluados detrás de la llama con el modelo unidimensional y el esquema de una única reacción para $\phi=0.53$ y 0.55 . Como puede verse, el balance convección-radiación típico de una llama plana que se da para el valor mayor de $\phi$ pasa a ser un balance conducciónradiación cerca del límite de inflamabilidad, porque el efecto de la convección es pequeño en la zona de baja velocidad. En estas condiciones, la disminución de la temperatura final de combustión es

$$
\delta T=O\left(\frac{L_{b} \ell}{\rho_{u} c_{p} u_{f}}\right),
$$

donde $\ell$ es el tamaño característico de la zona de baja velocidad, del orden del radio del tubo. Este resultado se obtiene del balance de entalpía a través de la llama, $\rho_{u} c_{p} u_{f} \delta T=q_{b}$, donde $q_{b}$ es el flujo de calor que pasa por conducción desde la llama al gas quemado, que es de orden $L_{b} \ell$ cuando la conducción y la radiación son importantes en la zona de baja velocidad (de modo que $\boldsymbol{\nabla} \cdot \boldsymbol{q} \sim L$ ). La estimación (5.11) da valores de $\delta T$ del orden de 


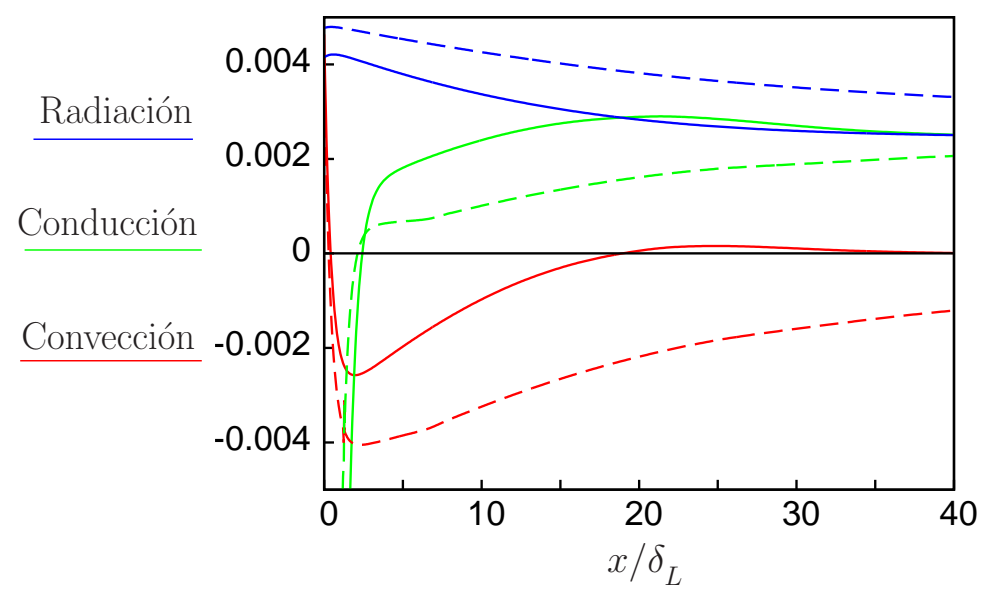

Figura 5.26: Términos de convección (rojo), conducción (verde) y radiación (azul) de la ecuación de la energía, escalados con $\rho_{u} U_{L} c_{p}\left(T_{e q}-T_{u}\right) / \delta_{L}$, como functiones de la distancia adimensional al punto de máxima temperatura para $\phi=0.53$ (curvas contínuas) y 0.55 (curvas de trazos).

la disminución de temperatura que la radiación causaría en una llama plana (mencionada en el párrafo anterior) multiplicada por $\ell / \delta_{f}$, donde $\delta_{f}=\lambda_{b} / \rho_{u} c_{p} u_{f}$ es el espesor de la llama. Este factor puede ser del orden de 20 o mayor, haciendo $\delta T$ en (5.11) del orden de la temperatura de Frank-Kamenetskii.

\subsubsection{Resultados experimentales}

\begin{tabular}{lccccccc}
\hline $\mathrm{N}_{2}: \mathrm{O}_{2}$ & 0 & 0.093 & 1.005 & 2.876 & 3.762 & 5.309 & 6.206 \\
$Y_{C H_{4} u}$ & 0.0313 & 0.0302 & 0.0299 & 0.0305 & 0.0302 & 0.0313 & 0.0314 \\
$\phi$ & 0.129 & 0.137 & 0.231 & 0.439 & 0.536 & 0.722 & 0.824 \\
\hline
\end{tabular}

Tabla 5.3: Fracción másica de metano y riqueza de la mezcla en el límite de inflamabilidad para varios valores de la relación de volúmenes $\mathrm{N}_{2}: \mathrm{O}_{2}$.

Se han realizado series de experimentos con diferentes diluciones, cambiando el valor de la relación $\mathrm{N}_{2}: \mathrm{O}_{2}$ entre el volumen de nitrógeno y el volumen de oxígeno por unidad de volumen de la mezcla fresca. Los resultados muestran que la fracción másica de metano en el límite de inflamabilidad, $Y_{C_{4 u}}$ recogida en la tabla 5.3, es aproximadamente constante, independiente del valor de $\mathrm{N}_{2}: \mathrm{O}_{2}$ y, por tanto, la riqueza de la mezcla en el límite de inflamabilidad aumenta al aumentar $\mathrm{N}_{2}: \mathrm{O}_{2}$. La consistencia de este resultado con la hipótesis de que la extinción en el límite de inflamabilidad se debe a las pérdidas por radiación se puede entender teniendo en cuenta que:

- Un balance global de entalpía muestra que la diferencia $T_{e q}-T_{u}$ entre la temperatura final de equilibrio y la temperatura de la mezcla fresca es proporcional a $Y_{\mathrm{CH}_{4 \mu}}$ e independiente de $\mathrm{N}_{2}: \mathrm{O}_{2}$ si se desprecian las pequeñas variaciones del calor específico 
debidas a la sustitución de oxígeno por nitrógeno y las pequeñas concentraciones de combustible y especies intermedias en el estado final de equilibrio.

- Las pérdidas por radiación son aproximadamente proporcionales a las fracciones másicas de las especies radiantes, principalmente $\mathrm{CO}_{2}$ y $\mathrm{H}_{2} \mathrm{O}$, cuyos valores en el gas quemado son a su vez proporcionales a $Y_{\mathrm{CH}_{4 u}}$.

Así pues, cuando las pérdidas por radiación son relevantes, la disminución $\delta T$ de la temperatura final de combustión, que pasa a ser $T_{b}=T_{e q}-\delta T$, depende únicamente de $Y_{C H_{4 u}}$ y no de la relación $\mathrm{N}_{2}: \mathrm{O}_{2}$. En particular, el valor de $Y_{C_{H_{4}}}$ para el que se produce la extinción debe ser constante, en buen acuerdo con los resultados experimentales. Este argumento también indica que la temperatura final de combustión en el límite de inflamabilidad debe ser independiente de la relación $\mathrm{N}_{2}: \mathrm{O}_{2}$, pero esta temperatura no se puede medir en nuestro experimento.

\begin{tabular}{llllll}
\hline$Y_{\mathrm{CO}_{2} u}$ & 0.0567 & 0.0725 & 0.0919 & 0.1148 & 0.1409 \\
$Y_{\mathrm{CH}_{4} u}$ & 0.0305 & 0.0309 & 0.0317 & 0.0325 & 0.0333 \\
\hline
\end{tabular}

Tabla 5.4: Fracción másica de metano en el límite de inflamabilidad para varios valores de la fracción másica de $\mathrm{CO}_{2}$ en el gas fresco. En todos los casos $\left(\left[\mathrm{N}_{2}\right]+\left[\mathrm{CO}_{2}\right]\right) /\left[\mathrm{O}_{2}\right]=3.762$ en el gas fresco.

El efecto de la radiación en la extinción de la llama se ha confirmado mediante experimentos en los que se varía la intensidad de las pérdidas cambiando la concentración de las especies radiantes. Para ello se ha sustituido parte del volumen de $\mathrm{N}_{2}$ en el gas fresco por un volumen igual de $\mathrm{CO}_{2}$. Los valores de la fracción másica de $\mathrm{CH}_{4}$ en el límite de inflamabilidad obtenidos en algunos de estos experimentos se muestran en la tabla 5.4. Como puede verse, esta fracción másica crece de forma aproximadamente lineal con la fracción másica de $\mathrm{CO}_{2}$ en el gas fresco. El resultado refleja la competición de dos efectos:

- Por una parte, las pérdidas por radiación aumentan al añadir $\mathrm{CO}_{2}$, tanto directamente, a causa de la radiación del $\mathrm{CO}_{2}$ ya presente en el gas fresco, como indirectamente, a causa de las cantidades adicionales de $\mathrm{CO}_{2}$ y $\mathrm{H}_{2} \mathrm{O}$ generadas por la combustión del exceso de $\mathrm{CH}_{4}$ en el límite de inflamabilidad comparado con el del caso $Y_{\mathrm{CO}_{2 u}}=0$.

- Por otra parte, la combustión de este exceso de $\mathrm{CH}_{4}$ genera un calor adicional que intensifica la llama.

Ambos efectos se pueden cuantificar de forma aproximada.

- El ritmo al que las pérdidas por radiación aumentan con la fracción másica de $\mathrm{CO}_{2}$ añadido, $Y_{\mathrm{CO}_{2 u}}$, se puede caracterizar mediante el valor de

$$
L_{b}^{\prime}=\frac{\partial L_{b}}{\partial Y_{\mathrm{CO}_{2}}}\left(1+\frac{44}{16} s\right)+\frac{\partial L_{b}}{\partial Y_{\mathrm{H}_{2} \mathrm{O}}} \frac{2 \times 18}{16} s
$$

donde $L_{b}$ es la intensidad de las pérdidas evaluada a la temperatura final de combustión; $s$ es el ritmo de variación de $Y_{C_{4 u}}$ en el límite de inflamabilidad con $Y_{C_{2} u}$, que 


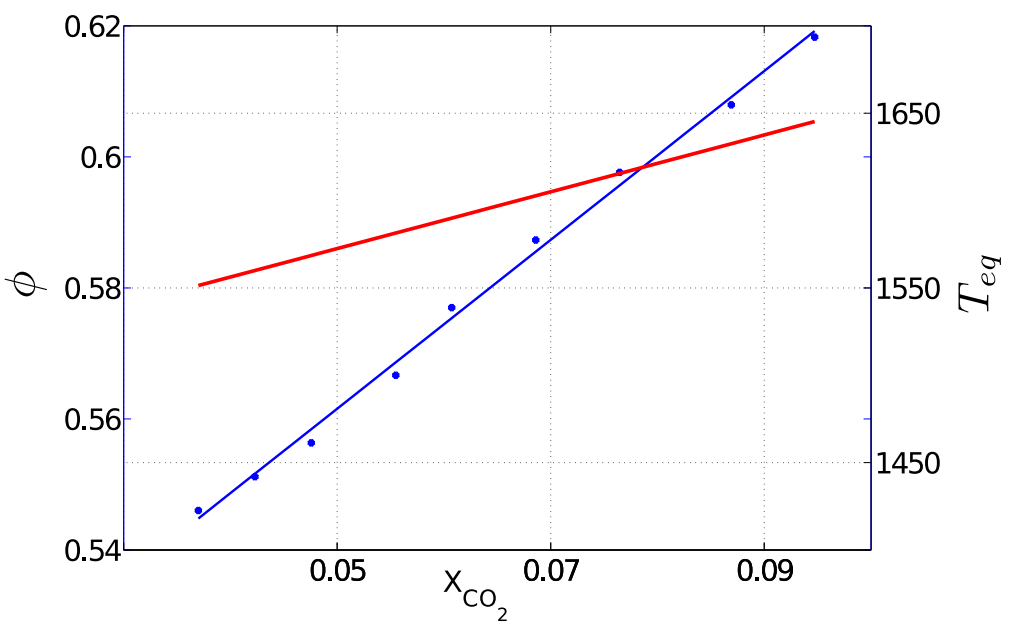

Figura 5.27: Valor medido de la riqueza de la mezcla en el límite de inflamabilidad (curva azul) y temperatura adiabática de llama límite (curva roja, escala de la derecha) como funciones de la fracción molar de $\mathrm{CO}_{2}$ en la mezcla fresca.

se puede determinar ajustando una recta a los resultados de la tabla 5.4; y los factores numéricos son las masas moleculares y factores estequiométricos de las diferentes especies. Los términos de (5.12) proporcionales a $s$ dan cuenta de las cantidades adicionales de $\mathrm{CO}_{2}$ y $\mathrm{H}_{2} \mathrm{O}$ en la gas debidas a la combustión del exceso de $\mathrm{CH}_{4}$. Llevando (5.12) a la estimación (5.11) de la disminución de la temperatura final de combustión debida a las pérdidas, se obtiene

$$
\delta T^{\prime} \equiv \frac{\mathrm{d}(\delta T)}{\mathrm{d} Y_{C O_{2 u}}}=O\left(\frac{L_{b}^{\prime} \ell}{\rho_{u} c_{p} u_{f}}\right) .
$$

- El ritmo de variación de la temperatura adiabática de llama debida a la variación de $Y_{\mathrm{CH}_{4 u}}$ motivada por la adición de $\mathrm{CO}_{2}$ es

$$
T_{e q}^{\prime}=\frac{\mathrm{d} T_{e q}}{\mathrm{~d} Y_{C O_{2 u}}}=\frac{s q}{c_{p}} .
$$

El cociente $\delta T^{\prime} / T_{e q}^{\prime}$ toma valores de orden unidad cuando se evalúa usando el valor experimental de $s$ y se reemplazan $\ell$ y $u_{f}$ en (5.13) por el radio del tubo y la velocidad de la llama adiabática calculada con el esquema de cuatro reacciones. El resultado confirma el importante papel jugado por la radiación en la extinción de la llama en el límite de inflamabilidad [42]. La figura 5.27 muestra los valores en el límite de inflamabilidad de la riqueza de la mezcla (curva azul) y la temperatura adiabática de llama ( $T_{e q}$, curva roja) como funciones de la fracción volumétrica de metano en el gas fresco.

\subsubsection{Cálculo de la temperatura}

Aunque la temperatura no se puede medir directamente en nuestro experimento, es posible calcularla, junto con las concentraciones de las diferentes especies, en la aproxima- 

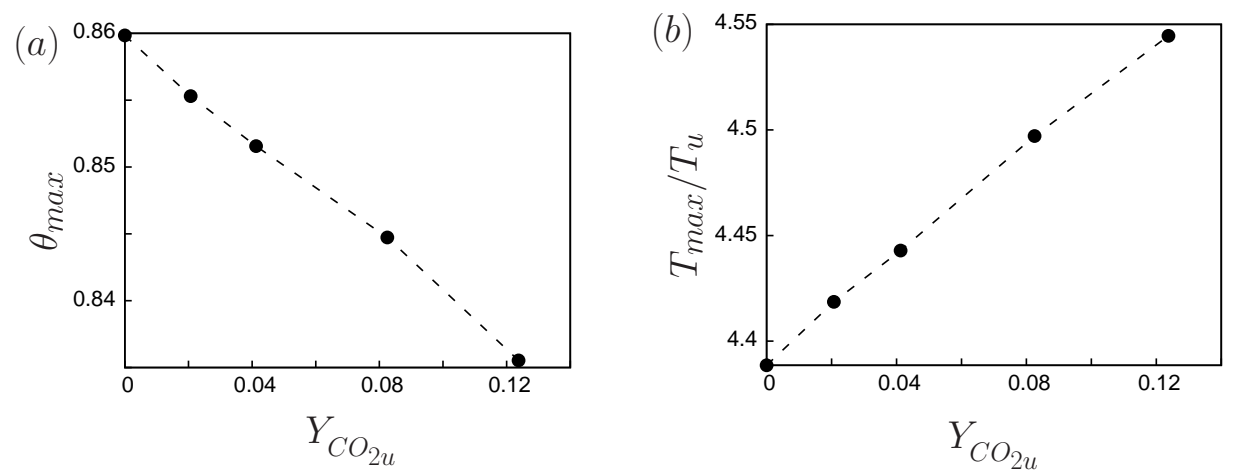

Figura 5.28: (a): Valores máximos de $\theta=\left(T-T_{u}\right) /\left(T_{e q}-T_{u}\right)(a)$ y $T / T_{u}(b)$ en el límite de inflamabilidad, calculados con el modelo unidimensional y el esquema de cuatro reacciones.

ción que proporciona el modelo unidimensional introducido en el capítulo 2. Los resultados de este cálculo, realizado con el esquema de cuatro reacciones para cinco valores de $Y_{\mathrm{CO}_{2 u}}$, se muestran en la figura 5.28, mientras que los correspondientes perfiles de las velocidades molares de las reacciones I a IV a lo largo del eje del tubo se muestran en la figura 5.29. Con la aproximación inherente al modelo, el hecho de que este tenga solución para todas las llamas límite consideradas muestra que la extinción en el límite de inflamabilidad no está determinada por la cinética de las reacciones de producción y consumo de radicales. Las velocidades de las cuatro reacciones I a IV aumentan con $Y_{\mathrm{CO}_{2 u}}$ (figura 5.29) porque este aumento conlleva un aumento de $Y_{C_{4 u}}$ y la riqueza, pero el ritmo de generación de radicales por la reacción II (curva verde) es suficiente en todos los casos para que la reacción I de ataque al combustible (curva roja) pueda ocurrir sin verse limitada por la recombinación de radicales representada por la reacción III (curva azul). Así mismo, la reacción IV de oxidación del CO (curva rosa), que siempre ocurre en una zona relativamente ancha aguas abajo de la zona donde ocurren las otras reacciones, mantiene su intensidad en el campo de velocidad en el que está inmersa la llama. Este resultado contrasta con el obtenido en el apartado 2.2 del capítulo 2 en ausencia de pérdidas por radiación.

La figura 5.30 muestra la temperatura máxima calculada con el modelo bidimensional de una reacción global única en función de la riqueza de la mezcla para los cinco valores de $Y_{\mathrm{CO}_{2 u}}$ considerados. La extinción en este modelo se debe necesariamente a los efectos térmicos de la radiación, y ocurre en buen acuerdo con los resultados experimentales. El máximo valor de $\theta$ para la llama límite disminuye ligeramente al aumentar $Y_{\mathrm{CO}_{2 u}}$ (figura 5.30a), si bien es algo mayor que el valor mostrado en la figura 5.28 para el modelo unidimensional con el esquema de cuatro reacciones, mientras que la temperatura final de combustión aumenta con $Y_{\mathrm{CO}_{2 u}}$ (figura 5.30b).

Estas variaciones se pueden explicar cualitativamente mediante un análisis análogo al de Joulin y Clavin [21] para la extinción por pérdidas de calor de una llama plana con una reacción global única en el límite de alta energía de activación, que se aplica aquí al punto más alto del frente de llama en el tubo. En este límite, la velocidad de la llama es una función muy rápidamente creciente de la temperatura final de combustión. El cociente entre la velocidad de la llama $\left(u_{f}\right)$ y su valor en ausencia de pérdidas $\left(U_{L}\right)$ es $\mu \equiv u_{f} / U_{L}=\exp (-\beta \delta \theta / 2)$ (Williams [64]), donde $\beta=T_{a}\left(T_{e q}-T_{u}\right) / T_{e q}^{2}$ es el número 

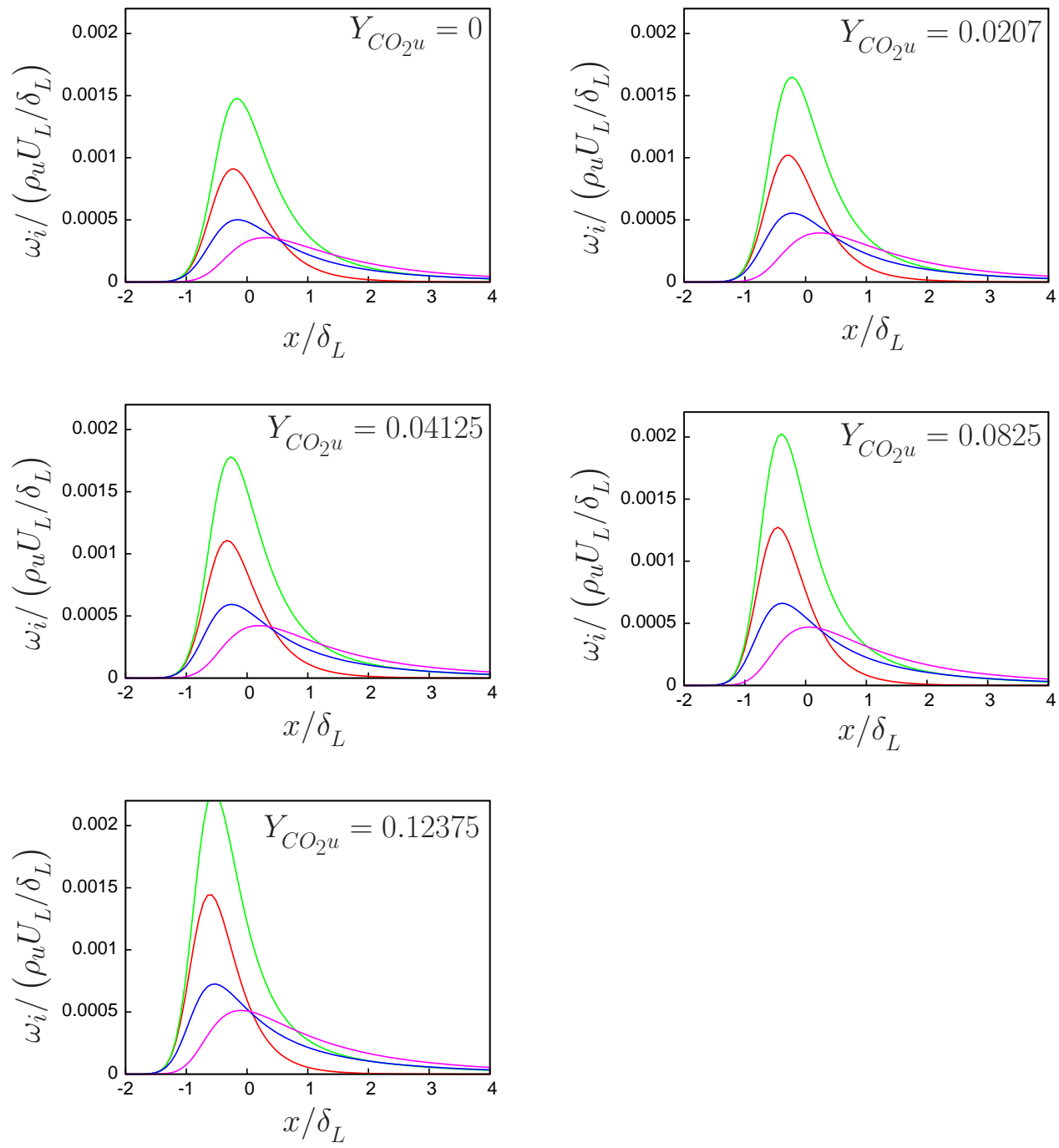

Figura 5.29: Velocidades de las reacciones I (curva roja), II (verde), III (azul) y IV (rosa) a lo largo del eje del tubo, calculadas en el límite de inflamabilidad con el modelo unidimensional y el esquema de cuatro reacciones, para cinco valores de $Y_{\mathrm{CO}_{2 u}}$. 

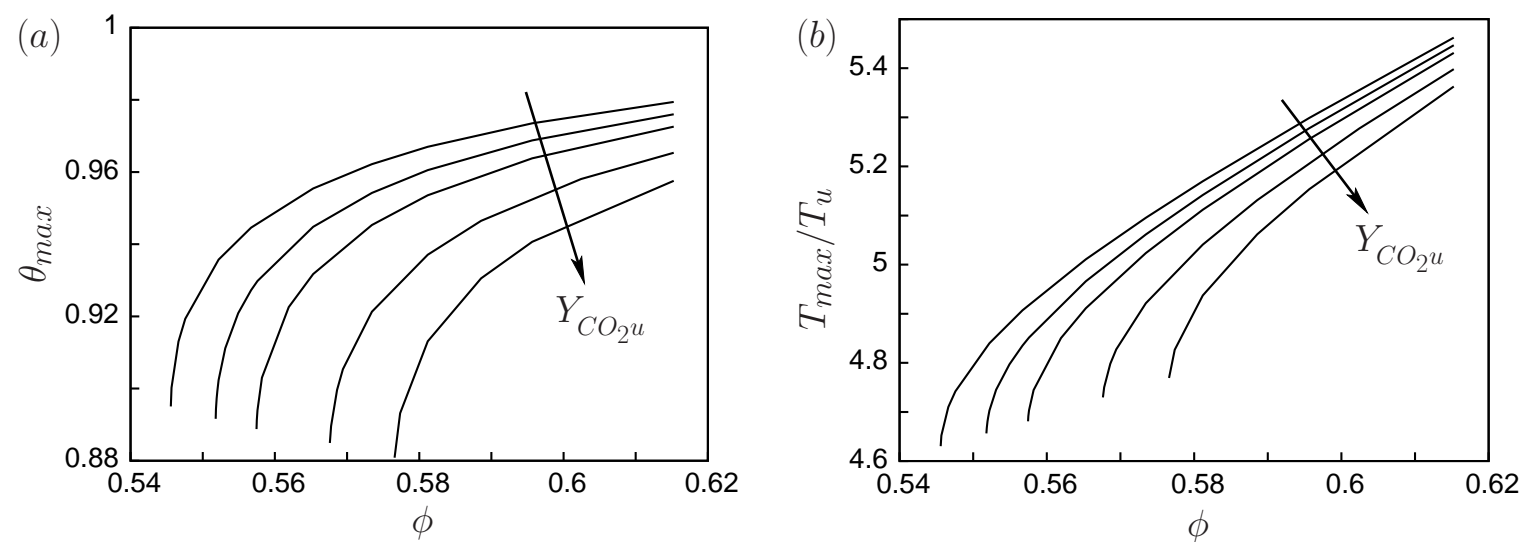

Figura 5.30: (a): Valores máximos de $\theta=\left(T-T_{u}\right) /\left(T_{e q}-T_{u}\right)(a)$ y $T / T_{u}(b)$ como funciones de la riqueza, calculados con el modelo bidimensional y el esquema de una reacción global única para $Y_{\mathrm{CO}_{2 u}}=0,0.0207,0.04125,0.0825$ y 0.12375 (aumentando como indican las flechas).

de Zeldovich definido en el capítulo 2 y $\delta \theta=\delta T /\left(T_{e q}-T_{u}\right)$ es la disminución de la temperatura final de combustión escalada con $T_{e q}-T_{u}$. Si, de acuerdo con (5.11), se admite que $\delta T=\chi L_{b} R / \rho_{u} c_{p} u_{f}$, donde $\chi$ es una constante adimensional de orden unidad, resulta $\delta \theta=A / \mu$ con $A=\chi L_{b} R / \rho_{u} c_{p} u_{f}$, y $\mu$ satisface la ecuación $\mu=\exp (-\beta A / 2 \mu)$. Esta ecuación deja de tener solución cuando $A$ supera el valor crítico de extinción $A_{e}=2 / e \beta$, para el que $\mu=1 / e$. En estas condiciones de extinción,

$$
\theta_{b}=1-\delta \theta=1-\frac{2}{\beta} \quad \text { y } \quad \frac{T_{b}}{T_{u}}=1+\gamma \theta_{b}=1+\gamma\left(1-\frac{2}{\beta}\right) .
$$

El aumento de $Y_{\mathrm{CH}_{4 u}}$ en el límite de inflamabilidad al aumentar $Y_{\mathrm{CO}_{2 u}}$ da lugar a un aumento de $\gamma$ y una disminución de $\beta$ (ver ecuación (2.18)), mientras que $\gamma(1-2 / \beta)$ aumenta. Esto explica las tendencias mostradas en las figuras 5.28 y 5.30 .

\subsection{Conclusiones}

En este capítulo se han presentado y discutido los resultados experimentales obtenidos en los ensayos realizados en mezclas de metano-aire con riquezas cercanas al límite inferior de inflamabilidad.

La observación visual de la propagación de estas llamas en el tubo de inflamabilidad estándar concuerda con las observaciones realizadas por otros investigadores. La llama tiene forma de semiesfera seguida de una falda cuya longitud aumenta al disminuir la riqueza de la mezcla, y su propagación es estacionaria. La extinción comienza en el punto más alto del frente y se propaga hacia sus laterales. La evolución de la llama antes de la extinción es igual a la de las llamas que no se extinguen.

La velocidad de ascenso de la llama se ha medido empleando tanto las señales de una línea de fotodiodos, como las imágenes de la llama tomadas con dos cámaras de fotos. El valor de esta velocidad es similar al de la velocidad de ascenso de una burbuja de aire 
en un tubo vertical lleno de líquido, que sólo depende de la aceleración de la gravedad y del radio del tubo. Esta velocidad es prácticamente constante para mezclas con riquezas cercanas al límite inferior de inflamabilidad.

En el análisis de los errores de estas medidas se ha visto que la velocidad media medida con ambos métodos es similar. Sin embargo, la desviación típica de las medidas es mayor al medir la velocidad a partir de las imágenes de la llama, mientras que las medidas empleando la línea de fotodiodos tiene peor resolución temporal.

Las medidas de la velocidad del gas alrededor de la llama usando la técnica de PIV muestran que el campo de velocidades del flujo delante de la llama es similar al que hay delante de una burbuja, mientras que detrás hay una zona donde el gas, que se ha acelerado al atravesar la llama, se decelera. Si se observan las líneas de corriente del campo de velocidades del gas en un sistema de referencia ligado a la llama, se ve que detrás de la llama la separación entre ellas aumenta al disminuir la riqueza, lo que refleja la aparición de una zona de baja velocidad. El tamaño de esta zona es muy sensible con la riqueza, lo que se ve claramente al observar la velocidad del gas en el eje del tubo. A veces, cuando la riqueza es próxima a la correspondiente al límite de inflamabilidad, la velocidad en el eje del tubo se hace negativa en esta región generando una zona de recirculación.

La probabilidad de que la extinción de la llama ocurra delante de la cámara de PIV y coincida con el momento del disparo del láser es pequeña, por lo que no se han registrado datos del momento exacto de la extinción. Sí se ha medido un campo de velocidades $100 \mathrm{~ms}$ después de la extinción, donde se ve que el frente de la llama se hace impermeable al gas y se convierte en una línea de corriente delante de la cual el flujo se comporta igual que delante de una burbuja, mientras que detrás la velocidad es negativa.

La presencia de la región de baja velocidad detrás de la llama aumenta el tiempo de residencia de los productos de la combustión, provocando un aumento de las pérdidas por radiación. La influencia de estas pérdidas sería muy pequeña para una llama plana sin alargamiento con la riqueza correspondiente al límite de inflamabilidad medido, pero aumenta al aumentar el tamaño de la región de baja velocidad detrás de la llama. En las llamas de mezclas pobres en el tubo de inflamabilidad estándar, las pérdidas por radiación son capaces de provocar la extinción.

El efecto de las pérdidas por radiación en la extinción de la llama se ha confirmado mediante experimentos en los que se han variado las concentraciones de las especies radiantes, que son el dióxido de carbono y el vapor de agua. Para ello se ha sustituido parte del $\mathrm{N}_{2}$ del aire por $\mathrm{CO}_{2}$ y se ha observado que la concentración de metano en el límite de inflamabilidad aumenta al aumentar su concentración.

$\mathrm{Al}$ no poder medir la temperatura en nuestros experimentos, ésta se ha calculado empleando los modelos presentados en el capítulo 2. Con el modelo unidimensional y el esquema de cuatro reacciones no se aprecian signos de extinción cinética al aumentar la concentración del $\mathrm{CO}_{2}$ en la mezcla, lo que parece indicar que la extinción no está determinada por la cinética de la combustión, aunque hay que tener presente que el modelo cinético empleado es un modelo reducido. Para el modelo bidimensional de una reacción global se observa que la extinción depende de la concentración de $\mathrm{CO}_{2}$ añadido a la mezcla, indicando que la extinción se debe necesariamente a los efectos térmicos de la radiación, y además ocurre en buen acuerdo con los resultados experimentales. 


\section{Capítulo 6}

\section{Conclusiones y trabajo futuro}

Se resumen a continuación los resultados más importantes obtenidos en la tesis y algunas extensiones posibles del trabajo realizado.

\subsection{Conclusiones}

Se ha investigado experimentalmente la propagación ascendente de llamas pobres de metano en un tubo vertical de cuarzo de dimensiones próximas a las del tubo de inflamabilidad estandar, abierto por el extremo inferior y cerrado por el superior, con el propósito de caracterizar la forma y propagación de la llama y su extinción en el límite de inflamabilidad.

La mezcla con la que se llena el tubo, con la composición deseada, se forma previamente a partir de sus componentes (o de aire filtrado y deshumidificado, metano y, en ocasiones, $\mathrm{CO}_{2}$ ). Los gastos másicos de estos gases se fijan y miden separadamente con controladores EL-Flow Bronkhorst. La precisión de estos controladores se ha aumentado calibrandolos con caudalímetros volumétricos Ritter TG05 y TG10 en condiciones próximas a las de utilización.

Cuando se minimizan el movimiento residual del gas fresco y las variaciones de temperatura de la pared del tubo, el frente de llama que se propaga en el tubo alcanza una forma y velocidad constantes después de un transitorio inicial. La forma estacionaria del frente es similar a la de una burbuja que asciende en un tubo lleno de líquido. Consiste en una cabeza aproximadamente hemiesférica seguida de una falda casi cilíndrica cuya longitud aumenta cuando disminuye la riqueza de la mezcla. La velocidad de ascenso y la forma del frente se han medido con una línea de fotodiodos equiespaciados a lo largo de la pared del tubo y con fotografía estática y de alta velocidad. Se han estudiado los efectos del llenado del tubo y del mecanismo de ignición de la mezcla sobre la propagación de la llama.

La velocidad inducida en el gas por la propagación del frente se ha medido mediante la técnica de PIV, sembrando el gas con partículas micrométricas de alúmina que se generan en un lecho fluidizado insertado en la línea de aire y se hacen pasar después por un impactador que limita su distribución de tamaños. La expansión térmica del gas a través de la llama causa una disminución importante de la densidad de partículas, que debe ajustarse para mantener la precisión de las medidas a ambos lados de la llama. Se han estudiado los efectos de la densidad de sembrado y de la resolución de las imágenes y el 
tamaño de las ventanas de interrogación usadas en la técnica de PIV, usando para ello imágenes sintéticas elaboradas a partir de soluciones numéricas del flujo en el tubo. Se han estudiado también los efectos de los fuertes gradientes de la concentración de partículas y la velocidad del gas en el interior de la llama, que originan un error sistemático en las medidas de velocidad.

Se ha estimado el efecto de la termofóresis en la zona de transporte de la llama, que retarda apreciablemente a las partículas con tamaños inferiores a unas pocas micras, las cuales no siguen al gas en esta zona y causan un error importante en las medidas. Como no es posible eliminar este error usando partículas más grandes, porque los efectos de la inercia y la gravedad impiden que estas partículas se muevan con el gas, se ha propuesto y empleado un método de corrección de la desviación de velocidad ocasionada por la termofóresis. El cálculo de esta desviación requiere conocer la distribución de temperatura a través de la llama. Ésta no puede medirse en nuestro experimento, pero puede calcularse usando un método aproximado, basado en formas simplificadas de las ecuaciones de conservación de la energía y las especies, que requieren a su vez conocer la distribución de velocidad del gas. El resultado es un esquema iterativo que permite calcular y corregir alternativamente las distribuciones de temperatura y velocidad. La convergencia de este esquema se ha comprobado usando campos sintéticos de ambas variables.

El estudio experimental se ha complementado con simulaciones numéricas con un modelo bidimensional en el que la llama y el flujo se suponen axilsimétricos, la combustión ocurre mediante una reacción global única, y las pérdidas de energía por radiación, debidas a las especies $\mathrm{CO}_{2}$ y $\mathrm{H}_{2} \mathrm{O}$, se incluyen admitiendo que el gas es ópticamente delgado y la pared del tubo es transparente e isoterma. También se ha formulado un modelo unidimensional aproximado que permite calcular las distribuciones de temperatura y concentración de las especies sobre el eje del tubo para una distribución de velocidad dada. Este modelo puede usarse en combinación con un esquema cinético de cuatro reacciones, más realista que la reacción única del modelo bidimensional.

Los resultados numéricos confirman las observaciones experimentales de otros autores, que muestran una región de baja velocidad y tamaño comparable al diámetro del tubo, que aparece detrás del frente de llama al aproximarse al límite de inflamabilidad. Esta región juega un papel importante en la extinción de la llama porque, debido al elevado tiempo de residencia del gas en ella, el enfriamiento debido a las pérdidas por radiación es apreciable a pesar de las pequeñas concentraciones de las especies radiantes. Esto da lugar a un flujo de calor desde la llama al gas quemado, que es capaz de extinguir la llama para un valor de la riqueza similar al medido en el límite de inflamabilidad.

Los resultados de series de experimentos en los que se añaden cantidades variables de $\mathrm{CO}_{2}$ al gas fresco para cambiar la intensidad de las pérdidas por radiación confirman el importante efecto de las mismas sobre el límite de inflamabilidad. Las distribuciones de temperatura calculadas a partir de los resultados experimentales usando el modelo unidimensional con el esquema de cuatro reacciones indican que la extinción se debe a efectos térmicos más que a una disminución de la concentración de radicales por causa de las reacciones de recombinación.

La importancia de las pérdidas por radiación disminuye con el radio del tubo. Los resultados numéricos muestran que cuando se suprimen estas pérdidas el límite de inflamabilidad se desplaza hacia valores menores de la riqueza, en consonancia con las medidas de otros autores, y que la extinción ocurre cuando la mayor parte de la llama está inmersa 
en una región de recirculación. La extinción en estas condiciones se hace dependiente de la reacción de oxidación del CO.

\subsection{Trabajo futuro}

Los resultado numéricos mencionados al final del apartado anterior indican que el efecto de las pérdidas por radiación puede ser ya despreciable en los tubos de $24 \mathrm{~mm}$ usados en los experimentos de Shoshin et al. [52], y que la extinción en este caso está ligada a la amplia región de recirculación ya comentada. La llama se ve entonces afectada por la corriente inversa de productos de la combustión, que, por una parte, limita el acceso de combustible por difusión desde el gas fresco y, por otra, afecta a la ancha zona donde ocurre la oxidación del CO. En el futuro estudiaremos experimentalmente este problema.

También extenderemos el estudio a la combustión de otros hidrocarburos con difusividades menores que la del metano. Los resultados existentes en la literatura muestran que la forma en que el límite de inflamabilidad varía con el diámetro del tubo es distinta para diferentes combustibles. Las extensiones comentadas en este párrafo y el anterior deberían permitir una descripción general cualitativa de las tendencias observadas.

La medida directa de la temperatura proporcionaría una información crucial. Los intentos realizados de medir la temperatura con termopares muy finos no han dado resultados concluyentes hasta ahora. También hemos empezado a trabajar en la aplicación de métodos ópticos basados en fluorescencia inducida por láser (que ya hemos empleado para visualizar las concentraciones de algunos radicales), y el posible uso de técnicas más recientes basadas en la fosforescencia de partículas trazadoras de $\mathrm{ZnO}$ y otros materiales, que podrían permitir la medida simultánea de la velocidad y la temperatura. 


\section{Apéndice A}

\section{Funcionamiento de los controladores Bronkhorst El-Flow}

Los controladores Bronkhorst El-Flow son unos medidores de gasto másico de gas que además permiten regular la cantidad de gas que llega a la salida del controlador mediante una electroválvula. El medidor está compuesto por un tubo principal a través del que pasa el flujo de gas y por un tubo capilar de acero inoxidable que sirve como sensor. El funcionamiento del sensor se basa en la transferencia de calor desde la pared del tubo capilar al gas que circula por él. A la entrada del tubo principal se situa un elemento laminarizador para garantizar que el flujo sea laminar. Aguas abajo de este elemento se encuentra otro laminarizador, pero cuya misión principal consiste en generar una caída de presión. La parte del tubo comprendida entre los dos laminarizadores está comunicada con la parte final del tubo mediante el tubo capilar, y la caída de presión causada por el segundo laminarizador obliga a que una pequeña parte del caudal pase por el tubo capilar. A la salida del tubo principal se sitúa una electroválvula que regula la cantidad de gas sale del controlador.

En la figura A.1 se presenta de manera esquemática el funcionamiento de los controladores Bronkhorst El-Flow. El sensor está formado por un tupo capilar de acero inoxidable dotado de una calentador que aporta un flujo de calor constante en la zona central del tubo y de dos detectores de temperatura resistivos situados simétricamente con respecto al punto medio del tubo. Cuando la electroválvula de la salida del medidor está cerrada, el gas que se encuentra en el tubo principal y en el capilar está parado, alcanzándose el equilibrio térmico entre la pared del tubo y el gas que contiene. En esta configuración el perfil de temperaturas de la pared del tubo capilar es un perfil simétrico con respecto al punto medio del tubo donde tiene su temperatura máxima. Las dos temperaturas medidas por los termómetros resistivos son iguales. Al abrir la electroválcula de la salida del medidor, el flujo de aire que se establece en el conducto principal genera una caída de presión en el segundo laminarizador. Esta diferencia de presión entre la entrada y la salida del tubo capilar induce un caudal de gas por su interior que modifica el equilibrio térmico alcanzado con caudal nulo, el gas enfría la parte izquierda del tubo capilar y calienta la derecha. Este transporte convectivo de calor genera una asimetría en el perfil de temperaturas de la pared. De esta manera hay una diferencia entre las dos lecturas de temperatura en los sensores instalados que es función del gasto másico de gas que pasa 
por el tubo capilar. Con un diseño adecuado del controlador, buscando que el gasto másico total sea proporcional al que pasa por el tubo capilar, se puede conocer el gasto total que pasa por el controlador midiendo solamente el gasto que pasa por el tubo capilar.
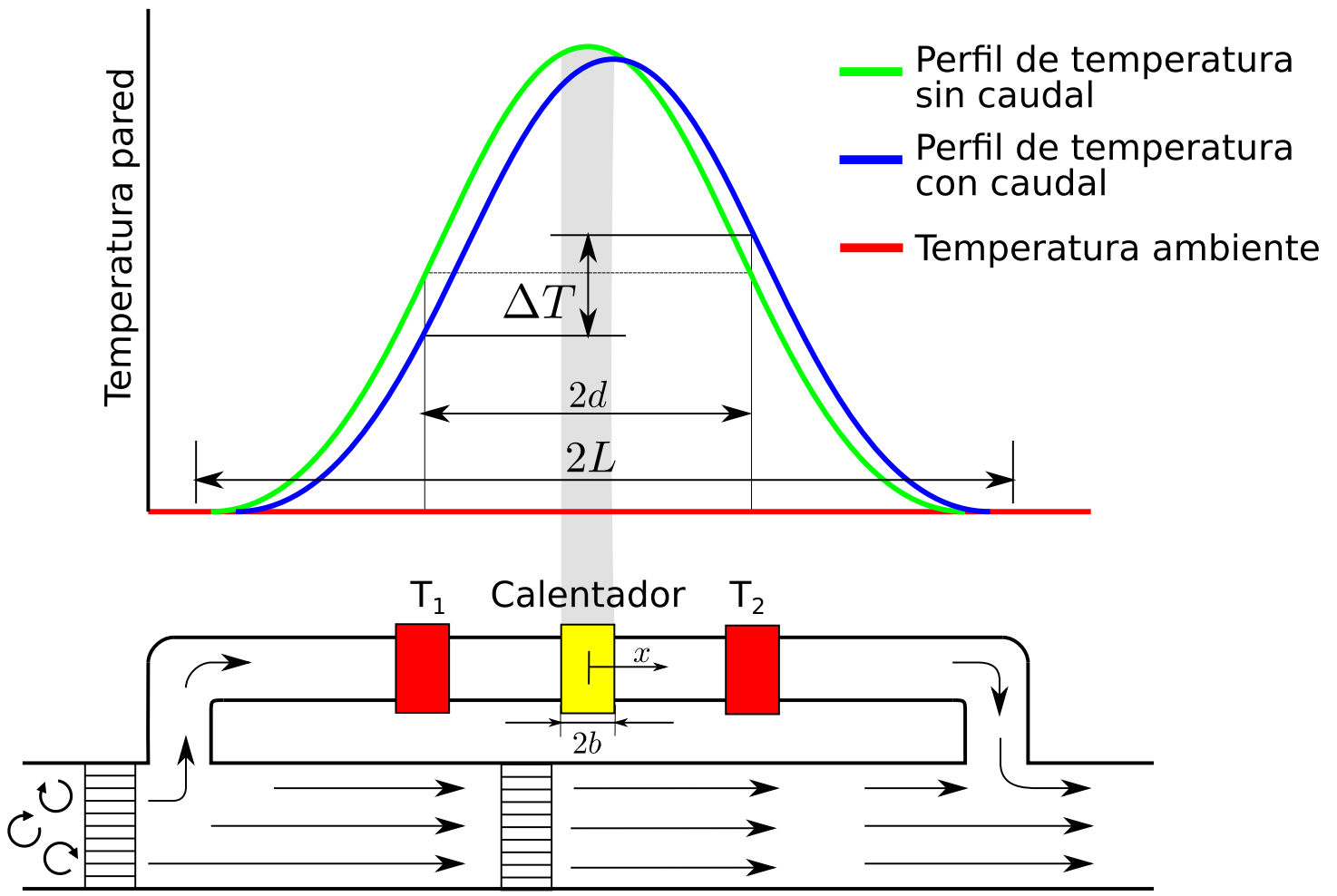

Figura A.1: Esquema de funcionamiento del controlador de flujo másico El-Flow. El tubo de mayor diámetro es el conducto principal y el de menor diámetro es el tubo capilar.

El diseño de estos controladores es complejo y no se va a entrar en sus detalles constructivos, tampoco de los laminarizadores ni de la electroválvula. En las patentes [10, 12, 22] se puede encontrar más información sobre los elementos internos de los medidores. Sin embargo, para comprender cómo afectan los distintos parámetros al funcionamiento del sensor y cuáles pueden ser las limitaciones en las mediciones, a continuación se formula un modelo matemático del proceso en el tubo capilar.

Se considera el problema de un tubo capilar de longitud $2 L$, radio interior $a$ y pared delgada de espesor $e$, por el que fluye un gas cuyo flujo se puede considerar axilsimétrico. Las variaciones de temperatura que experimenta el gas son pequeñas, por lo que la variación de densidad es pequeña y se desprecia. Como condiciones adicionales se supone que el flujo ha alcanzado el régimen de Poiseuille muy cerca de la entrada, que la temperatura del gas en la sección de entrada es $T_{0}$ y que $L \gg a$. La ecuación que describe el transporte de calor dentro del tubo es:

$$
\rho c_{p} v \frac{\partial T}{\partial x^{*}}=\lambda_{g}\left[\frac{1}{r^{*}} \frac{\partial}{\partial r^{*}}\left(r^{*} \frac{\partial T}{\partial r^{*}}\right)+\frac{\partial^{2} T}{\partial x^{* 2}}\right],
$$

donde $v$ es la velocidad de Poiseuille, $v=2 U_{m}\left(a^{2}-r^{* 2}\right) / a^{2}$, siendo $U_{m}$ la velocidad media en el tubo, $\lambda_{g}$ es la conductividad térmica del gas, y $x^{*}$ y $r^{*}$ son distancias a lo largo 
del eje del tubo capilar (medida desde su centro) y perpendicular al eje. Para completar el modelado del sensor, hay que calcular también el calentamiento del tubo capilar. La ecuación de conservación de la energía aplicada a la pared del tubo es la ecuación de Laplace

$$
\frac{1}{r^{*}} \frac{\partial T_{p}}{\partial r^{*}}\left(r^{*} \frac{\partial T_{p}}{\partial r^{*}}\right)+\frac{\partial^{2} T_{p}}{\partial x^{* 2}}=0
$$

Los dos extremos del tubo capilar están encastrados en la carcasa del controlador. Esta carcasa es de metal macizo y tiene una gran inercia térmica. Una vez ha pasado el tiempo de calentamiento del controlador para medir con máxima precisión, unos 30 minutos según el fabricante, se puede suponer que la carcasa ha alcanzado una temperatura $T_{0}$ que se mantiene constante durante las mediciones. Se supone que en la unión entre el tubo capilar y la carcasa la temperatura del tubo es igual a la de la carcasa:

$$
x^{*}= \pm L: \quad T_{p}=T_{0}
$$

No se conoce con detalle el funcionamiento del calentador central del sensor, ya que esta información no es pública. Sin embargo, en base a la patente [12] de un medidor similar, se puede suponer que consiste en una termoresistencia por la que se hace pasar una intensidad eléctrica tal que la resistencia se mantiene a una temperatura $T_{1}$ constante, independiente del flujo másico de gas que circula por el interior del tubo.

Sea $2 b$ la longitud del tramo de la pared exterior del capilar cubierto por la resistencia, y $q_{c s}^{\prime \prime}$ es el flujo de calor que recibe la pared de la resistencia, que supondremos uniforme. Usando esta notación,

$$
\begin{aligned}
& r^{*}=a+e:\left\{\begin{array}{cl}
\lambda_{s} \frac{\partial T_{p}}{\partial r^{*}}=q_{c s}^{\prime \prime}, & x^{*} \in[-b, b] \\
\lambda_{s} \frac{\partial T_{p}}{\partial r^{*}}=-q_{p}^{\prime \prime}, & x^{*} \in[-L,-b) \cup(b, L]
\end{array}\right. \\
& r^{*}=a: \quad \lambda_{s} \frac{\partial T_{p}}{\partial r^{*}}=\lambda_{g} \frac{\partial T}{\partial r^{*}} \quad \text { y } \quad T_{p}=T,
\end{aligned}
$$

donde $\lambda_{s}$ es la conductividad térmica de la pared del capilar. El valor uniforme de $q_{c s}^{\prime \prime}$ debe determinarse con la condición de que $\frac{1}{2 b} \int_{-b}^{b} T_{p}\left(x^{*}, a+e\right) \mathrm{d} x=T_{1}$. Sin embargo, dada la linealidad del problema, esta condición de normalización puede posponerse hasta el final del análisis. El calor por unidad del área que pierde el tubo por su superficie exterior se ha denominado $q_{p}{ }^{\prime \prime}$. El tubo capilar está rodeando de una cámara de aire circular cuyo radio es del mismo orden que la longitud del tubo. Además, en algunos casos está aislado con una capa cerámica, por lo que se espera que estas pérdidas de calor sean muy pequeñas y considerará que $q_{p}^{\prime \prime}=0$ para la simulación.

La ecuación (A.2) puede integrarse a través de la pared del tubo capilar para obtener

$$
\lambda_{s} \frac{\mathrm{d}^{2}}{\mathrm{~d} x^{* 2}} \int_{a}^{a+e} r^{*} T_{p} \mathrm{~d} r^{*}+(a+e) q_{c s}^{\prime \prime} \mathcal{H}\left(b^{2}-x^{* 2}\right)-\left.a \lambda_{g} \frac{\partial T}{\partial r^{*}}\right|_{a}=0,
$$

donde $\mathcal{H}$ es la función de Heaviside y se han usado las condiciones de contorno (A.4). Como la conductividad térmica de la pared es alta, las variaciones radiales de temperatura necesarias para transportar el calor generado por la resistencia hacia el interior del tubo 
son pequeñas, de modo que $T_{p}=T\left(x^{*}\right)$ en primera aproximación y la integral en el primer término esta ecuación es $\frac{1}{2}\left[(a+e)^{2}-a^{2}\right] T\left(x^{*}\right)$. Así pues,

$$
\frac{\partial^{2} T}{\partial x^{* 2}}=-\frac{2}{\lambda_{s}\left((a+e)^{2}-a^{2}\right)}\left[(a+e) q_{c s}^{\prime \prime} \mathcal{H}\left(b^{2}-x^{* 2}\right)-\left.a k_{g} \frac{\partial T}{\partial r^{*}}\right|_{a}\right] .
$$

Adimensionalizando las distancia con $a$ e introduciendo la variable $\theta=\lambda_{g}\left(T-T_{0}\right) /\left(q_{c s}^{\prime \prime} a\right)$ y los parámetros

$$
\mathrm{Pe}=\frac{2 \rho c_{p} U_{m} a}{\lambda_{g}}, \quad \lambda=\frac{\lambda_{s}}{\lambda_{g}}, \quad \tilde{e}=\frac{e}{a}, \quad \tilde{L}=\frac{L}{a}, \quad \tilde{b}=\frac{b}{a},
$$

el problema se puede escribir

$$
\begin{aligned}
& \operatorname{Pe}\left(1-r^{2}\right) \frac{\partial \theta}{\partial x}=\frac{1}{r} \frac{\partial}{\partial r}\left(r \frac{\partial \theta}{\partial r}\right)+\frac{\partial^{2} \theta}{\partial x^{2}} \\
& x= \pm \tilde{L}: \quad \theta=0 \\
& r=1: \quad \frac{\partial \theta}{\partial r}=(1+\tilde{e}) \mathcal{H}\left(\tilde{b}^{2}-x^{2}\right)+\lambda \frac{(1+\tilde{e})^{2}-1}{2} \frac{\partial^{2} \theta}{\partial x^{2}} \\
& r=0: \quad \frac{\partial \theta}{\partial r}=0 .
\end{aligned}
$$

Si el número de Péclet $(\mathrm{Pe})$ en la ecuación de la energía para el gas fuera mucho menor que la unidad, el término convectivo de esta ecuación se podría despreciar frente al de conducción y se tendría un problema de conducción pura. En este caso el sistema no sería útil para medir el flujo másico, ya que el gas se movería tan lentamente por el tubo que no habría transporte de calor desde la parte izquierda del tubo a la parte derecha, por lo que no se llegaría a tener una asimetría en el perfil de temperatura que permitiese evaluar el flujo de gas que circula por el tubo.

Por el contrario, si Pe $\gg 1$, la convección sería el término más importante en la ecuación de la energía. Pero, en este caso límite, la velocidad del gas sería tan grande que llegaría a la salida del tubo sin haberse calentado. En realidad casi todo el gas estaría a temperatura $T_{0}$, excepto una delgada capa límite térmica cercana a la pared del tubo. Esto implica que para el funcionamiento del caudalímetro basado en la asimetría del perfil de temperatura la longitud del tubo no puede ser cualquiera, sino que debe ser suficiente para que la capa límite térmica crezca hasta ser del orden del radio del tubo. En ese caso el término convectivo y el de conducción radial son del mismo orden. Esta condición relaciona los órdenes de magnitud de la longitud adimensionales del tubo y el número de Péclet: $\tilde{L}=\mathcal{O}(\mathrm{Pe}) \gg 1$, lo cual hace que el efecto de la conducción axial en el gas, representado por el último término de la ecuación de la energía se puede despreciar:

$$
\left(1-r^{2}\right) \frac{\partial \theta}{\partial x}=\frac{1}{r} \frac{\partial}{\partial r}\left(r \frac{\partial \theta}{\partial r}\right)+\frac{1}{\mathrm{Pe}^{2}} \frac{\partial^{2} \theta}{\partial x^{2}} .
$$

En lo que sigue se han usado las simplificaciones del problema (A.7)-(A.10) correspondientes a valores grandes del número de Péclet, y se ha calculado la solución numéricamente mediante un método iterativo que consta de las siguientes etapas:

1. Se fija la distribución de temperatura de la pared, $\theta_{p}(x)$. 
2. Se resuelve la ecuación de la energía en el gas con la condición de contorno en la pared (A.9) reemplazada por la condición $\theta(x, 1)=\theta_{p}(x)$.

3. La distribución $\partial \theta /\left.\partial r\right|_{r=1}$ determinada por la solución de este problema se lleva a (A.9) y se usa esta ecuación, con la condición de contorno $\theta( \pm \tilde{L})=0$, para actualizar $\theta_{p}(x)$.

El proceso se repite hasta que la máxima variación de $\theta_{p}$ de una iteración a la siguiente se hace menor que una cota preestablecida.

Una vez calculada la solución se puede evaluar la diferencia de temperatura adimensional entre los dos termistores, supuestos situados a una distancia adimensional $\tilde{d}$ (escalada con $a$ ) a ambos lados del centro del tubo: $\Delta \theta=\theta(\tilde{d}, 1)-\theta(-\tilde{d}, 1)$. También se puede evaluar la temperatura adimensional bajo la resistencia, así como el valor me$\operatorname{dio} \bar{\theta}=\frac{1}{2 \tilde{b}} \int_{-\tilde{b}}^{\tilde{b}} \theta(x, 1) \mathrm{d} x$. Usando la definición de $\theta$, esto determina el valor de $q_{c s}^{\prime \prime}$ necesario para la temperatura media bajo la resistencia tenga un valor $T_{1}$ determinado: $\tilde{q}_{c s}^{\prime \prime}=\lambda_{g} /\left(T_{1}-T_{0}\right) /(a \tilde{\theta})$, mientras que la diferencia de temperatura entre los termistores es $\Delta T=\left(T_{1}-T_{0}\right) \Delta \theta / \tilde{\theta}$.

En la simulación, para evaluar los parámetros adimensionales $(\lambda, \tilde{e}, \tilde{L}$, y $\tilde{b})$ en $($ A.6) se considera que el tubo tiene una longitud de $2 \mathrm{~cm}$, un diámetro interno de $0.8 \mathrm{~mm}$ y un espesor de la pared de $0.2 \mathrm{~mm}$. Hay tubos con estas características disponibles comercialmente. Para la pared se usa la conductividad del acero inoxidable y para el gas se usan las propiedades del nitrógeno. Una vez elegidos los parámetros, la solución depende únicamente del número de Péclet, que se puede reescribir en términos de gasto másico del gas:

$$
\mathrm{Pe}=\frac{2 c_{p} \dot{m}}{\pi a \lambda_{g}}
$$

La diferencia de temperatura calculada entre los termistores se muestra en la figura A.2 como función del número de Péclet para el caso en que la distancia entre los termistores sea $5 \mathrm{~mm}$.

Se han calculado los valores de $\Delta T$ para flujos másicos tales que el número de Péclet varíe entre 1 y 100. Como se puede observar en la figura A.2, hay una zona hasta $\mathrm{Pe}=25$ en la que el valor de $\Delta T$ es aproximadamente proporcional al número de Péclet. Para $P e>25$, $\Delta T$ deja de tener un comportamiento lineal con Pe, pero puede ajustarse con un polinomio de tercer grado. Esto está de acuerdo con las instrucciones de operación del controlador, donde se explica el funcionamiento de la memoria y el procesador del controlador, y se especifica que el ajuste de la calibración del controlador se realiza empleando un polinomio de tercer grado.

Por otra parte, en el manual de uso del controlador y su hoja técnica se especifica que el valor de $\Delta T$ es directamente proporcional al flujo másico multiplicado por la capacidad calorífica del gas. También es directamente proporcional al número de Péclet si se tiene en cuenta el modelo planteado y la relación entre Pe y $\dot{m}$ dada por la ecuación (A.12). En cualquier caso, ya sea porque el controlador se haya diseñado para que su máximo gasto no supere la zona lineal o porque la señal se reajuste en la calibración para que sea lineal con el gasto másico, se tendría

$$
V_{\text {signal }}=K \frac{c_{p}}{\lambda_{g}} \dot{m}
$$




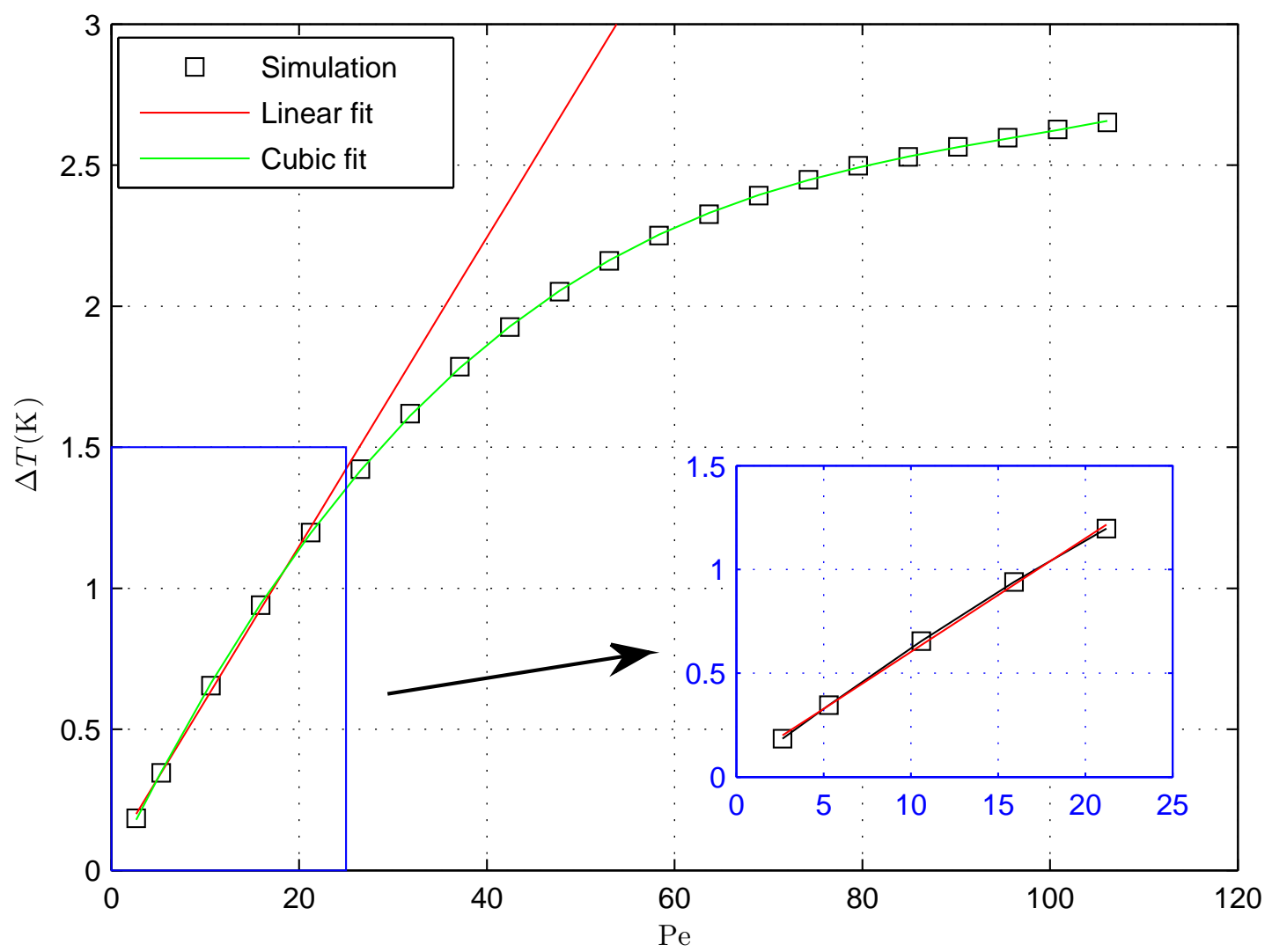

Figura A.2: Variación de la diferencia de temperatura entre los dos termistores con el número de Péclet del problema y $\left(T_{1}-T_{0}\right)=15 \mathrm{~K}$.

donde $K$ es una constante y $V_{\text {signal }}$ es el voltaje que mide el circuito electrónico del sensor. Esta fórmula difiere de la proporcionada por el fabricante en el manual de uso, donde no aparece la conductividad del gas en el denominador:

$$
V_{\text {signal }}=K_{1} c_{p} \dot{m},
$$

La discrepancia se puede deber al modelo desarrollado aquí, que es un modelo simplificado en el que se han hecho hipótesis que pueden diferir de las condiciones reales en las que funciona el controlador. Por ejemplo, el valor de $\left(T_{1}-T_{0}\right)$ no tiene por qué ser el mismo que el elegido para la simulación. Según el manual de uso, cualquier controlador se puede usar con un gas distinto al usado en la calibración, simplemente conociendo la capacidad calorífica a presión constante de los dos gases y reajustando la lectura empleando la ecuación (A.14). Según la ecuación (A.13) se tendrían que conocer también sus conductividades térmicas. De todas formas, aunque un mismo medidor pueda ser usado con distintos gases simplemente ajustando el valor de la lectura, el fabricante recomienda que se calibre el controlador con el gas que se va a medir para obtener máxima precisión en las medidas.

Por último, es importante señalar que el medidor mide gasto másico y no gasto volumétrico, un error en el que se podría incurrir debido a que la lectura del controlador 
se muestra en unidades de volumen por minuto para mayor comodidad del usuario. La ventaja de medir gasto másico en vez de volumétrico reside en que la lectura del sensor, una vez fijada la densidad de referencia para pasar de masa a volumen, es independiente de la presión del gas a la entrada. 


\section{Apéndice B}

\section{Imagen de una llama axilsimétrica en un tubo}

En este apéndice se emplean la óptica geométrica y la aproximación paraxial para calcular la imagen formada en el sensor de una cámara por la radiación de una llama axilsimétrica que se propaga en un tubo vertical. El propósito del análisis es determinar de forma aproximada:

- El efecto del enfoque, calculando la contribución a la imagen de las regiones no enfocadas de la llama y comparando el resultado con el que se obtendría en el límite de profundidad de campo nula.

- El efecto de la refracción de la luz en la pared del tubo.

\section{B.1. Óptica geométrica}

Supondremos que la radiación de la llama procede de una capa delgada en torno a una superficie de revolución $\Sigma_{f}$ coaxial con el tubo. Esta capa emite isótropamente un flujo de energía uniforme, $\varphi$ por unidad de área de la superficie $\Sigma_{f}$. El tubo tiene radio interior $a$ y pared de espesor $e$, de un material transparente cuyo índice de refracción es $n$.

El objetivo de la cámara se modela como una lente de distancia focal $f$ y apertura $R$. El eje óptico forma un ángulo $\alpha$ con el eje del tubo, y ambos se cortan a una distancia $b$ del objetivo.

Sea $P$ un punto objeto cuya radiación alcanza la lente sin atravesar ningún cuerpo interpuesto (la refracción en una pared transparente se analiza más abajo) y $P^{\prime}$ la imagen de $P$ formada por la lente. En la figura B.1a, $x$ es la distancia de $P$ al foco más próximo, $x^{\prime}$ es la distancia de la imagen $P^{\prime}$ al otro foco, y $z$ y $z^{\prime}$ son distancias perpendiculares al eje óptico en el plano de la figura. Las distancias $y$ e $y^{\prime}$ perpendiculares a este plano que no se representan en la figura. Con esta notación se tiene, en la aproximación paraxial [30],

$$
\frac{y^{\prime}}{y}=\frac{z^{\prime}}{z}=\frac{x^{\prime}}{f}=\frac{f}{x} .
$$

Estas ecuaciones determinan la imagen $P^{\prime}\left(x^{\prime}, y^{\prime}, z^{\prime}\right)$ de un punto $P(x, y, z)$ cualquiera, no necesariamente en el plano de la figura B.1a. En lo que sigue el plano $x-z$ es el plano 


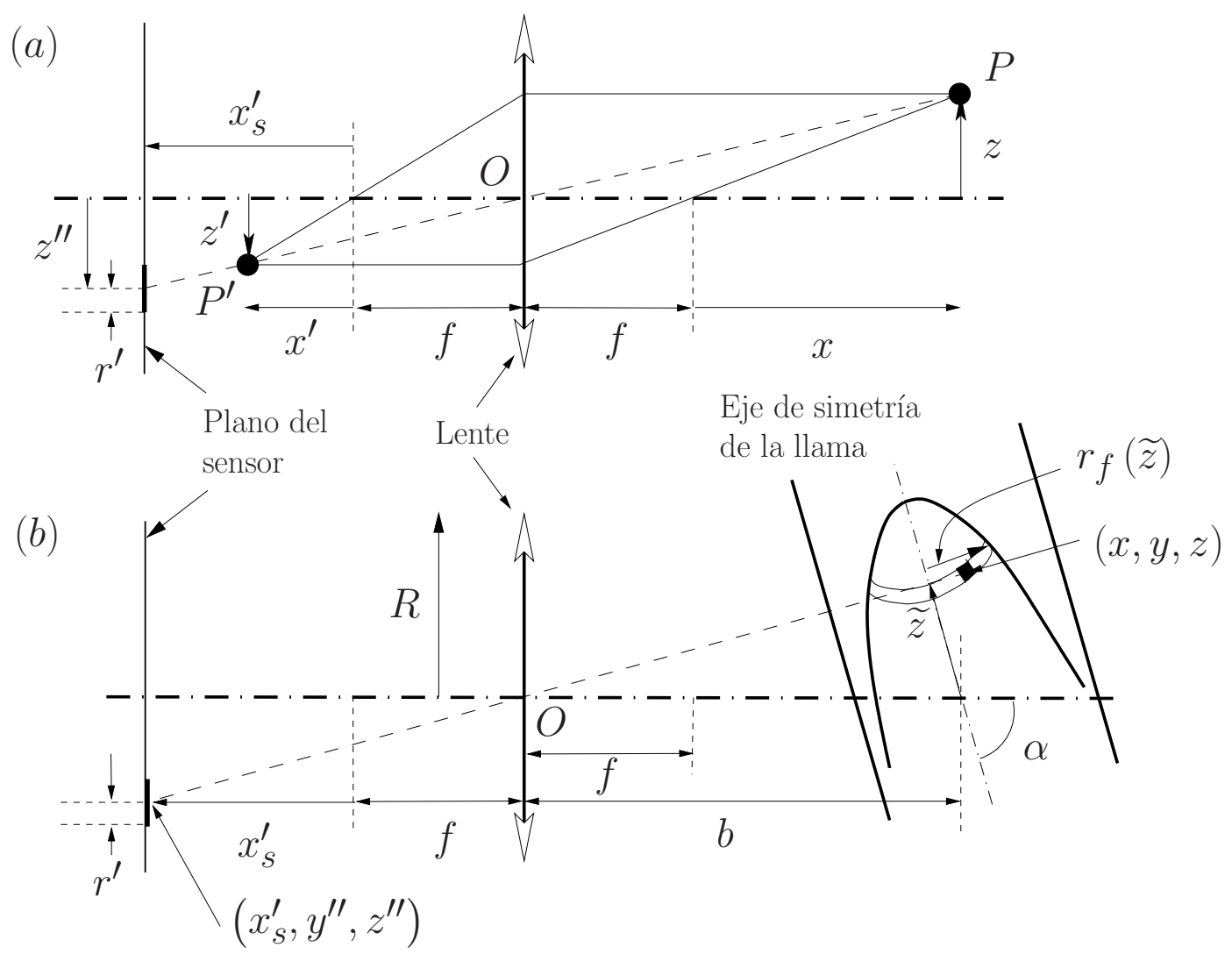

Figura B.1: Esquema y notación

determinado por el eje óptico y el eje del tubo. Observese que los orígenes de coordenadas son distintos para el objeto y la imagen. Las distancias a lo largo del eje óptico se miden desde los focos, a cada lado de la lente. Estas distancias y las distancias perpendiculares al eje se miden en sentidos opuestos para el objeto y la imagen.

El sensor de la cámara es un rectangulo en un plano perpendicular al eje óptico a una distancia $x_{s}^{\prime}$ del foco más próximo (a la izquierda en la figura), de forma que la cámara está enfocada a una distancia $x_{s}=f^{2} / x_{s}^{\prime}$. El sensor se extiende entre un vértice inferior izquierdo de coordenadas $\left(y_{l}^{\prime}, z_{b}^{\prime}\right)$ y un vértice superior derecho de coordenadas $\left(y_{r}^{\prime}, z_{t}^{\prime}\right)$. Consiste en una matriz de $n_{y} \times n_{z}$ celdas, cada una de área $\left(y_{r}^{\prime}-y_{l}^{\prime}\right) / n_{y} \times\left(z_{t}^{\prime}-z_{b}^{\prime}\right) / n_{z}$.

Si la imagen del punto $P$ no se forma sobre el sensor $\left(x^{\prime} \neq x_{s}^{\prime}\right)$, la luz emitida por $P$ ilumina sobre el plano del sensor un círculo de centro

$$
y^{\prime \prime}=\frac{x_{s}^{\prime}+f}{x^{\prime}+f} y^{\prime}=\frac{x_{s}^{\prime}+f}{x+f} y \quad, \quad z^{\prime \prime}=\frac{x_{s}^{\prime}+f}{x^{\prime}+f} z^{\prime}=\frac{x_{s}^{\prime}+f}{x+f} z
$$

y radio

$$
r^{\prime}=\frac{\left|x_{s}^{\prime} / f-f / x\right|}{f / x+1} R,
$$

donde $R$ es el radio de la lente, o de su diafragma. Este resultado puede obtenerse trazando los rayos que van del punto $P$ al borde de la lente y usando la aproximación paraxial 
$(y, z) \ll(f+x)$.

Si el punto $P$ emite isótropamente un flujo de energía $\Phi$, el flujo que pasa a través de la lente es $\Phi^{\prime}=\left[R^{2} / 4(x+f)^{2}\right] \Phi$. Este flujo se distribuye uniformemente sobre el círculo anterior, dando lugar a una intensidad

$$
\frac{\Phi^{\prime}}{\pi r^{\prime 2}}=\frac{\Phi}{4 \pi f^{2}\left(x x_{s}^{\prime} / f^{2}-1\right)^{2}}=\frac{\Phi}{4 \pi f^{2}\left(x / x_{s}-1\right)^{2}}
$$

en la región iluminada del sensor.

En ausencia de la pared del tubo, la intensidad de la radiación debida a la llama completa en un punto genérico $\left(y_{s}^{\prime}, z_{s}^{\prime}\right)$ del sensor es

$$
\int_{\Sigma_{f}} \frac{\varphi}{4 \pi f^{2}\left(x / x_{s}-1\right)^{2}} H\left(r^{\prime}-\left[\left(y_{s}^{\prime}-y^{\prime \prime}\right)^{2}+\left(z_{s}^{\prime}-z^{\prime \prime}\right)^{2}\right]^{1 / 2}\right) \mathrm{d} \sigma
$$

donde la integral se extiende a la superficie de la llama, $(x, y, z)$ es un punto genérico de esta superficie, $y^{\prime \prime}, z^{\prime \prime}$ y $r^{\prime}$ son funciones de $(x, y, z)$ dadas por (B.2) y (B.3), y $H$ es la función escalón unidad. Cada sección de la llama por un plano $x=$ constante origina sobre el sensor una banda luminosa de anchura local $2 r^{\prime}$ en torno a la curva $y_{s}=y^{\prime \prime}, z_{s}=z^{\prime \prime}$. La integral sobre cada una de estas secciones de la llama es una convolución, pero la integral sobre $x$ no lo es.

La integral (B.4) se puede calcular integrando por rodajas. Sea $\widetilde{z}$ la distancia a lo largo del eje de simetría de la llama medida desde el punto de intersección de este eje con el eje óptico, $r_{f}(\widetilde{z})$ el radio de la sección de la superficie $\Sigma_{f}$ perpendicular a su eje, y $\theta$ el ángulo en torno al eje de simetría, con $\theta=0$ en la sección meridional más próxima a la lente (ver figura B.1b). En términos de estas variables, $x=b-f-\widetilde{z} \cos \alpha-r_{f} \cos \theta \sin \alpha$, $y=r_{f} \sin \theta, z=\widetilde{z} \sin \alpha-r_{f} \cos \theta \cos \alpha, \mathrm{y} \mathrm{d} \sigma=r_{f} \sqrt{1+\left(\mathrm{d} r_{f} / \mathrm{d} \widetilde{z}\right)^{2}} \mathrm{~d} \widetilde{z} \mathrm{~d} \theta$.

La imagen de la llama sobre el sensor se calcula numéricamente discretizando la superficie de la llama. La superficie del sensor ya es discreta, porque el sensor está formado por un número finito de celdas. La intensidad procedente de cada elemento de la llama debe distribuirse sobre las celdas del sensor, y luego integrar sobre la superficie de la llama. Para simplificar este cálculo, que requiere determinar la intersección del círculo de radio $r^{\prime}$ debido a cada elemento de la llama con las celdas del sensor, el círculo se sustituye por un cuadrado de lado $\pi^{1 / 2} r^{\prime}$.

\section{B.2. Refracción en la pared del tubo}

El efecto de la pared del tubo se puede incluir fácilmente si se supone que la pared es delgada, $e \ll(a, b)$, y se desprecian las reflexiones múltiples. Para ello basta calcular $(i)$ el desplazamiento aparente de cada punto $P$ de la llama debido a las refracciones en las superficies interna y externa del tubo, que se traduce en un cambio de las coordenadas $(x, y, z)$ de $P$ en (B.2)-(B.4); y (ii) el coeficiente de transmisión en estas refracciones, que determina el cambio de $\varphi$ en (B.4) para cada punto.

Sea $P$ un punto de la llama, en el interior del tubo, y $O$ el centro de la lente. Calculemos el punto $I$ de intersección del segmento $O P$ con la pared interna del tubo (ver figura B.2a). Usamos como coordenadas la distancia $\widetilde{x}$ perpendicular al eje del tubo medida desde el punto $O$ en el plano determinado por este eje y el eje óptico, la distancia a este plano, 

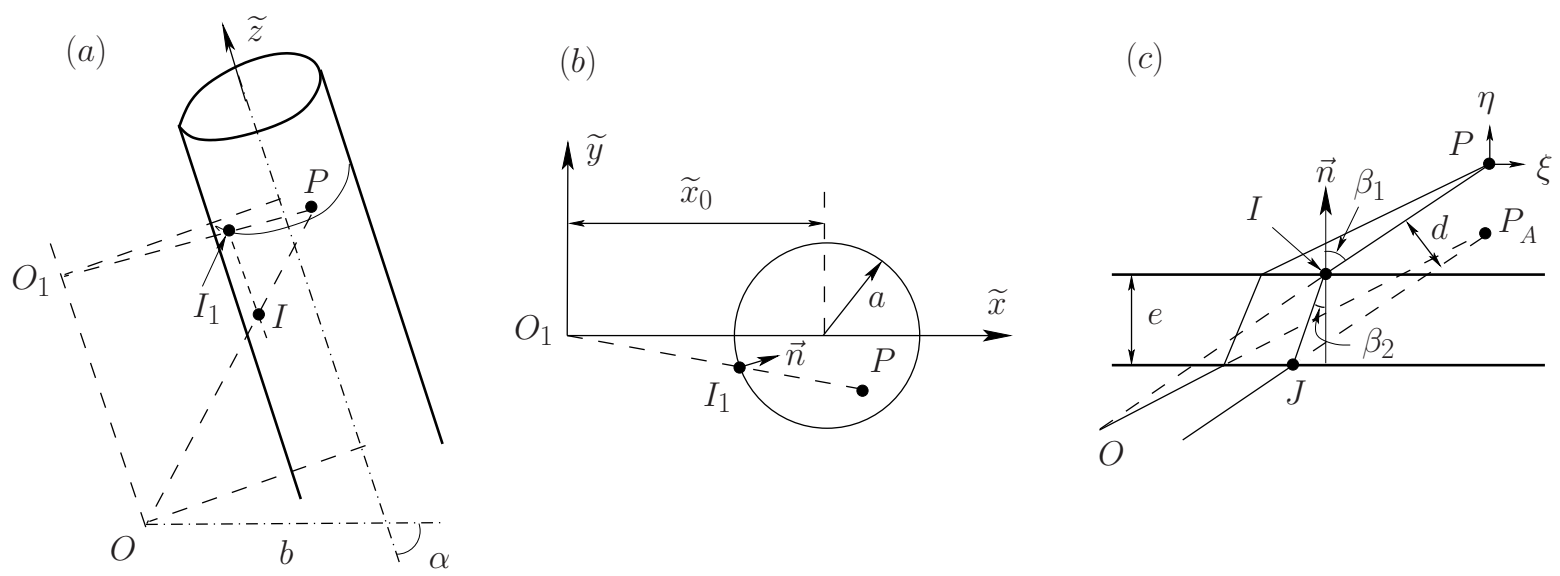

Figura B.2: Refracciones en las superficies interna y externa del tubo.

$\widetilde{y}=y$, y la distancia $\widetilde{z}$ a lo largo del eje del tubo introducida antes. La figura B.2b es una sección normal al eje del tubo por un plano que contiene al punto $P$. Los puntos $O_{1}$ e $I_{1}$ son las proyecciones de $O$ e $I$ sobre este plano. La distancia del centro de la sección del tubo al punto $O_{1}$ es $\widetilde{x}_{0}=b \sin \alpha$. Las coordenadas $\widetilde{x}_{I}$ e $\widetilde{y}_{I}$ del punto $I_{1}$ coinciden con las de $I$ y están determinadas por las ecuaciones $\widetilde{y}_{I} / \widetilde{x}_{I}=\widetilde{y} / \widetilde{x}$ y $\left(\widetilde{x}_{I}-\widetilde{x}_{0}\right)^{2}+\widetilde{y}_{I}^{2}=a^{2}$, que expresan las condiciones de que los puntos $O_{1}, I_{1}$ y $P$ estén alineados y que $I_{1}$ pertenezca a la sección del tubo. Resolviendo estas ecuaciones,

$$
\widetilde{x}_{I}=\frac{\widetilde{x_{0}}-\sqrt{a^{2}-\left(\widetilde{y}^{2} / \widetilde{x}^{2}\right)\left(\widetilde{x}_{0}-a^{2}\right)}}{1+\widetilde{y}^{2} / \widetilde{x}^{2}}, \quad \widetilde{y}_{I}=\frac{\widetilde{y}}{\widetilde{x}} \widetilde{x}_{I} .
$$

Finalmente, la coordenada $\widetilde{z}_{I}$ del punto $I$ se obtiene de la semejanza de los triángulos $P O_{1} O$ y $P I_{1} I$ en la figura B.2a, con $\overline{O O_{1}}=\widetilde{z}-b \cos \alpha$. Es decir,

$$
\frac{\widetilde{z}-\widetilde{z}_{I}}{\sqrt{\left(\widetilde{x}-\widetilde{x}_{I}\right)^{2}+\left(\widetilde{y}-\widetilde{y}_{I}\right)^{2}}}=\frac{\widetilde{z}-b \cos \alpha}{\sqrt{\widetilde{x}^{2}+\widetilde{y}^{2}}}
$$

de donde

$$
\widetilde{z}_{I}=\widetilde{z}-(\widetilde{z}-b \cos \alpha) \sqrt{\frac{\left(\widetilde{x}-\widetilde{x}_{I}\right)^{2}+\left(\widetilde{y}-\widetilde{y}_{I}\right)^{2}}{\widetilde{x}^{2}+\widetilde{y}^{2}}} .
$$

El ángulo que forma el segmento $O P$ con la normal interior a la pared del tubo en $I$ es $\beta_{1}=\arccos (\overrightarrow{O P} \cdot \vec{n} /|\overrightarrow{O P}|)$. Con

$$
\overrightarrow{O P}=(\widetilde{x}, \widetilde{y}, \widetilde{z}-b \cos \alpha) \quad \text { y } \quad \vec{n}=\frac{\left(\widetilde{x}_{0}-\widetilde{x}_{I},-\widetilde{y}_{I}, 0\right)}{\sqrt{\left(\widetilde{x}_{0}-\widetilde{x}_{I}\right)^{2}+\widetilde{y}_{I}^{2}}}
$$

resulta

$$
\beta_{1}=\arccos \frac{\widetilde{x}\left(\widetilde{x}_{0}-\widetilde{x}_{I}\right)-\widetilde{y} \widetilde{y}_{I}}{\sqrt{\widetilde{x}^{2}+\widetilde{y}^{2}+(\widetilde{z}-b \cos \alpha)^{2}} \sqrt{\left(\widetilde{x}_{0}-\widetilde{x}_{I}\right)^{2}+\widetilde{y}_{I}^{2}}} .
$$


La refracción del rayo $P I$ en la pared del tubo se muestra en la figura B.2c. Los ángulos de incidencia y refracción, $\beta_{1}$ y $\beta_{2}$, están ligados por la ley de Snell, $\sin \beta_{1}=n \sin \beta_{2}$. La distancia $\overline{I J}$ es del orden del espesor $e$ de la pared, que es pequeño frente a $a$ y $b$. Debido a ello se puede despreciar la curvatura de la pared, y el rayo que emerge del punto $J$ es paralelo a $P I$ y se mantiene en el plano determinado por los vectores $\overrightarrow{O P}$ y $\vec{n}$, que es el plano de la figura B.2c. Aproximadamente, $\overline{I J}=e / \cos \beta_{2}$ y la distancia entre el rayo incidente y el emergente es $d \approx \overline{I J} \cos \left(\beta_{2}+\pi / 2-\beta_{1}\right) \approx e \sin \left(\beta_{1}-\beta_{2}\right) / \cos \beta_{2}$. En las coordenadas $(\xi, \eta)$ de la figura B.2c, la ecuación del rayo emergente es

$$
\xi=\eta \tan \beta_{1}+e\left(\tan \beta_{1}-\tan \beta_{2}\right) .
$$

En la figura B.2c se muestra también el rayo que parte de $P$ y llega a $O$ tras las dos refracciones en las superficies del tubo. Debido al pequeño valor de $e$, este rayo es próximo a $P I$ y su ángulo de incidencia es próximo a $\beta_{1}$ en (B.7). En general, la familia de rayos que parten de $P$ originan, tras las dos refracciones en las superficies del tubo, una familia de rectas cuya ecuación es análoga a (B.8) con $\beta_{1}$ sustituido por un valor $\beta$ cualquiera y $\beta_{2}$ sustituido por $\arcsin \left(n^{-1} \sin \beta\right)$. El punto de la envolvente de la familia de rectas correspondiente a $\beta=\beta_{1}$ determina la posición aparente $P_{A}$ del punto $P$ visto desde $O$. En este punto se satisfacen (B.8) y la ecuación que resulta de derivar (B.8) respecto a $\beta_{1}$, lo que determina las coordenadas $\xi_{A}$ y $\eta_{A}$ del desplazamiento aparente de $P$ :

$$
\xi_{A}=\frac{e}{n}\left(\frac{\cos ^{2} \beta_{1}}{\cos ^{2} \beta_{2}}-1\right) \frac{\sin \beta_{1}}{\cos \beta_{2}}, \quad \eta_{A}=e\left(\frac{1}{n} \frac{\cos ^{3} \beta_{1}}{\cos ^{3} \beta_{2}}-1\right) \text {. }
$$

En términos de las coordenadas originales, los cambios de $(x, y, z)$ en (B.2)-(B.4) debidos al desplazamiento aparente son

$$
\begin{aligned}
& \delta x=\delta \widetilde{x} \sin \alpha-\delta \widetilde{z} \cos \alpha, \quad \delta y=\delta \widetilde{y}, \quad \delta z=\delta \widetilde{x} \cos \alpha+\delta \widetilde{z} \sin \alpha \quad \text { con } \\
&(\delta \widetilde{x}, \delta \widetilde{y}, \delta \widetilde{z})= \frac{(\widetilde{x}, \widetilde{y}, \widetilde{z}-b \cos \alpha)}{\sqrt{\widetilde{x}^{2}+\widetilde{y}^{2}+(\widetilde{z}-b \cos \alpha)^{2}}} \frac{\xi_{A}}{\sin \beta_{1}}+ \\
& \frac{\left(\widetilde{x}_{0}-\widetilde{x}_{I},-\widetilde{y}_{I}, 0\right)}{\sqrt{\left(\widetilde{x}_{0}-\widetilde{x}_{I}\right)^{2}+\widetilde{y}_{I}^{2}}}\left(\eta_{A}-\xi_{A} \frac{\cos \beta_{1}}{\sin \beta_{1}}\right) .
\end{aligned}
$$

El valor de $\varphi$ en (B.4) también cambia debido a las refracciones. Los coeficientes de transmisión en la refracción de la luz en la superficie interna del tubo son [29]

$$
T_{N_{i}}=n \frac{4 \cos ^{2} \beta_{1} \sin ^{2} \beta_{2}}{\sin ^{2}\left(\beta_{1}+\beta_{2}\right)} \quad \text { y } \quad T_{P_{i}}=\frac{1}{n} \frac{\sin ^{2} 2 \beta_{1}}{\sin ^{2}\left(\beta_{1}+\beta_{2}\right) \cos ^{2}\left(\beta_{1}-\beta_{2}\right)}
$$

para radiación polarizada normal y paralelamente al plano de incidencia, respectivamente. Los coeficientes de transmisión en la superficie externa del tubo, $T_{N e}$ y $T_{P_{e}}$, tienen expresiones análogas, con $\beta_{1}$ y $\beta_{2}$ intercambiados y $n$ sustituido por $1 / n$. Suponiendo que la radiación emitida por la llama no tiene una polarización preferente, el factor $\varphi$ en (B.4) debe multiplicarse por $\frac{1}{2}\left(T_{N_{i}} T_{N_{e}}+T_{P_{i}} T_{P_{e}}\right)$ para dar cuenta del cambio de intensidad en las refracciones. 


\section{B.3. Resultados}

La figura B.3 muestra varias imágenes de la luz emitida por la llama (blanco) y de su sección por el plano $x_{s}$ al que está enfocada la cámara (curvas rojas) sin tener en cuenta la refracción en la pared del tubo. En esta figura, usando como escala la distancia focal de la lente, $R / f=0.1, a / f=6, b / f=11 \mathrm{y}-y_{l} / f=y_{r} / f=-z_{b} / f=z_{t} / f=0.6$. La superficie $\Sigma_{f}$ es próxima a la región de reacción de la llama calculada numéricamente en el capítulo 2 para una riqueza $\phi=0.504$. Las figuras B.3a y B.3b son para un eje óptico horizontal, $\alpha=90^{\circ}$. En la figura B.3a es $x_{s} / f=10$, de modo que la cámara enfoca un plano que pasa por el eje de la llama y, por tanto, la curva roja casi coincide con la región de máxima luminosidad. En la figura B.3b es $x_{s} / f=6.67$, de modo que la cámara enfoca un plano que corta a la llama por delante de su eje. La sección de la llama (curva roja) es más baja que en el caso anterior. Sin embargo, la región de máxima luminosidad es muy parecida en ambos casos, aunque en el segundo está algo desenfocada. Las figuras B.3c y B.3d son para $\alpha=70^{\circ}$, con $x_{s} / f=8.97$ en B.3c (la cámara enfoca un plano que pasa por el punto más alto de la llama) y $x_{s} / f=7.14$ en B.3d. De nuevo la región de máxima luminosidad es parecida en ambos casos.

Si se aumenta el radio de la lente $R$, la intensidad de la luz que la atraviesa procedente un punto $P$ dado crece como $R^{2}$ y el radio $r^{\prime}$ del círculo iluminado sobre el sensor crece proporcionalmente a $R$. Si el criterio para considerar que el punto objeto está enfocado es que el área de este círculo no supere el área de una celda del sensor, entonces el valor máximo de la distancia $\left|x^{\prime}-x_{s}^{\prime}\right|$ decrece como $R^{-1}$; es decir, la profundidad de campo de la cámara (que debe ser el doble del valor máximo de $\left|x-x_{s}\right|$ para el que el punto objeto está enfocado) disminuye cuando $R$ aumenta. La intensidad que recibe una celda del sensor desde un punto objeto enfocado sobre ella crece como $R^{2}$.

Una celda dada también recibe luz desde puntos de la llama no enfocados por la cámara pero que den lugar a círculos luminosos que se solapen con esa celda. Como el radio $r^{\prime}$ de cada círculo crece como $R$, el tamaño de la región de la llama que cumple esta condición crece como $R$, y su área como $R^{2}$. La intensidad que recibe la celda dada desde cada uno de estos puntos de la llama es independiente de $R$, porque tanto $\Phi^{\prime}$ como $\pi{r^{\prime}}^{2}$ son proporcionales a $R^{2}$. Por tanto, la intensidad total que recibe una celda desde puntos no enfocados de la llama crece con la misma ley $R^{2}$ que la que que reciben las celdas iluminadas desde puntos enfocados. El efecto de aumentar $R$ es aumentar la intensidad total de la imagen, no su apariencia. Este efecto desaparece al normalizar las intensidades.

Aparentemente la propiedad de una cámara de formar imágenes enfocando no es tan importante cuando se fotografía una superficie cuyos puntos emiten luz isótropamente, en lugar de reflejar la que reciben. En la imagen de esta superficie predomina siempre su contorno, formado por los puntos de la misma donde la normal es perpendicular al eje óptico.

La figura B.4 muestra el efecto de la refracción en las superficies de un tubo de Plexiglass $(n=1.51)$, con la intensidad normalizada al mismo valor máximo que en la figura anterior. El eje óptico es horizontal $\left(\alpha=90^{\circ}\right)$ y la cámara está enfocada al eje del tubo. El espesor de la pared es $e / f=0.67$ en la figura B.4a y $e / f=1.33$ en la B.4b. Como se ve comparando estas figuras con la figura B.3a, la distorsión de la imagen debida a la refracción es mayor cerca de la pared del tubo que en su centro, y aumenta con el espesor de la pared. Sin embargo, la distorsión es moderada en una región central de la imagen. 

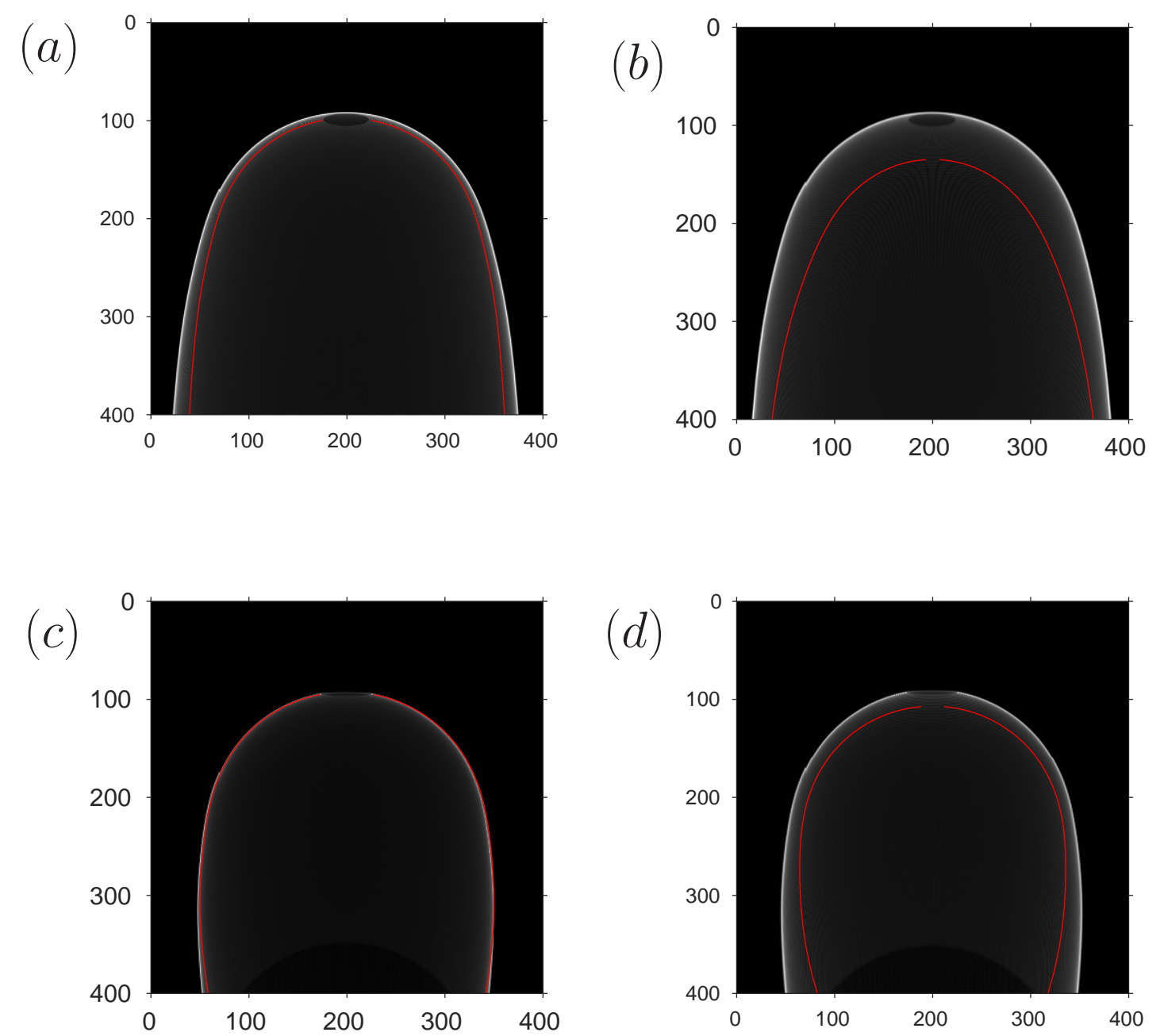

Figura B.3: Imágenes de la llama sin efecto de la refracción en la pared del tubo $(n=1)$ para $(a): x_{s} / f=10, \alpha=90^{\circ} ;(b): x_{s} / f=6.67, \alpha=90^{\circ} ;(c): x_{s} / f=8.97, \alpha=70^{\circ} ;(d)$ : $x_{s} / f=7.14, \alpha=70^{\circ}$. 

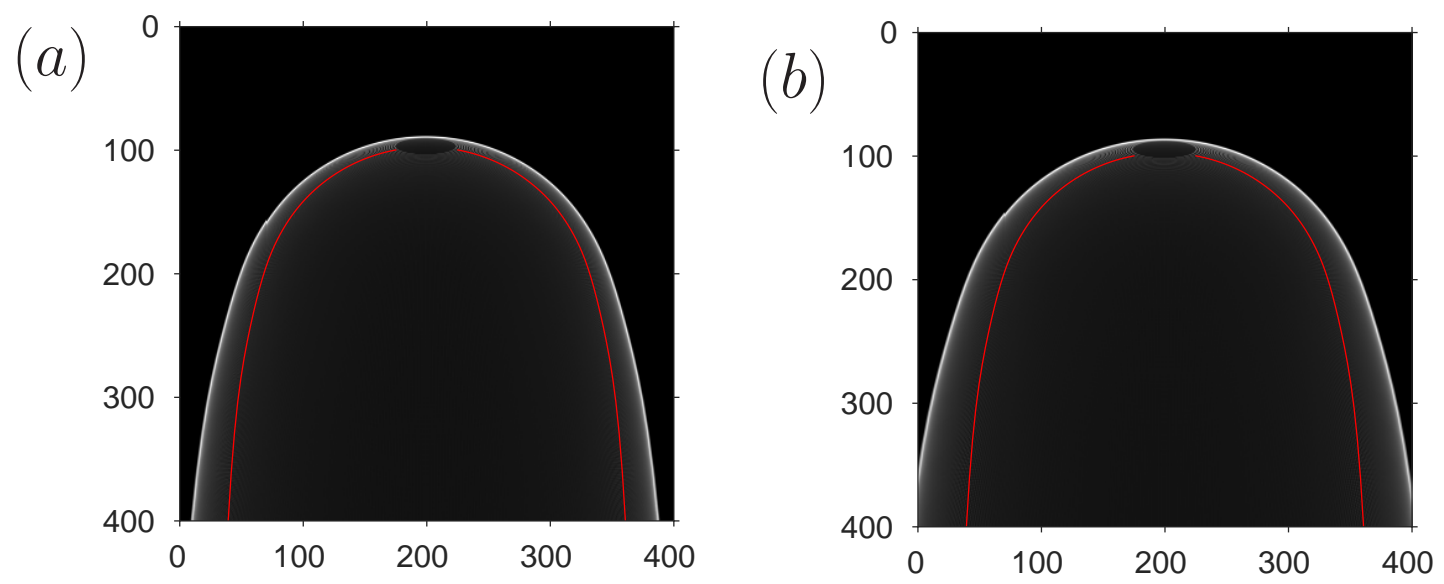

Figura B.4: Efecto de la refracción en la pared del tubo con $n=1.51$ (Plexiglass) para $(a): e / f=0.67 ;(b): e / f=1.33$. En ambos casos $x_{s} / f=10$ y $\alpha=90^{\circ}$. 


\section{Referencias}

[1] Babkin, V., Zamashchikov, V., Badalyan, A., Krivulin, V., Kudryavtsev, E. AND BARATOV, A. (1982). Effect of tube diameter on homogeneous gas flame propagation limits. Combustion, Explosion, and Shock Waves, 18, 164-171. 6

[2] Bohren, C. And Huffman, D. (2008). Absorption and scattering of light by small particles. John Wiley \& Sons. 79

[3] Buckmaster, J. and Mikolaitis, D. (1982). A flammability-limit model for upward propagation through lean methane/air mixtures in a standard flammability tube. Combustion and Flame, 45, 109-119. 6, 26

[4] Bychkov, V. and Liberman, M. (2000). Dynamics and stability of premixed flames. Physics reports, 325, 115-237. 109, 110

[5] Collins, R. (1967). The effect of a containing cylindrical boundary on the velocity of a large gas bubble in a liquid. Journal of Fluid Mechanics, 28, 97-112. 109

[6] Coward, H. and Jones, G. (1952). Limits of flammability of gases and vapors. Tech. rep., DTIC Document. 4, 5, 39, 48, 116

[7] Davies, R. and Taylor, G. (1950). The mechanics of large bubbles rising through extended liquids and through liquids in tubes. In Proceedings of the Royal Society of London A: Mathematical, Physical and Engineering Sciences, vol. 200, 375-390, The Royal Society. 5, 11, 21, 91, 108, 109

[8] Davis, S., Quinard, J. And Searby, G. (2002). Markstein numbers in counterflow, methane-and propane-air flames: a computational study. Combustion and Flame, 130, 123-136. 14

[9] Davy, H. (1816). On the fire-damp of coal mines, and on methods of lighting the mines so as to prevent its explosion. Philosophical Transactions of the Royal Society of London, 106, 1-22. 3

[10] Drexel, C. (1974). Fluid flowmeter. US Patent 3851526. 132

[11] Dumitrescu, D. (1943). Strömung an einer luftblase im senkrechten rohr. ZAMMJournal of Applied Mathematics and Mechanics/Zeitschrift für Angewandte Mathematik und Mechanik, 23, 139-149. 109, 110

[12] Ewing, J. and Ramberg, F. (1984). Thermal mass flowmetering. US Patent 4464932. 132, 133 
[13] Fodemski, T. And Gorecki, G. (2011). The particle image velocimetry experimental study of flame extinction in standard square flammability column resulting from stretching. Heat Transfer Engineering, 32, 109-126. 93, 94

[14] Gay-Lussac, J. and Humboldt, A. (1805). Expériences sur les moyens eudiométriques et sur la proportion des principes constituants de l'atmosphere. Journal de Physique, 60, 129-168. 2

[15] Hering, S. (2001). Impactors, cyclones, and other particle collectors. In Air Sampling Instruments for Evaluation of Atmospheric Contaminants, 315-376, ACGIH: Cincinnati, OH. 84

[16] Higuera, F. (2011). Numerical simulation of the upward propagation of a flame in a vertical tube filled with a very lean mixture. Combustion and Flame, 158, 885-892. 8,21

[17] Higuera, F. and Muntean, V. (2014). Effect of radiation losses on very lean methane/air flames propagating upward in a vertical tube. Combustion and Flame, 161, 2340-2347. 21

[18] Hinds, W. (2012). Aerosol technology: properties, behavior, and measurement of airborne particles. John Wiley \& Sons. 86

[19] Howell, J., Menguc, M. And Siegel, R. (2010). Thermal radiation heat transfer. CRC press. 18

[20] Jarosinski, J., Strehlow, R. And Azarbarzin, A. (1982). The mechanisms of lean limit extinguishment of an upward and downward propagating flame in a standard flammability tube. In Symposium (International) on Combustion, vol. 19, 15491557, Elsevier. 48, 49, 54, 108

[21] Joulin, G. And Clavin, P. (1976). Analyse asymptotique des conditions d'extinction des flammes laminaires. Acta Astronautica, 3, 223-240. 27, 123

[22] Jouwsma, W. (1984). Laminar flow element. US Patent 4427030. 132

[23] Ju, Y. and Masuya, P., G.And Ronney (1998). Effects of radiative emission and absorption on the propagation and extinction of premixed gas flames. In Symposium (international) on combustion, vol. 27, 2619-2626, Elsevier. 16

[24] Ju, Y., Guo, H., Liu, F. and Maruta, K. (1999). Effects of the lewis number and radiative heat loss on the bifurcation and extinction of ch 4/o 2-n 2-he flames. Journal of Fluid Mechanics, 379, 165-190. 16, 17

[25] Karlovitz, B., Denniston, D., Knapschaefer, D. and Wells, F. (1953). Studies on turbulent flames: A. flame propagation across velocity gradients b. turbulence measurement in flames. In Symposium (International) on Combustion, vol. 4, 613620, Elsevier. 5

[26] Keane, R. And Adrian, R. (1990). Optimization of particle image velocimeters. i. double pulsed systems. Measurement science and technology, 1, 1202. 66 
[27] Keane, R. and Adrian, R. (1992). Theory of cross-correlation analysis of piv images. Applied scientific research, 49, 191-215. 69

[28] Kennard, E. (1938). Kinetic theory of gases. 77

[29] Landau, L. And Lifshitz, E. (1960). Electrodynamics of Continuous Media. Pergamon, Oxford. 143

[30] Landau, L. And Lifshitz, E. (1971). The classical theory of fields. Pergamon, Oxford. 139

[31] Levy, A. (1965). An optical study of flammability limits. In Proceedings of the Royal Society of London A: Mathematical, Physical and Engineering Sciences, vol. 283, 134-145, The Royal Society. 5, 6, 26, 49, 93, 108, 118

[32] Libby, P. And Williams, F. (1982). Structure of laminar flamelets in premixed turbulent flames. Combustion and Flame, 44, 287-303. 5, 6

[33] Libby, P. And Williams, F. (1987). Premixed laminar flames with general rates of strain. Combustion science and technology, 54, 237-273. 5, 6

[34] Malkmus, W. (1967). Random lorentz band model with exponential-tailed s- 1 lineintensity distribution function. JOSA, 57, 323-329. 16

[35] Marple, V. And Liu, B. (1974). Characteristics of laminar jet impactors. Environmental Science \& Technology, 8, 648-654. 85, 87, 88

[36] Marple, V. And Willeke, K. (1976). Impactor design. Atmospheric Environment (1967), 10, 891-896. 87

[37] Mason, W. And Wheeler, R.V. (1918). The effect of temperature and of pressure on the limits of inflammability of mixtures of methane and air. Journal of the Chemical Society, Transactions, 113, 45-57. 4

[38] Maxey, M. And Riley, J. (1983). Equation of motion for a small rigid sphere in a nonuniform flow. Physics of Fluids (1958-1988), 26, 883-889. 74

[39] McBride, B. And Gordon, S. (1996). Computer program for calculation of complex chemical equilibrium compositions and applications. NASA Reference Publication, 1311. 110

[40] Millikan, R. (1923). Coefficients of slip in gases and the law of reflection of molecules from the surfaces of solids and liquids. Physical review, 21, 217. 77

[41] Muntean, V. And Higuera, F. (2016). Lean methane-air flames propagating upward in vertical tubes. Combustion Science and Technology, 188, 818-830. 80

[42] Muntean, V. And Higuera, F. (2016). Upward propagation of very lean methaneair flames in vertical tubes. Flow, Turbulence and Combustion, 96, 263-277. 122 
[43] PARker, A. (1914). The lower limits of inflammation of methane with mixtures of oxygen and nitrogen. Journal of the Chemical Society, Transactions, 105, 1002-1009. 4

[44] Perman, E. (1911). Limits of explosibility in gaseous mixtures. Nature, 87, 416. 3

[45] Peters, N. And Rogg, B. (2008). Reduced kinetic mechanisms for applications in combustion systems, vol. 15. Springer Science \& Business Media. 31

[46] Rader, D. and Marple, V. (1985). Effect of ultra-stokesian drag and particle interception on impaction characteristics. Aerosol Science and Technology, 4, 141156. 86,87

[47] Raffel, M., Willert, C., Wereley, S. and Kompenhans, J. (2007). Particle Image Velocimetry. Springer Berlin Heidelberg, 2nd edn. 64, 69

[48] Rimai, L., Marko, K. And Klick, D. (1982). Optical study of a 2-dimensional laminar flame: Relation between temperature and flow-velocity fields. In Symposium (International) on Combustion, vol. 19, 259-265, Elsevier. 7

[49] Sánchez, A., Lépinette, A., Bollig, M., Liñán, A. and Lázaro, B. (2000). The reduced kinetic description of lean premixed combustion. Combustion and Flame, 123, 436-464. 31, 32, 33

[50] Shoshin, Y. And De Goey, L. (2010). Experimental study of lean flammability limits of methane/hydrogen/air mixtures in tubes of different diameters. Experimental Thermal and Fluid Science, 34, 373-380. 108

[51] Shoshin, Y. and Jarosinski, J. (2009). On extinction mechanism of lean limit methane-air flame in a standard flammability tube. Proceedings of the Combustion Institute, 32, 1043-1050. 7, 8, 48, 93, 94, 119

[52] Shoshin, Y., Tecce, L. And Jarosinski, J. (2008). Experimental and computational study of lean limit methane-air flame propagating upward in a $24 \mathrm{~mm}$ diameter tube. Combustion Science and Technology, 180, 1812-1828. 8, 16, 21, 22, 29, 48, 108, 111,129

[53] Shoshin, Y., Gorecki, G., Jarosinski, J. and Fodemski, T. (2010). Experimental study of limit lean methane/air flame in a standard flammability tube using particle image velocimetry method. Combustion and Flame, 157, 884-892. 7, 8, 26, $54,55,94,111,116,117,119$

[54] Smoke, M. and Giovangigli, V. (1991). Formulation of the premixed and nonpremixed test problems. In Reduced Kinetic Mechanisms and Asymptotic Approximations for Methane-Air Flames, 1-28, Springer. 12

[55] Soufiani, A. And Taine, J. (1997). High temperature gas radiative property parameters of statistical narrow-band model for h2o, co2 and co, and correlated-k model for h2o and co2. International journal of heat and mass transfer, 40, 987-991. 16 
[56] Soufiani, A., Hartmann, J. and Taine, J. (1985). Validity of band-model calculations for $\mathrm{co} 2$ and $\mathrm{h} 2 \mathrm{o}$ applied to radiative properties and conductive-radiative transfer. Journal of Quantitative Spectroscopy and Radiative Transfer, 33, 243-257. 16

[57] Spalding, D. (1957). A theory of inflammability limits and flame-quenching. In Proc. R. Soc. Lond. 5, 8

[58] Stewart, P. And Davidson, J. (1967). Slug flow in fluidised beds. Powder Technology, 1, 61-80. 55

[59] Talbot, L., Cheng, R., Schefer, R. and Willis, D. (1980). Thermophoresis of particles in a heated boundary layer. Journal of Fluid Mechanics, 101, 737-758. 77

[60] Thielicke, W. and Stamhuis, E. (2014). Pivlab-towards user-friendly, affordable and accurate digital particle image velocimetry in matlab. Journal of Open Research Software, 2. 69

[61] von Lavante, E. And Strehlow, R. (1983). The mechanism of lean limit flame extinction. Combustion and Flame, 49, 123-140. 6, 7, 8, 23, 49, 93, 108

[62] Wang, S., Zhang, H., Jarosinski, J., Gorczakowski, A. and Podfilipski, J. (2010). Laminar burning velocities and markstein lengths of premixed methane/air flames near the lean flammability limit in microgravity. Combustion and Flame, 157, 667-675. 15

[63] Westbrook, C. And Dryer, F. (1981). Simplified reaction mechanisms for the oxidation of hydrocarbon fuels in flames. Combustion science and technology, 27, 31-43. 15

[64] Williams, F. (1985). Combustion Theory. Benjamin Cummings, Menlo Park, CA,. $5,7,14,23,24,27,78,119,123$

[65] Xue, Z., Charonko, J. and Vlachos, P. (2013). Signal-to-noise ratio, error and uncertainty of piv measurement. In PIV13; 10th International Symposium on Particle Image Velocimetry, Delft, The Netherlands, July 1-3, 2013, Delft University of Technology, Faculty of Mechanical, Maritime and Materials Engineering, and Faculty of Aerospace Engineering. 66

[66] Yamaoka, I. And Tsuji, H. (1985). Determination of burning velocity using counterflow flames. In Symposium (International) on Combustion, vol. 20, 1883-1892, Elsevier. 15 